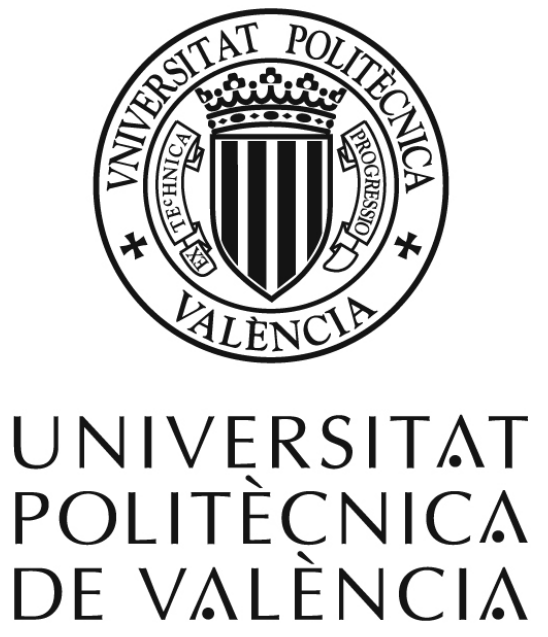

DEPARTAMENTO DE ORGANIZACIÓN DE EMPRESAS, ECONOMÍA FINANCIERA Y CONTABILIDAD

\title{
Efectos de la transferencia de conocimiento en el desempeño organizativo: Estudio empírico en empresas del sector hotelero de España
}

TESIS DOCTORAL presentada por:

D. Pablo Eduardo Zegarra Saldaña

DIRECTOR: Dr. D. Daniel Palacios Marqués

Valencia 2012 


\section{AGRADECIMIENTOS}

La presente investigación ha sido posible gracias a varias personas e instituciones que me han brindado su apoyo, para ellos van mis más sinceros agradecimientos.

Expresar un especial agradecimiento y reconocimiento a Daniel Palacios Marqués, por su colaboración, motivación y guía a lo largo de toda la investigación.

A la Universidad Privada Boliviana y la Universidad Politécnica de Valencia por brindarme la oportunidad de realizar los estudios doctorales

A las empresas hoteleras y gerentes que brindaron su tiempo e información para el estudio empírico.

Agradecer a mi familia, por su amor, entrega y apoyo en todos los aspectos de mi vida, dedico a ellos este logro.

A Elke, Eduardo y Eliana 


\section{RESUMEN}

El objetivo de la presente investigación es analizar el efecto de la transferencia de conocimiento en la mejora del desempeño organizativo. Para ello, a partir de la revisión de las diferentes perspectivas y enfoques en organización de empresas, se adopta como posicionamiento teórico el Enfoque Basado en Competencias.

El Enfoque Basado en Competencias centra su atención en el desarrollo de competencias como fuente de la ventaja competitiva sostenible. Las competencias distintivas juegan un rol fundamental para este propósito, la base del desarrollo de este tipo de competencias son los activos estratégicos y en especial el conocimiento. Las ventajas competitivas derivadas del conocimiento, dependen por una parte de la naturaleza misma de este recurso que lo hace estratégico y por otra parte de su adecuada gestión,: sin embargo la posesión de conocimiento no asegura la sostenibilidad de las ventajas competitivas, es necesaria la transferencia de conocimiento.

Con estas consideraciones se construyó el modelo teórico explicativo de la relación existente entre los factores antecedentes con la transferencia de conocimiento y su efecto en el desempeño organizativo. El modelo fue aplicado a empresas del sector hotelero español, cuyos resultados comprueban que existe un efecto positivo y significativo entre los factores antecedentes (visión holística de la organización, gestión por competencias, aprendizaje continuo e infraestructura técnica de las tecnologías de información) con la transferencia de conocimiento. 
Por otra parte se comprueba que la transferencia de conocimiento tiene un efecto positivo en el desempeño organizativo, estableciéndose que el efecto es directo.

Palabras claves: transferencia de conocimiento, visión holística, gestión por competencias, aprendizaje continuo, infraestructura técnica de las TI, ventaja competitiva, activos estratégicos. 


\section{ABSTRACT}

The purpose of this research is to analyze the effect of transfer of knowledge on the improvement of the organizational performance. Based on the review of different perspectives in business and organizational approaches, we have adopted the Approach Based on Competences as the theoretical guidelines.

This approach is focused on the development of competences as a source for a sustainable competitive advantage. The distinctive competences play a main role on this purpose because the base for the development of this kind of competences is strategic assets, especially knowledge. The competitive advantages that come from knowledge depend on one hand from the nature of this resource, which makes it strategic, and on the other hand from its correct management. However, the possession of knowledge does not guarantee the sustainability of the competitive advantages. In order to obtain a sustainable competitive advantage it is necessary the transfer of knowledge.

Under these considerations a theoretical model was established to explain the relationship between the antecedent factors with the transfer of knowledge and its effect on the organizational performance. The model was applied to companies of the hospitality sector in Spain. The outcomes proved the existence of a positive and significant effect of the antecedent factors (holistic vision of the organization, management for competencies, continue learning and technique infrastructure for 
information technologies) on the transfer of knowledge. On the other hand, they have also proved that the transfer of knowledge has a positive effect on the organizational performance, this effect can be considered as an indirect effect.

Key words: Transfer of knowledge, holistic vision, management for competences, continue learning, technique infrastructure for information technologies, competitive advantage, strategic assets. 


\section{RESUM}

L'objectiu de la present investigació és analitzar l'efecte de la transferència de coneixement en la millora del rendiment empresarial. Mitjançant la revisió de les diferents perspectives i enfocs en organizatció d'empreses, es considera com a posicionament teòric l'enfoc basat en competències.

L'enfoc basat en competències es centra en el desenvolupament de competències com a font d'advantatge competitiu sostenible. Les competències distintives tenen un rol fonamental per a aquest objectiu, la base per al desenvolupament d'aquest tipus de competències són els actius estratègics i especialment el coneixement. L'advantatge competitiu derivat del coneixement, depen per una part de la naturaletza d'aquest recurs i per altra banda d'una adequada gestió. Per tant es fa necessari la transferència de coneixement més que la mera possessió.

Amb aquestes consideracions s'ha desenvolupat un model teòric explicatiu de la relació existent entre els factors antecedents amb la transferència de coneixement $\mathrm{i}$ el seu efecte amb el rendiment empresarial. El model ha sigut aplicat a empreses del sector hoteler español, i els resultats constaten que hi ha un efecte positiu i significatiu entre els factors antecedentes (visió holística de la organització, gestió per competències, aprenentatge continu e infraestructura tècnica de les tecnologíes de la informació) amb la transferència de coneixement. Per altra part es constata 
que la transferència de coneixement té un efecte positiu i directe en el rendiment organitzatiu.

Paraules clau: transferència de coneixement, visió holística, gestió per competències, aprenentatge continu, infraestructura técnica de les TI, advantatge competitiu, actius estratègics. 


\section{INDICE GENERAL}

CAPITULO O INTRODUCCION............................................................. 1

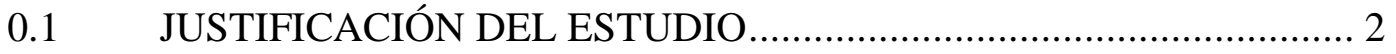

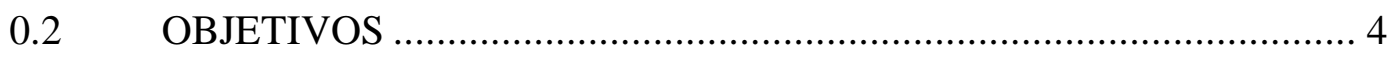

ETAPAS Y METODOLOGÍA DEL ESTUDIO ................................ 5

CAPÍTULO 1 REVISION DE LOS ENFOQUES EN ORGANIZACIÓN DE

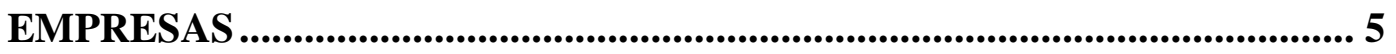

I.1 INTRODUCCIÓN Y OBJETIVOS DEL CAPÍTULO ........................ 8

1.2 REVISIÓN DE LOS ENFOQUES EN ORGANIZACIÓN DE

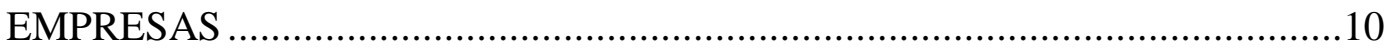

1.2.1 Enfoque de la Administración Científica ..................................11

1.2.2 Enfoque Funcional ….......................................................... 12

1.2.3 Enfoque de las Relaciones Humanas..........................................13

1.2.4 Enfoque Burocrático................................................................14

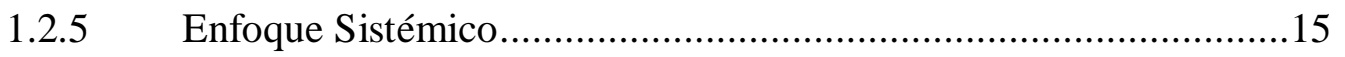

1.2.6 Enfoque del Comportamiento Administrativo .............................17

1.2.7 Enfoque del Desarrollo Organizacional .....................................18

1.2.8 Enfoque de la Contingencia ..................................................19

1.2.9 Enfoque de la Población Ecológica...........................................20 


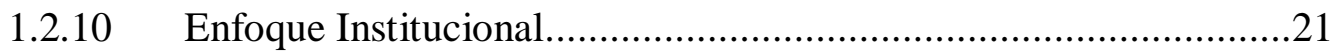

1.2.11 Enfoque de los Costes de Transacciones .....................................22

1.2.12 El Enfoque de la Agencia .......................................................23

1.2.13 Enfoque Competitivo de Porter....................................................24

1.3 ENFOQUE BASADO EN COMPETENCIAS .................................25

1.3.1 Enfoque Basado en Recursos y Capacidades.................................30

1.3.2 Enfoque de las Capacidades Dinámicas .......................................34

1.3.3 Enfoque Basado en el Conocimiento ............................................38

1.3.4 Enfoque Basado en el Aprendizaje ..........................................41

1.4 POSICIONAMIENTO TEÓRICO ADOPTADO PARA LA

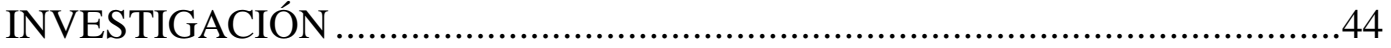

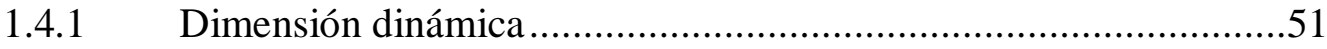

1.4.2 Dimensión sistémica y cognitiva ............................................52

1.4.3 Dimensión holística ....................................................................52

\section{CAPÍTULO 2 GESTION DEL CONOCIMIENTO Y VENTAJA}

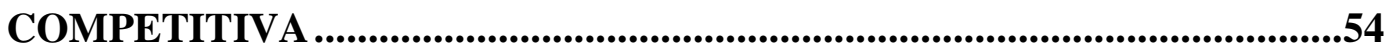

2.1 INTRODUCCIÓN Y OBJETIVOS DEL CAPÍTULO ...........................54

2.2 VENTAJA COMPETITIVA SOSTENIBLE, ENFOQUES Y MODELO

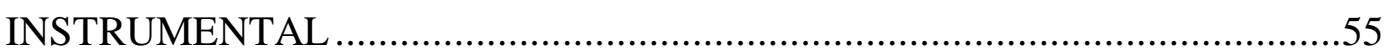

2.2.1 Ventaja Competitiva desde el Enfoque Basado en Competencias...58

2.2.2 Modelo instrumental de gestión estratégica.................................61 
2.2.3 La Estrategia, Orígenes y Definiciones .....................................64

2.2.4 Escuelas de pensamiento estratégico........................................67

2.2.5 Tipos de Estrategias y Verificación...............................................75

2.2.6 Verificación de la Estrategia .......................................................76

2.2.7 Recursos, Capacidades y Competencias.....................................78

2.2.8 Recursos, Conceptos y Clasificación .........................................80

2.2.8.1 Clasificación de los recursos ..................................................82

2.2.9 Capacidades, Conceptos y Clasificacion........................................... 85

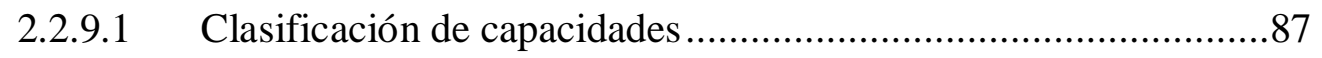

2.2.10 Competencias, Conceptos y Clasificación...................................91

2.2.10.1 Clasificación de competencias ...............................................93

2.2.11 Propuesta de reconfiguración del modelo BMS ..........................94

2.3 EL CONOCIMIENTO COMO ACTIVO ESTRATÉGICO Y SU

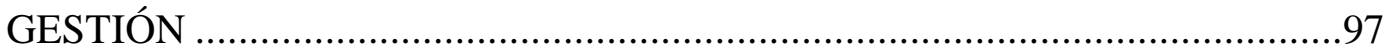

2.3.1 Datos, información y conocimiento ...........................................98

2.3.2 Diferencias entre información y conocimiento.............................98

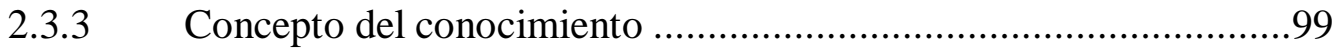

2.3.3.1 Conocimiento individual y conocimiento organizativo .............101

2.3.4 Características de los activos estratégicos .................................103

2.3.4.1 Movilidad imperfecta de los recursos .....................................104 
2.3.5 El conocimiento como activo estratégico .................................106

2.3.5.1 Taxonomías del conocimiento............................................107

2.3.6 Capital Intelectual ............................................................ 111

2.3.6.1 Valoración y gestión del capital intelectual .............................112

2.3.7 La gestión del conocimiento .................................................112

2.3.7.1 Etapas de la gestión del conocimiento ..................................115

\section{CAPITULO 3 TRANSFERENCIA DE CONOCIMIENTO Y DESEMPENO}

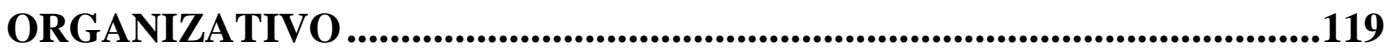

3.1 INTRODUCCIÓN Y OBJETIVOS DEL CAPÍTULO ........................119

3.2 ETAPAS DE LA GESTIÓN DEL CONOCIMIENTO........................120

3.2.1 Creación y adquisición del conocimiento...................................121

3.2.1.1 Creación de conocimiento .................................................122

3.2.1.2 Adquisición de conocimiento ............................................ 126

3.2.2 Almacenamiento, retención y retiro de conocimiento...................127

3.2.3 Aplicación del conocimiento .................................................129

3.3 LA TRANSFERENCIA DEL CONOCIMIENTO ...........................130

3.3.1 Transferencia interna de conocimiento.....................................133

3.3.2 Transferencia externa de conocimiento ......................................135

3.3.3 Proceso y factores que influyen en la transferencia conocimiento 136

3.3.3.1 El proceso de la transferencia interna del conocimiento............138 
3.3.4 Dimensiones de la transferencia de conocimiento ......................152

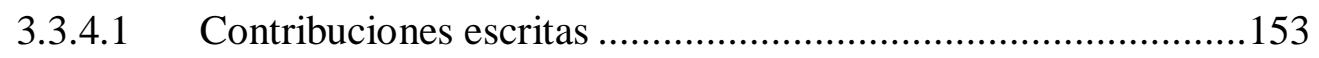

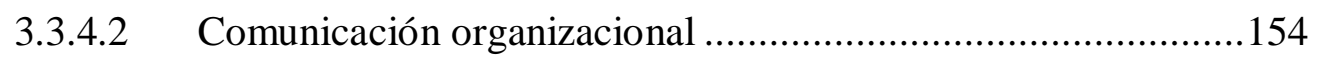

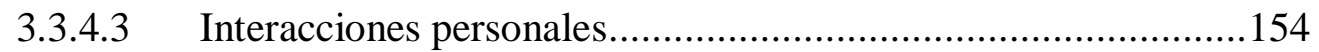

3.3.4.4 Comunidades de práctica ...................................................155

\subsection{LOS FACTORES ANTECEDENTES Y LA TRANSFERENCIA DE}

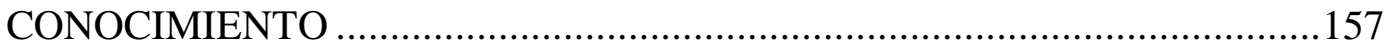

3.4.1 La visión holística de la organización ......................................158

3.4.2 La gestión por competencias...................................................161

3.4.3 El aprendizaje continuo ...................................................... 167

3.4.3.1 Niveles de aprendizaje continuo.........................................167

3.4.3.2 Conceptualización y proceso de aprendizaje............................169

3.4.3.3 Barreras al aprendizaje organizativo................................... 172

3.4.3.4 Dimensiones del aprendizaje continuo ................................175

3.4.4 Infraestructura técnica de las Tecnologías de Información TI.......176

3.4.5 Tecnologías de información (TI) y sistemas de información (SI) .178

3.4.5.1 Importancia de las TI y SI en la transferencia de conocimiento y

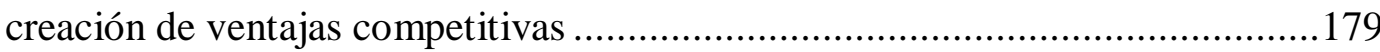

3.5 RELACIONES TEÓRICAS ENTRE LAS VARIABLES ...................182

3.5.1 Modelo teórico y planteamiento de las hipotesis .........................185 


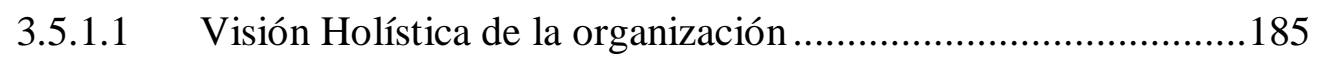

3.5.1.2 La gestión por competencias …............................................188

3.5.1.3 El aprendizaje continuo..................................................... 190

3.5.1.4 La infraestructura técnica de las TI........................................192

3.5.1.5 La transferencia de conocimiento y el desempeño organizativo 194

3.5.1.6 El papel mediador de la transferencia de conocimiento ............195

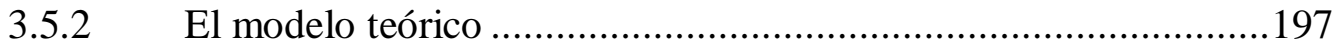

\section{CAPÍTULO 4 CARACTERIZACION DEL SECTOR DE ESTUDIO E} INSTRUMENTO DE MEDIDA...........................................................................200

4.1 INTRODUCCIÓN Y OBJETIVOS DEL CAPÍTULO .......................200

4.2 EL SECTOR TURÍSTICO Y SU IMPORTANCIA .........................201

$4.3 \quad$ EL SECTOR TURÍSTICO EN ESPAÑA ….................................208

4.3.1 Implicaciones económicas y sociales del turismo en España ........210

4.3.1.1 Aporte a la economía del sector turismo................................211

4.3.1.2 Aporte del sector turismo a la generación de empleo................214

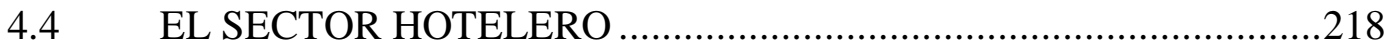

4.4.1 El sector hotelero en España .................................................222

4.4.1.1 Clasificación de Hoteles.........................................................223

4.4.1.2 Crecimiento y distribución de Hoteles....................................225

4.4.1.3 Número de Hoteles por Comunidades Autónomas ..................226 
4.4.1.4 Desempeño del sector hotelero..........................................229

4.4.1.5 Grado de ocupación por categorías.........................................233

\subsection{LA TRANSFERENCIA DE CONOCIMIENTO Y EL SECTOR}

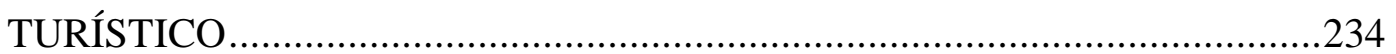

4.6 DISEÑO DEL INSTRUMENTO DE MEDICIÓN............................241

4.6.1 Visión holística de la organización ............................................243

4.6.2 Gestión por Competencias .........................................................244

4.6.3 Aprendizaje Continuo............................................................24

4.6.4 Infraestructura Técnica de las TI.........................................245

4.6.5 Transferencia de Conocimiento ...............................................247

4.6.6 Desempeño Organizativo.....................................................249

4.7 MODELOS DE ECUACIONES ESTRUCTURALES ......................250

CAPÍTULO 5 RESULTADOS DEL ESTUDIO EMPIRICO........................258

$5.1 \quad$ INTRODUCCIÓN Y OBJETIVOS DEL CAPÍTULO ........................258

5.2 ANÁLISIS DE LAS PROPIEDADES DE LAS ESCALAS DE

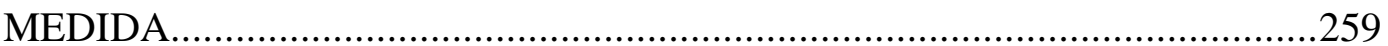

5.2.1 Evaluación de la Escala de medida de la Visión Holística de la Organización .259

5.2.2 Evaluación de la Escala de Medida de la Gestión Competencias..266

5.2.3 Evaluación de la Escala de Medida de Aprendizaje continuo .......272

5.2.4 Evaluación de la Escala de Medida de Infraestructura de las TI ..279 
5.2.5 Evaluación de la Escala de Medida de Transferencia de Conocimiento

5.2.6 Evaluación de la Escala de Medida de Desempeño Organizativo.296 5.3 CONTRASTE DE HIPÓTESIS MEDIANTE LA UTILIZACIÓN DE MODELOS DE ECUACIONES ESTRUCTURALES ....................................300

5.3.1 Primera Hipótesis: Estudio de la Relación entre Visión Holística de la Organización y la Transferencia de Conocimiento 301

5.3.1.1 Ajuste global del modelo .......................................................301

5.3.1.2 Ajuste del modelo de medida .................................................302

5.3.1.3 Ajuste del modelo estructural................................................304

5.3.2 Segunda Hipótesis: Estudio de la Relación entre la Gestión por Competencias y la Transferencia de Conocimiento 305

5.3.2.1 Ajuste global del modelo .......................................................306

5.3.2.2 Ajuste del modelo de medida ..................................................306

5.3.2.3 Ajuste del modelo estructural...................................................308

5.3.3. Tercera Hipotesis: Estudio de la Relacion entre el Aprendizaje Continuo y la Transferencia de Conocimiento

5.3.3.1 Ajuste global del modelo .....................................................310

5.3.3.2 Ajuste del modelo de medida .................................................310

5.3.3.3 Ajuste del modelo estructural ................................................312

5.3.4 Cuarta Hipótesis: Estudio de la Relación entre la Infraestructura Técnica de la TI y la Transferencia de Conocimiento ..........................................314 


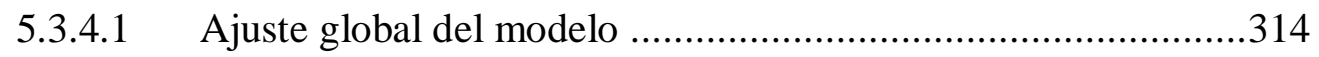

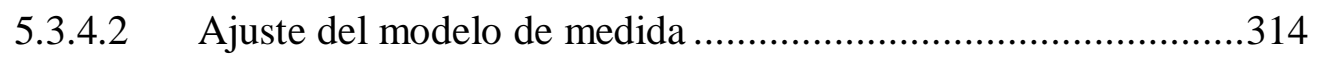

5.3.4.3 Ajuste del modelo estructural ..............................................316

5.3.5 Quinta Hipótesis: Estudio de la Relación entre la Transferencia de Conocimiento y el Desempeño Organizativo ................................................317

5.3.5.1 Ajuste global del modelo …................................................ 318

5.3.5.2 Ajuste del modelo de medida ................................................318

5.3.5.3 Ajuste del modelo estructural............................................319

5.3.6 Sexta Hipótesis: Análisis del papel mediador de la Transferencia de Conocimiento en el Desempeño Organizativo................................................321

5.3.6.1 Ajuste global del modelo .................................................321

5.3.6.2 Ajuste del modelo de medida ..............................................322

5.3.6.3 Ajuste del modelo estructural ............................................322

\section{CAPÍTULO 6 CONCLUSIONES, LIMITACIONES DEL ESTUDIO Y} FUTURAS INVESTIGACIONES ........................................................327

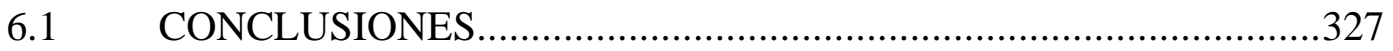

6.1.1 Conclusiones sobre la primera parte del trabajo............... 327;Error! Marcador no definido.

6.1.2 Conclusiones sobre la segunda parte del trabajo.................334

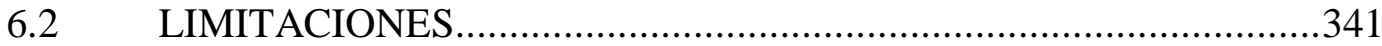

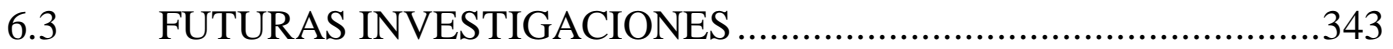




\section{INDICE DE TABLAS}

Tabla 1.1. Procesos de Aprendizaje y Niveles ..................................................42

Tabla 1.2. Síntesis de los Enfoques en Organización de Empresas ......................45

Tabla 2.1. Escuelas del Pensamiento Estratégico ..............................................68

Tabla 2.2. Resumen de los conceptos de recursos, capacidades y competencias ..79

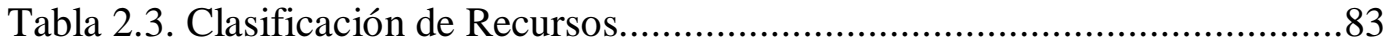

Tabla 2.4. Tareas y capacidades en el Modelo BMS .........................................88

Tabla 2.5. Taxonomías del conocimiento y ejemplos .................................... 109

Tabla 2.6. Etapas de la gestión del conocimiento ............................................117

Tabla 3.1. Características de la Transferencia de Conocimiento ........................132

Tabla 3.2. Dimensiones, elementos y factores que influyen en la transferencia de

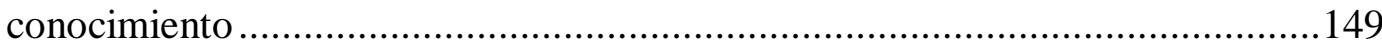

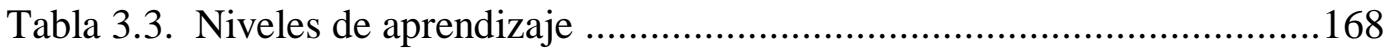

Tabla 3.4. Barreras del aprendizaje organizativo ...........................................173

Tabla 4.1.Países con mayor cantidad de llegadas de turismo internacional

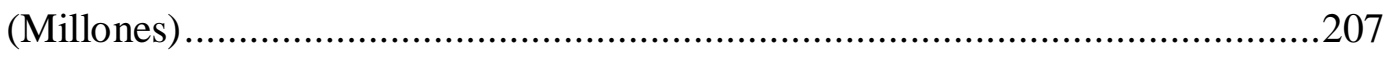

Tabla 4.2. Aporte de la industria del Turismo al PIB ......................................213

Tabla 4.3. Tasa de ocupación por regiones.......................................................219 
Tabla 4.4. Tasa de ocupación por ciudades .220

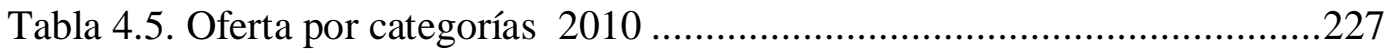

Tabla 4.6. Ingresos promedios por habitación disponible (RevPAR) ................231

Tabla 4.7. Grado de ocupación por categorías ..................................................233

Tabla 4.8. Variables de uso de TIC, en el sector de servicios de alojamiento.....239

Tabla 4.9. Bibliografía relevante para el desarrollo de los instrumentos de medición

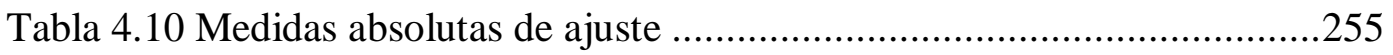

Tabla 5.1. Ficha técnica del estudio empírico ................................................259

Tabla 5.2. Índices de ajuste de las dimensiones individuales ..........................260

Tabla 5.3. Índices de ajuste del modelo medida de la visión holística................261

Tabla 5.4. Media y desviación típica de los ítems de la escala visión holística de la

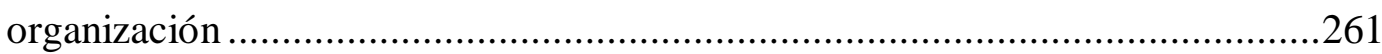

Tabla 5.5. Cargas factoriales estandarizadas y errores de medida .....................262

Tabla 5.6. Índices de ajuste del modelo de medida........................................265

Tabla 5.7. Matriz de correlaciones entre dimensiones de la visión holística.......266

Tabla 5.8. Índices de ajuste de los modelos de las dimensiones individuales ....267

Tabla 5.9. Índices de ajuste del modelo de segundo orden............................267

Tabla 5.10. Media y desviación típica de los ítems de la escala gestión por

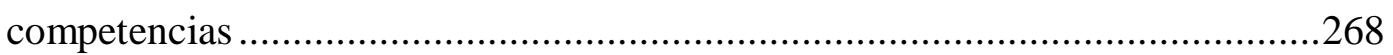

Tabla 5.11. Cargas factoriales estandarizadas y errores de medida ..................269 
Tabla 5.12. Índices de ajuste del modelo de medida .271

Tabla 5.13. Matriz de correlaciones entre dimensiones de la gestión por competencias

Tabla 5.14. Índices de ajuste de las subdimensiones del aprendizaje continuo...273

Tabla 5.15. Índices de ajuste del modelo de segundo orden del aprendizaje continuo

Tabla 5.16. Media y desviación típica de los ítems de la escala aprendizaje continuo

Tabla 5.17. Cargas factoriales estandarizadas y errores de medida 275

Tabla 5.18. Índices de ajuste del modelo de medida.... 277

Tabla 5.19. Matriz de correlaciones entre dimensiones del aprendizaje 278

Tabla 5.20. Índices de ajuste de las dimensiones de la infraestructura técnica de las TI 280

Tabla 5.21. Índices de ajuste del modelo medida de la infraestructura técnica en TI .281

Tabla 5.22. Media y desviación típica de los ítems de la escala infraestructura técnica de las TI

Tabla 5.23. Cargas factoriales estandarizadas y errores de medida 284

Tabla 5.24. Índices de ajuste del modelo de medida 286

Tabla 5.25. Matriz de correlaciones entre dimensiones de la infraestructura técnica de las TI

Tabla 5.26. Índices de ajuste de los modelos de las dimensiones individuales para la transferencia de conocimiento 
Tabla 5.28. Media y desviación típica de los ítems de la escala transferencia de conocimiento

Tabla 5.29. Cargas factoriales estandarizadas y errores de medida .292

Tabla 5.30. Índices de ajuste del modelo de medida .295

Tabla 5.31. Matriz de correlaciones entre dimensiones de la transferencia de conocimiento 296

Tabla 5.32. Media y desviación típica de los ítems de la escala desempeño organizativo

Tabla 5.33. Cargas factoriales estandarizadas y errores de medida .298

Tabla 5.34. Índices de ajuste del modelo de medida 299

Tabla 5.35. Índices del ajuste global del modelo 302

Tabla 5.36. Parámetros estimados en el modelo de medida 303

Tabla 5.37. Parámetro estimado e índice de fiabilidad en el modelo estructural de la primera hipótesis .304

Tabla 5.38. Índices del ajuste global del modelo .306

Tabla 5.39. Parámetros estimados en el modelo de medida 307

Tabla 5.40. Parámetro estimado e índice de fiabilidad en el modelo estructural de la segunda hipótesis .308

Tabla 5.41. Índices del ajuste global del modelo 310

Tabla 5.42. Parámetros estimados en el modelo exógeno y endógeno 311

Tabla 5.43. Parámetro estimado e índice de fiabilidad en el modelo estructural de la tercera hipótesis 
Tabla 5.44. Índices del ajuste global del modelo

Tabla 5.45. Parámetros estimados en el modelo exógeno y endógeno

Tabla 5.46. Parámetro estimado e índice de fiabilidad en el modelo estructural de la cuarta hipótesis

Tabla 5.47. Índices del ajuste global del modelo .318

Tabla 5.48. Parámetros estimados en el modelo exógeno y endógeno .319

Tabla 5.49. Parámetro estimado e índice de fiabilidad en el modelo estructural de la quinta hipótesis. 320

Tabla 5.50. Índices del ajuste global del modelo .322

Tabla 5.51. Parámetros estimados e índices de fiabilidad en los modelos estructurales de la sexta hipótesis.

Tabla 5.52. Efecto directo e indirecto de las variables antecedentes sobre el desempeño organizativo 


\section{INDICE DE FIGURAS}

Figura 1.1. Enfoques en Organización de Empresas ....................................... 9

Figura 2.1. Estructura del Modelo BMS .....................................................6 63

Figura 2.2. Flujos de información y conocimiento ........................................77

Figura 2.3. Jerarquía de Capacidades y Competencias .....................................92

Figura 2.4. Propuesta de Modelo Dinámico de gestión......................................96

Figura 3.1. Espiral de creación del conocimiento organizativo ........................124

Figura 3.2. Proceso de transferencia interna de conocimiento .........................140

Figura 3.3. Proceso de Gestión de Recursos Humanos Basada Competencias ...166

Figura 3.4. Aprendizaje organizativo como un proceso dinámico .................170

Figura 3.5. Marco Conceptual para la Gestión del Aprendizaje .....................171

Figura 3.6. Propuesta de modelo dinámico de gestión .....................................183

Figura 3.7. Modelo Teórico ................................................................... 197

Figura 4.1. Crecimiento del turismo entre los años de 1950 y el 2005 ..............202

Figura 4.2. Crecimiento de llegadas internacionales de turismo (Millones) .......203

Figura 4.3. Llegadas internacionales por regiones entre 2005 y 2010 ...............204

Figura 4.4. Participación porcentual por regiones entre 2005 y 2010 ................205

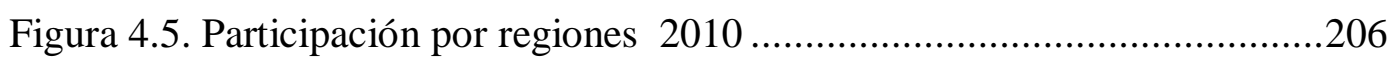


Figura 4.6. Llegadas de turismo internacional ............................................208

Figura 4.7. Evolución del ITCT - España ....................................................209

Figura 4.8. Aporte porcentual del Turismo al PIB .........................................2211

Figura 4.9. Contribución del Turismo al PIB ..................................................212

Figura 4.10. Turismo Receptor Vs. otros componentes del Turismo.................214

Figura 4.11. Empleo en el sector Turismo por ramas de actividad ....................215

Figura 4.12. Relación asalariados Vs. cuenta propia......................................216

Figura 4.13. Afiliados en el sector turístico por ramas de actividad ..................217

Figura 4.14. Relación porcentual del Sector Hotelero Español dentro de la Unión

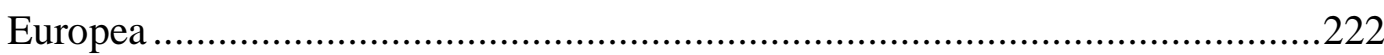

Figura 4.15. Número de plazas en España dentro de la Unión Europea .............223

Figura 4.16. Crecimiento del número de Hoteles..........................................225

Figura 4.17. Hoteles por Comunidades Autónomas en el 2009........................226

Figura 4.18. Hoteles por Categoría en el 2010..........................................227

Figura 4.19. Porcentaje de Hoteles y Plazas - 2010 ......................................228

Figura 4.20. Tasa Media Diaria (ADR) por categorías de Hoteles 2010 ............230

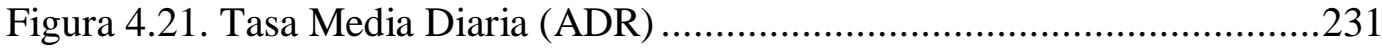

Figura 4.22. Ingresos promedios por habitación disponible (RevPAR) .............232

Figura 4.23. Tecnologías con mayor impacto en el 2009 ...............................240

Figura 4.24 Diagrama general de relaciones causales ..................................201 
Figura 5.1.Parámetros de la primera hipótesis .............................................241

Figura 5.2. Parámetros de la segunda hipótesis .........................................244

Figura 5.3. Parámetros de la tercera hipótesis...............................................313

Figura 5.4. Parámetros de la cuarta hipótesis....................................................317

Figura 5.5. Parámetros de la quinta hipótesis ..................................................320

Figura 5.6. Contraste de hipótesis del modelo completo..................................325 


\section{Capítulo o Introducción}




\section{CAPÍt ULO o}

\subsection{JUSTIFICACIÓN DEL ESTUDIO}

Es innegable que en las últimas décadas la sociedad ha sufrido una profunda transformación, de pasar de la base física de la producción a la base intelectual de la misma. La sociedad industrial que revolucionó en su tiempo y marcó cambios fundamentales, ha dado paso a la sociedad del conocimiento (Carrillo, 2005)

La trilogía de los factores de producción tradicionales (capital, tierra y trabajo) ya no son los únicos que se requieren para la transformación y producción de bienes y servicios, actualmente la información y el conocimiento se han convertido en los nuevos factores que requieren ser gestionados por los gerentes de empresas.

Los sistemas administrativos, contables y económicos fueron desarrollados para manejar la producción, basada fundamentalmente en recursos tangibles. En esta nueva coyuntura, donde el conocimiento se constituye en la principal fuente de riqueza, los sistemas tradicionales no logran captar, procesar y capitalizar esta nueva fuente de riqueza.

El "Big Bang" que ha experimentado la gestión del conocimiento en estos últimos años ha incrementado geométricamente la disponibilidad de publicaciones, modelos y herramientas. Ante esta explosión se percibe una aparente fragmentación en los ámbitos de la literatura académica así como en la formación y consultoría relacionada con la gestión del conocimiento. 


\section{Capitulo 0 Introducción}

En la sociedad del conocimiento, las empresas deben competir en un ámbito global, puesto que el gran desarrollo experimentado en las tecnologías de información y comunicación, infraestructura, medios de transporte e integración de mercados, han reducido las barreras geográficas de información y acceso a mercados.

Varios estudios coinciden en que la información y el conocimiento generan un efecto positivo en el desempeño de las organizaciones y se constituyen en fuente de la ventaja competitiva. Sin embargo, es necesario profundizar en la identificación de los factores antecedentes, los principios y prácticas relacionados a la gestión del conocimiento.

En el mundo académico se reconoce la importancia de la gestión del conocimiento, su aplicación y utilidad en las organizaciones; es por ello que recientemente la revista "Journal of Knowledge Management" ha sido incluida en el ranking Thomson Reuters (ISI).

Existe una cantidad considerable de publicaciones, modelos y herramientas disponibles para la gestión del conocimiento carentes de sustento teórico y contrastación empírica, de ahí la necesidad de la validación científica de modelos desde el ámbito académico para su aplicación en diversas organizaciones. 


\section{Capitulo 0 Introducción}

\subsection{OBJETIVOS}

Los objetivos de la presente investigación se desglosan a nivel teórico y a nivel empírico, siendo estos:

- Revisar los principales enfoques en organización de empresas y análisis de aquellos que tienen mayor relevancia para la gestión del conocimiento.

- Analizar el efecto de la transferencia de conocimiento en el desempeño organizacional, así como los factores antecedentes en la transferencia de conocimiento.

- Crear un modelo teórico en el que se introduzcan las variables comentadas anteriormente, analizando sus posibilidades de relaciones tanto directas como indirectas.

- Contrastar el modelo teórico desarrollado con el estudio empírico, llevado a cabo en el sector hotelero español; utilizando para ello la metodología de análisis de los modelos de ecuaciones estructurales, que permiten corroborar todas las propiedades sociométricas exigibles a las escalas de medición en ciencias sociales para cada una de las variables del estudio, además de determinar la existencia de relaciones causales entre los constructos teóricos.

- Proporcionar al gerente un conjunto de prácticas que le permita gestionar de manera eficiente la transferencia de conocimiento tanto a nivel interno como 


\section{Capitulo 0 Introducción}

externo a la organización y analizar la repercusión que ello podría tener en los resultados empresariales.

\subsection{ETAPAS Y METODOLOGÍA DEL ESTUDIO}

La primera parte del estudio, de naturaleza teórica, comprende los tres primeros capítulos.

En el primer capítulo se revisan los diferentes enfoques en organización de empresas, sus principales aportaciones y limitaciones, definiendo el posicionamiento teórico adoptado para el desarrollo de la investigación.

En el capítulo segundo se analiza los factores determinantes para la creación de ventaja competitiva, la distinción entre recursos, capacidades y competencias, el concepto de la gestión del conocimiento, la transferencia de conocimiento y su efecto en la creación de ventajas competitivas sostenibles.

En el capítulo tercero se construye el modelo teórico explicativo de la relación existente entre los factores antecedentes (visión holística de la organización, la gestión por competencias, el aprendizaje continuo y el uso de herramientas tecnológicas) con la transferencia de conocimiento y su efecto en el desempeño organizativo. 


\section{Capitulo 0 Introducción}

En la segunda parte del estudio, de naturaleza empírica, se aplica la metodología necesaria para la construcción de los instrumentos de medida, a fin de contrastar las hipótesis generadas en el modelo teórico.

En el cuarto capítulo se justifica la elección del sector hotelero en España para la realización del estudio, su importancia y características, así como el diseño de la investigación empírica y las ventajas del uso de ecuaciones estructurales para el análisis de los resultados y prueba de las hipótesis.

En el capítulo quinto se determina si los instrumentos utilizados para medir los constructos teóricos son adecuados y por otra parte si las hipótesis desarrolladas en el modelo teórico se comprueban o no en la muestra de estudio.

Finalmente, en el capítulo sexto se presentan las conclusiones del estudio, haciendo especial énfasis en los resultados obtenidos a nivel de investigación como a nivel pragmático para su aplicación en las empresas, así como las limitaciones del estudio y futuras líneas de investigación. 


\section{Capítulo 1}

\section{Revisión de los Enfoques en} Organización de Empresas 


\subsection{INTRODUCCIÓN Y OBJETIVOS DEL CAPÍTULO}

Si bien los emprendimientos organizados han existido desde la historia de la humanidad, la evolución de los enfoques en organización de empresas es relativamente reciente. Las imponentes construcciones de la antigüedad que perduran hasta la actualidad, así como otros eventos de los orígenes de la administración, reconocen la necesidad de planear, organizar, dirigir y controlar, así como la aplicación de principios administrativos universales (Chiavenato, 2006).

El desarrollo de los enfoques en organización de empresas ha sido lento hasta fines del siglo XIX. El punto de inflexión en el mismo se experimenta a partir de la revolución industrial, con elementos tales como el poder de las máquinas, la producción en masa y el transporte eficiente.

Los diversos enfoques en organización de empresas han sido desarrollados desde diversas disciplinas, como la economía, psicología y sociología. Entre los numerosos trabajos que han realizado una revisión de los enfoques sobre la organización se encuentran los de (Rivas, 2009; Sanchez y Heene, 1997; Koontz, O'Donnell y Weihrich, 1980) entre otros.

Rivas (2009) elabora un mapa donde sitúa los diversos enfoques, tomando en cuenta las dimensiones: gestión de la complejidad, universalidad y determinismo de sus conceptos. Sanchez y Heene (1997) ubican los diversos enfoques entre dos 
perspectivas teóricas: la económica, que tiene una orientación más hacia el entorno y la del comportamiento organizacional, que tiene una orientación más interna. Por su parte, Koontz et al. (1980) identifican al menos once escuelas o enfoques de la teoría de la administración, a la que denominan la "Jungla de la teoría administrativa".

En la siguiente figura se presenta los principales enfoques bajo las perspectivas económica y del comportamiento organizacional, así como la gestión de la complejidad.

Figura 1.1. Enfoques en Organización de Empresas

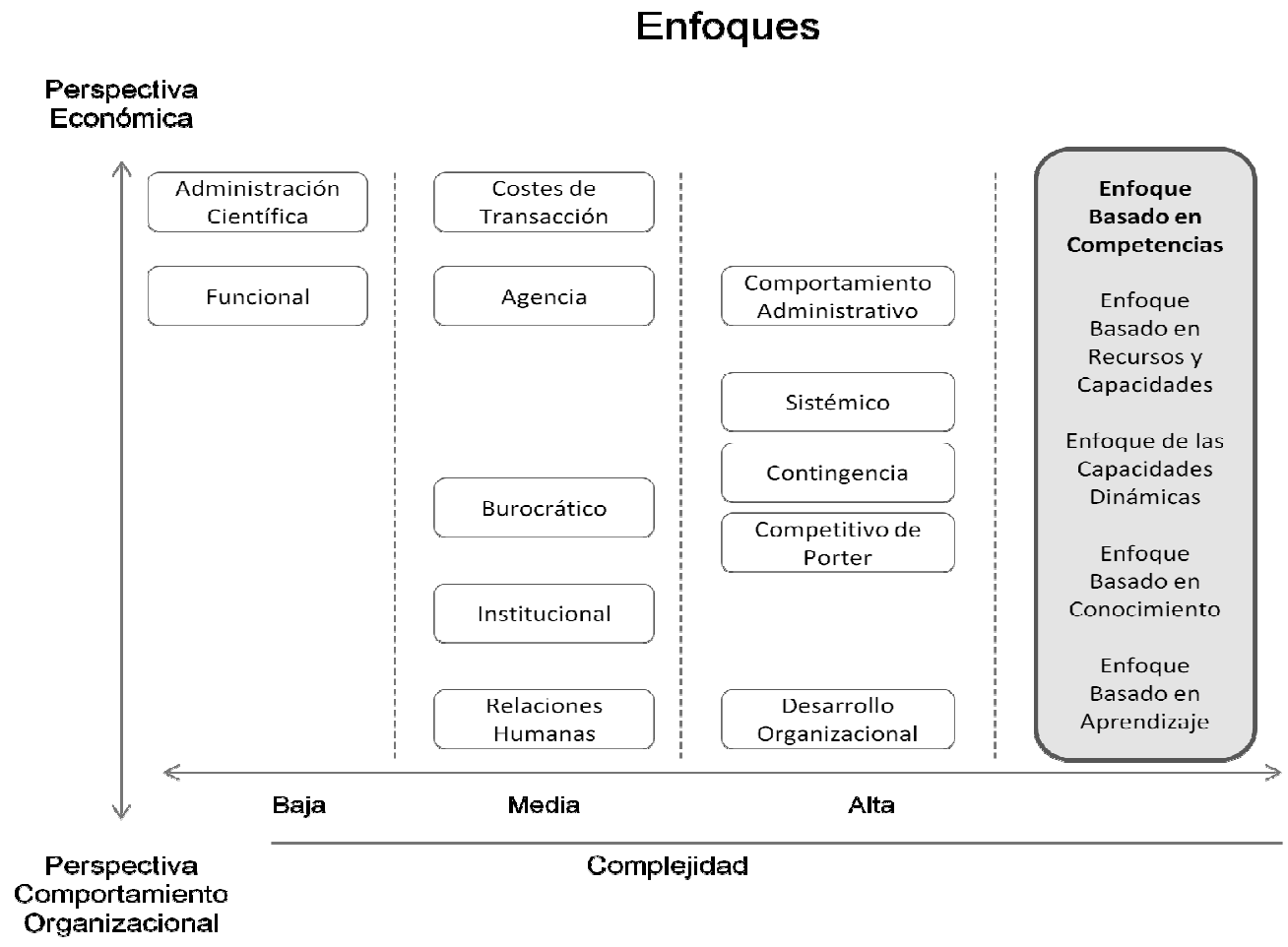

Fuente: Elaboración propia a partir de Rivas (2009) y Sanchez y Heene (1997) 
En el primer epígrafe del presente capítulo se presentan los enfoques en organización de empresas, con los cuales se pretende describir el desarrollo y evolución de los diversos enfoques a fin de comprender su énfasis y abordaje para lograr mayor eficiencia, eficacia y finalmente consolidar ventajas competitivas que se reflejen en un mejor desempeño organizativo.

En el segundo epígrafe se revisan los enfoques en organización de empresas, partiendo de los enfoques clásicos, que tienen su origen en la revolución industrial, hasta el enfoque competitivo de Porter (1980), que se centra en la relación existente entre la estrategia y el entorno externo.

El Enfoque Basado en Competencias y sus principales corrientes se revisa en el tercer epígrafe, cuyo aspecto común es resaltar el rol que juegan los activos intangibles en la generación de ventajas competitivas.

Con base en la revisión, las complementaciones y limitaciones de cada enfoque, en la parte final del capítulo se presenta el posicionamiento teórico adoptado para la presente investigación.

\subsection{REVISIÓN DE LOS ENFOQUES EN ORGANIZACIÓN DE EMPRESAS}

Como menciona Gutierrez (2008) en el área de administración de empresas, las teorías no son más que generalizaciones de la práctica entendiéndose como "Grupo coherente de supuestos que se presentan para explicar la relación entre dos o más hechos observables y proporcionar una base sólida para predecir 
futuros eventos". En esta área debido a las limitaciones de las teorías para cumplir con los aspectos de: supuestos, hechos observables y predicciones, en el presente trabajo utilizaremos el concepto de "enfoques en organización de empresas" por ser más pertinente.

A continuación se presenta la primera parte de la revisión de los enfoques en organización de empresas, sus principales aportaciones, énfasis y limitaciones.

\subsubsection{Enfoque de la Administración Científica}

La necesidad de incrementar los volúmenes de producción en el contexto de la revolución industrial, marcó la transición del sistema artesanal al industrial. Los primeros esfuerzos para estudiar el trabajo de forma sistemática fueron realizados por Frederick Taylor en su obra "Administración de talleres" Shop Management publicada en 1903. Con su conocido estudio de tiempos y movimientos puso énfasis en la optimización de las tareas de producción, buscando la racionalización del trabajo a nivel operativo, la racionalización de la remuneración y del trabajador.

En su obra más conocida, "Principios de la administración científica" Principles of Scientific Management, Taylor (1911) planteó cuatro principios: desarrollo de una ciencia de medición del trabajo de las personas; un proceso de selección científica, entrenamiento y desarrollo de los trabajadores; un esfuerzo cooperativo de los trabajadores para asegurar que todo el trabajo se realizará conforme a los principios de la administración científica y la idea de que el trabajo y la 


\section{Capítulo 1 Revisión de los Enfoques en Organización de Empresas}

responsabilidad son compartidos tanto por la administración como por el trabajador.

Otro aporte es el de Henry Gantt por su gráfica de control de avances de proyecto, muy utilizada hoy en día en la gestión de proyectos y planificación (Gantt, 1919); así como el de los esposos Frank y Lilian Gilbreth (Gilbreth y Gilbreth, 1920), con el análisis de los micro movimientos.

En este periodo, la oferta era menor que la demanda, por lo que la preocupación de las empresas fue lograr la mayor eficiencia y productividad. La principal crítica al enfoque de la administración científica es el excesivo énfasis en la idea de que el ser humano se guía únicamente por el interés económico.

\subsubsection{Enfoque Funcional}

Durante las primeras décadas del siglo XX, las organizaciones experimentaron un gran crecimiento, esto debido a que la oferta era menor que la demanda y se requería incrementar los volúmenes de producción. Este periodo se caracterizó por un proceso migratorio del campo a las ciudades, la transformación de los sistemas de producción y el crecimiento de las organizaciones en tamaño y complejidad; en el ámbito económico se vivió la crisis mundial conocida como la "Gran Depresión".

Henry Fayol (Fayol, 1916) definió cinco funciones básicas de una organización: seguridad, producción, contabilidad, comercialización y administración, además 
planteó catorce principios, hoy conocidos como los principios universales de la administración.

El énfasis del enfoque funcional se centra en la estructura, considerando que la mejor forma de organización es la que se basa en la división de funciones y estas en sub funciones y procedimientos, las cuales son desarrolladas por uno o más puestos.

Frente al crecimiento y complejidad de las organizaciones, el enfoque funcional proporcionó importantes instrumentos para la estructuración de las organizaciones, como ser los organigramas, manuales de funciones y procesos.

En este periodo los criterios de eficiencia fueron llevados al extremo, con la mecanización del ser humano, considerándolo como un apéndice de la máquina. Otra de las limitaciones de este enfoque está referida a considerar a la organización como un sistema cerrado.

\subsubsection{Enfoque de las Relaciones Humanas}

Los conflictos sociales generados por la relación obrero patronal, la creación de los sindicados y su ascenso al poder, la influencia de la legislación socio - laboral y el desarrollo de las ciencias humanas, marcan el contexto del enfoque de las relaciones humanas.

Los trabajos de Elton Mayo (Mayo, 1933) y resultados del experimento en la planta Hawthorne de la Western Electric, demostraron la importancia de los 


\section{Capítulo 1 Revisión de los Enfoques en Organización de Empresas}

grupos informales y evidenciaron que los aspectos emocionales son más importantes que los físicos. Por su parte, Lewin (1935) demostró que la participación social de los trabajadores influye positivamente en la productividad.

Metcalf y Urwick (2003) hacen referencia a los importantes aportes de Mary Parket Follet (1920) que desde un enfoque sociológico resaltó la importancia de identificar las motivaciones individuales y grupales para el desempeño de las tareas en las organizaciones. Maslow (1943) propuso la Teoría General de las Motivaciones, junto a McGregor (1960), Frederick Herzberg (1959), Chris Argyris (1957), Douglas y Rensis Likert (1932) entre otros, que aplicaron los principios de la psicología a las organizaciones.

Es importante resaltar la influencia de la psicología en el desarrollo del enfoque de las relaciones humanas, el estudio del comportamiento humano y sus motivaciones. Como se verá en los capítulos siguientes, este aspecto es fundamental para la gestión del conocimiento en las organizaciones.

Las principales limitaciones de este enfoque se refieren a su validez científica, puesto que se sustenta más en experimentos clínicos que controlados. Por otra parte, la excesiva preocupación por la "felicidad" del trabajador presenta una visión simplista del comportamiento humano.

\subsubsection{Enfoque Burocrático}

La burocracia surge como una crítica al enfoque clásico de la administración y de las relaciones humanas. Plantea que la forma más eficiente de una organización es 
la que se asemeja a una máquina, de ahí la importancia del establecimiento de reglas, controles y jerarquías.

El principal exponente de este enfoque fue el Alemán Max Weber (1864-1920). La burocracia busca la previsibilidad de funcionamiento de una organización, caracteriza a la autoridad en: carismática, tradicional y racional - legal. El enfoque basa su desarrollo en la autoridad racional - legal; promueve las relaciones de grupo impersonales, la división del trabajo y especialización, así como el carácter formal de las comunicaciones.

Las principales críticas a este enfoque se derivan de las disfunciones de la burocracia, así como la tendencia a convertir a la administración en un fin en sí misma y no en un medio para lograr los objetivos de la organización.

\subsubsection{Enfoque Sistémico}

Las principales críticas al enfoque de la administración científica y los enfoques funcionalistas, se refieren a la consideración de la organización como un sistema cerrado, en respuesta a estas críticas surge el enfoque sistémico de la organización.

El biólogo Alemán Ludwing von Bertalanffy propuso en 1936 la teoría general de sistemas, en la cual acentúo que los verdaderos sistemas son abiertos e interactúan con su entorno. Los sistemas pueden adquirir nuevas características, dando como resultado la evolución continua. 


\section{Capítulo 1 Revisión de los Enfoques en Organización de Empresas}

A partir de los trabajos de Bertalanffy (1956) surgen dos escuelas en el ámbito de la administración: La escuela de la teoría matemática o cuantitativa que aplica modelos matemáticos en las decisiones. Esta escuela se enfoca en la teoría de las decisiones y la investigación de operaciones (Savage, 1954; Wald y Doty, 1954; Neumann y Morgenstern, 1947) y por otra parte, la propia escuela de la teoría de sistemas.

Bajo esta última teoría, la organización está conformada por subsistemas e interactúa con el medio ambiente. La coordinación y ajuste de los diferentes subsistemas y la adaptación del sistema en su conjunto a los cambios del entorno, requieren de un sistema de información que guíe la toma de decisiones. Los subsistemas que conforman la organización son: metas y valores, técnico, psicosocial, estructural y administrativo (Kast y Rosenzweig, 1969).

El enfoque de los sistemas considera a la organización como un sistema abierto en interacción con su entorno. Por otra parte enfatiza la importancia de uno de los recursos intangibles, que es la información, para la toma de decisiones. El éxito de una organización dependerá entonces de la coordinación armónica de los diferentes subsistemas y la consideración de la organización como un sistema abierto.

Es importante mencionar el aporte de este enfoque que considera a la empresa como un sistema abierto que interactúa con su entorno, debiendo generar capacidades dinámicas para reconfigurar sus recursos. 


\section{Capítulo 1 Revisión de los Enfoques en Organización de Empresas}

Una de las principales limitaciones del enfoque de sistemas es la distinción entre un sistema abierto y cerrado, así como sus implicaciones administrativas, debido a la confrontación entre estas dos perspectivas.

\subsubsection{Enfoque del Comportamiento Administrativo}

Bajo este enfoque se concibe a la organización como un sistema articulado que promueve la consistencia de las decisiones y actividades a lo largo de la organización.

En este contexto, los directivos y empleados toman decisiones en cada nivel de la organización; los objetivos son los fines y estos se convierten en los medios del siguiente nivel (Simon, 1947)

De acuerdo a la jerarquía, complejidad e información con la que se cuenta, las decisiones pueden ser: estratégicas u operativas, programables y no programables o en condiciones de certeza, riesgo o incertidumbre.

En contraposición al "hombre económico" propuesto por Taylor (1911); Simon (1961) propone el concepto del "hombre administrativo", que es consciente de que tiene solo algunas alternativas posibles para tomar una decisión y que está dispuesto a elegir la solución adecuada en el proceso de la búsqueda de la solución óptima.

En el proceso de decisión se identifican las fases de: investigación, modelización y elección; tomando como principio el de la "racionalidad limitada", que 
considera las limitaciones cognoscitivas de los responsables de tomar decisiones. La mayoría de las personas son solamente en parte racionales y emocional/irracionales en la parte restante de sus acciones.

La mejor forma de organización es la que permite que los empleados en todos los niveles tomen decisiones y colaboren en el cumplimiento de los objetivos. Si bien la adecuada toma de decisiones en todos los niveles es fundamental para la dirección de una organización, una limitación del enfoque es no reconocer que existen otros factores internos y externos que influyen en la consolidación y mantenimiento de ventajas competitivas.

\subsubsection{Enfoque del Desarrollo Organizacional}

El enfoque del desarrollo organizacional toma como base al enfoque del comportamiento en camino al enfoque sistémico. Este considera a la empresa como un sistema orgánico, desarrollando los conceptos de cultura organizacional, cambio y desarrollo.

El desarrollo de la organización requiere de la participación de la alta dirección así como de los diferentes niveles de la organización. Los grupos son la clave del cambio, en el proceso de recolección de datos, diagnóstico organizacional y acción de intervención.

Los experimentos de Lewin (1935) y las complementaciones de McGregor (1960) demostraron la dificultad de trasladar las habilidades adquiridas en el entrenamiento a la vida laboral. 
La mejor forma de organización es la que promueve el cambio planeado basado en intervenciones, donde la colaboración de los diferentes niveles de la organización es fundamental.

Algunos críticos mencionan que el desarrollo organizacional no es más que un conjunto de descubrimientos y principios del enfoque de las relaciones humanas y del comportamiento. Por otra parte, el campo de acción no se encuentra lo suficientemente delimitado, existiendo una contradicción en que sus principios se basen en el conocimiento científico.

\subsubsection{Enfoque de la Contingencia}

El enfoque de la contingencia, que toma varias formas y surge como oposición a las teorías clásicas de la administración, propone que no existen principios rígidos y que los mismos no están limitados en número para su aplicación en cualquier organización o situación.

El enfoque de la contingencia o situacional tiene dos corrientes: la escuela de los Sistemas Socio - Técnicos (Burns y Stalker, 1961) y la corriente Contingencial (Woodward, 1965).

Las principales ideas de la teoría de la contingencia son: no existe una mejor manera o universal de organización; el diseño de una organización y sus subsistemas deben considerar al entorno; las organizaciones eficaces consideran al entorno pero también la relación interna de sus subsistemas; las necesidades de la organización son satisfechas de mejor manera cuando se diseña correctamente la 


\section{Capítulo 1 Revisión de los Enfoques en Organización de Empresas}

organización y el estilo gerencial es el apropiado para el tipo de tareas a ejecutar y la naturaleza del grupo de trabajo.

Con estas consideraciones, es necesario diseñar las organizaciones con estructuras y modelos diferentes: un área organizada con los principios burocráticos y otra como un sistema abierto con flexibilidad y autonomía. Burns y Stalker (1961) sostienen que el mejor diseño de organización depende de su tecnología, tamaño y medio ambiente.

El enfoque contingente se muestra eminentemente ecléctico e integrador, pero al mismo tiempo relativista y situacional (Chiavenato, 2006)

\subsubsection{Enfoque de la Población Ecológica}

La teoría de la evolución propuesta por Darwin en 1869 sostenía que existen rasgos que se pueden heredar de los organismos individuales de una especie y que estos mejoran la capacidad reproductiva llegando a ser dominantes en la especie.

La teoría evolutiva se ha aplicado a una amplia gama de situaciones que implican procesos de cambio. Por ejemplo, el campo de la informática ha considerado la introducción de algoritmos evolutivos, tales como algoritmos genéticos.

Los recursos son limitados para todas las organizaciones, por ello se debe diseñar la mejor forma de organización, a fin de que cuando exista un cambio en el entorno, la organización pueda adaptarse y sobrevivir, puesto que si no es así la inercia la conducirá a la desaparición. 
Nelson y Winter (1982) han presentado la selección como funcionamiento en el nivel de la organización, con algunas empresas que sobrevivían al ambiente competitivo mientras que otras desaparecen. Por lo tanto, la mejor forma de organización es la que consigue adaptarse al entorno y sigue operando con eficiencia.

Este enfoque deja sin resolver cuestiones tales como: las implicaciones del intercambio y la trascendencia de las habilidades individuales de los miembros de la empresa, con independencia de la interacción que logran al interior de la misma para contribuir individualmente a la respuesta estratégica requerida para enfrentar la competencia.

\subsubsection{Enfoque Institucional}

El enfoque institucional propone una distinción entre las instituciones propiamente dichas (iglesia, ejército, gobierno) y las organizaciones privadas, debido a su complejidad y sus fines.

Scott (1987) afirma que las instituciones son las estructuras sociales que han logrado un alto nivel de resistencia. Se componen de los elementos culturalcognoscitivos y normativos que, junto con actividades y recursos asociados, proporcionan estabilidad y significado a la vida social.

DiMaggio y Powell (1983) describen el isomorfismo institucional que identifica tres tipos de efectos: el coercitivo, referido a las presiones de las organizaciones de las que depende; el mimético, que es la imitación de las organizaciones con 
más éxito y el normativo, que hacen referencia a las normas compartidas por varias organizaciones.

La mejor forma de organización es la que considera e integra a las personas que las hacen funcionar y logra una aceptación social que garantiza su vigencia y sostenibilidad. El enfoque institucional atiende a los aspectos más profundos y más resistentes de la estructura social.

La limitación de este enfoque radica en que se aplica básicamente a instituciones no lucrativas, donde los aspectos básicos de sobrevivencia son las de legitimación y aceptación por parte de la sociedad.

\subsubsection{Enfoque de los Costes de Transacciones}

El enfoque de los costes de transacciones identifica básicamente dos tipos de costes: los costes de producción y los costes de transacción; estos últimos referidos a la búsqueda del producto, a establecer el contrato, supervisar y hacer cumplir en la práctica el mismo (Williamson, 1979)

Según Coase (1937) las transacciones suponen unos costes que dependen de la naturaleza de la transacción y de la forma como se organice. La mejor forma de organización es la que minimiza los costes de transacción.

Frente a la incertidumbre y los costes de transacción, las organizaciones internalizan sus operaciones, por lo que si economiza en sus transacciones la empresa se desarrollará. 
Las tres dimensiones clave de las transacciones son: la especificidad de los activos, la incertidumbre y la frecuencia de las relaciones. Las empresas, a la hora de elegir los límites organizativos, buscan la minimización de la suma de estos costes de transacción más los costes de producción (Williamson, 1979).

Este enfoque parte de la consideración del ser humano como "homus económicus", resaltando el comportamiento oportunista. Por otra parte, presenta un enfoque parcial, orientándose a predecir el comportamiento de las organizaciones sobretodo en mercados externos y a la vez un equilibrio parcial para la toma de decisiones de aprovisionamiento y la cadena de suministros (Grant, 1996).

\subsubsection{El Enfoque de la Agencia}

Una relación de agencia surge cada vez que un individuo depende de la acción del otro. En esta relación se pueden suscitar conflictos entre los deseos o las metas del principal (accionistas) y del agente (ejecutivos), ya que puede resultar difícil o costoso que el principal verifique lo que está haciendo el agente. Por otra parte, puede presentarse el problema de la distribución del riesgo, cuando el principal y el agente tienen diversas actitudes hacia el riesgo.

La teoría de la agencia estudia las formas óptimas para formalizar contratos entre un agente y el principal. Eisenhardt (1989) establece dos mecanismos de gobierno para controlar al agente: el establecimiento de contratos basados en resultados y el desarrollo de sistemas de información. 
La mejor forma de organización es la que crea los mecanismos que previenen que el agente actué a favor de sus propios intereses y lo premia si actúa a favor de los intereses de la organización.

La relación de agencia implica siempre la existencia del problema del riesgo moral: la posibilidad de que el agente busque objetivos personales en detrimento de los intereses del principal.

Entre las principales críticas a la teoría de la agencia están los riesgos asociados a los incentivos para los ejecutivos (agentes), el criterio oportunista de estos y las asimetrías de información generadas entre el principal y los agentes.

\subsubsection{Enfoque Competitivo de Porter}

Según Porter (1980) la naturaleza e intensidad de la competencia en una industria está dada por cinco fuerzas: la amenaza de nuevos competidores, el poder de negociación con los clientes, el poder de negociación con los proveedores, la amenaza de productos sustitutos y la rivalidad competitiva.

El análisis de las cinco fuerzas competitivas, el análisis de la cadena de valor y el planteamiento de estrategias genéricas (liderazgo en costes, diferenciación y enfoque), son los principales aportes de Michael Porter al enfoque de la estrategia competitiva.

Porter identifica como línea prometedora de investigación a la perspectiva de recursos y capacidades, aunque se muestra crítico con respecto a que la ventaja 
competitiva resida "dentro" la empresa y no en el "entorno industrial". En este sentido, ha reformulado su marco conceptual contemplando explícitamente la dimensión longitudinal y dinámica a través del tiempo.

Entre las limitaciones de este enfoque se tiene la subjetividad para la construcción de la matriz de Fortalezas, Oportunidades, Debilidades y Amenazas; su aplicación en entornos predecibles y estables; así como el hecho de que la estructura sigue a la estrategia.

\subsection{ENFOQUE BASADO EN COMPETENCIAS}

Durante la década de 1980 el principal desarrollo en el análisis estratégico estuvo enfocado hacia la relación existente entre la estrategia y el entorno externo (Grant, 1991). Con el paso del tiempo resurgió el interés en el rol de los recursos organizacionales como la fuente de las ventajas competitivas.

Sanchez, Heene y Thomas (1996) caracterizan a la empresa como un sistema de activos tangibles e intangibles organizados de una manera estratégicamente lógica para alcanzar sus metas y utilizar ciertos procesos administrativos para guiar la creación, producción y marketing de los productos. Mencionan, además, que el nuevo énfasis de esta perspectiva está en los activos intangibles, tales como la tecnología, habilidades y sinergias.

Por su parte, Foss y Knudsen (1996) indican que las organizaciones son vistas esencialmente como entidades heterogéneas, caracterizadas por sus bases únicas de conocimiento. Desde otra perspectiva, las empresas son vistas como una 


\section{Capítulo 1 Revisión de los Enfoques en Organización de Empresas}

entidad contractual eficiente, en el sentido de que alinear los incentivos de varios propietarios de inputs que intervienen en una relación contractual con la entidad legal conocida como la firma.

Otra alternativa es ver a la empresa en términos de su dotación de stocks de capital de conocimiento, competencias esencialmente heterogéneas pero a la vez productivas, las mismas que están asociadas a diferentes niveles de eficiencia.

En este sentido, Foss y Knudsen (1996) describen a las competencias como el capital del conocimiento idiosincrático que permite al que lo contiene el desarrollo de actividades de manera más eficiente. Por otro lado, argumentan que el conocimiento tiene un componente tácito y que el mismo está distribuido de manera asimétrica en la organización, puesto que reside en los individuos.

Algunas competencias son nucleares y otras no. La perspectiva de competencias nucleares permite incorporar el aspecto dinámico de la competencia, en el cual las diferencias entre las capacidades idiosincráticas de la firma son importantes y se constituyen en la base de la generación de ventajas competitivas (Sanchez et al., 1996)

Un aspecto importante que mencionan Sanchez et al. (1996) es que las firmas deben verse como organizaciones de aprendizaje que mantienen su flexibilidad estratégica y operacional al pensar y actuar sistemáticamente, buscando la renovación a través de un repensar continuo de sus fuentes fundamentales de ventajas competitivas. 


\section{Capítulo 1 Revisión de los Enfoques en Organización de Empresas}

Estos autores definen a la flexibilidad organizacional como la habilidad y voluntad de la firma para configurar cualquiera de sus capacidades de gestión y recursos organizacionales, en un sinfín de maneras, de modo que pueda dar una respuesta positiva a las oportunidades o necesidades de mercado.

Para ello, es necesario crear una infraestructura de información que promueva el flujo de información interna y externa, así como utilizar equipos de auto regulación para alcanzar una estructura organizacional no jerárquica que incentive la creatividad e iniciativa. Resaltan también la importancia de crear una visión compartida que guíe a la organización hacia ese futuro deseado, coordinando las decisiones y acciones en el proceso de identificación, creación y renovación de competencias.

Las empresas son sistemas abiertos cuyas acciones están motivadas por la búsqueda colectiva de metas por parte de sus empleados y otros actores. Las firmas persiguen metas estratégicas que consisten en un set distintivo de objetivos para cerrar las brechas entre los estados percibidos y deseados.

Siguiendo esta línea de pensamiento, Montresor (2004) define a la firma como un set de recursos tangibles e intangibles, que tiene capacidades específicas para configurar, explotar y posiblemente renovarlas, así como competencias idiosincráticas para utilizarlas en las actividades de resolución de problemas y rutinas.

Respecto a la generación de ventajas competitivas sostenibles en las organizaciones, Barney (1991) sugirió que se logra mediante la implementación 


\section{Capítulo 1 Revisión de los Enfoques en Organización de Empresas}

de estrategias que permiten explotar sus fortalezas internas, a través de sus respuestas a las oportunidades del entorno, mientras que al mismo tiempo neutralizan sus amenazas externas y evitan sus debilidades internas.

Menciona también que las organizaciones deben implementar estrategias con las siguientes características: que creen valor, que las mismas no hayan sido implementadas simultáneamente por otro competidor potencial y que los competidores no sean capaces de duplicar los beneficios de dicha estrategia.

Otros autores, como Prahalad y Hamel (1990), argumentan que la verdadera fuente de ventajas competitivas se encuentra en la habilidad gerencial de consolidar las tecnologías corporativas y las habilidades productivas dentro de lo que son las competencias de la organización, las mismas que permiten fortalecer los negocios individuales y su adaptación rápida a las oportunidades cambiantes del entorno.

Camisón y Boronat (2004) señalan que los trabajos en esta área tienen como denominador común la importancia que tienen las competencias específicas de cada empresa para la estrategia y el logro de su éxito como empresa.

Algunos indican que el término de sostenible hace referencia únicamente a un periodo de tiempo específico (Porter, 1985); sin embargo, otros autores indican que el mismo puede referirse a la posibilidad de que dicha estrategia se duplique.

El Enfoque basado en competencias $(\mathrm{EBC})$ proporciona un vehículo para entender cómo las diferencias y similitudes entre empresas pueden aparecer 


\section{Capítulo 1 Revisión de los Enfoques en Organización de Empresas}

sistemáticamente dentro de una industria, en el que las empresas individualmente buscan distinguir sus productos que sirven a las necesidades similares de los clientes (Sanchez et al., 1996).

El EBC tiene la virtud de recoger varias líneas de pensamiento, cuyo aspecto común es resaltar el rol que juegan los activos intangibles en la generación de ventajas competitivas sostenibles. Por ello, la empresa debe poseer la habilidad para acumular, proteger y desarrollar competencias (Foss y Knudsen, 1996)

Entre sus principales líneas de pensamiento están: el enfoque basado en recursos y capacidades, el enfoque de las capacidades dinámicas, el enfoque basado en el conocimiento y el enfoque basado en el aprendizaje.

El EBC es considerado como la perspectiva teórica dominante en la gestión estratégica (Foss y Knudsen, 1996) . Sin embargo, se identifican algunas limitaciones y críticas que se presentan a continuación.

Las críticas a este enfoque están basadas en su carácter estático, puesto que las ventajas o desventajas competitivas se forman a lo largo del tiempo y a la vez cambian con el tiempo (Helfat y Peteraf, 2003), hecho que debe ser considerado. Por otro lado, se concentran exclusivamente en los recursos individuales que poseen las empresas (Foss y Knudsen, 1996).

Camisón (2002) destaca tres puntos oscuros que el EBC tiene todavía pendientes: el propósito ciertamente paradójico de su objetivo científico ("generalizar lo único"), que se plasma en la proliferación de métodos para los contrastes empíricos; la ambigüedad terminológica de su marco conceptual; y los fallos de operativización. 


\subsubsection{Enfoque Basado en Recursos y Capacidades}

El punto de partida para la formulación estratégica, de acuerdo a Michael Porter, es la posición relativa que tiene una empresa en una industria específica y a partir de esta visión externa determinar que estrategia es la que puede maximizar el rendimiento de la misma. En esta perspectiva, conceptos como atractivo del sector, grupo estratégico o crecimiento de mercado, son utilizados para explicar la rentabilidad de la empresa.

Este análisis supone que las empresas pertenecientes a un mismo sector son iguales en cuanto a recursos y estrategias disponibles, y que las diferencias entre las empresas solo se pueden mantener a corto plazo.

La aparición de trabajos que demuestran cómo las diferencias de resultados entre sectores son menos significativas que las diferencias en el seno de un mismo sector (Rumelt, 1991; Hansen y Wernerfelt, 1989), motiva el interés de volverse a centrar en los aspectos internos de la empresa como factores explicativos de los resultados de la misma.

En este sentido y en contraposición al enfoque de Porter, el Enfoque basado en recursos y capacidades (EBR) parte por evaluar los recursos que posee la empresa y su potencial para la generación de valor, para luego generar una estrategia que le permita captar el máximo valor de forma sostenible.

Una pionera definición de la firma bajo esta este enfoque es la de Penrose en su libro The Theory of the Growth of the Firm como "un conjunto de recursos 
productivos cuya distribución entre los diferentes usos y en el curso del tiempo, se determina por decisiones administrativas" (Penrose y Pitelis, 2009).

El EBR se basa en las siguientes proposiciones: las empresas pueden ser heterogéneas con respecto a los recursos que controlan; los recursos no son perfectamente móviles entre las organizaciones; siempre y cuando se asegure la heterogeneidad en el tiempo, la heterogeneidad explicará la diferencia de resultados entre las empresas; y la capacidad organizativa es la habilidad para realizar rutinas organizacionales (Barney, 1991).

Eisenhardt y Martin (2000) indican que este enfoque es un marco teórico influyente para entender como la ventaja competitiva dentro de las firmas es alcanzada y como esta ventaja puede sostenerse en el tiempo. Definen a la empresa como un ramo de recursos que están heterogéneamente distribuidos a lo largo de las empresas y que esas diferencias entre recursos persisten en el tiempo.

Peteraf y Barney (2003) explican las diferencias de desempeño entre empresas competitivas debido a las diferencias entre sus recursos. Coinciden en que la heterogeneidad puede ser el resultado de la incertidumbre y la inamovilidad, pero a la vez puede resultar de la dependencia de un patrón, el cambio en los eventos, la duración gubernamental, la distribución inapropiada de los derechos de propiedad, entre otros.

Los recursos heterogéneos pueden resultar en ventajas competitivas sostenibles incluso cuando existe certeza acerca de la naturaleza de la ventaja. Solo porque es 


\section{Capítulo 1 Revisión de los Enfoques en Organización de Empresas}

posible identificar la causa de una ventaja, esto no implica que la misma pueda ser duplicada.

Adicionalmente mencionan que este enfoque se basa en los recursos y capacidades que son controlados por la empresa y que contribuyen a generar diferentes desempeños persistentes entre las firmas. Pero a la vez, atribuyen estas diferencias directamente a factores externos, tales como la estructura del mercado, factores institucionales o interacciones estratégicas.

Las variaciones en los beneficios son explicados por fuerzas que ocurren a nivel de la empresa, pero también a nivel de la industria y del grupo empresarial. Los factores empresariales, si bien no explican todo, ofrecen un gran poder explicativo.

De igual manera, Conner y Prahalad (1996) mencionaron que el enfoque de recursos indica que las diferencias en el desempeño entre las compañías están dadas por las asimetrías que existen en el uso del conocimiento, capacidades organizacionales y recursos. En esta misma línea, Mahoney y Pandian (1992) sostienen que el desarrollo de capacidades distintivas es la fuente de la ventaja competitiva en las organizaciones y que la mejor forma de organización será aquella que gestione más racionalmente sus recursos y capacidades.

El EBR permite entender mejor el vínculo que existe entre las tecnologías de la información y el desempeño organizacional. El argumento se basa en que las firmas poseen recursos y que los organizan de manera que se alcance una ventaja 
competitiva, la misma que ayudará a la organización para alcanzar un mejor desempeño a largo plazo (Mills y Smith, 2011).

Camisón y Boronat (2004) indican que este enfoque resalta la importancia de los elementos internos (idiosincrásicos) que posee una empresa como diferenciales para el logro de resultados. Mencionan, además, que el origen de las ventajas competitivas sostenibles y de las rentas económicas se encuentra en la propia empresa.

Se identifican dos escuelas en el EBR: la escuela estructural, que se centra en los atributos que deben poseer los recursos para generar una ventaja competitiva (Barney 1986, 1991); (Wernerfelt, 1984); (Dierickx y Cool, 1989) y la escuela de proceso, que se centra en la adquisición, desarrollo y generación de conocimiento (Nonaka, 1991; Nonaka, 1994; Grant, 1991; Kogut y Zander, 1992; Teece, Pisano y Shuen, 1997).

La evolución de la escuela de proceso deriva del desarrollo de otras corrientes de pensamiento, como el enfoque basado en el conocimiento y el enfoque de las capacidades dinámicas, que se analizan más adelante.

Una de las principales críticas efectuadas al EBR está basada en su carácter estático, puesto que no toma en consideración a los factores externos que rodean a los recursos. Por otro lado, tampoco considera que las ventajas y/o desventajas competitivas cambian en el tiempo, por lo que estos aspectos deberían ser tomados en cuenta (Helfat y Peteraf 2003). 


\section{Capítulo 1 Revisión de los Enfoques en Organización de Empresas}

El carácter estático de la EBR no explica porque algunas empresas son capaces de lograr y sostener ventajas competitivas en entornos dinámicos e impredecibles (Foss y Knudsen, 1996).

Por otro lado, no existe una conceptualización clara que incluya una explicación de cómo surge la heterogeneidad entre los recursos. La ausencia de claridad en este proceso, dificulta la explicación proporcionada a la forma en que las firmas utilizan los recursos y capacidades para crear ventajas competitivas (Helfat y Peteraf, 2003).

Otra limitación mencionada es la ambigüedad y diversidad en las definiciones sobre los recursos, capacidades y competencias.

Javidan (1998) critica la definición de Prahalad y Hamel respecto a las competencias nucleares, mencionando que utilizan los conceptos de competencia, competencias nucleares y capacidades como sinónimos e incluso definen estos términos como una combinación de habilidades de producción y tecnológicas además de que su definición ha generado confusión en la relación existente entre competencia y capacidades.

\subsubsection{Enfoque de las Capacidades Dinámicas}

El enfoque de recursos y capacidades se centra en la selección de recursos apropiados, cuyas principales limitaciones se encuentran en su carácter estático. En cambio, el Enfoque de capacidades dinámicas (ECD) acentúa el desarrollo y la renovación de los recursos. 
El ECD intenta llenar estos vacíos adoptando un acercamiento de proceso; actuando como almacenador e intermediario entre los recursos y el entorno empresarial cambiante. Los recursos dinámicos ayudan a una organización a ajustar su mezcla de recursos de tal modo que pueda mantenerse la continuidad de la ventaja competitiva.

Las capacidades dinámicas se refieren a aquellas que desarrolla la organización a fin de reconfigurar sus competencias en congruencia con el cambiante entorno. Por otra parte, las capacidades dinámicas permiten crear, aplicar y proteger los activos intangibles que apoyan a sostener la ventaja competitiva a largo plazo (Teece, 2007).

Teece et al. (1997) definen las capacidades dinámicas como: "La habilidad de la organización para integrar, construir, y reconfigurar las competencias y alinearlas a los cambios del mercado".

Prahalad y Hamel (1990) complementan la visualización de la empresa como un conjunto de productos y servicios, con la visión de la empresa como un conjunto de competencias, por lo que el equipo gerencial debe: a) identificar las competencias centrales existentes, b) establecer la agenda de adquisición de competencias centrales, c) desarrollar competencias centrales, e) aplicar competencias centrales, y f) proteger y defender el liderazgo de competencias centrales. 
De acuerdo a Prahalad y Hamel (1990) las competencias centrales se refieren al aprendizaje colectivo, entendidas como la coordinación de diversas habilidades de producción e integración de múltiples corrientes de tecnología.

Por su parte, Eisenhardt y Martin (2000) conceptualizan a las capacidades dinámicas como rutinas estratégicas que ayudan a las empresas a alcanzar nuevas configuraciones de recursos en función de los cambios en los mercados, los cuales: emergen, colisionan, dividen, evolucionan y mueren.

Winter (2003) desarrolla su trabajo en torno a la existencia de jerarquías o niveles en la aplicación de las capacidades dinámicas dentro de la organización. Por otro lado, reconoce que las capacidades son complejas y multidimensionales, además de que poseen cierto grado de estructuración.

Javidan (1998) propone una jerarquización de necesidades, diferenciando los recursos, capacidades, competencias y competencias centrales, en función del grado de dificultad y valor para la organización. Los recursos son los insumos de la cadena de valor de la empresa y se constituyen en los cimientos de las competencias; mientras que las competencias se refieren a la habilidad de la empresa de explotar sus recursos mediante procesos de negocios y rutinas que gestionan la interacción de los recursos. Una característica distintiva de las capacidades es que éstas residen en las funciones de la empresa.

Respecto a la ventaja competitiva de las organizaciones, Teece et al. (1997) afirman que las mismas están centradas en procesos distintivos y en su capacidad de gestionar adecuadamente sus habilidades organizativas, de recursos y 


\section{Capítulo 1 Revisión de los Enfoques en Organización de Empresas}

competencias. Por otro lado, hacen referencia a la habilidad que tienen las organizaciones de adaptar sus competencias a su entorno. Por lo que este enfoque debe partir de una clara definición del término dinámicas y capacidades.

El primer término hace referencia a la capacidad de renovar competencias, pero de manera congruente con el entorno empresarial cambiante. Por otro lado, el término de capacidades se refiere al rol de la gestión estratégica en la adaptación, integración y reconfiguración de las habilidades internas, externas, recursos, competencias y funciones, que de igual manera deben estar acordes al entorno.

Otras características de las ventajas competitivas mencionadas por los mismos autores hacen referencia a que las mismas están constituidas por el mercado de productos, por la idiosincrasia de la organización y por la dificultad que conlleva el imitar esos recursos.

Palacios (2002) indica que las capacidades pueden clasificarse en individuales y colectivas, a la vez que en estáticas o dinámicas; pudiéndose encontrar una serie de combinaciones entre estas dimensiones. En este sentido, las capacidades individuales estáticas están relacionadas a las habilidades que tienen las personas, siendo que las capacidades colectivas - estáticas se refieren más a las habilidades o destrezas de interacción colectiva. En el campo de las capacidades dinámicas individuales, se hace mención al aprendizaje como elemento crítico y dentro de lo que son las capacidades dinámicas - colectivas se mencionan a la innovación como proceso interactivo de aprendizaje. 
Pese a los aportes proporcionados por este enfoque, Eisenhardt y Martin (2000) mencionaron que las capacidades dinámicas por si solas pueden ser fuente de ventajas competitivas, pero no necesariamente de ventajas competitivas sostenibles.

Adicionalmente, indican que las capacidades dinámicas tienen una alta dependencia del conocimiento existente y que la sostenibilidad de las mismas depende y varía de acuerdo a la velocidad en que el mercado cambia.

\subsubsection{Enfoque Basado en el Conocimiento}

El Enfoque basado en el conocimiento (EBO) emergió en la década de los noventa como consecuencia de la importancia de los recursos intangibles frente a los tangibles.

Los cambios registrados en el mercado de los productos y recursos han cobrado dinamismo e intensidad en los últimos tiempos, afectando de esta manera la evolución de las estrategias organizacionales hacia el conocimiento y la era de la información (Spender y Grant, 1996).

Al respecto, Spender (1996) señala que la ventaja competitiva no deriva totalmente de información asimétrica de los mercados, sino que las capacidades de incrementar las rentas se originan dentro de la organización. El origen de los recursos tangibles se encuentra fuera de la empresa, por lo que sea más probable que la ventaja competitiva derive de los recursos intangibles y más concretamente del conocimiento. 
De esta manera, el conocimiento emerge como el recurso de mayor significancia estratégica en las organizaciones, puesto que permite dar valor añadido y generar barreras en la transferencia y replicación del mismo, como un aspecto estratégico de importancia (Grant, 1996)

Teece (1998) refuerza los argumentos de Spender (1996), resaltando la importancia de los recursos intangibles como la base para la obtención de ventajas competitivas. El EBO considera al conocimiento como el recurso estratégicamente más importante de la empresa.

Bajo este enfoque se considera a la empresa, por una parte, como una institución que crea y aplica conocimiento (Nonaka, 1994; Nonaka y Takeuchi, 1995; Spender, 1996), así como una distribuidora e integradora de conocimiento (Grant, 1996), resaltando la importancia de los mecanismos de coordinación.

En esta misma línea, la integración del conocimiento se constituye en la esencia de la capacidad organizacional. Sin embargo, algunos autores critican que este enfoque es demasiado estático.

El aspecto dinámico a este enfoque fue revelado por Zander y Kogut (1995), quienes especificaron cinco constructos que caracterizan al conocimiento organizacional a nivel individual, grupal y a la vez a la capacidad organizacional. Estos constructos son: codificabilidad, tecnicidad, complejidad, dependencia sistémica y capacidad del producto de ser observable. Miden a la vez la facilidad con que las capacidades son gestionadas, transferidas e imitadas. 
Zander y Kogut (1995) mencionaron también que la transferencia e imitación de las capacidades organizacionales son los elementos gemelos para la competencia e innovación en los mercados crecientes.

Las organizaciones deben entenderse como una fuente de reposición del conocimiento social, en las que el set de capacidades competitivas es replicado a lo largo del tiempo y está sujeto a imitación. Esta orientación hacia el dinamismo en la generación y transferencia de capacidades organizaciones, es congruente con la propuesta presentada por Grant (1996), quien menciona que las empresas generan, almacenan e integran el conocimiento.

A lo largo del tiempo el conocimiento ha sido categorizado de diferentes maneras: Zander y Kogut (1995) indicaron que el conocimiento puede dividirse en información o en "know - how". Nonaka (1994) presentó la distinción entre el conocimiento explicito y tácito, siendo el primero el conocimiento que se encuentra en la organización y el tácito en los individuos.

Por esta razón o característica básica del conocimiento, surge la principal limitación a este enfoque. El conocimiento, si no es aplicado en las firmas, no tendrá un impacto sobre el desempeño organizativo, por lo que se hace evidente la alta dependencia que tiene al factor humano para ello. En este sentido, otros aspectos, como la tecnología, la cultura organizacional y la estructura organizacional, deben ser consideradas en este enfoque (Mills y Smith, 2011). 


\subsubsection{Enfoque Basado en el Aprendizaje}

Templeton, Lewis, y Snyder (2002) definen el aprendizaje organizacional como "un conjunto de acciones (adquisición de conocimiento, distribución de información, interpretación de información y memoria organizacional) dentro de la organización que influye intencional o no intencionalmente el cambio organizacional positivo".

El aprendizaje continuo implica un movimiento interactivo y dinámico basado en conocimiento entre diferentes niveles: individual, grupal y organizacional; por lo que conceptualizarlo no es una tarea fácil (Huber, 1991).

Por su parte Teece et al. (1997) conceptualizan al aprendizaje organizacional como una capacidad dinámica, que permite a las organizaciones y sus empleados generar nuevo conocimiento.

El aprendizaje organizacional ocurre en varios niveles e involucra diferentes procesos. Crossan, Lane, y White (1999) identifican los siguientes procesos relacionados a los niveles, insumos y resultados. 
Capítulo 1 Revisión de los Enfoques en Organización de Empresas

Tabla 1.1. Procesos de Aprendizaje y Niveles

\begin{tabular}{||l|l|l||}
\hline \multicolumn{1}{||c|}{ Niveles } & \multicolumn{1}{|c|}{ Procesos } & \multicolumn{1}{c||}{ Insumos/Resultados } \\
\hline Individual & Intuición & Experiencias \\
Grupal & Imágenes \\
& Metáforas \\
Organizacional & Integración & Idioma \\
& & Mapa Cognitivo \\
& & Conversación/Diálogo \\
& & Entendimientos compartidos \\
& Institucionalización & Rutinas Mutuo \\
& & Sistemas interactivos \\
& & Reglas y Procedimientos \\
\hline
\end{tabular}

Fuente: Crossan, H. W Lane, y White (1999)

De acuerdo a Sanchez et al. (1996) las empresas compiten proactivamente a través del aprendizaje y la experiencia para la generación de competencias, resaltando el papel del aprendizaje en las organizaciones como facilitador en el proceso de creación de competencias. Por tal motivo, el enfoque basado en el aprendizaje ha cobrado importancia. 
Spender (1996) define al aprendizaje como: "el proceso de experimentación y análisis, o el proceso de comunicación del conocimiento que ha sido previamente generado por otros".

Bajo esta definición, en una era en que es crucial el aprendizaje organizacional y tener un mejoramiento contínuo del desempeño para permanecer competitivo. Las compañías deben enfocarse en la transferencia interna de las capacidades, lo cual en la práctica no resulta fácil (Szulanski, 1996).

Entre las razones que dificultan la transferencia interna de las capacidades, es la existencia de una relación entre el aprendizaje y el involucramiento activo de los empleados en el mismo, quienes en última instancia son los responsables de desarrollar diferentes actividades dentro de la organización y de interactuar directamente con los clientes, quienes también son importantes para el aprendizaje y crecimiento de la organización (Spender, 1996).

Sin embargo, Szulanski (1996) demostró que, contrariamente a la creencia convencional que culpa a factores motivacionales, como aquellos que dificultan la transferencia del conocimiento; los que no permiten una adecuada transferencia del conocimiento son los factores relacionados al conocimiento, como la falta de capacidad de absorción por parte del receptor, la ambigüedad causal o una relación difícil entre la fuente y el receptor. 


\subsection{POSICIONAMIENTO TEÓRICO ADOPTADO PARA LA INVESTIGACIÓN}

La evolución de los diferentes enfoques en organización de empresas muestra una transición de la focalización en aspectos internos de la organización hacia una visión holística que considera a la organización como un sistema abierto que interactúa con su entorno. Por otra parte, es necesario pasar de un enfoque estático a uno dinámico, como una forma de renovación tanto de recursos como de capacidades, a fin de sostener la ventaja competitiva en el tiempo.

Los enfoques en organización de empresas presentan una complementariedad desde el abordaje de las diferentes ciencias: la Economía aporta la racionalidad y maximización del beneficio; la Psicología estudia las motivaciones y emociones de los individuos así como los aspectos internos que explican el comportamiento; y finalmente, la Sociología considera las fuerzas externas del ambiente. En este sentido, es necesario considerar la complejidad del ser humano y no su reduccionismo a uno u otro ámbito (Grandío, 1997).

En la siguiente tabla se presenta una síntesis de la revisión de los diversos enfoques en organización de empresas, sus principales aportes y/o énfasis, el nivel de gestión de la complejidad, perspectiva y las limitaciones y/o críticas de cada uno de ellos. 
Capítulo 1 Revisión de los Enfoques en Organización de Empresas

Tabla 1.2. Síntesis de los Enfoques en Organización de Empresas

\begin{tabular}{|c|c|c|c|}
\hline Enfoque & Aportes / Énfasis & $\begin{array}{c}\text { Complejidad / } \\
\text { Perspectiva }\end{array}$ & $\begin{array}{c}\text { Limitaciones / } \\
\text { Críticas }\end{array}$ \\
\hline $\begin{array}{l}\text { Administración } \\
\text { Científica }\end{array}$ & $\begin{array}{ll}- & \text { Estudio de } \\
\text { Tiempos y } \\
\text { Movimientos } \\
\text { - } \\
\text { Funciones de la } \\
\text { Administración } \\
\text { - Énfasis en las } \\
\text { Tareas }\end{array}$ & $\begin{array}{l}\text { Baja } \\
\text { Económica }\end{array}$ & $\begin{array}{l}\text { Excesivo énfasis en } \\
\text { que el ser humano se } \\
\text { guía únicamente por } \\
\text { aspectos económicos }\end{array}$ \\
\hline Funcional & $\begin{array}{l}\text { - } \begin{array}{l}\text { Cinco funciones } \\
\text { de la } \\
\text { organización }\end{array} \\
\text { - } \begin{array}{l}\text { Catorce } \\
\text { principios } \\
\text { universales de la } \\
\text { administración }\end{array} \\
\text { - Instrumentos } \\
\text { formales } \\
\text { Énfasis en la } \\
\text { Estructura }\end{array}$ & $\begin{array}{l}\text { Baja } \\
\text { Económica }\end{array}$ & $\begin{array}{l}\text { Mecanización del ser } \\
\text { humano } \\
\text { Considerar la } \\
\text { organización como } \\
\text { un sistema cerrado }\end{array}$ \\
\hline $\begin{array}{l}\text { Relaciones } \\
\text { Humanas }\end{array}$ & $\begin{array}{ll}\text { - } & \text { Importancia de } \\
\text { los grupos } \\
\text { informales } \\
\text { - }\end{array}$ & $\begin{array}{l}\text { Media } \\
\text { Comportamiento } \\
\text { Organizacional }\end{array}$ & $\begin{array}{l}\text { Validez científica } \\
\text { Énfasis en la } \\
\text { "felicidad" del } \\
\text { trabajador presenta } \\
\text { una visión simplista } \\
\text { del comportamiento }\end{array}$ \\
\hline
\end{tabular}


Capítulo 1 Revisión de los Enfoques en Organización de Empresas

\begin{tabular}{|c|c|c|c|}
\hline Enfoque & Aportes / Énfasis & $\begin{array}{l}\text { Complejidad / } \\
\text { Perspectiva }\end{array}$ & $\begin{array}{c}\text { Limitaciones / } \\
\text { Críticas }\end{array}$ \\
\hline & $\begin{array}{l}\text { grupales } \\
\text { - Énfasis en las } \\
\text { personas }\end{array}$ & & humano \\
\hline Burocrático & $\begin{array}{ll}\text { - } & \text { Previsibilidad de } \\
\text { funcionamiento } \\
\text { - } & \begin{array}{l}\text { Caracterización } \\
\text { de la autoridad y } \\
\text { poder }\end{array} \\
\text { - } & \text { Formalización de } \\
\text { la Organización }\end{array}$ & $\begin{array}{l}\text { Media } \\
\text { Comportamiento } \\
\text { Organizacional }\end{array}$ & $\begin{array}{l}\text { Disfunciones de la } \\
\text { burocracia: } \\
\text { Excesivo énfasis en } \\
\text { el proceso y no en } \\
\text { los resultados } \\
\text { Administración } \\
\text { como un fin y no un } \\
\text { medio }\end{array}$ \\
\hline Sistémico & $\begin{array}{l}\text { - La organización } \\
\text { como sistema } \\
\text { - } \begin{array}{l}\text { Identificación de } \\
\text { los subsistemas }\end{array} \\
\text { - Consideración } \\
\text { del entorno }\end{array}$ & $\begin{array}{l}\text { Alta } \\
\text { Económica } \\
\text { Comportamiento } \\
\text { Organizacional, }\end{array}$ & $\begin{array}{l}\text { Distinción entre } \\
\text { sistemas abiertos y } \\
\text { cerrados }\end{array}$ \\
\hline $\begin{array}{l}\text { Comportamiento } \\
\text { Administrativo }\end{array}$ & $\begin{array}{ll}\text { - } & \begin{array}{l}\text { Organización } \\
\text { como un sistema } \\
\text { de decisiones }\end{array} \\
\text { - } & \begin{array}{l}\text { Tipos de } \\
\text { decisiones }\end{array} \\
\text { - } & \begin{array}{l}\text { Principio de la } \\
\text { racionalidad }\end{array}\end{array}$ & $\begin{array}{l}\text { Alta } \\
\text { Económica }\end{array}$ & $\begin{array}{l}\text { Factores internos y } \\
\text { externos que influyen } \\
\text { en la consolidación y } \\
\text { mantenimiento de } \\
\text { ventajas competitivas }\end{array}$ \\
\hline
\end{tabular}


Capítulo 1 Revisión de los Enfoques en Organización de Empresas

\begin{tabular}{|c|c|c|c|}
\hline Enfoque & Aportes / Énfasis & $\begin{array}{l}\text { Complejidad / } \\
\text { Perspectiva }\end{array}$ & $\begin{array}{c}\text { Limitaciones / } \\
\text { Críticas }\end{array}$ \\
\hline & limitada & & \\
\hline $\begin{array}{l}\text { Desarrollo } \\
\text { Organizacional }\end{array}$ & $\begin{array}{l}\text { Empresa como } \\
\text { un sistema } \\
\text { orgánico } \\
\text { - Cultura } \\
\text { organizacional, } \\
\text { cambio y } \\
\text { desarrollo }\end{array}$ & $\begin{array}{l}\text { Alta } \\
\text { Comportamiento } \\
\text { Organizacional }\end{array}$ & $\begin{array}{l}\text { El campo de acción } \\
\text { no se encuentra lo } \\
\text { suficientemente } \\
\text { delimitado, } \\
\text { existiendo una } \\
\text { contradicción en que } \\
\text { se base en } \\
\text { conocimiento } \\
\text { científico }\end{array}$ \\
\hline Contingencia & $\begin{array}{l}\text { - La configuración } \\
\text { de la } \\
\text { organización } \\
\text { depende del } \\
\text { entorno, tamaño } \\
\text { y tecnología }\end{array}$ & $\begin{array}{l}\text { Alta } \\
\text { Económica } \\
\text { Comportamiento } \\
\text { Organizacional }\end{array}$ & $\begin{array}{l}\text { El enfoque } \\
\text { contingente se } \\
\text { muestra } \\
\text { eminentemente } \\
\text { ecléctico e } \\
\text { integrador, pero al } \\
\text { mismo tiempo } \\
\text { relativista y } \\
\text { situacional }\end{array}$ \\
\hline $\begin{array}{l}\text { Población } \\
\text { Ecológica }\end{array}$ & $\begin{array}{l}\text { - Los recursos son } \\
\text { limitados } \\
\text { - La mejor forma } \\
\text { de organización } \\
\text { es la que } \\
\text { consigue } \\
\text { adaptarse al } \\
\text { entorno }\end{array}$ & $\begin{array}{l}\text { Alta } \\
\text { Comportamiento } \\
\text { Organizacional }\end{array}$ & $\begin{array}{l}\text { Las implicaciones } \\
\text { del intercambio y la } \\
\text { trascendencia de las } \\
\text { habilidades } \\
\text { individuales de los } \\
\text { miembros de la } \\
\text { empresa }\end{array}$ \\
\hline Institucional & $\begin{array}{l}\text { Distinción entre } \\
\text { instituciones y }\end{array}$ & Media & $\begin{array}{l}\text { Su aplicación es } \\
\text { limitada }\end{array}$ \\
\hline
\end{tabular}


Capítulo 1 Revisión de los Enfoques en Organización de Empresas

\begin{tabular}{|c|c|c|c|}
\hline Enfoque & Aportes / Énfasis & $\begin{array}{c}\text { Complejidad / } \\
\text { Perspectiva }\end{array}$ & $\begin{array}{c}\text { Limitaciones / } \\
\text { Críticas }\end{array}$ \\
\hline & $\begin{array}{l}\text { organizaciones } \\
\text { privadas } \\
\text { - Isomorfismo } \\
\text { institucional }\end{array}$ & $\begin{array}{l}\text { Comportamiento } \\
\text { Organizacional }\end{array}$ & $\begin{array}{l}\text { principalmente } \\
\text { orientada } \\
\text { instituciones no } \\
\text { lucrativas que basan } \\
\text { su vigencia y } \\
\text { supervivencia en la } \\
\text { aceptación social }\end{array}$ \\
\hline $\begin{array}{l}\text { Costes de } \\
\text { Transacción }\end{array}$ & $\begin{array}{l}\text { - La mejor forma } \\
\text { de organización } \\
\text { es la que } \\
\text { minimiza los } \\
\text { costes de } \\
\text { transacción } \\
\text { - } \begin{array}{l}\text { Dimensiones } \\
\text { claves de las } \\
\text { transacciones }\end{array}\end{array}$ & $\begin{array}{l}\text { Media } \\
\text { Económica }\end{array}$ & $\begin{array}{l}\text { Resalta el } \\
\text { comportamiento } \\
\text { oportunista } \\
\text { La organización } \\
\text { como una caja negra } \\
\text { Más orientado a } \\
\text { mercados externos }\end{array}$ \\
\hline Agencia & $\begin{array}{l}\text { - } \begin{array}{l}\text { Relación entre el } \\
\text { principal y } \\
\text { agente }\end{array} \\
\text { - Mecanismos de } \\
\text { control } \\
\text { (incentivos e } \\
\text { información) } \\
\text { - Formas óptimas } \\
\text { para formalizar } \\
\text { contratos }\end{array}$ & $\begin{array}{l}\text { Media } \\
\text { Económica }\end{array}$ & $\begin{array}{l}\text { Riesgos asociados a } \\
\text { los incentivos para } \\
\text { los ejecutivos } \\
\text { (agentes), el criterio } \\
\text { oportunista de estos } \\
\text { y las asimetrías de } \\
\text { información } \\
\text { generadas entre el } \\
\text { principal y agente. }\end{array}$ \\
\hline Competitivo & $\begin{array}{l}\text { - } \quad \text { Cinco fuerzas } \\
\text { competitivas }\end{array}$ & Alta & $\begin{array}{l}\text { Subjetividad para la } \\
\text { construcción de la }\end{array}$ \\
\hline
\end{tabular}


Capítulo 1 Revisión de los Enfoques en Organización de Empresas

\begin{tabular}{|c|c|c|c|}
\hline Enfoque & Aportes / Énfasis & $\begin{array}{l}\text { Complejidad / } \\
\text { Perspectiva }\end{array}$ & $\begin{array}{c}\text { Limitaciones / } \\
\text { Críticas }\end{array}$ \\
\hline Porter & $\begin{array}{l}\text { - Cadena de valor } \\
\text { - Estrategias } \\
\text { genéricas }\end{array}$ & $\begin{array}{l}\text { Comportamiento } \\
\text { Organizacional }\end{array}$ & $\begin{array}{l}\text { matriz FODA, la } \\
\text { estructura sigue a la } \\
\text { estrategia }\end{array}$ \\
\hline $\begin{array}{l}\text { Basado en } \\
\text { Competencias }\end{array}$ & $\begin{array}{ll}\text { Rol de los } \\
\text { recursos } \\
\text { organizacionales } \\
\text { para generar } \\
\text { ventajas } \\
\text { competitivas } \\
\text { Énfasis en las } \\
\text { competencias } \\
\text { organizacionales }\end{array}$ & Integral & $\begin{array}{l}\text { Carácter estático que } \\
\text { no toma en cuenta } \\
\text { que las competencias } \\
\text { se forman y varían en } \\
\text { el tiempo. } \\
\text { Concentración } \\
\text { excesiva sobre los } \\
\text { recursos individuales } \\
\text { que poseen las firmas }\end{array}$ \\
\hline $\begin{array}{l}\text { Recursos y } \\
\text { Capacidades }\end{array}$ & $\begin{array}{ll}\text { La } \\
\text { heterogeneidad } \\
\text { de recursos } \\
\text { explica la } \\
\text { diferencia de } \\
\text { resultados } \\
\text { Desarrollo de } \\
\text { capacidades } \\
\text { distintivas es la } \\
\text { fuente de } \\
\text { ventajas } \\
\text { competitivas }\end{array}$ & $\begin{array}{l}\text { Alta } \\
\text { Económica } \\
\text { Comportamiento } \\
\text { Organizacional }\end{array}$ & $\begin{array}{l}\text { Carácter estático que } \\
\text { no toma en cuenta } \\
\text { los factores externos } \\
\text { que rodean a los } \\
\text { recursos } \\
\text { No considera que las } \\
\text { ventajas competitivas } \\
\text { cambian en el tiempo } \\
\text { Ambigüedad en la } \\
\text { conceptualización } \\
\text { del termino de } \\
\text { recursos }\end{array}$ \\
\hline $\begin{array}{l}\text { Capacidades } \\
\text { Dinámicas }\end{array}$ & $\begin{array}{ll} & \text { Se acentúa el } \\
\text { desarrollo y } \\
\text { renovación de }\end{array}$ & Alta & $\begin{array}{l}\text { Las capacidades } \\
\text { dinámicas son fuente } \\
\text { de ventajas } \\
\text { competitivas, pero no }\end{array}$ \\
\hline
\end{tabular}


Capítulo 1 Revisión de los Enfoques en Organización de Empresas

\begin{tabular}{|c|c|c|c|}
\hline Enfoque & Aportes / Énfasis & $\begin{array}{l}\text { Complejidad / } \\
\text { Perspectiva }\end{array}$ & $\begin{array}{c}\text { Limitaciones / } \\
\text { Críticas }\end{array}$ \\
\hline & $\begin{array}{l}\text { recursos } \\
\text { - Competencias } \\
\text { complejas y } \\
\text { multidimensional } \\
\text { es } \\
\text { - Dimensión } \\
\text { individual o } \\
\text { colectiva, estática } \\
\text { o dinámica }\end{array}$ & Integral & $\begin{array}{l}\text { necesariamente de } \\
\text { ventajas competitivas } \\
\text { sostenibles } \\
\text { Alta dependencia del } \\
\text { conocimiento } \\
\text { Sostenibilidad de las } \\
\text { capacidades } \\
\text { dinámicas depende y } \\
\text { varía de acuerdo al } \\
\text { dinamismo del } \\
\text { mercado }\end{array}$ \\
\hline $\begin{array}{l}\text { Basado en } \\
\text { Conocimiento }\end{array}$ & 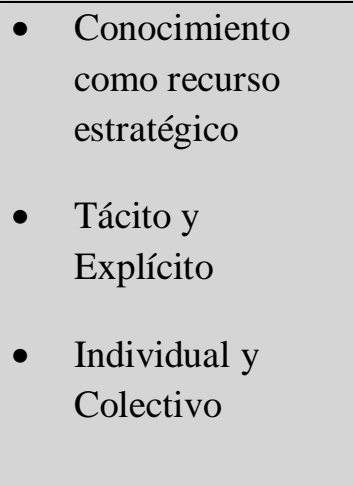 & $\begin{array}{l}\text { Alta } \\
\text { Integral }\end{array}$ & $\begin{array}{l}\text { Alta dependencia del } \\
\text { factor humano para } \\
\text { su aplicación } \\
\text { Debe considerar } \\
\text { factores como la } \\
\text { cultura y estructura } \\
\text { organizacional, y la } \\
\text { disponibilidad de } \\
\text { tecnologías }\end{array}$ \\
\hline $\begin{array}{l}\text { Basado en } \\
\text { Aprendizaje }\end{array}$ & $\begin{array}{l}\text { El aprendizaje } \\
\text { como generador } \\
\text { de competencias }\end{array}$ & $\begin{array}{l}\text { Alta } \\
\text { Integral }\end{array}$ & $\begin{array}{l}\text { Alta dependencia del } \\
\text { factor humano }\end{array}$ \\
\hline
\end{tabular}

Fuente: Elaboración Propia 


\section{Capítulo 1 Revisión de los Enfoques en Organización de Empresas}

Los cuatro enfoques que conforman el EBC considerados para este estudio, definen a las empresas como entidades heterogéneas que contienen conocimiento; por lo cual las empresas ya no son vistas solamente en el sentido contractual, sino como depósitos de conocimiento productivo distintivo (tecnológico y organizacional) y como entidades que pueden aprender y crecer con base en ese conocimiento (Foss y Knudsen, 1996).

La generación de ventajas competitivas sostenibles requiere de un enfoque integral y, considerando la dificultad de situarse en una sola perspectiva teórica, para el desarrollo de la presente investigación se adopta el Enfoque Basado en Competencias (EBC) y en sus corrientes de pensamiento: el enfoque basado en recursos y capacidades, el enfoque de las capacidades dinámicas, el enfoque basado en el conocimiento y el enfoque basado en el aprendizaje.

Como se analizó en los epígrafes anteriores, las diferentes perspectivas y enfoques en organización de empresas y la gestión de la complejidad en entornos cambiantes, confluye en la necesidad de contar con un enfoque dinámico, sistémico, cognitivo y holístico, como examinan Sanchez y Heene (1997) estas dimensiones se encuentran integradas en el EBC.

\subsubsection{Dimensión dinámica}

Existe un claro consenso en que la interacción de la empresa y su entorno es un elemento vital de la dinámica de competencias. El análisis de las competencias con relación a los cambios de un entorno turbulento y su configuración interna, proporciona una dinámica competitiva de corto y mediano plazo. 


\subsubsection{Dimensión sistémica y cognitiva}

Una visión sistémica considera a la organización como un sistema abierto. En este sentido, los gerentes deben escanear el entorno (competidores, clientes, proveedores), analizarlo y evaluarlo, a fin de identificar brechas estratégicas. Con base en estas, evaluar la composición de stocks y flujos de activos actuales, así como los cambios necesarios para alcanzar las metas empresariales en un entorno competitivo.

El trabajo de los gerentes estratégicos es percibir las posibilidades para el desarrollo de nuevas competencias y nuevas formas de apalancar las competencias existentes en la empresa.

\subsubsection{Dimensión holística}

La gestión estratégica debe establecer y coordinar multiples metas interrelacionadas para desarrollar y apalancar competencias, por ello debe integrar la tradicional perspectiva de la estrategia sobre la asignación de los recursos con la perspectiva externa sobre el valor económico de las empresas. 


\section{Capítulo 2}

Gestión del Conocimiento y

Ventaja Competitiva 
CAPÍTULO 2

\subsection{INTRODUCCIÓN Y OBJETIVOS DEL CAPÍTULO}

El desempeño de las organizaciones está ligado a la consolidación y mantenimiento de la ventaja competitiva, al respecto, son diversas las aproximaciones y enfoques que explican la obtención de la ventaja competitiva sostenible y los factores que influyen en la misma.

En el presente capítulo, desde el Enfoque basado en Competencias (EBC) y sus principales corrientes de pensamiento, se establece el marco conceptual teórico en el que se basa la presente investigación. En el primer epígrafe se presentan los objetivos y la estructura del capítulo.

En el segundo epígrafe de este capítulo se desarrollan conceptos relacionados a los factores que influyen en la consolidación de una ventaja competitiva sostenible en las organizaciones desde el EBC y sus corrientes de pensamiento: enfoque basado en recursos y capacidades, enfoque de capacidades dinámicas, enfoque basado en conocimiento y enfoque basado en el aprendizaje; puesto que todos tienen al conocimiento como elemento básico de análisis.

En el tercer epígrafe, se presenta al conocimiento y su gestión como un activo estratégico para el mejoramiento de los procesos, sistemas y por ende del desempeño organizativo. A la vez se desarrollan las diversas taxonomías, perspectivas y etapas de la gestión del conocimiento. 


\section{Capítulo 2 Gestión del Conocimiento y Ventaja Competitiva}

\subsection{VENTAJA COMPETITIVA SOSTENIBLE, ENFOQUES Y MODELO INSTRUMENTAL}

Tal como se analizó en el capítulo uno, los diferentes enfoques en organización de empresas han buscado lograr mayor eficiencia, eficacia y finalmente consolidar ventajas competitivas que se reflejen en un mejor desempeño organizativo.

Del análisis realizado en el capítulo uno y siguiendo a Sanchez y Heene (1997) los diversos enfoques en organización de empresas se pueden agrupar en dos perspectivas: la económica, que considera una visión más orientada a lo externo (como el enfoque competitivo de Porter) y la perspectiva del comportamiento organizacional, que atiende principalmente preocupaciones internas, como los diseños organizacionales (enfoque funcionalista) y las motivaciones de los empleados (recursos humanos).

En la literatura sobre dirección estratégica no se encuentra un consenso sobre las diferentes perspectivas respecto a los factores que explican el éxito empresarial. Camisón y Boronat (2004) mencionan que la clasificación predominante, respecto a esta área, agrupa los factores causantes de la heterogeneidad en el logro del éxito empresarial en:

a) El efecto país, relacionado con las ventajas comparativas que poseen las empresas en un determinado país, sostenido en la teoría de las ventajas comparativas del comercio internacional.

b) El efecto industria, sostenido por los postulados de la economía industrial 


\section{Capítulo 2 Gestión del Conocimiento y Ventaja Competitiva}

c) El efecto corporación, influenciado por la diversificación de sus actividades

d) El efecto empresa, sostenido por el enfoque basado en competencias, que identifica a las competencias distintivas que influyen en el desempeño organizativo.

Respecto al efecto país, la teoría desarrollada por David Ricardo (a principios del siglo XIX) postula que, aunque un país no tenga ventaja absoluta en la producción de ningún bien, le convendrá especializarse en aquellas mercancías para las que su ventaja sea comparativamente mayor o su desventaja comparativamente menor. Como consecuencia, el bienestar de un país aumenta a través del comercio internacional.

En la actualidad, los supuestos de David Ricardo son criticados, fundamentalmente porque consideraba los costos constantes a cualquier nivel de producción y no tomó en cuenta los rendimientos decrecientes. Por otra parte, como mencionan (Asensio, Martínez y García, 2000) la premisa que las ventajas comparativas se basan en la inmovilidad internacional de los factores de producción, en especial del capital, actualmente no es válida.

Uno de los principales aportes sobre cómo establecer una ventaja competitiva, es el de Porter (1980), que introduce conceptos relativos a los modelos de la organización industrial al desarrollo de la estrategia de negocios. Propuso reemplazar la planificación estratégica por el pensamiento estratégico, para crear y sostener una ventaja competitiva. 


\section{Capítulo 2 Gestión del Conocimiento y Ventaja Competitiva}

Porter planteaba que la decisión estratégica estaba sustentada en el análisis del atractivo de largo plazo de la rentabilidad de la industria y los determinantes de la posición competitiva que la empresa adopta dentro de la industria (liderazgo de costos, diferenciación o enfoque). Por tanto, una empresa tiene ventaja competitiva cuando cuenta con una mejor posición que la de sus rivales para asegurar a sus clientes y defenderse contra las fuerzas competitivas (Porter, 1985).

El modelo de Porter es probablemente uno de los modelos más conocidos que se aplican en el análisis estratégico, en particular para el análisis de los aspectos que influyen en la intensidad de la competencia en un sector de actividad.

Sin embargo, algunas observaciones críticas y limitaciones al modelo son: a) es un modelo de análisis genérico referido a las características del sector de actividad, más allá del papel que juega cada una de las empresas en el mismo, b) la definición formal de los límites del sector de actividad (competidores y sustitutivos) y c) la diferencia entre rivalidad competitiva e intensidad de la competencia (Mata y Rodríguez, 2010).

Por su parte, Barney $(1986,1991)$ menciona que los supuestos y limitaciones de este enfoque se refieren a que las empresas poseen recursos homogéneos y que estos son altamente móviles.

Diversos estudios muestran que el efecto industria y el efecto empresa influyen en el desempeño organizativo. Sin embargo, algunos estudios centrados en las pequeñas y medianas empresas (Pymes) muestran una reducción considerable del efecto industria (efecto estable y transitorio), que se traduce en un incremento en 


\section{Capítulo 2 Gestión del Conocimiento y Ventaja Competitiva}

el efecto empresa; lo que indica que las Pymes presentan una gran heterogeneidad de resultados que se deben a sus características internas (Banón y Aragón, 2007).

\subsubsection{Ventaja Competitiva desde el Enfoque Basado en Competencias}

Según Barney (1991) una empresa tiene una ventaja competitiva cuando está implementando una estrategia de creación de valor que no está simultáneamente implementada por ningún competidor actual o potencial y ésta es sostenible cuando otras empresas son incapaces de duplicar los beneficios de esa estrategia.

Foss y Knudsen (1996) indican que la ventaja de las firmas, de acuerdo a Kogut y Zander (1992) es su capacidad de proveer "principios organizacionales de orden mayor", los mismos que el mercado supuestamente no puede proveer y en los cuales los miembros de la organización están involucrados. Estos principios incluyen esquemas codificados para compartir valores, un lenguaje común y mecanismos para codificar tecnologías en lenguajes accesibles a un amplio círculo de individuos.

De acuerdo a Peteraf y Barney (2003) la ventaja competitiva puede ser expresada en términos de la habilidad que tiene una empresa para crear relativamente mayor valor económico frente al de sus competidores, a través de una diferenciación superior y/o costos más bajos. Estos autores, mencionan que para lograr ventajas competitivas sostenibles, las condiciones que deben establecerse son la incertidumbre e inamovilidad. 


\section{Capítulo 2 Gestión del Conocimiento y Ventaja Competitiva}

El enfoque basado en recursos y capacidades identifica la relación existente entre los recursos, capacidades, ventaja competitiva y estrategia. En este marco, los recursos son la fuente de las capacidades de la empresa y las capacidades son la principal fuente de su ventaja competitiva. Este enfoque explica, además, que la diferencia de rentabilidad entre las empresas surge a partir de la heterogeneidad de los recursos que estas poseen (Grant, 1991).

De acuerdo a Javidan (1998), la ventaja competitiva es proporcionada por los recursos, capacidades o competencias de la empresa; sin embargo, no todas las ventajas competitivas están relacionadas a las competencias y no todas las competencias o capacidades resultan en una ventaja competitiva.

De acuerdo a Coyne (1986) en estrategia una ventaja competitiva será significativa si cumple con las siguientes tres condiciones:

- Una diferencia importante en los atributos del producto o servicio en comparación con los de sus competidores es percibida por los consumidores

- Esta diferencia se genera a partir de la brecha en las capacidades entre la empresa y sus competidores

- Se mantendrán en el tiempo tanto la diferencia de atributos importantes como la brecha en capacidades.

Como se analizó en el capítulo anterior, una limitación al enfoque basado en recursos y capacidades es que no explica adecuadamente cómo y por qué ciertas 


\section{Capítulo 2 Gestión del Conocimiento y Ventaja Competitiva}

firmas tienen ventajas competitivas en situaciones de rápido e impredecible cambio.

En estos mercados, donde el marco competitivo está cambiando, las capacidades dinámicas por las cuales las firmas integran, construyen y reconfiguran las competencias internas y externas para enfrentar estos ambientes tan cambiantes, se convierten en la fuente de las ventajas competitivas sostenibles. Por tanto, las ventajas competitivas sostenibles se generan a partir de la utilización, por parte de la empresa, de sus capacidades dinámicas más rápida y hábilmente en comparación con la dinámica del mercado (Eisenhardt y Martin, 2000).

El enfoque de recursos y capacidades parte del supuesto de que la empresa que posea y desarrolle recursos estratégicos contará con la base de la ventaja competitiva (Grant, 1991).

Como recursos estratégicos se mencionan: al conocimiento, al capital intelectual y a los activos intangibles (Bueno, 1998). Es por ello, que en los últimos tiempos la comunidad científica ha mostrando un creciente interés por la gestión del conocimiento, como fuente de ventaja competitiva.

La ventaja competitiva ha sido abordada desde distintas perspectivas y enfoques. Por un lado se tiene los enfoques estáticos, que consideran las características del sector (economía industrial) en el que compiten y la posición estratégica que la empresa decide adoptar, o el énfasis en la posesión de activos valiosos y escasos que le permiten en un momento dado formular una estrategia que ningún otro competidor puede implementar. Por otro lado, los enfoques dinámicos, que se 


\section{Capítulo 2 Gestión del Conocimiento y Ventaja Competitiva}

centran en los procesos de acumulación y renovación de recursos, así como competencias, en respuesta a los cambios en un entorno altamente cambiante.

\subsubsection{Modelo instrumental de gestión estratégica}

Tradicionalmente, las estructuras organizacionales se modificaban en función de la estrategia, pasando de una estructura funcional a una divisional o matricial, donde no se cuestionaba el principio jerárquico. Hoy se busca la flexibilización del principio de autoridad como mecanismo de coordinación y la introducción de elementos de mercado dentro de la empresa. Esta nueva situación se asemeja al “dilema del prisionero”: ¿cooperar o competir? .Por una parte se busca cooperar en el intercambio de conocimiento y por otra competir por los recursos y la eficiencia.

Con el desarrollo de la tecnología y comunicaciones se han logrado reducir los problemas de incertidumbre y las asimetrías de la información, desarrollando una cultura de confianza y cooperación que se traduce en una reducción de los costes de transacción.

Frente a la necesidad de gestionar la complejidad y adoptar un enfoque integrado basado en una visión sistémica, dinámica, cognitiva y holística, se requiere la aplicación de modelos conceptuales e instrumentales que integren la estrategia con la operación y se facilite el diseño organizacional orientado a impulsar la gestión del conocimiento. 


\section{Capítulo 2 Gestión del Conocimiento y Ventaja Competitiva}

Entre los diversos modelos instrumentales se encuentra el modelo de gestión integral de negocios "Business Management System"1 (Atac, 2002); que se denominará BMS a partir de ahora.

Este modelo facilita la comprensión de la labor gerencial, al separar la operación del negocio de la gestión. Por otra parte, considera como recursos no solo a los "tradicionales" (recursos humanos, activos físicos y financieros) sino también a los recursos intangibles, como la información y el conocimiento, así como la generación de redes y contactos.

Se utiliza el modelo instrumental BMS como complementación al enfoque teórico EBC adoptado para el desarrollo de la presente investigación.

\footnotetext{
${ }^{1}$ El "Business Management System" - BMS fue desarrollado por Osman Atac, Ph.D. en el año 2002, forma parte de los materiales del "International Trade Center" - ITC, una Agencia de las Naciones Unidas y la Organización Mundial del Comercio. El BMS se utiliza por las instituciones socias del ITC en más de 40 países. El BMS es un modelo conceptual que permite integrar los aspectos de la gerencia de negocios, articulando la estrategia y los objetivos de una empresa con sus capacidades de comercialización y producción y ésos con la gestión de sus transacciones.
} 
En la siguiente figura se puede apreciar el esquema general del modelo:

Figura 2.1. Estructura del Modelo BMS

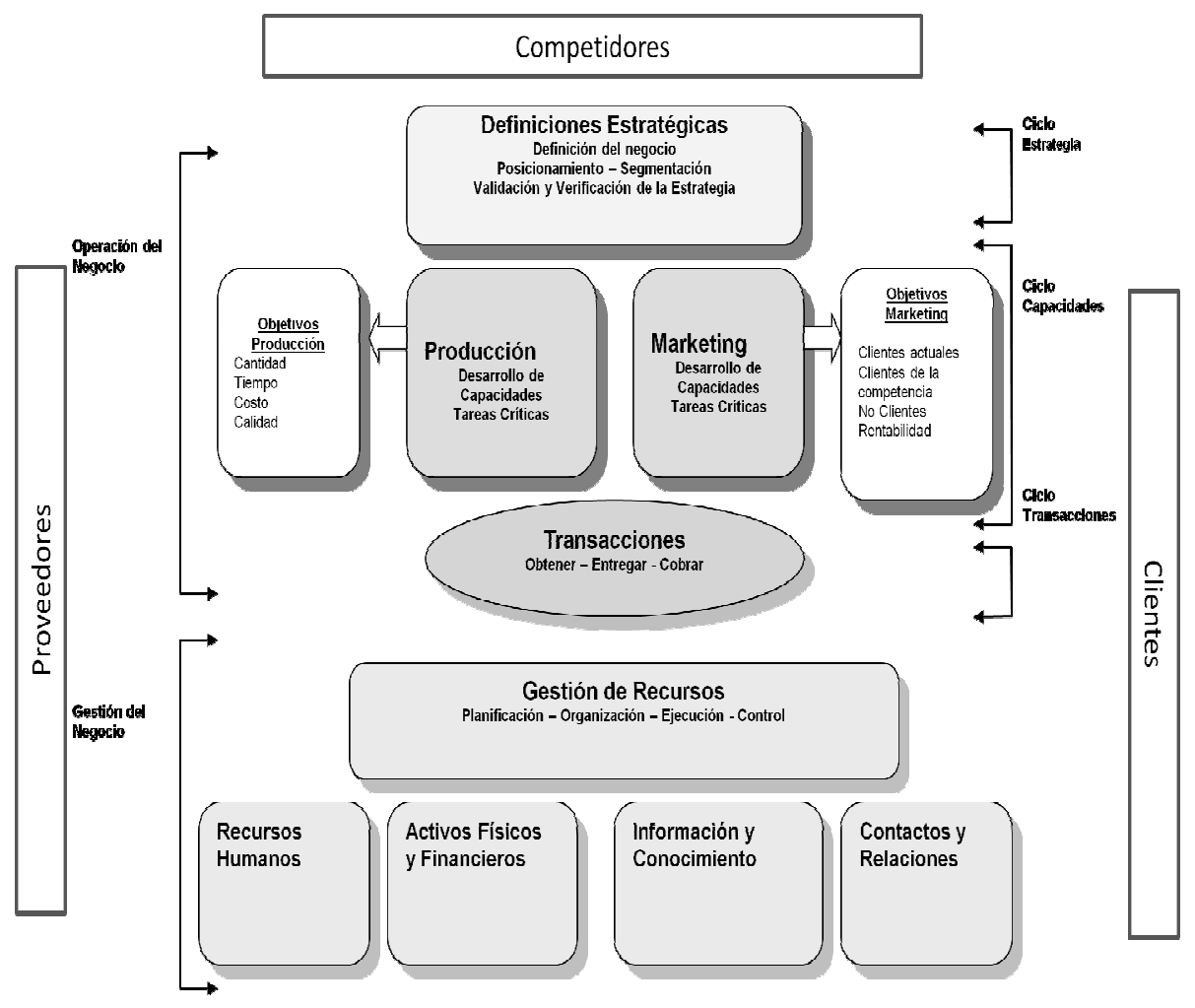

Fuente: Elaboración propia a partir del modelo BMS

El modelo BMS está basado en el enfoque de recursos y capacidades, como se puede apreciar en su estructura. Los recursos (tanto tangibles como intangibles) 


\section{Capítulo 2 Gestión del Conocimiento y Ventaja Competitiva}

deben ser gestionados para generar capacidades operativas (producción, marketing y transacciones). Este modelo también toma en cuenta la estrategia, buscando consolidar a la organización como un monopolio competitivo.

Si bien este modelo instrumental proporciona importantes elementos para la investigación, también presenta varias limitaciones, como se analiza más adelante.

\subsubsection{La Estrategia, Orígenes y Definiciones}

Probablemente los escritos más antiguos sobre la estrategia provengan del ámbito militar. Sun Tzu escribió el Arte de la Guerra aproximadamente en el siglo IV A.C, entre cuyos pensamientos y máximas están:

"Si no conoces a tu enemigo ni te conoces a ti mismo, perderás todas tus batallas Si conoces a tu enemigo, pero no te conoces a ti mismo, ganarás algunas de tus batallas

Si conoces a tu enemigo y te conoces a ti mismo, ganaras todas tus batallas"

De estos pensamientos se puede extractar la importancia del conocimiento del entorno, los competidores y su estrategia, puesto que la batalla es contra su estrategia. Por otra parte, la importancia de conocer las capacidades y competencias internas para sostener la estrategia.

La palabra estrategia proviene del vocablo "strategos", que se refería al nombramiento del General o Jefe del ejercito (Mintzberg, Quinn, y Voyer, 1997); y al verbo griego "stratego", que significa "planificar la destrucción del enemigo 


\section{Capítulo 2 Gestión del Conocimiento y Ventaja Competitiva}

en razón del uso eficaz de los recursos". Es importante resaltar el criterio de la utilización de los recursos en esta definición, que en el EBC se complementa con las capacidades y competencias.

En la obra de Mintzberg et al. (1997) "El proceso estratégico: conceptos, contextos y casos" se identifican las siguientes apreciaciones de estrategia:

Una de las primeras definiciones en el ámbito empresarial es la de Alfred Chandler en 1962, que definió a la estrategia como la fijación de las metas básicas a largo plazo, así como la adopción de cursos de acción y asignación de recursos para alcanzar estas metas.

Por su parte, Kenneth Andrews define la estrategia como un patrón de objetivos, propósitos o metas que permiten definir la actividad a la que se dedica o dedicará la empresa y qué tipo de empresa es o será. Asimismo, Igor Ansoff consideraba a la estrategia como el hilo conductor de las acciones, con cuatro componentes: producto, mercado, vector de crecimiento y ventaja competitiva.

El enfoque de Andrews da curso a la "escuela del diseño" y la de Ansoff a la "escuela de la planificación". Estas primeras definiciones tienen como elementos en común a los conceptos de ambiente, misión, análisis de la situación y aplicación de recursos.

Mintzberg et al. (1997) definen el término de estrategia como el patrón de una serie de acciones que ocurren en el tiempo, conciben a la estrategia fundamentada 


\section{Capítulo 2 Gestión del Conocimiento y Ventaja Competitiva}

en las intenciones estratégicas, la estrategia realizada, la estrategia deliberada y la estrategia emergente.

De acuerdo a Foss y Knudsen (1996) la estrategia consiste en extender los activos del conocimiento y aplicarlos en nuevas áreas. Estos autores definen la estrategia como una cuestión de alcanzar el ajuste entre las fortalezas de la firma y las oportunidades del ambiente, mientras que simultáneamente se salvaguarda las debilidades de la firma contra las amenazas provenientes del mismo ambiente.

Por su parte, Atac (2002) define la estrategia como "la configuración de cantidad, calidad, coste y tiempo de producción y entrega que garantiza que la función de marketing pueda lograr sus objetivos maximizando el poder de negociación de la empresa y venciendo a la competencia".

En esta definición la estrategia tiene dos componentes: la oferta, que nace de la manipulación de las variables de cantidad, calidad, coste y plazo; y el mercado, que es el "lugar" donde la oferta diseñada puede satisfacer las expectativas, necesidades y hábitos de los clientes para así vencer o evitar la competencia.

Existen tres tipos de segmentos de mercado para el negocio: los clientes habituales, los clientes de la competencia y los que nunca han usado o comprado el producto o servicio. Hacia estos tres segmentos se dirigen los esfuerzos de posicionamiento de la empresa para poder definir y ejecutar una estrategia exitosa, y por esta razón se constituyen los objetivos genéricos de la función de marketing.

Cada uno de esos segmentos tiene necesidades que satisfacer (desde las más elementales hasta las más sofisticadas), expectativas que cubrir (percepciones del 


\section{Capítulo 2 Gestión del Conocimiento y Ventaja Competitiva}

mercado que deben ser ratificadas, anuladas o modificadas) y oportunidades o hábitos de compra y uso. En la medida que el posicionamiento de la empresa satisface o cubre estas categorías, la estrategia de la empresa será exitosa y podrá obtener pedidos del mercado.

Resumiendo, estrategia es la adecuación oportuna y eficiente de la oferta a las características del mercado. Es decir, la combinación más adecuada de cantidad, calidad, plazo y coste a las necesidades, expectativas y oportunidades del mercado. Es, en suma, encontrar el mejor "qué" para que el "quién" prefiera a la empresa por sobre la competencia.

\subsubsection{Escuelas de pensamiento estratégico}

Mintzberg, Ahlstrand, y Lampel (1999), en su libro "Safari a la Estrategia", agrupan la vasta bibliografía y enfoques sobre estrategia en lo que denominan las 5 "P"s: estrategia como plan (proyectada hacia adelante), como patrón (realizado hacia atrás), posición (por arriba), perspectiva (por abajo) y estratagema (burlar al oponente).

Estos autores mencionan que la estrategia establece una dirección, concentra el esfuerzo, define la organización y proporciona consistencia, para cada uno de estos aspectos se pueden identificar tanto ventajas como desventajas.

Las diversas escuelas de pensamiento estratégico, en algunos casos con postulados opuestos, aportan cada una de ellas a la visión global de la estrategia. Estos autores utilizan la metáfora del "Elefante", donde cada escuela es vista 


\section{Capítulo 2 Gestión del Conocimiento y Ventaja Competitiva}

como una hormiga que solo logra ver una parte del "Elefante", que vendría a ser la estrategia.

Tomando las dimensiones de los procesos que articulan la estrategia (deliberada o emergente) y los resultados (plural o maximización de beneficios), Whittington (2002) propone una clasificación que integra las diferentes escuelas en: clásica, evolucionista, procesualista y sistémica.

Los clásicos y evolucionistas persiguen la maximización de beneficios principalmente económicos, los evolucionistas y procesualistas consideran otros beneficios adicionales a los económicos. Los evolucionistas y procesualistas consideran la creación de estrategias como emergentes, mientras que los clásicos y sistémicos como estrategias deliberadas.

En el siguiente cuadro se presenta una síntesis de las principales escuelas de pensamiento estratégico, así como sus principales aspectos y características:

Tabla 2.1. Escuelas del Pensamiento Estratégico

\begin{tabular}{|c|c|c|c|c|c|}
\hline Escuela & $\begin{array}{l}\text { Periodo } \\
\text { (década) }\end{array}$ & $\begin{array}{c}\text { Principales } \\
\text { Autores }\end{array}$ & $\begin{array}{l}\text { Aspectos } \\
\text { Centrales }\end{array}$ & \multicolumn{2}{|c|}{$\begin{array}{l}\text { Características } \\
\text { /Clasificación }\end{array}$} \\
\hline Diseño & $\begin{array}{l}\text { Entre los } \\
50 \text { y } 60\end{array}$ & $\begin{array}{ll}\text { Selznik } \quad \mathrm{y} \\
\text { Andrews }\end{array}$ & $\begin{array}{l}\text { Herramienta } \\
\text { de análisis } \\
\text { FODA, énfasis } \\
\text { en el análisis } \\
\text { estratégico }\end{array}$ & \multirow{2}{*}{$\begin{array}{l}\text { Prescriptivas } \\
\text { o normativas } \\
\text { Plantean } \\
\text { cómo debe } \\
\text { formularse la } \\
\text { estrategia, } \\
\text { pero no }\end{array}$} & Clásicos \\
\hline Planificación & 60 & Ansoff & $\begin{array}{l}\text { El análisis } \\
\text { formal, no deja }\end{array}$ & & Clásicos \\
\hline
\end{tabular}


Capítulo 2 Gestión del Conocimiento y Ventaja Competitiva

\begin{tabular}{|c|c|c|c|c|c|}
\hline Escuela & $\begin{array}{r}\text { Periodo } \\
\text { (década) }\end{array}$ & $\begin{array}{c}\text { Principales } \\
\text { Autores }\end{array}$ & $\begin{array}{l}\text { Aspectos } \\
\text { Centrales }\end{array}$ & \multicolumn{2}{|c|}{$\begin{array}{l}\text { Características } \\
\text { /Clasificación }\end{array}$} \\
\hline & & & $\begin{array}{l}\text { paso a la } \\
\text { intuición }\end{array}$ & \multirow[t]{2}{*}{$\begin{array}{l}\text { como se crea } \\
\text { realmente en } \\
\text { la práctica }\end{array}$} & \\
\hline $\begin{array}{l}\text { Posiciona- } \\
\text { miento }\end{array}$ & $\begin{array}{l}\text { Mediados } \\
\text { de los } 70\end{array}$ & $\begin{array}{l}\text { Schendel y } \\
\text { Hatten } \\
\text { Porter }\end{array}$ & $\begin{array}{l}\text { Preocupación } \\
\text { por los } \\
\text { sectores, } \\
\text { modelo de las } \\
\text { cinco fuerzas, } \\
\text { concepto de la } \\
\text { cadena de } \\
\text { valor. }\end{array}$ & & Clásicos \\
\hline Empresarial & 50 & $\begin{array}{l}\text { Schumpeter } \\
\text { y Cole }\end{array}$ & $\begin{array}{lr}\text { Análisis } & \text { del } \\
\text { liderazgo } & \\
\text { formal, } & \text { los } \\
\text { procesos } & \text { y } \\
\text { estados } & \\
\text { mentales } & \text { que } \\
\text { sigue } & \text { el } \\
\text { principal } & \\
\text { directivo. } & \end{array}$ & \multirow{2}{*}{$\begin{array}{l}\text { Decriptivas, } \\
\text { cómo se } \\
\text { forma la } \\
\text { estrategia (en } \\
\text { la mente } \\
\text { individual } \\
\text { del } \\
\text { estratega), } \\
\text { no } \\
\text { proporcionan } \\
\text { "recetas" } \\
\text { mágicas para } \\
\text { formular } \\
\text { estrategias } \\
\text { perfectas }\end{array}$} & \\
\hline Congnoscitiva & $\begin{array}{l}\text { Finales } \\
\text { de los } 40\end{array}$ & $\begin{array}{l}\text { March y } \\
\text { Simon }\end{array}$ & $\begin{array}{l}\text { El proceso de } \\
\text { creación de la } \\
\text { estrategia } \\
\text { desde la mente } \\
\text { del estratega. } \\
\text { La rama } \\
\text { positivista y la } \\
\text { rama } \\
\text { subjetivista. }\end{array}$ & & \\
\hline Aprendizaje & $\begin{array}{l}\text { Orígenes } \\
\text { en los } 60\end{array}$ & $\begin{array}{l}\text { Lindblom, } \\
\text { Cyert y }\end{array}$ & $\begin{array}{l}\text { Relacionada } \\
\text { con las teorías }\end{array}$ & $\begin{array}{l}\text { La } \\
\text { formulación }\end{array}$ & Procesualista \\
\hline
\end{tabular}


Capítulo 2 Gestión del Conocimiento y Ventaja Competitiva

\begin{tabular}{|c|c|c|c|c|c|}
\hline Escuela & $\begin{array}{l}\text { Periodo } \\
\text { (década) }\end{array}$ & $\begin{array}{c}\text { Principales } \\
\text { Autores }\end{array}$ & $\begin{array}{l}\text { Aspectos } \\
\text { Centrales }\end{array}$ & \multicolumn{2}{|c|}{$\begin{array}{l}\text { Características } \\
\text { /Clasificación }\end{array}$} \\
\hline & $\begin{array}{l}\text { Gana } \\
\text { impor- } \\
\text { tancia en } \\
\text { los } 80 \text { y } \\
90\end{array}$ & $\begin{array}{l}\text { March } \\
\text { Quinn } \\
\text { Prahalad y } \\
\text { Hamel }\end{array}$ & $\begin{array}{l}\text { sicológicas del } \\
\text { aprendizaje y } \\
\text { la teoría del } \\
\text { caos. } \\
\text { La estrategia } \\
\text { se crea a través } \\
\text { del aprendizaje } \\
\text { continuo de } \\
\text { los directivos } \\
\text { Conceptos } \\
\text { como: el } \\
\text { aprendizaje } \\
\text { continuo, } \\
\text { capacidades } \\
\text { dinámicas, } \\
\text { modelos de } \\
\text { creación de } \\
\text { conocimiento, } \\
\text { recursos y } \\
\text { capacidades. }\end{array}$ & $\begin{array}{l}\text { de la } \\
\text { estrategia } \\
\text { como un } \\
\text { proceso } \\
\text { ampliado a } \\
\text { lo social. } \\
\\
\text { Identifican } \\
\text { grupos y } \\
\text { agentes que } \\
\text { se relacionan } \\
\text { con la } \\
\text { empresa } \\
\text { como parte } \\
\text { importante } \\
\text { para la } \\
\text { creación de } \\
\text { la estrategia }\end{array}$ & \\
\hline Poder & $70-80$ & $\begin{array}{l}\text { Allison } \\
\text { Peffer y } \\
\text { Salancik } \\
\text { Astley }\end{array}$ & $\begin{array}{l}\text { La creación de } \\
\text { la estratega } \\
\text { como un } \\
\text { proceso de } \\
\text { influencia } \\
\text { abierta. El uso } \\
\text { del poder y la } \\
\text { política interna }\end{array}$ & & \\
\hline Cultural & 60 & $\begin{array}{l}\text { Rhenman y } \\
\text { Normann }\end{array}$ & $\begin{array}{l}\text { Relacionada } \\
\text { con la }\end{array}$ & & Sistémico \\
\hline
\end{tabular}


Capítulo 2 Gestión del Conocimiento y Ventaja Competitiva

\begin{tabular}{|c|c|c|c|c|c|}
\hline \multirow[t]{2}{*}{ Escuela } & \multirow[t]{2}{*}{$\begin{array}{l}\text { Periodo } \\
\text { (década) }\end{array}$} & \multirow[t]{2}{*}{$\begin{array}{l}\text { Principales } \\
\text { Autores }\end{array}$} & $\begin{array}{l}\text { Aspectos } \\
\text { Centrales }\end{array}$ & \multicolumn{2}{|c|}{$\begin{array}{l}\text { Características } \\
\text { /Clasificación }\end{array}$} \\
\hline & & & $\begin{array}{l}\text { sociología y } \\
\text { antropología } \\
\text { La estrategia } \\
\text { como un } \\
\text { proceso } \\
\text { integrado en el } \\
\text { entorno } \\
\text { cultural de la } \\
\text { organización }\end{array}$ & & \\
\hline Ambiental & $60-70$ & $\begin{array}{l}\text { Pugh } \\
\text { Hannan y } \\
\text { Freeman }\end{array}$ & $\begin{array}{l}\text { Base } \\
\text { conceptual de } \\
\text { la biología y la } \\
\text { sociología } \\
\text { política. } \\
\text { La creación de } \\
\text { la estrategia } \\
\text { como el efecto } \\
\text { de una sola } \\
\text { causa, el } \\
\text { entorno. } \\
\text { Conceptos de } \\
\text { adaptación, } \\
\text { evolución, } \\
\text { contingencia, } \\
\text { selección } \\
\text { natural, } \\
\text { complejidad }\end{array}$ & & Evolucionista \\
\hline Configuración & $60-70$ & $\begin{array}{l}\text { Chandler } \\
\text { Mintzberg, }\end{array}$ & $\begin{array}{l}\text { Pretente } \\
\text { integrar las } \\
\text { aportaciones }\end{array}$ & \begin{tabular}{l}
\multicolumn{2}{l}{ Integración } \\
de los \\
difentes
\end{tabular} & Procesualista \\
\hline
\end{tabular}


Capítulo 2 Gestión del Conocimiento y Ventaja Competitiva

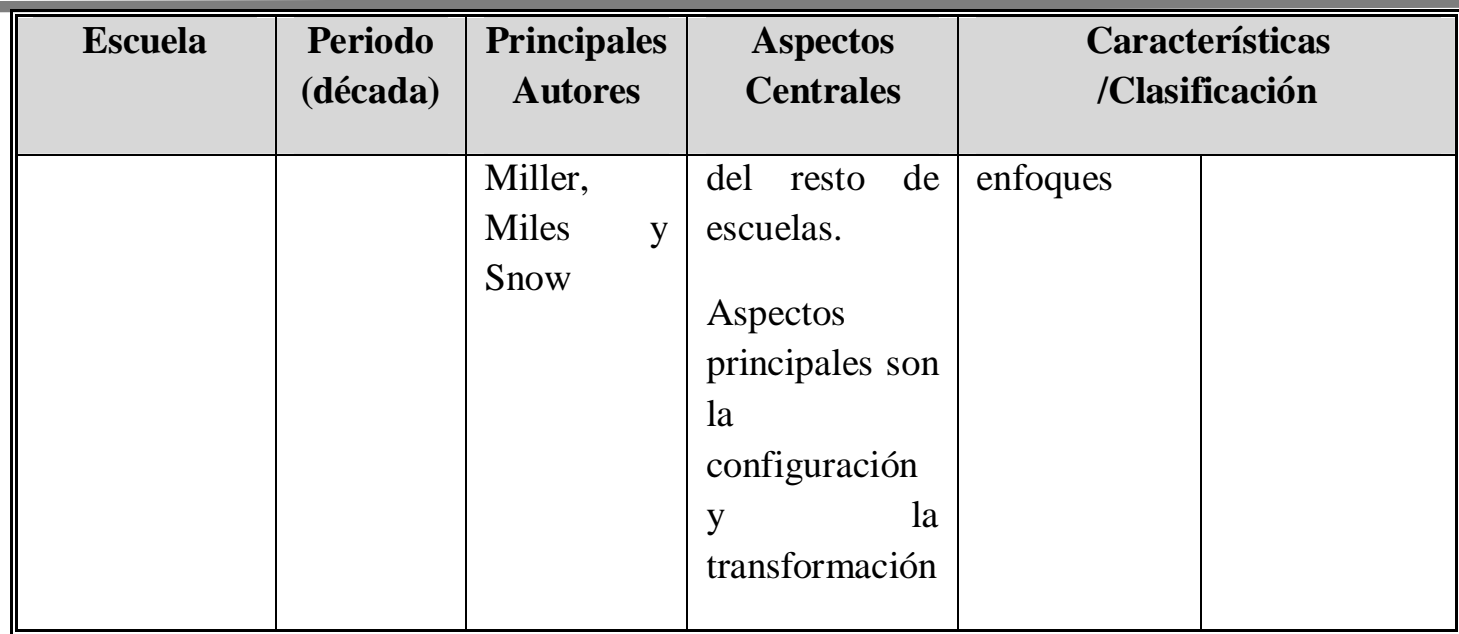

Fuente: Elaboración propia a partir de Mintzberg (1999), Carrión (2007) y Whittington (2002)

Las diversas escuelas de pensamiento estratégico, desde sus distintas perspectivas y enfoques, buscan que la organización pueda conseguir sus propósitos, objetivos y metas en el corto y largo plazo. Por otra parte, la estrategia se constituye en una guía para el funcionamiento de la organización.

De acuerdo a Atac (2002), el ciclo de la estrategia está relacionado con la definición del negocio, la declaración de la estrategia y la verificación y validación de la misma. La elección de la definición del negocio es un aspecto crítico, puesto que responder a las preguntas de “¿qué produzco?” y “¿para quién?", encierran la esencia de la naturaleza del negocio y la base para la declaración de la estrategia. 


\section{Capítulo 2 Gestión del Conocimiento y Ventaja Competitiva}

El negocio es distinto a lo que se entiende por gestión y distinto a la empresa. Gestionar es como conducir un automóvil. Cada pieza del mismo tiene una función específica: unas giran para posibilitar desplazamiento, otras giran para posibilitar dirección y otras simplemente resisten; pero todas funcionan bajo un imperativo, desplazar el automóvil desde un punto A hacia un punto B; todo esto bajo la dirección de un conductor.

El gerente es el conductor, y como tal, necesita habilidades y conocimientos. El automóvil es la empresa y funciona de acuerdo a las especificaciones y organización. Pero, un mismo automóvil puede tener más de un objetivo: puede servir de auto de carreras el fin de semana y para transportar a la familia en los días hábiles. Es decir, se tienen "varios negocios", aunque el auto sea el mismo. Además, cada "negocio" tiene una particular forma de ser conducido: veloz y arriesgado en un caso, seguro y prudente en el otro (Atac, 2002).

Por ello, la empresa puede tener uno o más negocios y cada uno debe ser encarado como tal, con sus particularidades propias. Es lo mismo que decir que no son las empresas las que desarrollan sus estrategias, sino los negocios que esas empresas contienen.

Cuando se le pide a un empresario que defina su negocio en términos de responder estas dos preguntas engañosamente simples (¿qué produzco?” y “¿para quién?), de acuerdo a la experiencia recogida en varios programas de desarrollo de 


\section{Capítulo 2 Gestión del Conocimiento y Ventaja Competitiva}

la Universidad Privada Boliviana, las respuestas normalmente son muy generales y confusas ${ }^{2}$.

Una definición muy amplia del negocio no es útil para el empresario ni ayuda en el establecimiento de la estrategia, por ello es necesario que la definición del negocio tome en cuenta un grupo de clientes específicos.

Por tanto, es necesario utilizar los criterios de segmentación a fin de identificar un grupo de clientes con necesidades, hábitos, costumbres, resultados y expectativas más o menos similares. La oferta de la empresa deberá responder a estas necesidades, hábitos y costumbres, resultados o expectativas en términos de calidad, cantidad, tiempo y costo. La segmentación consiste en identificar grupos de consumidores con el mayor parecido entre ellos y muy diferentes respecto a otros grupos de consumidores (Kotler y Keller, 2009).

La segmentación de mercado, permite "adecuar" de mejor manera los productos o servicios para un grupo homogéneo de la población. Esto asegura una mayor satisfacción en cada segmento y que la empresa pueda convertirse en un "monopolio competitivo ", esto es, que sea líder en su nicho de mercado.

\footnotetext{
2 Durante la gestión 2003, en el marco del Proyecto CCl - BOL 6180: La División de Consultoría de la Universidad Privada Boliviana, aplicó la herramienta de diagnóstico "Needsme" basada en el modelo BMS a 50 empresas con perfil exportador Con respecto a la definición del negocio, la principal debilidad encontrada se basada en las respuestas proporcionadas "para quien", puesto que la identificación de los segmentos - mercados fueron muy generales e imprecisos. Otra dificultad es que en muchas empresas se tienen "varios negocios" y estos no están claramente diferenciados.
} 


\section{Capítulo 2 Gestión del Conocimiento y Ventaja Competitiva}

Una adecuada segmentación permitirá establecer mejor las prioridades respecto a los segmentos más atractivos, como también identificar con más claridad el tipo de competencia en cada segmento.

\subsubsection{Tipos de Estrategias y Verificación}

Entre las diferentes tipologías de estrategias se encuentran las genéricas de Porter (1980), que hacen referencia a conceptos generales como los costos, la diferenciación y enfoque. Las tipologías propuestas por Miles et al. (1978) que hacen referencia al comportamiento de la organización frente al mercado, clasificándolas en: defensoras, prospectoras, analíticas y reactivas. Por su parte, Buzell y Gale (1987) introducen los principios "The PIMS Principles" que han sido asociados a las investigaciones sobre las relaciones entre la estructura del mercado, las estrategias de mercado y los resultados de la organización.

Sin embargo, (Chrisman, Hofer y Boulton, 1988) analizan y cuestionan los objetivos y atributos de los sistemas de clasificación de Porter (1980), mientras que (Llonch y Belbeze, 2004) validan la clasificación de Miles y Snow (1978).

De acuerdo a la priorización de los objetivos de la función de producción, el modelo BMS identifica cuatro tipos de estrategias genéricas:

- Estrategias simples: en las que el posicionamiento está orientado a un solo objetivo de la función de producción, 


\section{Capítulo 2 Gestión del Conocimiento y Ventaja Competitiva}

- Estrategias compuestas: en las que el posicionamiento toma en cuenta una combinación de dos objetivos de la función de producción,

- Estrategias complejas: en las que el posicionamiento toma en cuenta una combinación de tres objetivos de la función de producción

- Estrategia total, en la cual se priorizan los cuatro objetivos de la función de producción.

Lógicamente que la elección de la estrategia estará condicionada por el análisis del segmento al que estará dirigida y por otra parte por los recursos y capacidades que posea la empresa.

\subsubsection{Verificación de la Estrategia}

El diseño de la estrategia estará en función de la definición del negocio, por una parte y de la evaluación de las capacidades, por otra. Para la verificación de la estrategia la "materia prima" es la información y el conocimiento, de ahí la importancia de obtener la información tanto interna como externa. En el siguiente diagrama se presenta la estructura del modelo BMS, así como los flujos de información y conocimiento de entrada y salida: 
Figura 2.2. Flujos de información y conocimiento

Finformación y conocimiento de salida

Flujos de imitormación y conocimiento de entrada

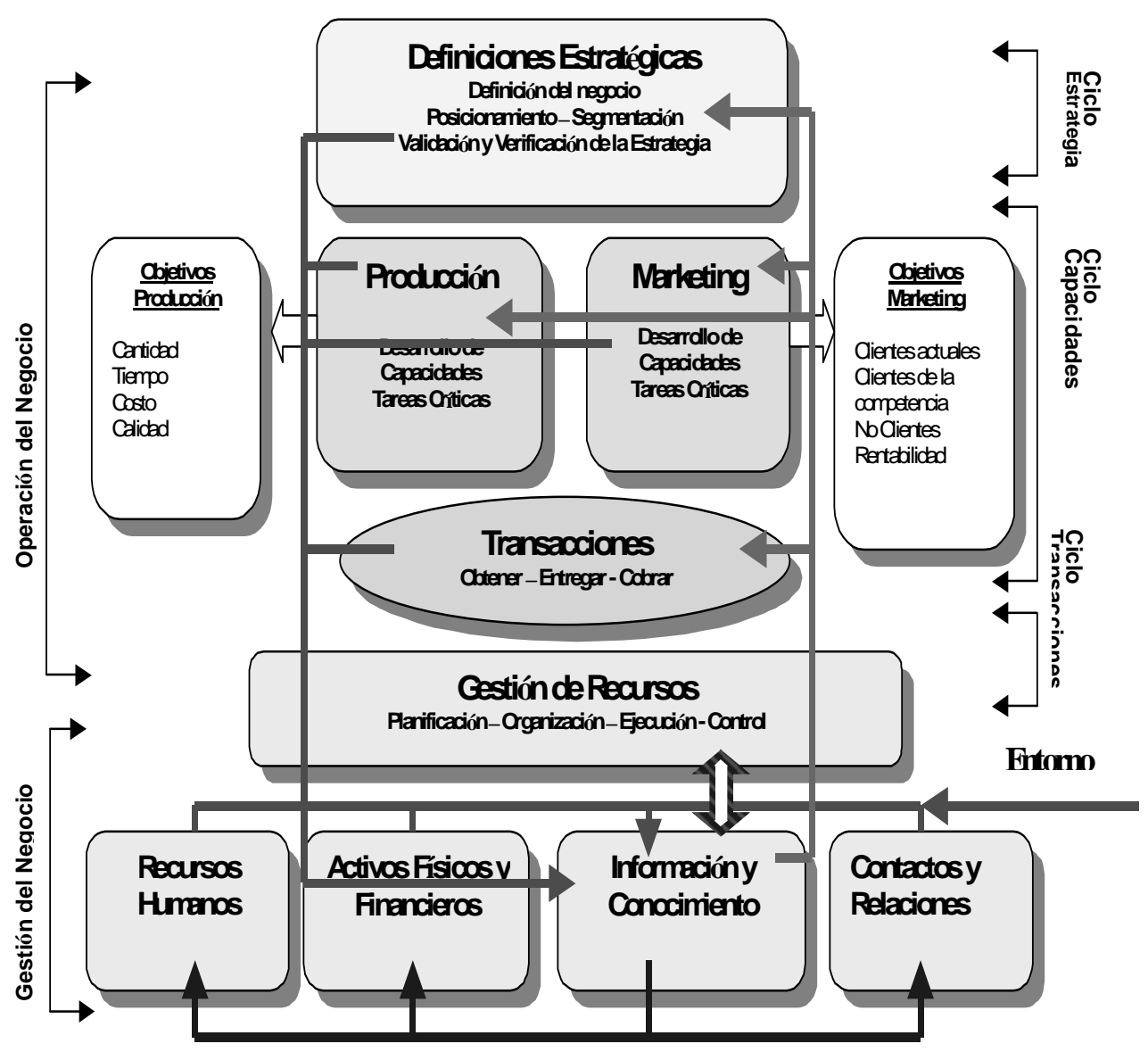

Fuente: Elaboración propia con base en el modelo BMS 


\subsubsection{Recursos, Capacidades y Competencias}

La abundante literatura generada en torno a los recursos, capacidades y competencias, muestran diversas interpretaciones en la concepción de estos constructos, ello lleva a una confusión sobre la delimitación y alcance de cada uno de los términos. Por ello, es importante hacer una distinción entre lo que son los recursos, capacidades y competencias.

Para Grant (1991) los recursos están más orientados a los inputs de los procesos productivos y se constituyen en la fuente de las capacidades organizacionales, mientras que las capacidades se refieren mas a la capacidad del set de recursos para desempeñar actividades especificas y son la fuente para la consolidación de ventajas competitivas.

Por su parte, Teece et al. (1997) diferencian las capacidades de los recursos: mientras los recursos pueden ser adquiridos en el mercado, las capacidades deben desarrollarse en la empresa, lo que hace que sean propias de la empresa e imposibilitan su transferencia. El proposito de las capacidades es el de mejorar la productividad de los recursos.

En este sentido, Palacios (2002) indica que los recursos pueden funcionar de manera independiente a las personas y que incluye a los activos tangibles e intangibles de una organización que requieren de protección legal. En cambio, las capacidades son los activos intangibles vinculados a las personas que los sustentan o a la empresa como tal. 
Los recursos, de acuerdo a Amit y Schoemaker (1993), son factores disponibles que posee y controla la empresa. Estos recursos se convertirán en productos o servicios mediante la utilización y combinación de otros recursos, como ser: la tecnología, la información, los incentivos, la mano de obra y la dirección. Las capacidades se refieren a las rutinas organizacionales que desarrolla la empresa, utilizando una combinación de recursos mediante procesos organizacionales que son desarrollados en el tiempo para alcanzar un fin deseado.

Para Teece (2007), Prahalad y Hamel (1990), las definiciones asignadas a las competencias tienen como aspecto común a las diversas habilidades propias de cada organización y que las mismas se constituyen en la base para la generación de estrategias competitivas.

En la siguiente tabla se presenta un resumen de los conceptos de recursos, capacidades y competencias:

Tabla 2.2. Resumen de los conceptos de recursos, capacidades y competencias

\begin{tabular}{|c|c|c|}
\hline Recursos & "Capacidades & Competencias \\
\hline 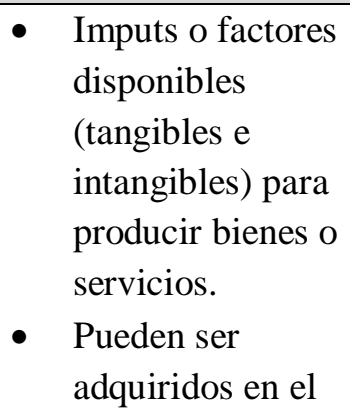 & $\begin{array}{ll}\text { - } & \text { Set de recursos para } \\
\text { desempeñar } \\
\text { actividades especificas } \\
\text { - } & \text { Se desarrollan en la } \\
\text { empresa como rutinas } \\
\text { organizacionales. } \\
\text { Difícilmente } \\
\text { transferibles }\end{array}$ & $\begin{array}{l}\text { - } \begin{array}{l}\text { Habilidades propias } \\
\text { de cada organización }\end{array} \\
\text { Son la base para la } \\
\text { generación de } \\
\text { estrategias } \\
\text { competitivas }\end{array}$ \\
\hline
\end{tabular}




\section{Capítulo 2 Gestión del Conocimiento y Ventaja Competitiva}

\begin{tabular}{||l|l|l||}
\hline mercado & $\bullet$ Activos intangibles & \\
vinculados a las & \\
independientemente & personas u \\
organización & \\
de las personas & & \\
Requieren de & & \\
\hline
\end{tabular}

Fuente: Elaboración propia a partir de las definiciones de Grant (1991), Teece et al. (1997), Palacios (2002), Amit y Schoemaker (1993), Teece (2007) y Prahalad y Hamel (1990)

A continuación se profundiza el análisis de los conceptos de recursos, capacidades y competencias.

\subsubsection{Recursos, Conceptos y Clasificación}

Los recursos son definidos como imputs o stocks (tanto tangibles, como los activos físicos y recursos humanos ; e intangibles, como las marcas y patentes) que son poseídos o controlados por la empresa y se traducen en outputs o productos y/o servicios mediante la utilización de otros recursos o activos (Grant, 1991; Amit y Schoemaker, 1993).

Por otra parte, Coyne (1986) añade que los recursos se convierten en productos finales o servicios utilizando una amplia gama de otros activos de la empresa y mecanismos vinculadores, tales como la tecnología, los sistemas de información administrativa, sistemas de incentivos, confianza entre la dirección y mano de obra. 


\section{Capítulo 2 Gestión del Conocimiento y Ventaja Competitiva}

Otro grupo de autores definen a los recursos de una forma más amplia, que incluye a las capacidades dentro del mismo término (Wernerfelt, 1984; Barney, 1991; Hall, 1993).

Barney (1991) indica que los recursos organizacionales están constituidos por todos los activos, capacidades, procesos organizacionales, información y conocimiento que son controlados por una empresa y la habilitan para concebir e implantar estrategias para el mejoramiento de su eficacia y eficiencia. A la vez, sostiene que los recursos organizacionales necesarios para la generación de ventajas competitivas sostenibles cumplen los siguientes atributos: valor, rareza, inimitabilidad y substituibilidad.

En esta línea, (Teece et al., 1997:516) definen a los recursos como "activos específicos de la firma que son difíciles o imposibles de imitar". De acuerdo a estos autores, estos activos son difíciles de transferir entre las firmas debido a los altos costes de transacción, transferencia y también porque contienen altos niveles de conocimiento tácito.

Eisenhardt y Martin (2000) consideran a los recursos como activos específicos físicos, humanos y organizacionales que pueden ser utilizados en la implementación de nuevas estrategias de valor. Son aquellos que incluyen a las habilidades locales o competencias, que son fundamentales para las ventajas competitivas de las empresas. En este contexto, los recursos pueden ser valuables, raros, inimitables y no sustituibles. 


\section{Capítulo 2 Gestión del Conocimiento y Ventaja Competitiva}

Peteraf y Barney (2003) definen a los recursos como críticos debido a que: a) son esenciales para los esfuerzos de la empresa por generar mayor valor diferenciado y b) son factores limitantes para determinar la demanda que la empresa puede satisfacer.

Al ser limitantes, son escasos en el sentido que su oferta es insuficiente para cubrir la demanda del mercado. La escasez de los recursos implica una restricción natural de la oferta en relación a la demanda de los recursos.

De acuerdo a esta amplia concepción, los recursos que poseen el potencial de generar ventajas competitivas sostenibles deben tener cuatro atributos: ser valiosos, en el sentido que explotan oportunidades y/o neutralizan amenazas en el ambiente; escasos entre las firmas competidoras actuales y potenciales; ser imperfectamente imitables ; y no debe existir un substituto equivalente (Coyne, 1986).

\subsubsection{Clasificación de los recursos}

Al igual que las diferencias encontradas en la definición de los recursos, se encuentra en la literatura diferentes clasificaciones. Wernerfelt (1984) los clasifica en tangibles e intangibles, Hall (1993) considera en la clasificación de los recursos la protección legal y los que no están protegidos legalmente y Coyne (1986) identifica características de los recursos para generar ventajas competitivas. 
Tabla 2.3. Clasificación de Recursos

\begin{tabular}{|c|c|c|}
\hline & Tangibles & Intangibles \\
\hline $\begin{array}{l}\text { Difíciles de } \\
\text { proteger }\end{array}$ & $\begin{array}{l}\text { - Ubicación } \\
\text { geográfica } \\
\text { - Acceso a } \\
\text { materias primas }\end{array}$ & $\begin{array}{l}\text { Reputación de los } \\
\text { productos de la } \\
\text { empresa } \\
\text { - Cultura de la } \\
\text { organización } \\
\text { - Conocimiento de } \\
\text { los empleados, } \\
\text { proveedores y } \\
\text { distribuidores } \\
\text { Información de } \\
\text { dominio público } \\
\text { Redes personales y } \\
\text { organizacionales }\end{array}$ \\
\hline $\begin{array}{l}\text { Con } \\
\text { protección } \\
\text { legal }\end{array}$ & $\begin{array}{ll}- & \text { Cuentan con } \\
\text { soporte físico } \\
\text { - } & \text { Claramente } \\
\text { identificados en } \\
\text { la contabilidad }\end{array}$ & $\begin{array}{ll}\text { - } & \text { Marcas } \\
\text { - } & \text { Patentes, diseños } \\
\text { - } & \text { Contratos, } \\
& \text { Licencias } \\
\text { - } & \text { Bases de datos }\end{array}$ \\
\hline Estratégicos & \multicolumn{2}{|c|}{$\begin{array}{l}\text { Valiosos, escasos, imperfectamente imitables y no debe } \\
\text { existir un substituto equivalente }\end{array}$} \\
\hline
\end{tabular}

Fuente: Elaboración propia a partir de Wernerfelt (1984); Hall (1993) y Coyne (1986)

Entre otras clasificaciones de recursos se tiene a la de Barney (1991:101), que clasifica los mismos en tres grupos: 


\section{Capítulo 2 Gestión del Conocimiento y Ventaja Competitiva}

- Recursos de capital físico: tecnología física, equipos, ubicación geográfica y accesos a materias primas

- Recursos de capital humano: capacitación, experiencia, juicio, inteligencia, relaciones y opiniones de gerentes y del personal

- Recursos de capital organizacional: estructura formal de reportes de la empresa, planificación formal e informal, sistemas de coordinación y control, relaciones informales entre grupos dentro de la empresa y entre grupos fuera de la empresa

En toda empresa se puede diferenciar el proceso del negocio de la gestión de los recursos. La gestión de los recursos es llevada principalmente por el propietario/gerente de la empresa y apoyada por sus colaboradores más cercanos. Adicionalmente a los recursos "tangibles" se deben gestionar los recursos “intangibles", entre ellos la información y el conocimiento.

Por tanto, una empresa puede volverse competitiva si gestiona - administra de manera eficaz y eficiente sus recursos, para producir y comercializar bienes y servicios basándose en una estrategia de negocios competitiva (Atac, 2002).

En el BMS se entiende por gestión o administración el llevar a cabo las actividades necesarias para poder tomar decisiones sobre:

1. La cantidad de cada uno de los recursos que se necesita para desarrollar el negocio de la empresa (planificar);

2. Proveer y asignar tales recursos a determinadas tareas (ejecutar);

3. Dar seguimiento a la utilización de dichos recursos para comprobar que se alcanzan los objetivos esperados (controlar). 
Los recursos necesarios, tanto para la gestión como para el proceso de negocio de la empresa, se obtienen del entorno de la empresa a través de distintas “actividades de gestión". La ejecución de actividades consume parte de los recursos disponibles de la empresa. Por esto, la eficiencia de la gestión se mide en el BMS por la cantidad de recursos utilizados tanto para gestionar como para desarrollar el negocio de la empresa.

\subsubsection{Capacidades, conceptos y clasificación}

Grant (1991:122) define a las capacidades como "patrones complejos de coordinación entre personas y entre recursos y personas, cuya perfecta coordinación requiere de aprendizaje a través de la repetición”.

Siguiendo esta definición, las capacidades se constituyen con base en la capacidad del equipo de recursos para desempeñar tareas o actividades específicas, constituyéndose en rutinas organizativas (Winter, 2003). Esta definición es reforzada por Sanchez et al. (1996) que definen a las capacidades como patrones de acción repetitivos para la creación, producción y/o oferta de productos al mercado.

Estos autores mencionan a las habilidades como una forma especial de capacidad, con la connotación de que es una capacidad específica útil en una situación específica o relacionada al uso de activos especializados. 


\section{Capítulo 2 Gestión del Conocimiento y Ventaja Competitiva}

Por su parte, Javidan (1998) indica que las capacidades son la habilidad de la empresa para explotar sus recursos. Sitúa a las capacidades en el segundo nivel de la jerarquía, considerándolas como una serie de procesos y rutinas que gestiona la interacción entre sus recursos transformando los imputs en outputs. Una característica de las capacidades es su fundamento funcional, ya que residen en una función en particular.

Makadok (2001:389) complementa la definición destacando el carácter intransferible de las capacidades y diferenciándolas de los recursos. Define a la capacidad como "un recurso incrustado en la organización, no transferible y específico de la empresa, cuyo propósito es mejorar la productividad de otros recursos poseídos por la empresa".

Otras definiciones como la de Amit y Schoemaker (1993:35) conceptualizan a la capacidad como competencia "la competencia de una empresa para desplegar los recursos, usualmente en combinación, usando procesos organizativos, para producir un bien deseado"

En resumen, las capacidades se refieren a la capacidad de la empresa para implementar los recuros usualmente en combinación, utilizando procesos organizacionales, para efectuar un fin deseado. Éstas están basadas en información, procesos tangibles o intangibles específicos de la empresa y desarrollados en el tiempo a través de interacciones complejas entre los recursos de la empresa. A diferencia de los recursos, las capacidades se basan en desarrollar, llevar e intercambiar información a través del capital humano de la empresa (Coyne, 1986). 


\subsubsection{Clasificación de capacidades}

Grant (1996) considera dos enfoques para clasificar las capacidades: el análisis funcional, que toma como base las áreas funcionales de una empresa y las relaciona con las capacidades (producción, marketing, entre otras); y el análisis de la cadena de valor, que identifica las actividades que agregan valor en una cadena secuencial.

La clasificación general de capacidades encontrada en la literatura, se realiza de acuerdo a niveles (Collis y Montgomery, 1995; Teece et al., 1997; Grant, 1996; Dosi, Nelson y Winter, 2000). Las capacidades de primer nivel o estáticas están asociadas a las actividades funcionales de la empresa; las de segundo nivel contemplan las capacidades dinámicas que están relacionadas con el cambio y la innovación; y las de tercer nivel, en las que se sitúan las capacidades de aprender a aprender, además de aprender más rápido que la competencia.

Los entornos altamente cambiantes requieren el desarrollo de capacidades que respondan a estos desafíos, estas son las capacidades dinámicas. Eisenhardt y Martin (2000) definen a las capacidades dinámicas como procesos de la firma que utilizan recursos específicamente para integrar, reconfigurar, ganar y soltar recursos para combinar e incluso crear cambios en el mercado.

Las capacidades dinámicas son rutinas organizacionales y estratégicas por las cuales las empresas alcanzan nuevas configuraciones de recursos y capacidades en respuesta a los cambios que se dan en los mercados (emergen, colisionan, se dividen, evolucionan o mueren). 
Para poder llevar adelante las funciones de producción y marketing, es necesario ejecutar una serie de tareas, las cuales generarán las capacidades de producir con la calidad deseada, la cantidad requerida, en el tiempo esperado y a un coste aceptable. Las tareas de la función de marketing estarán orientadas a generar la capacidad de comunicarse con el mercado y de establecer canales de distribución y las tareas de transacciones están orientadas a generar las capacidades de obtener y cumplir con los pedidos (Atac, 2002).

Tabla 2.4. Tareas y capacidades en el Modelo BMS

\begin{tabular}{|c|c|c|}
\hline \multicolumn{2}{|c|}{ Tareas de Producción } & Tareas de Marketing \\
\hline $\begin{array}{c}\text { Capacidad } \\
\text { para producir } \\
\text { cantidades } \\
\text { requeridas: }\end{array}$ & $\begin{array}{l}\text { - } \begin{array}{l}\text { Diseño e Instalación } \\
\text { de Planta }\end{array} \\
\text { - Procesos de } \\
\text { Ingeniería de } \\
\text { Producción } \\
\text { - Ubicación y } \\
\text { Evaluación de Planta } \\
\text { - Herramientas }\end{array}$ & \\
\hline
\end{tabular}


Capítulo 2 Gestión del Conocimiento y Ventaja Competitiva

\begin{tabular}{|c|c|c|c|}
\hline $\begin{array}{c}\text { Capacidad } \\
\text { para producir } \\
\text { a tiempo } \\
\text { esperado: }\end{array}$ & $\begin{array}{ll}\text { - } & \text { Determinar las } \\
\text { Necesidades de } \\
\text { Inventario } \\
\text { - } \\
\text { Manejo de } \\
\text { Materiales } \\
\text { - Compras y } \\
\text { Suministros } \\
\text { - Mantenimiento de } \\
\text { Inventarios }\end{array}$ & $\begin{array}{c}\text { Capacidad } \\
\text { para } \\
\text { comunicarse } \\
\text { con los } \\
\text { clientes }\end{array}$ & $\begin{array}{ll}\text { - } & \text { Elaborar } \\
& \text { Literatura de } \\
\text { Ventas } \\
\text { - } & \text { Programar } \\
\text { Promociones } \\
\text { - }\end{array}$ \\
\hline $\begin{array}{c}\text { Capacidad } \\
\text { para producir } \\
\text { a un coste } \\
\text { aceptable: }\end{array}$ & $\begin{array}{ll}\text { - } & \begin{array}{l}\text { Equilibrar la } \\
\text { Producción }\end{array} \\
\text { - } & \begin{array}{l}\text { Desarrollar Sistemas } \\
\text { de Mantenimiento }\end{array} \\
\text { - } & \text { Mejora de Métodos } \\
\text { - } & \begin{array}{l}\text { Instaurar Programas } \\
\text { de Reducción de }\end{array} \\
\text { Costes }\end{array}$ & $\begin{array}{l}\text { Capacidad } \\
\text { para } \\
\text { distribuir }\end{array}$ & $\begin{array}{ll}\text { Establecer } \\
\text { Canales de } \\
\text { Distribución }\end{array}$ \\
\hline
\end{tabular}


Capítulo 2 Gestión del Conocimiento y Ventaja Competitiva

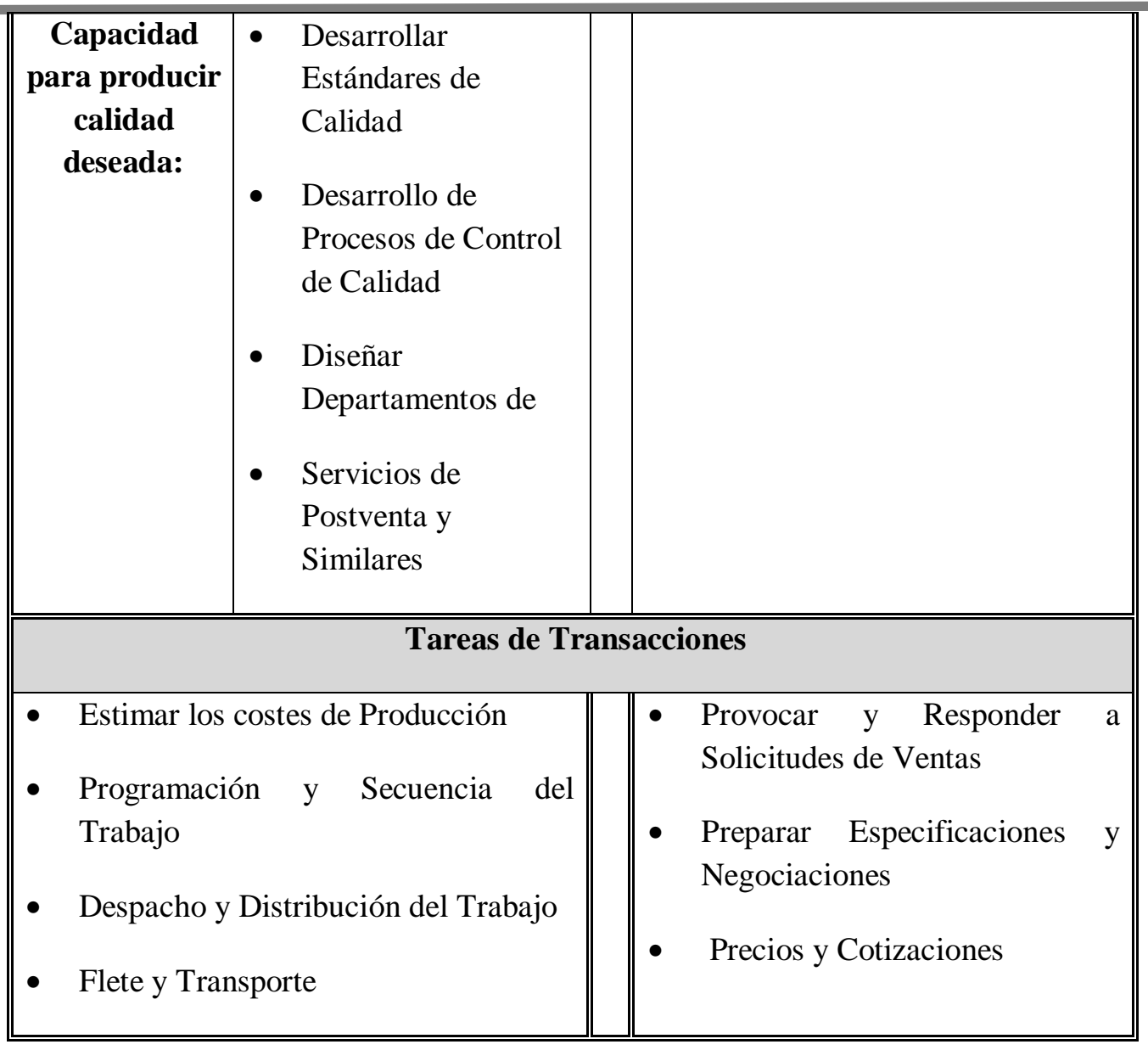

Fuente: Elaboración propia a partir del modelo BMS

Para que un negocio sea exitoso debe existir una coherencia entre la estrategia adoptada y las capacidades que ha desarrollado la empresa. El desarrollo de las capacidades está relacionado con un grupo de tareas que debe llevar adelante la empresa para poder producir y vender, con base en la estrategia elegida. 


\section{Capítulo 2 Gestión del Conocimiento y Ventaja Competitiva}

De acuerdo al modelo BMS, la ejecución de cada una de las tareas requiere de recursos (humanos; físicos y financieros; información y conocimiento; contactos y relaciones) y en virtud de que los mismos son escasos, como se mencionó anteriormente, es necesario priorizar las tareas críticas.

Una limitación del modelo BMS es que se concentra principalmente en las capacidades de primer nivel (producción y marketing) y no explícitamente en las de segundo o de tercer nivel.

\subsubsection{Competencias, Conceptos y Clasificación}

Sanchez et al. (1996) definen a la competencia como la habilidad para sostener la implementación coordinada de los activos de manera que ayude a la firma a alcanzar sus objetivos. El aprovechamiento de oportunidades de mercado actuales o nuevas, puede lograrse mediante la aplicación de las competencias existentes de la firma, de manera que no requiere cambios cualitativos en los activos o capacidades de la misma.

Sin embargo, en un ambiente dinámico, el mantenimiento de las competencias requiere la adaptación continua para mantener la implementación coordinada de los activos bajo condiciones cambiantes.

En consecuencia, la construcción de competencias implica implementar procesos que permitan lograr cambios cualitativos en el stock existente de los activos y capacidades, incluyendo nuevas habilidades para coordinar e implementar los 


\section{Capítulo 2 Gestión del Conocimiento y Ventaja Competitiva}

activos nuevos o existentes y las capacidades a fin de lograr los objetivos de la firma.

Javidan (1998) menciona que las competencias se encuentran en el tercer nivel de la jerarquía y las define como la integración funcional y la coordinación de capacidades.

\section{Figura 2.3. Jerarquía de Capacidades y Competencias}

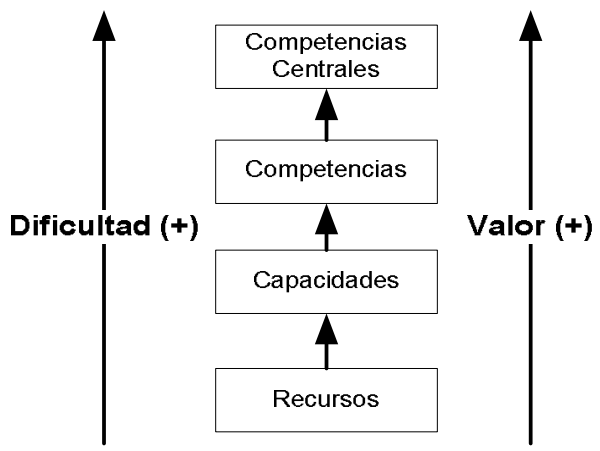

Fuente: Elaboración propia con base en Javidan (1998)

Foss y Knudsen (1996) resaltan que las competencias están basadas en activos específicos relacionados al conocimiento idiosincrásico, por lo que poseen un gran componente tácito (reside en los individuos); por tanto, asimétricamente distribuido, difícil de comercializar y compartir. Las competencias permiten desarrollar actividades, en particular, resolver problemas y por lo general de forma más eficiente que otros que no las poseen. 


\section{Capítulo 2 Gestión del Conocimiento y Ventaja Competitiva}

Las competencias son difíciles de transferir debido a las siguientes razones: a) ambigüedad causal, b) conocimiento que no ha sido probado, c) falta de motivación por parte de la fuente o del receptor del conocimiento, c) cultura organizacional que no incentiva el aprendizaje (Javidan, 1998)

\subsubsection{Clasificación de competencias}

Camisón (2002) clasifica las competencias distintivas de una organización en tres niveles:

- Competencias estáticas o de primer nivel, asociadas a las actividades funcionales de la empresa (producción, marketing y finanzas).

- Competencias de coordinación y cohesión o de segundo nivel (directivas, tecnológicas, de organización y recursos humanos).

- Competencias dinámicas o de tercer nivel, incluyen las destrezas para la gestión del cambio y la innovación, así como la capacidad para aprender más rápidamente que la competencia (dinámicas, aprendizaje y conocimiento).

Prahalad y Hamel (1990) incorporan el término de competencias distintivas o esenciales "core competence", como un conjunto de capacidades que pueden contribuir a la prosperidad a largo plazo de la empresa, siendo estas la fuente de ventajas competitivas. Sin embargo, no todas las ventajas competitivas derivarán de las competencias distintivas.

Prahalad y Hamel (1990:82) definen a las competencias esenciales como:"el aprendizaje colectivo dentro de la organización, especialmente al relacionado a la 


\section{Capítulo 2 Gestión del Conocimiento y Ventaja Competitiva}

coordinación de las diversas habilidades productivas y la integración de múltiples vertientes tecnológicas".

Una característica de este tipo de competencias es que no disminuye con el uso o el tiempo, por el contrario, se enriquece a medida que las competencias son aplicadas y compartidas. Por otro lado, estas competencias proveen acceso a una gran variedad de mercados potenciales, contribuyen a la percepción que tienen los clientes sobre los beneficios de los productos finales y por último, son difíciles de imitar debido a la dificultad que conlleva la armonización de tecnologías individuales y las habilidades de producción (Prahalad y Hamel, 1990).

Hamel y Prahalad (1994) identifican tres requisitos para que las competencias sean esenciales: que contribuyan a la creación de valor que es percibido por los clientes, que sean difíciles de imitar por los competidores y que faciliten el acceso a nuevos mercados.

Javidan (1998) ubica en el nivel más alto de la jerarquía de competencias a las nucleares, que son consideradas como una colección de competencias que están dispersas en la empresa y que requieren el aprendizaje organizacional colectivo, involucramiento y compromiso entre las unidades estratégicas.

\subsubsection{Propuesta de reconfiguración del modelo BMS}

Si bien el modelo BMS presenta importantes aportes para la comprensión de la relación entre los recursos, capacidades, la implementación de la estrategia y el 


\section{Capítulo 2 Gestión del Conocimiento y Ventaja Competitiva}

logro de ventajas competitivas; su principal limitación está dada por su carácter estático, puesto que su base conceptual es el enfoque de recursos y capacidades.

Por otra parte, se centra en las capacidades principalmente de primer nivel o funcionales y no contempla explícitamente las capacidades dinámicas en respuesta a cambios en el entorno y la creación de competencias, como base para lograr y sostener ventajas competitivas.

El "International Trade Center", con miembros de la red global que operan el modelo BMS en varias regiones del mundo, organizó un evento del 25 al 29 de Julio del 2011 en Ginebra Suiza. El objetivo de dicho evento fue el de realizar mejoras al modelo y su metodología de aplicación, así como el intercambio de experiencias en los diferentes países. En este evento se presentó y valido la propuesta de reconfiguración del modelo BMS, el mismo que será utilizado por la red y se incorporará una línea de investigación en el área de gestión del conocimiento. En el anexo 1 se presentan detalles de este evento.

En la siguiente figura se presenta una complementación al modelo de BMS, incorporando explícitamente la consideración del entorno y dinamización del modelo mediante la generación de capacidades dinámicas que reconfiguran la composición de los recursos y competencias en respuesta al entorno y resultados internos. 


\section{Capítulo 2 Gestión del Conocimiento y Ventaja Competitiva}

\section{Figura 2.4. Propuesta de Modelo Dinámico de gestión}

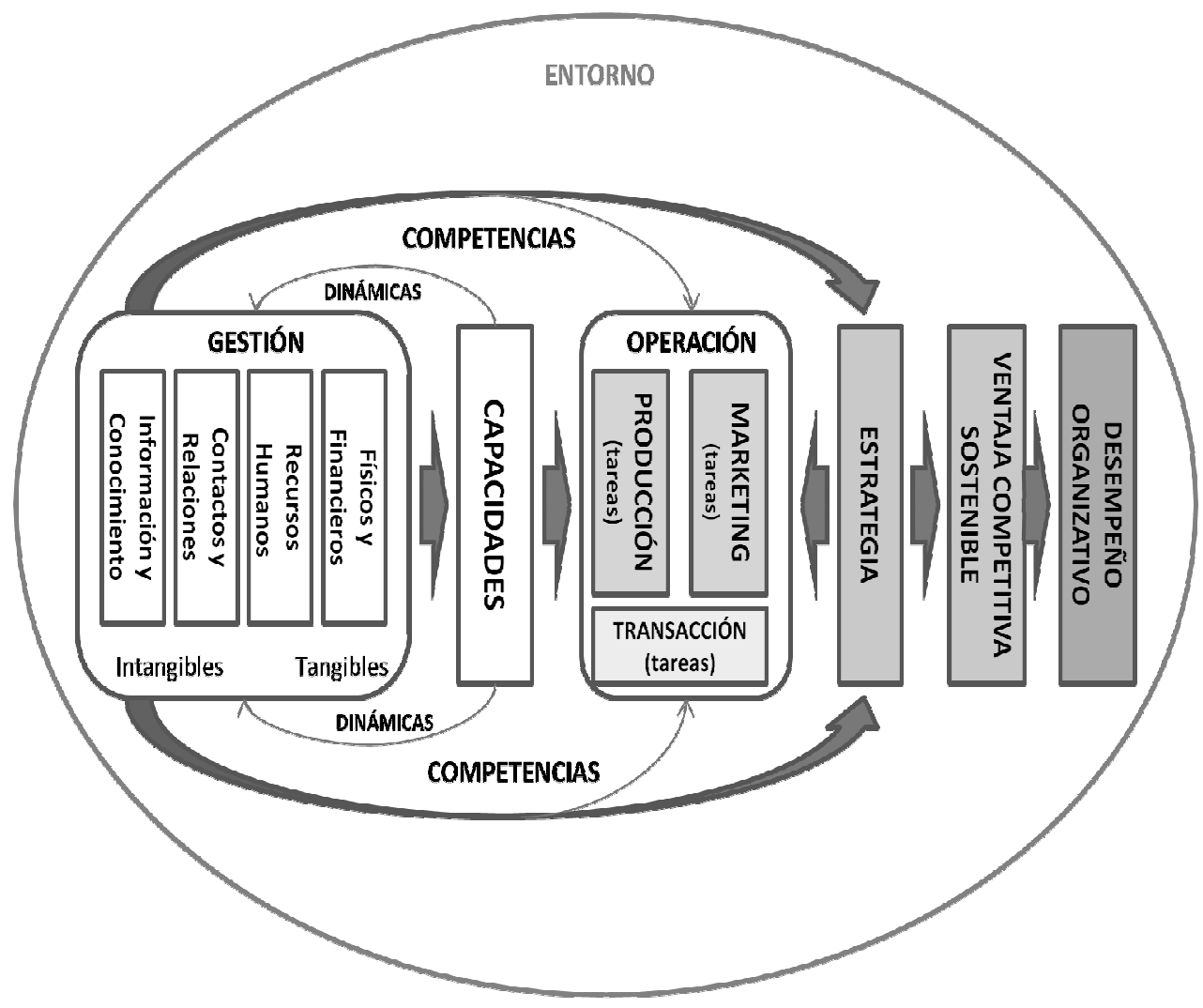

Fuente: Elaboración Propia a partir del modelo BMS

El EBC centra su atención en el desarrollo de competencias como fuente de la ventaja competitiva sostenible. Las competencias distintivas, esenciales o nucleares, como las denominan distintos autores, juegan un rol fundamental para este propósito, la base del desarrollo de este tipo de competencias son los activos estratégicos y en especial el conocimiento. 


\section{Capítulo 2 Gestión del Conocimiento y Ventaja Competitiva}

\subsection{EL CONOCIMIENTO COMO ACTIVO ESTRATÉGICO Y SU GESTIÓN}

La preocupación por definir y entender el significado del conocimiento ha estado presente a lo largo de la historia de la humanidad, grandes pensadores como Aristóteles y Platón han aportado al entendimiento del conocimiento. Como menciona Grant (1996), la respuesta sobre una definición del conocimiento ha sido cuestionada por grandes pensadores desde Platón hasta Popper sin llegar a un claro consenso.

Debido a la amplia literatura sobre el conocimiento y diversos abordajes, es importante delimitar el significado del concepto de conocimiento al contexto de las organizaciones y gestión de empresas. En este sentido, diversas perspectivas definen al conocimiento, ya sea como un objeto a ser almacenado y manipulado, o como un proceso simultáneo entre el conocimiento y la acción.

Kulkarni, Ravindran, y Freeze (2007) mencionan que el conocimiento es un constructo multidimensional con características más complejas que aquellas contenidas en la información, por tal razón, es importante distinguir entre conocimiento, información y datos.

Para esta investigación se revisará el concepto del conocimiento y su gestión partiendo de la diferenciación de los datos, información y conocimiento. 


\section{Capítulo 2 Gestión del Conocimiento y Ventaja Competitiva}

\subsubsection{Datos, información y conocimiento}

Según Davenport y Prusak (1998) así como Alavi y Leidner (2001), dato se refiere a un registro sobre un hecho real, que se constituye en la materia prima para la creación de información. Los datos que carecen de valor, se convierten en información cuando se les añade significado y son organizados para algún propósito; lo cuál se logra mediante: la contextualización (cuando existe un propósito), la categorización, el cálculo, la corrección y la condensación.

El conocimiento, para Davenport y Prusak (1998), es un flujo en el que se mezclan la experiencia, valores importantes, información contextual y puntos de vista de expertos, que facilitan un marco de análisis para la evaluación e incorporación de nuevas experiencias e información.

Bierly, Kessler, y Christensen (2000) consideran que el aprendizaje es relacionar, expandir y mejorar los datos, la información, el conocimiento y sabiduría. Los sistemas de representación (por ejemplo el lenguaje) son importantes para darle significado a los datos, su procesamiento para la generación de información y comprensión por parte del receptor.

\subsubsection{Diferencias entre información y conocimiento}

Respecto a las diferencias entre información y conocimiento, Nonaka y Takeuchi (1995) realizan las siguientes observaciones: el conocimiento se refiere a creencias y compromisos que está en función de una postura, perspectiva o intención particular; a diferencia de la información el conocimiento es acción; el 


\section{Capítulo 2 Gestión del Conocimiento y Ventaja Competitiva}

conocimiento, trata de significados, depende de contextos específicos y es relacional.

El conocimiento no puede ser gestionado de igual manera que la información, requiere de diferentes herramientas, es necesario desarrollar otros métodos no digitales de captura y almacenamiento. Al respecto, los sistemas de gestión de la información basados en sistemas informáticos se encuentran más desarrollados que los sistemas de gestión del conocimiento (Blumentritt y Johnston, 1999).

De acuerdo a Staples, Greenaway y McKeen (2001) la información se convierte en conocimiento cuando interviene la inteligencia humana, de ahí que la misma información dirigida a diferentes personas derive en puntos de vista diferentes y tipos de conocimientos.

En resumen, el conocimiento tiene mayor riqueza que la información, requiere de diferentes herramientas para su gestión y la participación de la inteligencia humana, ya sea de forma individual o colectiva.

\subsubsection{Concepto del conocimiento}

El conocimiento de acuerdo a Venzin, von Krogh y Roos (1998) puede ser analizado desde tres epistemologías:

- la cognitiva como una entidad fija y representable, entiende el conocimiento como representaciones del mundo 


\section{Capítulo 2 Gestión del Conocimiento y Ventaja Competitiva}

- la de las conexiones que considera a la organización como redes basadas en relaciones y conducidas por la comunicación; cuyas reglas forman parte esencial del conocimiento

- la constructiva centrada en la interpretación y no en la recogida de información, considera que el conocimiento reside en la mente, el cuerpo y sistema social, depende del observador y por lo tanto no se puede transmitir

Nonaka y Takeuchi (1995) diferencian dos concepciones del conocimiento: la epistemología occidental, que considera al conocimiento como algo abstracto, estático, basado en la lógica formal y centrado en la verdad como atributo esencial. La otra concepción con la que se identifican estos autores, considera al conocimiento como un proceso humano dinámico que busca la justificación de la creencia personal en busca de la verdad.

Alavi y Leidner (2001) mencionan que el conocimiento puede ser visto desde diversas perspectivas: como un estado mental, un objeto, un proceso, como la condición para tener acceso a la información o como una capacidad. Como un estado mental hace referencia al conocimiento de los individuos que puede ser aplicado a las necesidades de la organización. Al ser reconocido como un objeto, se ve al conocimiento como algo que puede ser almacenado y manipulado.

Kulkarni et al. (2007) caracterizan al conocimiento como un concepto muy amplio, "rico" y multidimensional. Nonaka (1994) identifica dos dimensiones del conocimiento dentro de las organizaciones: tácita y explicita. Conner y Prahalad 


\section{Capítulo 2 Gestión del Conocimiento y Ventaja Competitiva}

(1996) mencionan que el conocimiento tácito es aquel que es adquirido a través de las experiencias personales, las mismas que están en estrecha relación con las diferencias y limitaciones cognitivas que existen entre los individuos. Girdauskienė y Savanevičienė (2007) añaden que el conocimiento individual puede ser formalizado y transferido a otros individuos.

\subsubsection{Conocimiento individual y conocimiento organizativo}

Nonaka y Takeuchi (1995) conciben al conocimiento individual y colectivo como dos representaciones de la dimensión ontológica del conocimiento, considerando distintos niveles de análisis del conocimiento: individual, grupal, organizacional e interorganizacional; explicando la creación del conocimiento a partir de la interacción de dichos niveles.

El conocimiento es el set de creencias poseídas por un individuo sobre las relaciones causales entre fenómenos (Sanchez et al., 1996). En la medida en que el grupo de individuos dentro de la empresa compartan este set de creencias sobre las causalidades, este set se constituye en conocimiento organizacional.

Davenport y Prusak (1998) consideran al conocimiento como un flujo en que se mezclan la experiencia, los valores, información contextual y puntos de vista de expertos; que se origina en la mente de los conocedores. En las organizaciones el conocimiento se encuentra en los documentos, rutinas organizacionales, procesos, prácticas y normas. 


\section{Capítulo 2 Gestión del Conocimiento y Ventaja Competitiva}

Por su parte, Foss y Knudsen (1996) mencionan que según el trabajo de Kogut y Zander (1992), el conocimiento se produce y reproduce en un ambiente social y es inseparable de este ambiente, por lo que no puede ser completamente reducible a los individuos.

Brown y Duguid (1998), respecto a la generación de conocimiento, indican que se facilita cuando se trabaja en conjunto, siendo este fenómeno denominado comunidades de práctica. En este sentido, una comunidad de práctica es definida como un forma de compartir conocimiento cuando los miembros de un grupo trabajan conjuntamente, de forma que se genera conocimiento al compartir su "Know How" y aplicarlo en la práctica.

Teece (1998b) considera que el conocimiento se encuentra en múltiples depósitos, tanto individuales como colectivos, esta diversidad contribuye a que se puedan desarrollar distintas competencias. Si bien el conocimiento se encuentra arraigado a nivel individual, las organizaciones facilitan una estructura física, social y de asignación de recursos. Teece diferencia el conocimiento individual del organizativo, siendo este último más difícil de transferir, en el caso individual las transferencias se suelen dar mediante el mecanismo de contrataciones.

Finalmente, el conocimiento ha sido definido como información personalizada acerca de hechos, procedimientos, conceptos, interpretaciones y juicios elaborados en la mente de los individuos (Alavi y Leidner, 2001). Palacios (2002) define al conocimiento organizacional como stocks y flujos de conocimiento. Se presenta como un stock, ya que los activos del conocimiento se acumulan dentro de las 


\section{Capítulo 2 Gestión del Conocimiento y Ventaja Competitiva}

organizaciones; y como flujos, puesto que diversos elementos pueden modificar dicho stock.

\subsubsection{Características de los activos estratégicos}

Los activos estratégicos se definen como un conjunto de recursos y capacidades que son difíciles de adquirir, imitar, escasos, apropiables y especializados; que confieren la ventaja competitiva de la empresa (Coyne, 1986).

Barney (1991) indica que los recursos están distribuidos dentro de las organizaciones y tienen la característica de ser valiosos, raros, inimitables y no sustituibles. En esta línea, menciona que los recursos están constituidos por: ventajas, capacidades, procesos organizacionales, atributos, información y conocimiento, entre otros.

De acuerdo a Kannan y Aulbur (2004) una de las características de los activos intangibles es la dificultad que conlleva su medición y el hecho de que incluyen diversas variables organizacionales e individuales. En este entendido, la utilización tan solo de mediciones financieras no recoge ni refleja la naturaleza compleja de estos activos.

Prahalad y Hamel (1990) indican que la competitividad de una organización en el corto plazo deriva de los atributos precio/desempeño de sus productos actuales. Sin embargo, la competitividad a largo plazo se deriva de la habilidad de la empresa para construir al costo mínimo y más rápidamente que sus competidores las competencias fundamentales que se incluirán en productos no anticipados. 


\section{Capítulo 2 Gestión del Conocimiento y Ventaja Competitiva}

En este sentido, las características de los recursos y capacidades que son determinantes para la generación de ventajas competitivas sostenibles son: durabilidad, transparencia, transferibilidad y replicabilidad (Grant, 1991).

En resumen, los activos poseen un carácter estratégico cuando cuentan con los siguientes atributos: movilidad imperfecta, dificultad de imitación, dificultad de sustitución y durabilidad.

\subsubsection{Movilidad imperfecta de los recursos}

La movilidad de los recursos esta relacionada a si estos son comercializables o no comercializables (Dierickx y Cool, 1989). Por otra parte, como identifica Peteraf (1993), entre los recursos comercializables, se tienen algunos recursos que son perfectamente móviles, los mismos que se comercializan libremente en el mercado y otros que son imperfectamente móviles, siendo estos recursos específicos a una empresa y que en otras perderían su valor.

Finalmente, se tienen los recursos perfectamente inmóviles, los cuales no son comercializables, siendo estos los recursos idiosincrásicos que poseen las empresas, como ser: la reputación, la cultura y el conocimiento tácito.

\section{A. Dificultad de imitación}

Rumelt (1984) relaciona la dificultad de imitación con los obstáculos para la imitación generados por los mecanismos de aislamiento, entre ellos están los derechos de propiedad y las asimetrías de información. 


\section{Capítulo 2 Gestión del Conocimiento y Ventaja Competitiva}

Uno de los factores que previenen la imitación es la ambigüedad causal, que se refiere a la dificultad de comprensión por parte de los competidores del vínculo entre los recursos de la empresa y la sostenibilidad de la ventaja competitiva derivada de la relación de determinados recursos (Barney, 1991).

La ambigüedad causal puede influir de forma positiva o negativa. Es positiva para la empresa al ejercer una influencia en los competidores que genera una barrera a la imitación, y puede ser negativa al influir en los directivos dificultando la transferencia interna de las competencias distintivas de una empresa.

\section{B. Dificultad de sustitución}

En caso de que la imitación no sea posible, los competidores pueden desarrollar recursos estratégicamente equivalentes, por lo que los competidores pueden alcanzar la misma estrategia utilizando recursos similares o recursos muy diferentes, pero que sean sustitutos estratégicos (Barney, 1991).

\section{Durabilidad}

La durabilidad de un recurso está relacionada con la tasa de depreciación u obsolescencia del mismo. En este entendido, algunos recursos tendrán menor durabilidad que otros, como los bienes de equipos o los tecnológicos, que cambian rápidamente. Amit y Schoemaker (1993) identifican a la durabilidad como una característica de los recursos estratégicos, puesto que, cuanta mayor duración tengan, menor será la inversión requerida para compensar su depreciación. 


\section{Capítulo 2 Gestión del Conocimiento y Ventaja Competitiva}

\subsubsection{El conocimiento como activo estratégico}

El conocimiento y su gestión han suscitado el interés tanto de académicos, investigadores así como de empresarios; puesto que ha transformado las antiguas reglas sobre estrategia y competencia (Lee y Choi, 2003). Palacios, Garrigós y Devece (2006) resaltan al conocimiento como un activo estratégico y fuente indiscutible de ventajas competitivas sostenibles para las organizaciones, ya que ayuda a mejorar los procesos y por ende el desempeño en las mismas, a través de la generación de nuevas ideas e innovaciones.

Yi (2009) así como Alavi y Leidner (2001) reconocieron que el conocimiento es un recurso crítico tanto para las empresas como para la economía de los países, debido a que permite crear una ventaja competitiva sostenible a largo plazo.

La consolidación de estas ventajas competitivas a largo plazo son cruciales, puesto que los mercados actuales ya no están delimitados geográficamente (Girdauskienè y Savanevičiené, 2007) y porque el dinamismo e intensidad competitiva existente en los mercados de productos y recursos se ha incrementado considerablemente (Grant, 1996). Por esta razón, en las últimas décadas las organizaciones reconocieron la importancia de gestionar sus activos intangibles, entre ellos sus activos intelectuales, tales como el conocimiento, como uno de sus recursos estratégicos más importantes (Lee y Choi, 2003).

Zander y Kogut (1995) resaltan las diferencias entre el carácter tácito y explícito del conocimiento, siendo el conocimiento tácito más difícil de expresar, codificar y transmitir; en consecuencia más fácil de proteger que el explícito. Por su parte, 


\section{Capítulo 2 Gestión del Conocimiento y Ventaja Competitiva}

Davenport y Prusak (1998) consideran que los activos tangibles pierden valor con su utilización, en cambio los activos de conocimiento se incrementan con su uso.

Por tal motivo, el desarrollo de marcas, patentes, relaciones entre actores y el énfasis en la consolidación de una adecuada cultura organizacional, son considerados como elementos esenciales para fortalecer el valor de estos activos intangibles, que se constituyen a la vez en el núcleo de las ventajas competitivas de una organización (Kannan y Aulbur, 2004).

Por lo anteriormente mencionado, es importante discernir entre conocimiento estratégico y no estratégico, siendo las condiciones que confieren un carácter estratégico: la movilidad imperfecta, dificultad de imitación, dificultad de sustitución y durabilidad, como se vio en el punto anterior. La posesión de conocimiento estratégico es una condición necesaria, más no suficiente, para sostener la ventaja competitiva, es necesario desarrollar capacidades de gestión de conocimiento, como se analizará más adelante.

En el caso del conocimiento, el carácter tácito del mismo constituye una de las características que define al conocimiento como activo estratégico. Por otra parte, mientras más sistémico, específico y estratégico sea el conocimiento, será más difícil su transferencia involuntaria hacia el exterior.

\subsubsection{Taxonomías del conocimiento}

En la literatura sobre gestión del conocimiento se encuentran distintas clasificaciones sobre el conocimiento, como las siguientes: 


\section{Capítulo 2 Gestión del Conocimiento y Ventaja Competitiva}

Nonaka y Takeuchi (1995) clasifican el conocimiento tomando en cuenta las dimensiones de tácito y explícito: armonizado (tácito a tácito), conceptual (tácito a explícito), operacional (explícito a tácito), sistémico (explícito a explícito).

Spender (1996) incorpora la dimensión individual y social, clasificando el conocimiento en: consciente (explícito e individual), objetivo (explícito y social), automático (implícito e individual), colectivo (implícito y social).

Teece (1998) clasifica el conocimiento tomando en cuenta las siguientes dimensiones: tácito / codificado, observable / no observable, positivo / negativo, y sistémico / autónomo.

Zack (1999) clasifica el conocimiento en: declarativo, de procedimiento y causal

Como se puede apreciar en los ejemplos anteriores, existe una diversidad de tipos de conocimiento y falta de unanimidad. En un esfuerzo por clasificar el conocimiento, Alavi y Leidner (2001) propusieron las siguientes taxonomías del conocimiento. 


\section{Capítulo 2 Gestión del Conocimiento y Ventaja Competitiva}

Tabla 2.5. Taxonomías del conocimiento y ejemplos

\begin{tabular}{|c|c|c|}
\hline $\begin{array}{c}\text { Tipos de } \\
\text { conocimiento }\end{array}$ & Definiciones & Ejemplos \\
\hline $\begin{array}{l}\text { Tácito } \\
\text { Tácito cognitivo } \\
\text { Tácito técnico }\end{array}$ & $\begin{array}{l}\text { Conocimiento que está en las } \\
\text { acciones, experiencia y forma } \\
\text { parte de un contexto } \\
\text { especifico } \\
\text { Modelos mentales } \\
\text { Know - how aplicable a un } \\
\text { trabajo especifico }\end{array}$ & $\begin{array}{l}\text { Formas de relacionarse con } \\
\text { un cliente específico. } \\
\text { Creencias individuales } \\
\text { sobre relaciones causa - } \\
\text { efecto } \\
\text { Habilidades en cirugía }\end{array}$ \\
\hline Explicito & $\begin{array}{l}\text { Articulado, conocimiento } \\
\text { generalizado. }\end{array}$ & $\begin{array}{l}\text { Conocimiento sobre los } \\
\text { principales clientes de una } \\
\text { zona. }\end{array}$ \\
\hline Individual & $\begin{array}{l}\text { Creado por e inherente al } \\
\text { individuo }\end{array}$ & $\begin{array}{l}\text { Percepciones conseguidas a } \\
\text { través de un proyecto } \\
\text { concluido }\end{array}$ \\
\hline Social & $\begin{array}{l}\text { Creado por e inherente a las } \\
\text { acciones colectivas de un } \\
\text { grupo }\end{array}$ & $\begin{array}{l}\text { Normas de comunicación } \\
\text { entre grupos }\end{array}$ \\
\hline Declarativo & Know-about & $\begin{array}{l}\text { Qué medicamento } \text { es } \\
\text { apropiado para una } \\
\text { enfermedad }\end{array}$ \\
\hline $\begin{array}{l}\text { De } \\
\text { procedimiento } \\
\text { (procedual) }\end{array}$ & Know-how & $\begin{array}{l}\text { Cómo administrar } \\
\text { determinado medicamento. }\end{array}$ \\
\hline Causal & Know-why & $\begin{array}{l}\text { Comprender por qué los } \\
\text { medicamentos son eficaces }\end{array}$ \\
\hline
\end{tabular}


Capítulo 2 Gestión del Conocimiento y Ventaja Competitiva

\begin{tabular}{||l|l|l||}
\hline Condicional & Know - when & $\begin{array}{l}\text { Comprender cuándo } \\
\text { prescribe un medicamento. }\end{array}$ \\
\hline Relacional & Know - with & $\begin{array}{l}\text { Comprender mómo } \\
\text { interactúa un medicamento } \\
\text { con otros grupos de } \\
\text { medicamentos. }\end{array}$ \\
\hline Pragmático & $\begin{array}{l}\text { Utilidad de un conocimiento } \\
\text { para una organización }\end{array}$ & $\begin{array}{l}\text { Mejores prácticas, } \\
\text { estructura de negocio, } \\
\text { experiencias en proyectos, } \\
\text { dibujos de ingeniería, } \\
\text { informes de mercado. }\end{array}$ \\
\hline
\end{tabular}

Fuente: Alavi y Leidner (2001)

Con base en las clasificaciones anteriores y los trabajos pioneros de (Winter, 1987; Reed y DeFillippi, 1990; Nonaka, 1994; Spender, 1996), se considerarán para la presente investigación las siguientes dimensiones del conocimiento:

Tácito - Explícito

Complejo - Simple

Específico - No específico

Dependiente - Independiente 


\section{Capítulo 2 Gestión del Conocimiento y Ventaja Competitiva}

\subsubsection{Capital Intelectual}

Kannan y Aulbur (2004:389) definen al capital intelectual como: "Los recursos intelectuales que han sido formalizados, capturados y apalancados para crear activos de mayor valor". Este tipo de capital engloba al conocimiento, información, propiedad intelectual y experiencia (Davenport y Prusak, 1998). Estos autores reconocieron también la importancia que tiene la medición del capital intelectual y la gestión del conocimiento para las organizaciones, puesto que les ayuda a determinar su estrategia competitiva y por ende a crear bienestar.

Un aspecto particular de los activos intangibles es que no son reflejados totalmente en los estados financieros, lo que genera divergencias entre el valor de mercado y el valor contable la cuál afecta a las decisiones de los diversos actores (Canibano y Sanchez, 1998).

Tomando en cuenta que el capital intelectual puede ser originado por diversas fuentes, Bontis (1999) identifica tres componentes o constructos específicos: el capital humano, como valor creado por las personas; el capital estructural, generado por la organización y la tecnología; y el capital relacional, derivado de las relaciones con el mercado y agentes sociales.

El capital humano se define como el stock de conocimiento de los empleados, que contribuyen a la generación del capital intelectual

El capital relacional se refleja en el conjunto de relaciones que tiene la empresa con los actores internos y externos, constituyendo redes por las que fluye el conocimiento. 


\section{Capítulo 2 Gestión del Conocimiento y Ventaja Competitiva}

El capital estructural puede ser subdividido, de acuerdo a Bueno (1998) en: el capital organizativo (proceso de toma de decisiones, cultura organizativa, diseño estructural, rutinas organizativas, sistemas de planificación y control) y el tecnológico, relacionado con la utilización e innovación de técnicas de producción.

\subsubsection{Valoración y gestión del capital intelectual}

Es importante poder medir y valorar el capital intelectual, puesto que lo que no se puede medir es difícil de gestionar. El modelo contable actual no está diseñado para valorar y contabilizar los activos intangibles, como el capital intelectual; a pesar de que autores como Teece (1998) han reconocido la importancia de la medición y valoración del mismo.

La valoración del capital intelectual se puede realizar mediante la elaboración de informes, los mismos que son de utilidad para los actores internos y externos.

\subsubsection{La gestión del conocimiento}

Desde los años noventa la gestión del conocimiento ha motivado un auge en el campo de las investigaciones, que han demostrado que el conocimiento se constituye en un factor clave para generar y sostener ventajas competitivas en las organizaciones. Sin embargo, quedan aún por resolver y demostrar varias cuestiones sobre los factores que anteceden a la gestión del conocimiento y su profundización en las diferentes etapas del proceso de gestión del conocimiento en particular sobre la transferencia de conocimiento. 


\section{Capítulo 2 Gestión del Conocimiento y Ventaja Competitiva}

Si bien la gestión del conocimiento se desarrolla a partir de los años noventa, existen aportaciones previas a esta corriente de pensamiento, que introducen conceptos como "competencias distintivas" (Selznik, 1957), la "heterogeneidad de los recursos" (Penrose, 1959), entre otros, que sientan las bases de que la diferencia de rentas en las empresas se fundamenta en la heterogeneidad de sus recursos y su imperfecta movilidad (Barney, 1991).

Por su parte, Lambe (2011) resalta que la actual gestión del conocimiento no ha conectado con antecedentes significativos al pensamiento y la práctica de la gestión del conocimiento que data de los años 60.

Lambe toma como ejemplo las publicaciones realizadas en 1962, entre las que se encuentran la de Fritz Machlup, en la que reconoce la necesidad de estudiar el conocimiento y como apoya este en la ventaja competitiva. Por otra parte, plantea nociones sobre los stocks y flujos de conocimiento. Kenneth Arrow proporcionó en 1962 un modelo teórico que ayudó a la nueva área de la investigación económica "teoría endógena del crecimiento", que estudia las maneras en las que la innovación y el nuevo conocimiento pueden estimular el nuevo desarrollo económico. Everett Rogers presenta un marco global para entender los factores que influyen en la transferencia y uso del conocimiento a través de grupos sociales.

Handzic (2011) menciona que la gestión de conocimiento ha sido abordada desde distintas perspectivas y enfoques, identificándose tres escuelas: la económica, del comportamiento y tecnocrática. Sugiere que es necesaria una visión holística que 


\section{Capítulo 2 Gestión del Conocimiento y Ventaja Competitiva}

proporcione un modelo integrado socio - técnico para la gestión del conocimiento.

La información y conocimiento son dos conceptos diferentes, pero están muy relacionados; la gestión de la información se ha centrado en aspectos tecnológicos, mientras que la gestión del conocimiento se ha centrado en aspectos humanos (Alvensoon y Kärreman, 2001).

Si bien la información y el conocimiento implican diferentes sistemas de gestión, el proceso puede ser similar, como apuntan Alavi y Leidner (2001): adquisición, creación, retención, almacenamiento, transferencia y aplicación.

La gestión del conocimiento ha sido definida por Kulkarni, Ravindran y Freeze (2007:310) como: "El proceso mediante el cual la empresa apalanca y extrae valor de sus activos intelectuales o de conocimiento".

Palacios y Garrigos (2006) mencionaron que la gestión del conocimiento puede verse como una innovación organizacional que involucra diversos cambios en la introducción de la estrategia y en las prácticas tradicionales de gestión organizacional.

Para el desarrollo de la presente investigación, se tomará como base la concepción de la gestión del conocimiento como una herramienta de gestión caracterizada por una serie de principios y prácticas; donde los principios guían la organización y estos son implementados a través de las prácticas, que representan las actividades 


\section{Capítulo 2 Gestión del Conocimiento y Ventaja Competitiva}

y métodos para institucionalizar la gestión del conocimiento (Palacios, Garrigos y Gil, 2010).

\subsubsection{Etapas de la gestión del conocimiento}

En la literatura existe una diversidad de interpretaciones y clasificaciones sobre los componentes de la gestión del conocimiento.

Gupta y Govindarajan (2000) identifican los componentes de la gestión del conocimiento desde una perspectiva social, resaltando la importancia de construir una ecología social, que implica la cultura, estructura, sistemas de información, de recompensa, las personas y los líderes.

Por su parte, Alavi y Leidner (2001) consideran que el conocimiento se puede interpretar de formas diferentes: como un estado de ánimo, como un objeto que puede ser manipulado y almacenado, como un proceso debido a su simultaneidad entre conocimiento y acción, como condición de acceso a información y como capacidad como el potencial para influir en acciones futuras.

De acuerdo a las formas de interpretar la gestión del conocimiento, se orienta a construir y dirigir "stocks" de conocimiento (objeto o acceso a información), centrarse a construir flujos de conocimiento (proceso) que conforman una cadena de valor (Shin y Holden, 2001) o en construir capacidades esenciales (capacidad) utilizando el capital intelectual y la creación de la riqueza en la organización (Staples, Greenaway y McKeen, 2001). 


\section{Capítulo 2 Gestión del Conocimiento y Ventaja Competitiva}

Chakravarthy et al. (2003) sostienen que ciertas características del conocimiento (tácito, complejo y específico) ayudan a generar mecanismos de protección que ayudan a sostener la ventaja competitiva.

Argote, McEvily y Reagans (2003) plantean un marco teórico para situar los trabajos relacionados a la literatura sobre gestión del conocimiento, identificando dos dimensiones: los resultados de la gestión del conocimiento (creación, retención y transferencia de conocimiento) y las propiedades del contexto de la gestión del conocimiento (propiedades de las unidades, propiedades de las relaciones entre las unidades y las propiedades del conocimiento).

En la siguiente tabla se agrupan en cuatro las diferentes etapas de la gestión del conocimiento: la creación y adquisición del conocimiento; su almacenamiento, retención y recuperación; la transferencia e intercambio; y su aplicación. 


\section{Capítulo 2 Gestión del Conocimiento y Ventaja Competitiva}

Tabla 2.6. Etapas de la gestión del conocimiento

\begin{tabular}{||l|l|l|l|l||}
\hline Autores & $\begin{array}{c}\text { Creación / } \\
\text { Adquisición }\end{array}$ & $\begin{array}{l}\text { Almacenamiento } \\
\text { / Retención }\end{array}$ & $\begin{array}{l}\text { Transferencia / } \\
\text { Difusión }\end{array}$ & Aplicación \\
\hline $\begin{array}{l}\text { Girdauskiené y } \\
\text { Savanevičiené } \\
(2007)\end{array}$ & $\begin{array}{l}\text { identificació } \\
\text { n, } \\
\text { adquisición, } \\
\text { desarrollo }\end{array}$ & Retención & $\begin{array}{l}\text { intercambio/ } \\
\text { distribución }\end{array}$ & Aplicación \\
\hline $\begin{array}{l}\text { Argote, } \\
\text { McEvily, y } \\
\text { Reagans (2003) }\end{array}$ & Creación & Retención & Transferencia & \\
\hline $\begin{array}{l}\text { Chakravarthy et } \\
\text { al. (2003) }\end{array}$ & Acumulación & Aplicación \\
\hline $\begin{array}{l}\text { Alavi y Leidner } \\
(2001)\end{array}$ & Creación & $\begin{array}{l}\text { almacenaje, } \\
\text { recuperación }\end{array}$ & Transferencia & Aplicación \\
\hline $\begin{array}{l}\text { Gupta } \\
\text { Govindarajan } \\
\text { (2000) }\end{array}$ & $\begin{array}{l}\text { creación, } \\
\text { adquisión }\end{array}$ & retención & $\begin{array}{l}\text { transferencia, } \\
\text { recibir } \\
\text { compartir }\end{array}$ & y \\
\hline \hline
\end{tabular}

Fuente: Elaboración propia

En el siguiente capítulo se profundizaran las etapas de la gestión del conocimiento y en particular la transferencia interna de conocimiento, sus factores antecedentes y su relación con la generación de ventajas competitivas sostenibles, que se reflejan en un desempeño organizativo superior. 


\section{Capítulo 3}

\section{Transferencia de}

Conocimiento y Desempeño Organizativo 


\subsection{INTRODUCCIÓN Y OBJETIVOS DEL CAPÍTULO}

En el capítulo dos, desde el Enfoque Basado en Competencias se ha evidenciado que el conocimiento es un recurso estratégico que genera ventajas competitivas. Las ventajas competitivas derivadas del conocimiento, dependen por una parte de la naturaleza misma de este recurso que lo hace estratégico y por otra parte de su adecuada gestión.

La gestión del conocimiento es posible gracias a los siguientes procesos cognitivos sociales e individuales que no siempre ocurren de manera secuencial: creación, almacenaje y retiro, transferencia y aplicación del conocimiento (Alavi y Leidner, 2001).

La posesión de conocimiento no asegura la sostenibilidad de las ventajas competitivas, es necesaria la transferencia de conocimiento para que otras unidades de la organización se beneficien del mismo. De ahí la importancia que tiene la transferencia de conocimiento, particularmente a nivel interno de la organización.

El objetivo del presente capítulo se centra en el desarrollo del modelo teórico para la investigación.

En el primer epígrafe se presenta el objetivo y estructura del capítulo, en el segundo epígrafe, partiendo de las etapas de la gestión del conocimiento y en particular de los factores que influyen en la transferencia del conocimiento, sus 


\section{Capítulo 3 Transferencia de Conocimiento y Desempeño Organizativo}

implicaciones, su proceso y taxonomía, se identifican las variables antecedentes de la transferencia interna de conocimiento y la relación de esta con el desempeño organizativo.

En el tercer epígrafe se presentan los aspectos relacionados con la transferencia del conocimiento, describiendo los aspectos relacionados con la conceptualización y dimensionalización del constructo teórico.

En el cuarto epígrafe se identifican las variables antecedentes de la transferencia de conocimiento: visión holística de la organización, gestión por competencias, aprendizaje continuo e infraestructura de las tecnologías de información y comunicación.

Finalmente en el quinto epígrafe se identifica la relación existente entre las variables antecedentes que tienen influencia sobre la transferencia de conocimiento, y el efecto en el desempeño organizativo, obteniendo como resultado un conjunto de hipótesis que constituyen las relaciones causales que se desprenden del modelo teórico de la investigación.

\subsection{ETAPAS DE LA GESTIÓN DEL CONOCIMIENTO}

Como se planteó en el capítulo dos, las diferentes etapas de la gestión del conocimiento serán agrupadas en cuatro: La creación y adquisición del conocimiento; su almacenamiento, retención y recuperación; la transferencia e intercambio y su aplicación. 


\section{Capítulo 3 Transferencia de Conocimiento y Desempeño Organizativo}

\subsubsection{Creación y adquisición del conocimiento}

La creación y adquisición son actividades que buscan la obtención de nuevo conocimiento para la organización. El nuevo conocimiento puede desarrollarse internamente en la organización mediante procesos de creación de conocimiento o mediante procesos de adquisición externa.

Davenport y Prusak (1998) identifican cinco formas de generar conocimiento: la adquisición de conocimiento (mediante la compra de una organización o la contratación de nuevo personal); la dedicación de recursos especializados, como es el caso de investigación y desarrollo; las fusiones de empresas; el desarrollo de redes de conocimiento y como forma de adaptación a los cambios del entorno.

Dierickx y Cool (1989) sostienen que la creación de conocimiento está relacionada con los stocks de conocimiento (activos de conocimiento acumulados internamente) y los flujos, que vienen a ser una corriente de conocimiento que puede ser acumulada por la organización y deriva en nuevos stocks de conocimientos.

Tanto la creación como la adquisición de conocimiento deben enmarcarse en una estrategia. Al respecto Zack (1999) plantea el concepto del gap estratégico, entendido como la desviación entre lo que una empresa debe hacer para competir y lo que realmente está haciendo; por tanto el gap de conocimiento representa lo que la empresa debe saber para ejecutar su estrategia y lo que sabe actualmente. 


\section{Capítulo 3 Transferencia de Conocimiento y Desempeño Organizativo}

Para Zack (1999), el conocimiento se puede obtener de diferentes formas: la adquisición del entorno (exploración); la creación (explotación de conocimiento actual a nuevos usos) y la adquisición y creación de forma simultánea (innovación).

\subsubsection{Creación de conocimiento}

Existe una discusión en la literatura sobre el tema, en cuanto a si el individuo es el elemento clave para la creación de conocimiento y la organización se limita a proporcionar el contexto apropiado para la creación de conocimiento (Nonaka y Takeuchi, 1995; Brown y Duguid, 1998) o si la capacidad para la creación y aprendizaje es también organizacional (Grant, 1996; Spender, 1996).

Brown y Duguid (1998) destacan la importancia de las comunidades de práctica para la creación de conocimiento. Sin embargo, la comunidad de práctica generará conocimiento colectivo que no reduce el contenido del conocimiento individual. Por ejemplo: El conocimiento individual de cada actor en una obra de teatro, donde cada uno debe conocer su rol, aunque en sí mismo no puede tener sentido hasta que se ensambla con los demás.

Los dos trabajos claves en la literatura que se constituyen en referentes para el proceso de creación del conocimiento son los de Nonaka y Takeuchi (1995) y Grant (1996). A continuación se presentan los modelos propuestos por estos autores: 


\section{Capítulo 3 Transferencia de Conocimiento y Desempeño Organizativo}

Nonaka y Takeuchi (1995) desarrollan su modelo de creación de conocimiento sustentada en dos dimensiones: la epistemológica y la ontológica.

- La dimensión epistemológica considera el conocimiento tácito y explícito. El primero es personal, difícil de formalizar y comunicar. El segundo puede ser codificado $\mathrm{y}$ transmitido mediante un lenguaje formal $\mathrm{y}$ sistemático.

- La dimensión ontológica diferencia los niveles de conocimiento en individual, grupal, organizacional e inter organizacional. De acuerdo a estos autores, el conocimiento solo puede ser creado por el nivel individual, siendo el papel de la organización apoyar a los individuos creativos y facilitar contextos que favorezcan la creación de conocimiento.

El modelo dinámico de creación de conocimiento se basa en que el conocimiento humano se crea y expande a través de una interacción social del conocimiento tácito y explicito. Las formas de conversión del conocimiento comprenden los procesos de: socialización, exteriorización, interiorización y combinación.

Tomando en cuenta las dimensiones epistemológica y ontológica, la creación de conocimiento es concebida como un "proceso en espiral" que se inicia en el nivel individual y se mueve hacia adelante pasando por los grupos, organización y llegando al nivel inter organizacional. 


\section{Capítulo 3 Transferencia de Conocimiento y Desempeño Organizativo}

\section{Figura 3.1. Espiral de creación del conocimiento organizativo}

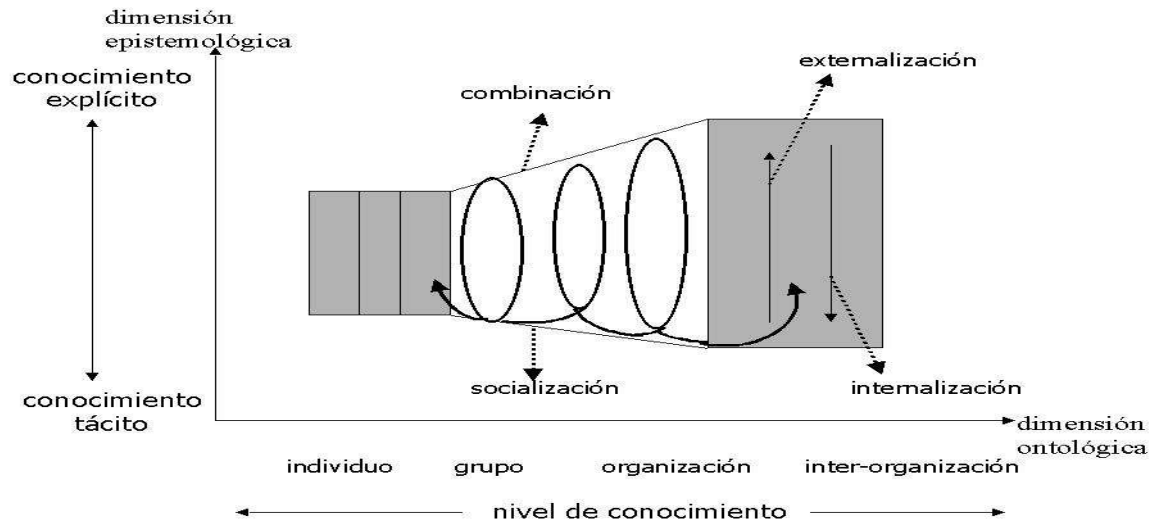

Fuente: Nonaka, 1994

Para que la espiral de creación de conocimiento se genere, es necesario que la organización desarrolle una serie de condiciones: la intención (reflejada en la estrategia), autonomía (expresada en la libertad motivadora), fluctuación o caos creativo (ruptura de rutinas y situaciones de crisis), redundancia (sobrepasar los límites funcionales) y variedad de requisitos (acceso a una amplia gama de información).

El nuevo conocimiento se crea para asegurar el éxito de una organización en un entorno cada vez más dinámico. Nonaka (2003) resalta que en una economía donde la única certeza es la incertidumbre la mejor fuente para obtener ventajas competitivas duraderas es el conocimiento. 


\section{Capítulo 3 Transferencia de Conocimiento y Desempeño Organizativo}

Respecto a las cuatro categorías de Nonaka y Takeuchi para la creación de conocimiento, Arling y Chun (2011) sostienen que si bien son útiles a un alto nivel, proporcionan poca dirección en cuanto a medidas específicas para facilitar la creación del conocimiento.

De acuerdo con su investigación, proponen como actividades claves para la creación de nuevo conocimiento: la generación, organización e integración de las relaciones. Entre las prácticas más eficaces para la generación de nuevo conocimiento se encuentran: los seminarios, la interacción de persona a persona y foros.

Alavi y Leidner (2001) sostienen que la creación del conocimiento organizacional involucra el desarrollo o reemplazo de nuevos contenidos del conocimiento tácito y explicito dentro de la organización. Adicionalmente, Lee y Choi (2003) indican que la creación del conocimiento es un proceso continuo por el cual los individuos y grupos dentro de una empresa y entre empresas comparten el conocimiento tácito y explicito.

Para Grant (1996) la creación y mantenimiento de la ventaja competitiva en mercados altamente dinámicos se basa en la integración del conocimiento.

El conocimiento no es suficiente como fuente de ventajas competitivas sostenibles, es necesaria la capacidad de integración del conocimiento, debido a que el conocimiento especializado reside en los individuos y estos pueden ser transferidos entre organizaciones. 


\section{Capítulo 3 Transferencia de Conocimiento y Desempeño Organizativo}

Grant (1996) considera la capacidad de integración de conocimiento como una capacidad organizacional (no es de los individuos, debido a las limitaciones cognitivas, ni del mercado ya que no existen mecanismos para integrar el conocimiento tácito).

Para la integración del conocimiento, deben desarrollarse los mecanismos adecuados de acuerdo a si el conocimiento es explícito o tácito. En el caso de conocimiento explícito, este es más fácil de integrar y los mecanismos más adecuados serían la codificación, almacenamiento y transferencia. En el caso de conocimiento tácito, este es más difícil de integrar y algunos mecanismos serían la dirección o rutinas organizacionales.

Las premisas que sustentan el modelo de empresa como integradora de conocimiento propuesto por Grant, son: 1) el conocimiento es un imput para todos los procesos productivos 2) la eficiencia requiere que sea creado y almacenado por individuos de forma especializada 3) la producción requiere de la aplicación de varios tipos de conocimientos especializados. Por ejemplo: la capacidad de un hospital en el quirófano cardiovascular, depende de la capacidad de integración del conocimiento especializado de cirujanos, anestesistas, radiólogos y enfermeras.

\subsubsection{Adquisición de conocimiento}

La adquisición de conocimiento del exterior comprende actividades como la búsqueda, identificación y acceso a conocimiento que es relevante para la empresa. La adquisición es particularmente importante para empresas que actúan 


\section{Capítulo 3 Transferencia de Conocimiento y Desempeño Organizativo}

en entornos dinámicos e innovadores y requieren complementar su conocimiento interno con el externo para el desarrollo de sus innovaciones (Almeida, Phene y Grant, 2003).

Entre las fuentes externas de conocimiento están la cooperación con otras empresas mediante relaciones formales y de redes informales.

\subsubsection{Almacenamiento, retención y retiro de conocimiento}

El almacenamiento, retención y retiro de conocimiento se refiere al lugar o depósito en el que se encuentra el conocimiento a fin de utilizarlo cuando fuere necesario.

Esta actividad ha sido menos vinculada a la gestión de conocimiento y más a la gestión de información, por lo tanto un aspecto importante para el almacenaje y retención de conocimiento está en; cómo compatibilizar las tecnologías de información con los aspectos humanos, ya que la captura de conocimiento requiere de individuos que añadan su experiencia y aprendizaje.

En esta etapa las tecnologías computarizadas de almacenaje, son herramientas tecnológicas para fortalecer la memoria organizacional y para acelerar el acceso a la misma (Alavi y Leidner, 2001).

Una forma de almacenamiento y retención de conocimiento es la codificación, para ello es necesario decidir para qué objetivos puede ser útil el conocimiento codificado, identificar el conocimiento existente para alcanzar los objetivos; 


\section{Capítulo 3 Transferencia de Conocimiento y Desempeño Organizativo}

evaluar el conocimiento en función de su utilidad y posibilidades de codificación; e identificar una forma apropiada para la codificación y distribución (Davenport y Prusak, 1998).

Staples et al. (2001) identifican dos mecanismos para el almacenamiento y retención de conocimiento: la codificación, que permite capturar y almacenar fácilmente conocimiento estructurado; y los procesos de conversión, que permiten capturar y almacenar conocimiento menos fácil de estructurar. Sin embargo, estos procesos pueden resultar paradógicos, puesto que el conocimiento codificado no necesariamente es el más valioso para la empresa y por otra parte la conversión puede hacer que el conocimiento pierda su valor.

Zack (1999) considera que las empresas pueden utilizar dos enfoques distintos para la gestión de conocimiento: empresas que se han centrado en el desarrollo de aplicaciones tecnológicas para la captura, almacenamiento y recuperación de conocimiento documentado explícitamente y otras empresas que consideran que el conocimiento tácito es el más valioso y que es aumentado o compartido a través de interacciones interpersonales o relaciones sociales.

El mismo autor considera que ambos enfoques son complementarios ya que las iniciativas tecnológicas y organizativas, pueden facilitar una infraestructura completa para la gestión de conocimiento.

El conocimiento tácito es el más difícil de almacenar, puesto que los miembros de la organización se constituyen en el depósito de este tipo de conocimiento (Walsh y Ungson, 1991; Staples et al., 2001; McGrath y Argote, 2004). Por otra parte el 


\section{Capítulo 3 Transferencia de Conocimiento y Desempeño Organizativo}

conocimiento explicito puede depositarse en forma de: rutinas organizativas, procesos y procedimientos, normas, prácticas, documentos, manuales, roles y estructura organizativa (Walsh y Ungson, 1991; Davenport y Prusak, 1998; Teece, 2007; Staples et al., 2001; McGrath y Argote, 2004).

\subsubsection{Aplicación del conocimiento}

Desde mediados de los 80`s, la sociedad focalizada en la producción cambió su orientación hacia el mercado. En esta etapa los consumidores se volvieron altamente discriminadores y comenzaron a demandar productos y servicios que les proporcionen las mejores ventajas, es así que la competencia entre empresas basada en el conocimiento se volvió una realidad. A fines de los 90’s se pasó a la sociedad del conocimiento, en la que los recursos económicos estan basados en el conocimiento y no en el capital, recursos naturales o mano de obra (Hallin y Marnburg, 2008).

Dentro de la etapa de aplicación del conocimiento, las tecnologías de información juegan un papel fundamental, puesto que pueden fortalecer y acelerar la integración y aplicación del conocimiento al facilitar la captura, actualización y accesibilidad al mismo (Alavi y Leidner, 2001).

La industria del turismo y hotelera se adapta lentamente a las estrategias de la gestión del conocimiento y sus aplicaciones, debido a la complejidad del concepto, el mismo que requiere de ciertas herramientas para la búsqueda de datos, así como conocimiento estadístico y substancial sobre la gestión del turismo y hotelería (Hallin y Marnburg, 2008). 


\section{Capítulo 3 Transferencia de Conocimiento y Desempeño Organizativo}

De acuerdo a Yang y Wan (2004) el conocimiento dentro de las operaciones hoteleras puede definirse como el conocimiento relativo a los clientes, productos, servicios, procedimientos operacionales, competidores y asociados a la empresa.

\subsection{LA TRANSFERENCIA DEL CONOCIMIENTO}

Como se ha analizado en el capítulo anterior, la posesión de conocimiento no asegura la sostenibilidad de las ventajas competitivas. En este sentido, es necesaria la transferencia para que otras unidades se beneficien del mismo.

La transferencia de conocimiento está relacionada con la creación de conocimiento, puesto que la utilidad de la creación de conocimiento está limitada por la posibilidad de compartir ese conocimiento, por lo cuál deben considerarse como dos procesos interdependientes (Schulz y Jobe, 2001).

Gururajan y Fink (2010) corroboran que la transferencia del conocimiento no ha sido explorada suficientemente y por ende existe la necesidad de mayores investigaciones sobre el tema, considerando una visión y el impacto socio psicológico (confianza y cultura) sobre la transferencia del conocimiento. Para estos autores el conocimiento no debería ser visto como un depósito, sino como un flujo libre entre las personas.

La literatura sobre la transferencia del conocimiento dentro del sector turístico no se ha desarrollado tanto como la aplicada en otro tipo de sectores o negocios (Shaw y Williams, 2009). 


\section{Capítulo 3 Transferencia de Conocimiento y Desempeño Organizativo}

La transferencia de conocimiento es el intercambio de conocimiento que se da entre dos unidades dentro la empresa (transferencia interna) o entre distintas empresas (transferencia externa), siendo que esta puede ser voluntaria o involuntaria.

Los beneficios de la transferencia de conocimiento pueden variar en función de si este se da de forma voluntaria o involuntaria (Winter, 1987).

Argote y Ingram (2000:151) definen la transferencia de conocimiento como "el proceso a través del cual una unidad (sea individuo, grupo, departamento o división) es afectada por la experiencia de otra". Por lo tanto, cabe recalcar que la transferencia de conocimiento se puede dar a nivel individual o grupal.

La transferencia del conocimiento ha sido definida como "una cultura social de interacción, que involucra el intercambio de conocimiento, experiencias y habilidades entre los empleados a través de todo el departamento u organización" (Lin, 2007:315).

De acuerdo a Shaw y Williams (2009) el conocimiento y su transferencia está inserto en los tres elementos básicos de las organizaciones: las personas, herramientas y tareas.

En la literatura sobre transferencia de conocimiento se pueden identificar dos posiciones: centrarse en la coordinación de las partes dentro de la organización para la transferencia de conocimiento, o proteger los activos estratégicos de la transferencia involuntaria hacia el exterior. 


\section{Capítulo 3 Transferencia de Conocimiento y Desempeño Organizativo}

El conocimiento que es fácil de transferir es menos estratégico, puesto que no genera ventajas competitivas, adicionalmente es más permisivo a la transferencia involuntaria al exterior.

En este mismo sentido, Teece (2000) recomienda que el conocimiento estratégico sea transferible y útil dentro la organización, pero difícil de transferir al exterior de la organización.

Las aplicaciones de la transferencia de conocimiento pueden ser muy diversas, podría orientarse a compartir las mejores prácticas de la empresa o la transferencia de tecnologías e innovación en el producto.

Schulz y Jobe (2001) identifican como beneficios de la transferencia de conocimiento a: facilitar la transferencia de Know How de una unidad a otras partes de la misma; ayudar en la coordinación entre las partes; permitir, reconocer y explotar economías de escala.

Tabla 3.1. Características de la Transferencia de Conocimiento

\begin{tabular}{|c|c|c|c|}
\hline $\begin{array}{c}\text { Nivel de } \\
\text { transferencia }\end{array}$ & Intención & Posición & $\begin{array}{c}\text { Tipo de } \\
\text { conocimiento }\end{array}$ \\
\hline $\begin{array}{l}\text { Interno (entre } \\
\text { unidades de la } \\
\text { organización) }\end{array}$ & Voluntario & $\begin{array}{l}\text { Centrado en la } \\
\text { coordinación }\end{array}$ & $\begin{array}{l}\text { Estratégico } \\
\text { (difícil de transferir) }\end{array}$ \\
\hline
\end{tabular}


Capítulo 3 Transferencia de Conocimiento y Desempeño Organizativo

\begin{tabular}{|c|c|c|c|}
\hline $\begin{array}{l}\text { Externo (entre } \\
\text { organizaciones) }\end{array}$ & $\begin{array}{l}\text { Involuntario / } \\
\text { voluntario en } \\
\text { algunos casos }\end{array}$ & $\begin{array}{l}\text { Centrado en la } \\
\text { protección de } \\
\text { conocimiento } \\
\text { estratégico }\end{array}$ & $\begin{array}{l}\text { No estratégico } \\
\text { (fácil de transferir) }\end{array}$ \\
\hline
\end{tabular}

Fuente: Elaboración propia

\subsubsection{Transferencia interna de conocimiento}

Este tipo de transferencia se refiere al intercambio de conocimiento entre unidades dentro la empresa, siendo esta a nivel de transferencia interdepartamental o a un nivel mayor en el caso de unidades de multinacionales o cadenas.

Existen numerosos estudios que confirman la utilidad de la transferencia interna de conocimiento, traducida en beneficios económicos, particularmente en casos de empresas multinacionales. Sin embargo, para la transferencia de conocimiento se pueden presentar algunas dificultades o barreras que se presentan a continuación:

O' Dell y Grayson (1998) identifican al desconocimiento que tienen los trabajadores sobre las tareas que realizan otros como un problema en la transferencia de conocimiento que afecta al receptor, fuente y relación.

Por su parte, Becker (2001) identifica varios problemas que afectan a los actores de la transferencia de conocimiento: la necesidad de recursos para juntar todas las partes en la organización; la limitada visión de conjunto de los actores; las asimetrías de conocimiento profundizado por la división de trabajo y de la especialización, puesto que lo que uno aprende está limitado a lo que hace; y la 


\section{Capítulo 3 Transferencia de Conocimiento y Desempeño Organizativo}

dispersión del conocimiento, que causa una incertidumbre sobre los resultados a lograr.

Una barrera para la transferencia de conocimiento es la especificidad del contexto; cuanto más específico sea el contexto del conocimiento, menor será la capacidad de absorción del receptor y menor la utilidad para otras unidades de la organización (Foss y Pedersen, 2002).

Lee y Yang (2000) hacen referencia a la dimensión tácito - explícito del conocimiento, donde este último es más fácil de transferir.

Davenport y Prusak (1998) diferencian los problemas de la transferencia de conocimiento relativos a la fuente, la limitada capacidad de absorción de la unidad receptora, la falta de confianza entre ambos y el efecto negativo de la jerarquía.

Proponen incentivos, fomentar la flexibilidad y el aprendizaje como una forma de reducir estas barreras e incentivar la transferencia de conocimiento.

En resumen, las soluciones que plantean Davenport y Prusak (1998) para hacer frente a las barreras y limitaciones de la transferencia de conocimiento son: construir relaciones de confianza; incentivar las reuniones cara a cara; crear un terreno común mediante la educación, diálogos, publicaciones, equipos de trabajo y rotación de puestos; establecer tiempos y lugares (salas para hablar, conferencias); evaluar los resultados y facilitar incentivos basados en compartir; educar a los empleados en la flexibilidad; facilitar tiempo para el aprendizaje; 


\section{Capítulo 3 Transferencia de Conocimiento y Desempeño Organizativo}

incentivar un enfoque de índole no jerárquica al conocimiento; aceptar errores y fomentar la colaboración.

Szulanski (2000) identifica cuatro fases del proceso de transferencia y sus problemas: fase de inicio, en la que la unidad fuente no da confianza; fase de implementación, con los problemas de incompatibilidad de lenguajes, es decir, pobre comunicación entre las unidades fuente y receptora; fase de Ramp - Up, referida a la utilización de conocimiento por la unidad receptora, cuyo problema se refiere al grado de ambigüedad causal del conocimiento transferido; y fase de integración, que convierte el nuevo conocimiento en rutina, donde las expectativas pueden no ser satisfechas.

Szulanski (2000) ofrece una visión completa de la transferencia de conocimiento, siendo interpretada como un proceso cuyos elementos son el conocimiento transferido, las unidades fuente y receptora, así como el contexto en el que se efectúa la transferencia.

\subsubsection{Transferencia externa de conocimiento}

La transferencia externa de conocimiento se refiere a las acciones de intercambio de conocimiento entre empresas con algún tipo de relación, la misma que se realiza principalmente de forma voluntaria.

Una de las motivaciones para la conformación de relaciones entre las empresas es la adquisición de nuevo conocimiento y luego la generación de conocimiento (Reid, Bussiere y Greenaway, 2001). 


\section{Capítulo 3 Transferencia de Conocimiento y Desempeño Organizativo}

Dyer y Nobeoka (2000) sostienen que en una red de empresas en las que se genera una identidad y tienen reglas de coordinación, el valor de la transferencia de conocimiento será mayor que a nivel de empresa, debido a la diversidad de conocimiento que reside en la red.

Las barreras y limitaciones para la transferencia externa de conocimiento son similares a las presentadas para la transferencia interna, principalmente por la falta de confianza en la unidad fuente y la deficiente capacidad de absorción de la unidad receptora.

Brown y Duguid (1998) argumentan que la transferencia de conocimiento se mueve más rápidamente entre organizaciones que dentro los límites de una empresa, esto debido a que la transferencia externa se da principalmente en comunidades de empresas que comparten de forma implícita un mismo significado sobre una práctica; en cambio al interior de la empresa, la división del trabajo presenta fuertes barreras a la transferencia interna.

\subsubsection{Proceso $y$ factores que influyen en la transferencia del conocimiento}

Diversos autores identificaron los factores que influyen o fomentan la creación, protección y transferencia del conocimiento dentro de una organización.

Estos factores proveen la infraestructura necesaria en la organización para incrementar la eficiencia del proceso de transferencia del conocimiento. Entre estos factores se encuentran la cultura y estructura organizacional, así como las 


\section{Capítulo 3 Transferencia de Conocimiento y Desempeño Organizativo}

personas y las tecnologías de información que han sido incorporadas y son utilizadas (Lee y Choi, 2003).

Conner y Prahalad (1996) mencionaron que la forma organizacional determina la manera en que los individuos cooperan dentro de la organización para emplear y adquirir el conocimiento y también sobre la manera en que responderán a los nuevos desarrollos.

En esta misma línea, Girdauskienė y Savanevičienè (2007) indicaron que para una gestión exitosa del conocimiento y a la vez para asegurar una ventaja competitiva a largo plazo, los factores que deben tomarse en cuenta son: la estructura organizacional; la cultura; la implementación y utilización de estrategias; sistemas e infraestructura de las tecnologías de información y procesos sistemáticos.

Alavi y Leidner (2001) mencionaron que la transferencia del conocimiento puede darse a través de canales informales o formales entre individuos, desde individuos a fuentes explicitas, de individuos a grupos, entre grupos y desde un grupo hacia la organización. Esto tiene un efecto positivo en las organizaciones, puesto que el conocimiento adquiere características especificas del contexto o medio ambiente (Lee y Choi, 2003).

Por otro lado, Palacios y Garrigos (2005) identificaron seis principios que rigen en las empresas focalizadas hacia la gestión del conocimiento:

1. La orientación hacia el desarrollo, la transferencia y la protección del conocimiento 


\section{Capítulo 3 Transferencia de Conocimiento y Desempeño Organizativo}

2. El aprendizaje contínuo en la organización

3. La organización como un sistema global, cuyos objetivos organizacionales concuerdan con los trazados por sus miembros

4. El desarrollo de una cultura innovadora que impulse proyectos de investigación y desarrollo.

5. El enfoque en las personas

6. La gestión por competencias y el desarrollo de nuevas competencias.

\subsubsection{El proceso de la transferencia interna del conocimiento}

Szulanski (1996) sostiene que la transferencia de conocimiento es conducida por procesos de comunicación y flujos de información.

El proceso de comunicación comprende los siguientes elementos básicos: el mensaje, emisor, el código, el canal, la transmisión a través del canal, el receptor, la decodificación y la asignación de significado al mensaje decodificado (Krone, Jablin y Putnam, 1987).

En este sentido, la capacidad de absorción - asimilación de la unidad receptora juega un papel importante para la transferencia interna de conocimiento.

Capacidad de absorción es una función ampliamente relacionada al conocimiento, ya que dicha capacidad o la falta de ella tiene un impacto en la efectividad de la transferencia del conocimiento (Gururajan y Fink, 2010). 


\section{Capítulo 3 Transferencia de Conocimiento y Desempeño Organizativo}

La capacidad de asimilación y de transferencia está dada por la similitud de las bases de conocimiento, motivación y habilidades. Por otra parte, la transferencia de conocimiento dependerá de la intensidad de la relación entre las partes y esta, a su vez, estará influenciada por el nivel de coordinación, comunicación y afinidad (Segarra, 2006).

De acuerdo a Segarra (2006), el éxito de la transferencia interna de conocimiento puede estar influenciado por:

- Las características del conocimiento transferido

- Las características de la unidad receptora

- Las características de la unidad fuente

- Las características del contexto en el que se realiza la transferencia 
Capítulo 3 Transferencia de Conocimiento y Desempeño Organizativo

Figura 3.2. Proceso de transferencia interna de conocimiento

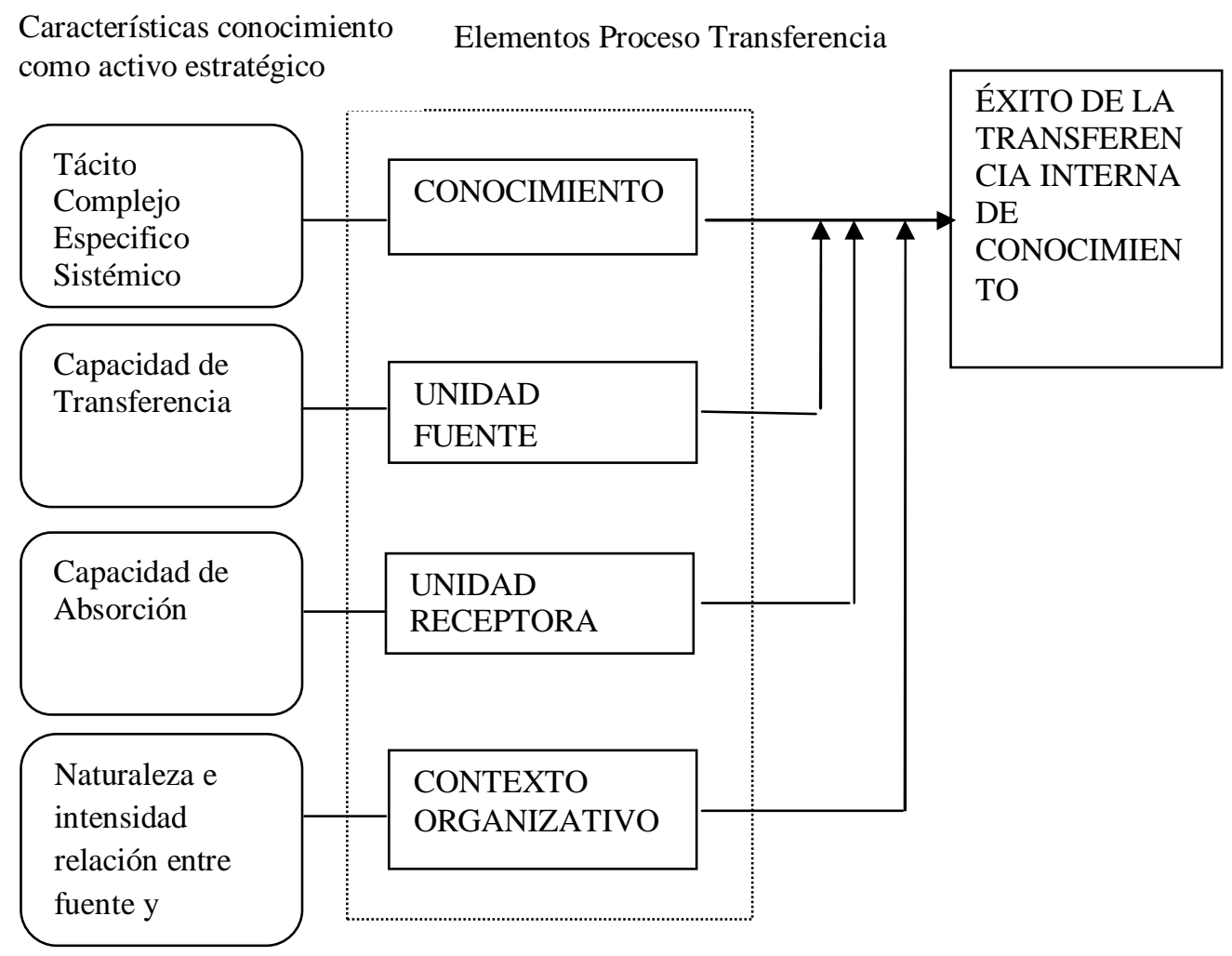

Fuente: Segarra (2006)

El conocimiento posee un carácter multidimensional: tácito - explícito, complejo simple, específico - general y dependiente o sistémico - independiente o autónomo. 


\section{Capítulo 3 Transferencia de Conocimiento y Desempeño Organizativo}

\section{A. La dimensión tácito - explícita y la transferencia interna de conocimiento}

Esta dimensión ha sido identificada en la literatura mucho antes del "big ban" de la gestión del conocimiento. Polanyi (1966) distingue entre conocimiento tácito y explícito en general; por su parte Nelson y Winter (1982) introducen este concepto en las organizaciones.

El conocimiento tácito es personal, difícil de formalizar y por lo tanto difícil de comunicar; mientras el conocimiento explícito es formal y sistemático, por lo que es más fácil de comunicar y compartir (Nonaka, 1991).

Lubit (2001) identifica cuatro categorías de conocimiento tácito: habilidades que no pueden ser explicadas totalmente con palabras; los modelos mentales que facilitan la comprensión de las conexiones causa - efecto; los hábitos y patrones que ayudan a resolver problemas; y finalmente, las rutinas que incorporan gran parte del conocimiento tácito de una empresa.

Existe cierto consenso en la literatura sobre gestión del conocimiento, en cuanto a que el conocimiento explícito es más fácil de transferir que el tácito.

Teece (2000:41) al respecto menciona que "la conversión de conocimiento tácito a codificado o explícito facilita la transferencia de conocimiento y que éste sea compartido, por lo que puede facilitar que las empresas sean más innovadoras y productivas". Sin embargo, existen cuestionamientos sobre la conveniencia de mantener el carácter tácito del conocimiento o bien transformarlo en explícito para facilitar su transferencia. 


\section{Capítulo 3 Transferencia de Conocimiento y Desempeño Organizativo}

Nonaka (1991) sostiene que el conocimiento tácito se puede compartir mediante la observación, imitación y la práctica. Por su lado, Lubit (2001) señala una serie de soluciones para compartir el conocimiento tácito, como: dar la oportunidad a los empleados de trabajar con expertos; trabajar en grupo; desarrollar y propagar rutinas.

Zander y Kogut (1995) mencionan que una forma de protección frente a la competencia, sería no transformar el conocimiento tácito en explícito. En contraposición, Schulz y Jobe (2001) mencionan que la transmisión eficiente del conocimiento tácito requiere de su codificación en formas explícitas.

La codificación de cada tipo de conocimiento requiere de una forma distinta de codificación, esto facilita los flujos de conocimiento al interior de la organización y tiene una repercusión positiva en los resultados de las empresas (Schulz y Jobe, 2001).

En resumen, el conocimiento explícito para el proceso de transferencia es más fácil de gestionar que el conocimiento tácito, por lo que es necesario el desarrollo de una serie de habilidades por parte de los receptores y de un contexto propicio para la transferencia.

\section{B. Grado de complejidad del conocimiento y la transferencia interna de conocimiento}

Zander y Kogut (1995:82) definen la complejidad como el "número de distintas habilidades o competencias integradas en una actividad". Simon (1961) relaciona 


\section{Capítulo 3 Transferencia de Conocimiento y Desempeño Organizativo}

la complejidad del conocimiento al número de elementos que componen un sistema y el grado de interacción entre ellos.

El carácter complejo del conocimiento es una de las características que dificulta la transferencia de conocimiento, tanto interno como entre organizaciones que tienen alianzas estratégicas, puesto que genera barreras debido a que es más difícil de reconstruir. Por otra parte, podría aumentar los costes de transferencia interna de conocimiento (McEvily y Chakravarthy, 2002; Simonin, 1999)

Hansen (1999) sugiere que las relaciones más intensas y frecuentes entre las unidades de transferencia pueden generar un contexto favorable para la transferencia de conocimiento complejo.

\section{Grado de especificidad del conocimiento y la transferencia interna de conocimiento}

Williamson (1991:281) define el carácter específico de un activo como "el grado en el que un activo puede ser reempleado en usos alternativos por usuarios alternativos sin sacrificar su valor productivo". Identifica seis tipos de activos específicos relacionados a la: especificidad de lugar, especificidad del activo físico, especificidad del activo humano, nombre de marca, especificidad del activo especializado y especificidad temporal. La especificidad de activos es fuente de ambigüedad causal y por tanto de ventajas competitivas sostenibles.

Grant (1996) menciona que el desarrollo de mecanismos de integración de conocimiento especializado (como las normas de comportamiento compartidas o 


\section{Capítulo 3 Transferencia de Conocimiento y Desempeño Organizativo}

la cultura organizacional) permite aumentar el nivel de conocimiento común entre las partes, lo que facilita la transferencia de conocimiento.

De acuerdo con Demsetz (1991), la existencia de cierto nivel de conocimiento común es un requisito previo en la comunicación de las partes. El conocimiento común dependerá del tipo de dirección del flujo. Si la transferencia es horizontal, los diferentes lenguajes profesionales son menores; a diferencia de si el flujo es vertical, ya que los códigos de los diferentes grupos funcionales difieren.

El conocimiento específico puede implicar la necesidad de desarrollar nuevas habilidades por parte de los receptores de conocimiento o la inversión en maquinarias o equipos para que el conocimiento transferido pueda ser utilizado por el receptor.

Cuanto más especializado sea el conocimiento que se desea transferir internamente, mayores serán las barreras, debido a que existe mayor dificultad de movilidad de conocimiento entre grupos heterogéneos dentro la empresa que entre grupos con similares prácticas entre empresas (Brown y Duguid, 1998).

\section{Grado de dependencia del conocimiento y la transferencia interna de conocimiento}

El grado de dependencia del conocimiento está relacionado con la dimensión sistémica, es el caso de un equipo de trabajo que depende el uno del otro y hace que el conocimiento de uno de ellos carezca de valor sin la presencia del otro. En cambio, el conocimiento autónomo $\mathrm{o}$ independiente se da cuando un 


\section{Capítulo 3 Transferencia de Conocimiento y Desempeño Organizativo}

conocimiento tiene la posibilidad de ser operativo por sí mismo. Por ejemplo: una computadora posee partes dependientes, por lo que no podría funcionan si faltara una de ellas, versus una calculadora que tiene un funcionamiento autónonomo.

Hansen (1999) analiza la relación entre la transferencia de conocimiento sistémico y la intensidad de la relación entre la unidad emisora y receptora de conocimiento, concluyendo que el conocimiento sistémico requerirá de relaciones más fuertes y una mayor interacción entre los miembros del equipo, lo que implica generar un contexto adecuado para la transferencia.

En resumen, el conocimiento estratégico reúne, en mayor grado, las características de: tácito, complejo, específico y sistémico; las mismas que influyen en el éxito de la transferencia interna de conocimiento.

\section{E. La unidad receptora en el proceso de transferencia de conocimiento}

La unidad receptora puede ser un individuo, departamento, unidad estratégica de negocio o unidades multinacionales; y es la que recibe el conocimiento transferido por la unidad fuente. Tiene como función la asimilación del conocimiento transferido con el fin de incorporarlo en las operaciones que desarrolla (Szulanski, 1996).

La capacidad de asimilación de la unidad receptora, es el conjunto de rutinas y procesos que permiten a dicha unidad analizar, interpretar y comprender el conocimiento transferido (Zahra y George, 2002). 


\section{Capítulo 3 Transferencia de Conocimiento y Desempeño Organizativo}

Existe consenso en la literatura en sentido de que la capacidad de absorción de la unidad receptora facilita el proceso de transferencia de conocimiento, tanto interno como externo. En consecuencia, al ser la capacidad de asimilación parte constituyente de la capacidad de absorción, facilitará la transferencia interna de conocimiento.

La motivación de la unidad receptora de conocimiento se constituye en una característica fundamental para superar una de las barreras a la transferencia interna de conocimiento (Gururajan y Fink, 2010; Szulanski, 1996).

Finalmente, las habilidades de la unidad receptora, relacionadas con las características personales de los trabajadores en función de su cualificación y actitud hacia el conocimiento e innovación, facilíta la transferencia de conocimiento y su aplicación (Leonard-Barton y Deschamps, 1988; Hallin y Marnburg, 2008).

\section{F. Unidad fuente en el proceso de transferencia de conocimiento}

Es la persona o unidad cuya función consiste en compartir conocimiento con otras unidades receptoras dentro la empresa.

Al igual que en la unidad receptora, la motivación y habilidades se constituyen en características fundamentales para la transferencia de conocimiento, tanto interna como externa. 


\section{Capítulo 3 Transferencia de Conocimiento y Desempeño Organizativo}

Szulanski (1996) identifica como inhibidores de la transferencia interna de conocimiento a la carencia de motivación y la percepción de la unidad fuente como no fiable.

\section{G. El contexto de la transferencia de conocimiento}

Kogut y Zander (1996) sostienen que la empresa facilita un sentido de comunidad a través del cual la coordinación, el discurso y el aprendizaje son estructurados a partir de la identidad. Este contexto promueve la innovación, la motivación, así como la transferencia interna de conocimiento.

Para la transferencia de conocimiento se han identificado aspectos estructurales y aspectos sociales que influyen en la misma. Respecto a los aspectos sociales se pueden diferenciar dos niveles de análisis: el contexto social de las empresas y las relaciones entre la unidad fuente y receptora.

\section{H. Relación entre la unidad fuente y receptora}

Grant (1996) considera que la eficiencia deriva de la especialización, por lo que la tarea fundamental de la organización consiste en coordinar los esfuerzos de distintos especialistas. En este sentido, considera a la empresa como una institución integradora de conocimiento, explorando mecanismos de coordinación a través de los cuales las empresas integran conocimiento especializado de los miembros. 


\section{Capítulo 3 Transferencia de Conocimiento y Desempeño Organizativo}

La comunicación entre las partes implicadas en el proceso de transferencia de conocimiento promueve el aprendizaje continuo y facilita la misma. La interacción social entre unidades es, por ende, un mecanismo de coordinación que facilita la transferencia de conocimiento (Tsai, 2001).

Reagans y McEvily (2003) sostienen que los individuos que se comunican con otros más frecuentemente o tienen una relación emocional más fuerte, más probablemente compartirán el conocimiento entre ellos.

Szulanski (1996) considera que la relación entre la unidad fuente y receptora está en función de la facilidad de comunicación y la afinidad entendida como la intimidad de la relación entre ambas partes.

Mientras mayor sea la complejidad del conocimiento que se desea transferir, será necesaria una mayor intensidad de la relación entre las unidades de transferencia (Hansen, 1999).

La confianza ha sido identificada como un factor importante para la transferencia de conocimiento, puesto que incentiva el aprendizaje colectivo al impulsar que la información organizacional y el conocimiento sea compartido (Niu, 2010; Gururajan y Fink, 2010).

Es necesario eliminar las barreras o rigideces internas que dificultan los flujos de conocimiento, mediante la intervención en la unidad fuente, receptora y la generación de un contexto adecuado para la transferencia. 


\section{Capítulo 3 Transferencia de Conocimiento y Desempeño Organizativo}

En la siguente tabla, a manera de resumen, se presentan las dimensiones de la transferencia de conocimiento, los elementos identificados en la literatura y la propuesta de factores antecedentes que serán desarrollados con mayor profundidad en el siguiente epígrafe.

Tabla 3.2. Dimensiones, elementos y factores que influyen en la transferencia de conocimiento

\begin{tabular}{|c|c|c|}
\hline Dimensiones & $\begin{array}{l}\text { Elementos que influyen en la } \\
\text { transferencia de conocimiento }\end{array}$ & Factores \\
\hline $\begin{array}{l}\text { Contexto de la } \\
\text { transferencia }\end{array}$ & 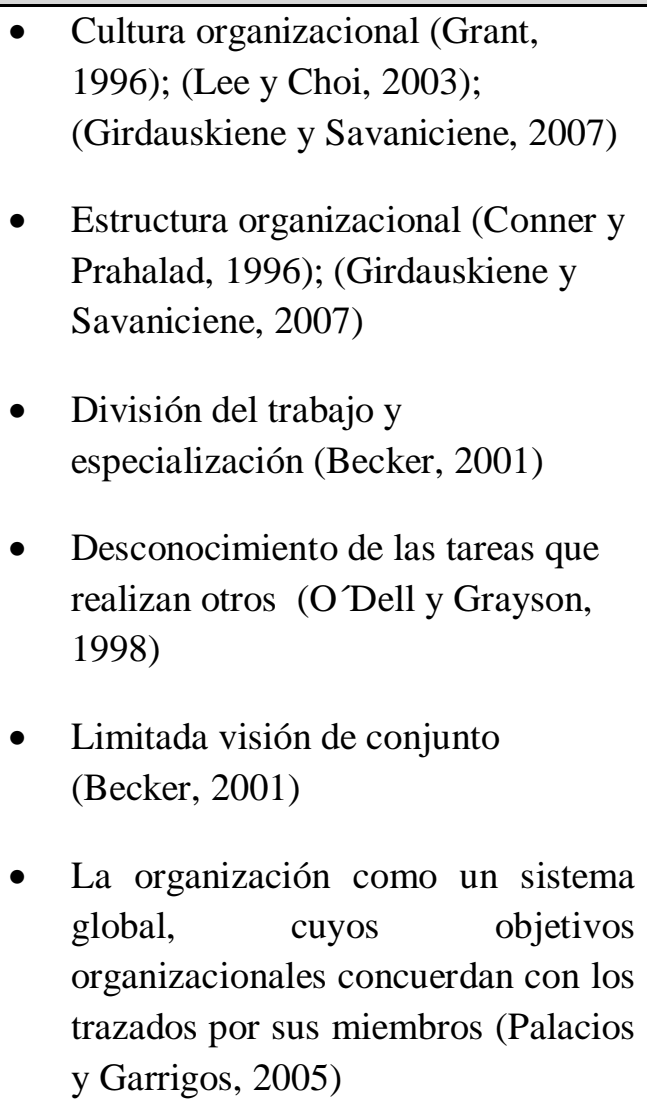 & $\begin{array}{l}\text { Visión holística de la } \\
\text { organización }\end{array}$ \\
\hline
\end{tabular}


Capítulo 3 Transferencia de Conocimiento y Desempeño Organizativo

\begin{tabular}{|c|c|c|}
\hline Dimensiones & $\begin{array}{l}\text { Elementos que influyen en la } \\
\text { transferencia de conocimiento }\end{array}$ & Factores \\
\hline $\begin{array}{l}\text { Relación entre la } \\
\text { unidad fuente y } \\
\text { receptora para } \\
\text { coordinarse y } \\
\text { comunicarse }\end{array}$ & $\begin{array}{l}\text { - Cualificación y actitudes hacia el } \\
\text { conocimiento e innovación (Leonard } \\
\text { - Barton y Deschamps, 1998) } \\
\text { - } \quad \text { Incentivos por compartir } \\
\text { conocimiento (Davenport y Prusak, } \\
\text { 1998) } \\
\text { Construir relaciones de confianza } \\
\text { (Davenport y Prusak, 1998); (Niu } \\
\text { 2010);(Gururajan y Fink 2010) } \\
\text { Evaluación de resultados } \\
\text { (Davenport y Prusak, 1998) } \\
\text { Especificidad del contexto (Foss y } \\
\text { Pedersen, 2002) } \\
\text { Habilidades de las Personas (Lee y } \\
\text { Choi, 2003); (Hallin y Marnburg, } \\
\text { 2008). } \\
\text { Ha gestión por competencias y el } \\
\text { desarrollo de nuevas competencias } \\
\text { (Palacios y Garrigos, 2005) } \\
\text { receptora (Segarra, 2006) }\end{array}$ & $\begin{array}{l}\text { Gestión por } \\
\text { competencias }\end{array}$ \\
\hline $\begin{array}{l}\text { Relación entre la } \\
\text { unidad fuente y } \\
\text { receptora para } \\
\text { coordinarse y } \\
\text { comunicarse }\end{array}$ & $\begin{array}{l}\text { Fomentar el aprendizaje (Davenport } \\
\text { y Prusak, 1998) } \\
\text { - } \quad \text { Rotación de puestos (Davenport y } \\
\text { Prusak, 1998) } \\
\text { - } \quad \text { Lo que uno aprende está limitado a }\end{array}$ & Aprendizaje contínuo \\
\hline
\end{tabular}


Capítulo 3 Transferencia de Conocimiento y Desempeño Organizativo

\begin{tabular}{||l|l|l||}
\hline \multicolumn{1}{|c||}{ Dimensiones } & \multicolumn{1}{c||}{$\begin{array}{c}\text { Elementos que influyen en la } \\
\text { transferencia de conocimiento }\end{array}$} & Factores \\
\hline & $\begin{array}{l}\text { lo que hace (Becker, 2001) } \\
\text { Relaciones más fuertes e intensas } \\
\text { (Hansen, 1999); (Reagans y } \\
\text { McEvily, 2003) }\end{array}$ & \\
& $\begin{array}{l}\text { Dar la oportunidad de trabajar con } \\
\text { expertos (Lubit, 2001) }\end{array}$ & \\
& $\begin{array}{l}\text { El aprendizaje contínuo en la } \\
\text { organización (Palacios y Garrigos, } \\
\text { 2005) }\end{array}$ & \\
& $\begin{array}{l}\text { Motivación de la unidad fuente y } \\
\text { receptora (Segarra, } \\
\text { 2006);(Gururajan y Fink, 2010) }\end{array}$ & \\
\hline $\begin{array}{l}\text { Facilitadores para } \\
\text { la transferencia } \\
\text { de conocimiento }\end{array}$ & $\begin{array}{l}\text { Tecnologías de información (Alavi y } \\
\text { Leidner, 2001); (Lee y Choi, 2003) } \\
\text { Estrategias, sistemas e } \\
\text { infraestructura de tecnologías de } \\
\text { información (Girdauskiene y } \\
\text { Savaniciene, 2007) }\end{array}$ & técnica de las TI \\
\hline
\end{tabular}

Fuente: Elaboración propia 


\section{Capítulo 3 Transferencia de Conocimiento y Desempeño Organizativo}

\subsubsection{Dimensiones de la transferencia de conocimiento}

Existe un consenso general sobre el hecho de que "lo que no se puede medir no se puede gestionar". Por tanto, es necesario contar con instrumentos que permitan medir la transferencia de conocimiento, a fin de que los gerentes puedan impulsar y recompensar que se comparta conocimiento en la organización.

Sin embargo, esto no es una taréa fácil, puesto que al ser el conocimiento un activo intangible y un constructo de tercer orden, identificar y evaluar la transferencia de conocimiento, especialmente el conocimiento tácito, presenta sus dificultades.

Algunos métodos que se han utilizado para medir la transfercia de conocimiento son:

Número de aportaciones: hits, reportes escritos, nuevas ideas, número de presentaciones, número de repuestas, entre otras. Esta forma de medición puede ser útil si se cuenta con sistemas de gestión de conocimiento apoyados por sistemas informáticos. Existen varios ejemplos de su utilización, los mismos que han sido ligados a incentivos y recompensas. Sin embargo, este método presenta limitaciones, por la dificultad de medición y por que muchas veces las aportaciones a nivel informal no son registradas (Huysman y Wit, 2002).

Otra forma de medición radica en solicitar de forma directa las percepciones sobre el grado de "comportamientos para compartir conocimiento" Knowledge Sharing Behaviors KSBs (Zárraga y Bonache, 2003). Sin embargo, la principal limitación 


\section{Capítulo 3 Transferencia de Conocimiento y Desempeño Organizativo}

de este método está dada por la necesidad de discutir y evaluar si el conocimiento compartido es apropiado y útil.

No existe un consenso en la literatura respecto a las dimensiones que conforman el KSB, por tanto se hace difícil medirlo. Bock y Kim (2002) han utilizado el tipo de conocimiento compartido y el tipo de tecnología utilizada para la medición del grado de KSB. Entre el tipo de conocimiento compartido se encuentran: informes, manuales, metodologías, saber donde, saber cómo. Sobre el tipo de tecnología utilizada se encuentran: el correo electrónico, el sitio web, el chat, entre otros. Bartol y Srivastava (2002) identifican cuatro mecanismos o modos para que los individuos puedan compartir sus conocimientos en las organizaciones, estos son: contribución de los conocimientos en la base de datos de la organización; el intercambio de conocimiento en interacciones formales, ya sea en grupos o unidades de trabajo; compartir conocimiento mediante interacciones informales; y compartir conocimiento en comunidades de práctica.

Las dimensiones para el KSB propuestas por Bartol y Srivastava son consistentes con las estrategias para la transferencia de conocimiento identificadas por Hansen, Nohria, y Tierney (1999), siendo estas la de codificación y la de personalización.

\subsubsection{Contribuciones escritas}

En esta dimensión el canal de transferencia es de persona a documento, para las contribuciones escritas se acentúa la estrategia de codificación del conocimiento por parte de la gerencia y la distribución de conocimiento explícito. Este tipo de contribución esta fácilmente asociada a sistemas de recompensas debido a la 


\section{Capítulo 3 Transferencia de Conocimiento y Desempeño Organizativo}

facilidad para su seguimiento, accesibilidad, evaluación y registro. Para este tipo de distribución la motivación intrínseca viene basada en incentivos, ya sea monetarios o de reconocimiento (Käser y Miles, 2001).

\subsubsection{Comunicación organizacional}

En esta dimensión la transferencia de conocimiento viene dada por interacciones formales (reuniones regulares, de reflexión, o de búsqueda de soluciones), y el canal de transferencia es de persona a grupo. En este tipo de interacción la estrategia de transferencia de conocimiento utilizada es la personalización y la distribución de conocimiento tácito (cara a cara); los empleados se motivan por la voluntad de lograr mejores resultados en la organización y no para sus intereses propios (Gurteen, 1998).

La predisposición de la organización es fundamental para este tipo de distribución (Hislop, 2003; MacNeil, 2003). Este tipo de KSB ocurre en rutinas formalizadas, por lo que se puede contar con registros que sean utilizados en el sistema de incentivos (Bartol y Srivastava, 2002).

\subsubsection{Interacciones personales}

Este tipo de mecanismo de transferencia se da mediante interacciones sociales informales en un canal personal; la estrategia de transferencia es la de personalización y distribución de conocimiento tácito. 


\section{Capítulo 3 Transferencia de Conocimiento y Desempeño Organizativo}

Las interacciones personales implican comportamientos voluntarios y naturales, así que el enfoque está orientado a ayudar a los empleados con problemas específicos a trabajar mejor, evitar riesgos, compartir la pasión y entusiasmo por algún tema.

Cuanto mayor son las redes sociales y la calidad de las relaciones, se lograrán mejores resultados (Kubo, Saka y Pam, 2001). La motivación para este tipo de transferencia, por ende, es intrínseca (Käser y Miles, 2001). En este tipo de transferencia se dificulta la visibilidad, registro y evaluación, en consecuencia, implementar un sistema de incentivos.

\subsubsection{Comunidades de práctica}

Las comunidades de práctica están conformadas por grupos de empleados voluntarios que se comunican alrededor de un asunto de intereses común. La forma de comunicación es realizada de manera no rutinaria y personal.

Lave y Wenger (1991) introdujeron inicialmente el concepto de "Comunidades de Práctica" (CoPs), basándose en sus observaciones de la relación tradicional aprendiz - maestro; categorizando este proceso gradual de aprendizaje como "legitimación periférica de la participación".

Wenger, McDermott y Snyder (2002) definen a una Comunidad de Práctica como un grupo informal de personas que comparten la pasión y experiencia respecto a una empresa común. 


\section{Capítulo 3 Transferencia de Conocimiento y Desempeño Organizativo}

Saint-Onge y Wallace (2003) dividen a las CoPs en tres grupos: informales, apoyadas y estructuradas; las dos últimas son consideradas como estratégicas que son autorizadas y apoyadas formalmente por la empresa. Caracterizan a los CoPs informales y formales tomando en cuenta el rol, la membresía, el soporte institucional, la evolución del grupo, la motivación, recompensas y ciclo de vida.

Wolf et al. (2011) sostienen que las CoPs se han constituido en un buen soporte para apoyar la creación y compartir conocimiento; han encontrado que los beneficios percibidos y disposición de los empleados para invertir esfuerzos individuales en su comunidad de trabajo, son más fuertes en aquellas CoPs que tienen mejor desempeño.

Identifican tres tipos de beneficios percibidos: los efectos del aprendizaje e intercambio de conocimiento en procesos de aprendizaje social; la participación en procesos de decisión; y la construcción de relaciones y redes.

Jeon et al. (2011) resaltan que las motivaciones sociales en Comunidades de Práctica $(\mathrm{CoP})$ pueden tener mayor impacto en actitudes hacia el comportamiento que las motivaciones personales o económicas. Las CoP están ganando mayor reconocimiento como un mecanismo de organización eficaz, que permite a sus miembros crear y compartir conocimiento implícito y explícito. 


\subsection{LOS FACTORES ANTECEDENTES Y LA TRANSFERENCIA DE CONOCIMIENTO}

Handzic (2011) identifica como factores antecedentes de la gestión del conocimiento, aspectos sociales y técnicos. Resalta que las organizaciones deben capitalizar el liderazgo, la cultura organizacional y sus habilidades para la medición del conocimiento, junto con el potencial de las tecnologías de información como facilitadores de la gestión del conocimiento.

Hofstede (1991) diferencia la cultura nacional de la cultura organizacional. Sus investigaciones apuntan a que la cultura nacional se basa en la consistencia de valores, mientras que la cultura organizacional se basa en la consistencia de sus prácticas.

Al-Adaileh y Al-Atawi (2011) estudian el impacto de la cultura organizacional en el intercambio de conocimiento. En su estudio sobre la Compañía Saudi Telecom, identifican las siguientes variables relacionadas con el intercambio de conocimiento: apertura al cambio, innovación, trabajo en equipo, moral, el flujo de información, involucramiento, supervisión, orientación hacia el cliente, confianza y recompensa.

Jeon et al. (2011) analizaron los factores antecedentes en el contexto de empresas de alta tecnología coreanas, que influyen en el comportamiento para compartir conocimiento en comunidades de práctica. Entre sus principales conclusiones identifican a los factores motivacionales intrínsecos (necesidad de afiliación, gusto por ayudar) y a los extrínsecos (imagen, reciprocidad), que pueden influir 


\section{Capítulo 3 Transferencia de Conocimiento y Desempeño Organizativo}

positivamente en las actitudes para compartir conocimiento. Por otra parte, la intención de compartir conocimiento está relacionada con las actitudes, las normas subjetivas y control del comportamiento percibido.

Xue, Bradley y Liang (2011) consideran dos factores que influyen en las actitudes y comportamientos para compartir conocimiento: el clima del equipo y el liderazgo orientado a empoderar. El clima del equipo está relacionado con la cohesión, confianza y capacidad de innovación; mientras que el liderazgo orientado a empoderar se consigue con: dar el ejemplo, entrenar, tomar decisiones participativamente, mostrar preocupación por el bienestar de los empleados e informar. Los mencionados autores resaltan la importancia del aspecto social, por una parte, y el papel del líder del equipo, por otro.

A continuación se profundizarán los factores antecedentes de la transferencia de conocimiento, agrupados de acuerdo al anterior epígrafe en: visión holística de la organización, gestión por competencias, aprendizaje continuo e infraestructura tecnológica.

\subsubsection{La visión holística de la organización}

Palacios et al. (2006) mencionan que en la organización debe existir una visión holística de la organización, la misma que debe tener alineados sus objetivos corporativos con las metas que todos los miembros de la organización se han trazado, de manera que estos estén comprometidos en la generación del conocimiento, en compartir y socializar el mismo. 


\section{Capítulo 3 Transferencia de Conocimiento y Desempeño Organizativo}

Para tal fin, Lee y Choi (2003) resaltan la importancia de la cultura organizacional como el factor más importante en el éxito de la gestión del conocimiento. De esta manera, la cultura define no solamente qué tipo de conocimiento es valioso, sino también cuál conocimiento debe permanecer dentro de la organización. A la vez, incita a las personas a crear y compartir el conocimiento dentro de la organización (Girdauskienė y Savanevičienė, 2007).

Kannan y Aulbur (2004) definen a la cultura organizacional como los valores compartidos y las practicas desempeñadas por las personas en la organización.

La cultura organizacional debe ser entendida antes de que cualquier solución proveniente de la gestión del conocimiento sea implementada. Las iniciativas de gestión de conocimiento deben apoyar y ser apoyadas por las normas culturales, las expectativas y las practicas de la organización (Levy et al., 2010).

El clima organizacional y la estructura organizacional han sido reconocidas como factores que afectan la gestión del conocimiento. Entre las características organizacionales se encuentra la estructura, la membresia, las relaciones y estrategias (Magnier-Watanabe y Senno, 2010).

El apoyo de la alta gerencia se considera como un elemento importante para poder influir en la transferencia del conocimiento organizacional y el mantenimiento de una adecuada cultura organizacional que favorezca a la misma (Lin, 2007).

Camisón y Boronat (2004) mencionan que es necesaria la existencia de ciertas capacidades directivas y organizativas, como por ejemplo: la creación de una 


\section{Capítulo 3 Transferencia de Conocimiento y Desempeño Organizativo}

visión estratégica, su comunicación y transmisión a toda la organización, así como la capacidad para detectar y explotar asimetrías en los mercados de factores estratégicos.

Javidan (1998) resalta que la evolución de capacidades a competencias y de competencias a competencias nucleares requiere altos niveles de colaboración entre diferentes grupos a lo largo y ancho de la organización. Sin embargo, la colaboración no es algo que se logre mediante la imposición, es necesaria la habilidad y el compromiso por parte de todos.

La industria hotelera es intensiva en conocimiento como resultado de la naturaleza de sus servicios. En este entendido, el servicio ofrecido es el resultado de la interacción entre consumidores y empleados (Hallin y Marnburg, 2008).

Buhalis y Law (2008) mencionan que la clave del éxito radica en la rápida identificación de las necesidades de los consumidores y en alcanzar a clientes potenciales a través de servicios y productos personalizados que satisfagan sus necesidades. Actualmente, los viajeros más experimentados y sofisticados requieren de mayor interacción con los proveedores de servicios.

Yang y Wan (2004) indican que un sistema de gestión del conocimiento no solo incluye la percepción de los clientes, sino también de los competidores, proveedores, compañías locales y la tendencia del ambiente exterior.

El reto es que los altos ejecutivos remuevan los obstáculos que impiden el desarrollo de las mejores prácticas para la gestión del conocimiento y se muevan 


\section{Capítulo 3 Transferencia de Conocimiento y Desempeño Organizativo}

hacia una cultura organizacional óptima para la promoción de la gestión del conocimiento.

Una forma de remover obstáculos e incentivar a los empleados a compartir su conocimiento entre ellos es implementar sistemas de recompensas económicas y/o no económicas (Shaw y Williams, 2009; Yang y Wan, 2004; Szulanski, 1996).

En esta misma línea, una compañía puede promover la transferencia del conocimiento a través de la consolidación de una cultura organizacional que no solo induzca al cambio en la actitud de sus empleados, sino que promueva el intercambio voluntario y consistente del conocimiento a través de interacciones sociales (Lin, 2007). De esta manera, estarán conscientes de que a través de la transferencia del conocimiento pueden ayudar a la organización a alcanzar sus objetivos (Yi, 2009).

Debe prestarse atención a la actitud entre los compañeros de trabajo, los supervisores, los incentivos proporcionados a aquellos que contribuyen a la creación y uso del conocimiento, así como a las necesidades del liderazgo organizacional y la dirección, que facilitan en última instancia la gestión del conocimiento (Kulkarni et al., 2007).

\subsubsection{La gestión por competencias}

Como se ha analizado en el capítulo dos, el desempeño organizativo dependerá de la consistencia de las ventajas competitivas que sostenga la empresa y de las habilidades distintivas para generarlas, protegerlas, potenciarlas y regenerarlas. 
La consolidación de ventajas competitivas sostenibles depende de la construcción y explotación de competencias principales, es decir, de aquellas capacidades que son fundamentales para las compañías (Grant, 1996). En este entendido, el conocimiento, particularmente el conocimiento tácito, es el recurso estratégico más importante que una empresa posee.

Bueno y Morcillo (2006), en su modelo de competitividad integral, identifican tres competencias básicas distintivas que deben interactuar: las de carácter tecnológico, personal y organizativo.

Por su parte, Hamel y Prahalad (1994) mencionan que para gestionar el stock de competencias esenciales de una empresa, es necesario desagregar las competencias esenciales en sus componentes, hasta llegar a las personas que poseen un talento específico.

Estas aseveraciones llevan a replantear los modelos de gestión de recursos humanos y bajo este enfoque aplicar los conceptos de la gestión por competencias para la gestión del talento humano.

En la revisión de la literatura sobre competencias personales, se pueden identificar dos escuelas de pensamiento. La primera establece que la competencia implica conocimiento o habilidad y la segunda interpreta la competencia como una característica que apoya el rendimiento de una persona. La segunda va más allá de conocimiento o habilidades, ya que puede tomar en cuenta a otros factores, como la motivación y atributos de personalidad. 
Para la presente investigación se adoptará la definición de competencia propuesta por Spencer y Spencer (1993), que considera a las competencias como una característica subyacente en un individuo, que se relaciona a un estándar de rendimiento superior en un trabajo o situación.

La gestión por competencias se enfoca en las personas y resultados, ya que las actividades específicas son cambiantes en la empresa, pero las competencias del personal son duraderas y pueden evolucionar fácilmente con la empresa (Rothwell y Duboise, 2004).

La gestión por competencias implica un cambio filosófico, conceptual y de actuación respecto del tradicional enfoque de la dirección de personal. Este cambio significa pasar de un enfoque reactivo a uno proactivo; de trabajar con funciones aisladas a una gestión integral; de un nivel funcional a un nivel estratégico; y, finalmente, del enfoque del rasgo (relacionado con el puesto) al enfoque de las competencias (Pereda, Berrocal y López, 2010).

Lo que se pretende lograr con este cambio es:

- Alinear el aporte humano con la estrategia de negocios

- Una gestión eficiente de los activos estratégicos centrados en los individuos

- La selección, formación, promoción, evaluación y remuneración basados en las competencias y valor agregado 


\section{Capítulo 3 Transferencia de Conocimiento y Desempeño Organizativo}

La competencia personal esta relacionada con que la persona pueda desempeñar sus labores en la empresa, considerando su estrategia, cultura y actividad. Para ello, como mencionan Pereda et al. (2010), la competencia personal involucra el:

- Saber: conformado por el conjunto de conocimientos

- Saber hacer: relacionado con las habilidades y destrezas

- Saber estar: relacionado con adoptar un comportamiento adecuado a las normas, reglas y cultura de la organización

- Querer hacer: relacionado con las motivaciones

- Poder hacer: referido a disponer de los medios y recursos adecuados

El enfoque tradicional de recursos humanos se basa en el análisis del trabajo y descripciones de puestos. Este método solamente describe actividades de trabajo, pero no analiza resultados esperados de los empleados.

El proceso de gestión de recursos humanos esta conformado por las siguientes tareas: reclutamiento y selección; integración; formación; planificación y gestión de carrera; evaluación del desempeño y recompensas. Con base en estas tareas, Moreno, Pelayo y Vargas (2004) plantean una serie de recomendaciones y prácticas para la gestión por competencias:

- Para las tareas de reclutamiento y selección en base a competencias deben confeccionarse los perfiles y descripciones de puestos considerando: a) cada competencia debe tener una denominación precisa, b) cada competencia tiene un número de niveles que responden a conductas 


\section{Capítulo 3 Transferencia de Conocimiento y Desempeño Organizativo}

observables, c) todas las competencias se pueden desarrollar, d) diferenciar entre competencias genéricas y específicas, e) identificar las competencias críticas o imprescindibles.

- Para la tarea de integración, se puede lograr mejores resultados mediante el desarrollo de programas de mentoría.

- En las tareas de formación y desarrollo de las competencias, debe ser potenciado el aprendizaje continuo como una actitud general. Una práctica es la del "coaching", que implica el entrenamiento + aprendizaje + progreso.

- Respecto a la planificación y gestión de la carrera profesional, es necesario contar con el catálogo de competencias de la empresa. Una barrera común es que los empleados consideran que su promoción depende de la experiencia que tienen y no de cuanto ayudan a otros (Levy et al., 2010).

- La evaluación del desempeño en base a competencias, debe incorporar a los estándares tradicionales aquellas conductas necesarias para un buen rendimiento. Un método recomendado es la evaluación de 360 grados, que considera la evaluación no solo de los superiores, sino también de todos aquellos que reciben sus servicios internos y externos.

- La remuneración en base a competencias, considera un sistema global de retribuciones basado en los principios de equidad interna y competitividad 


\section{Capítulo 3 Transferencia de Conocimiento y Desempeño Organizativo}

externa. Una práctica es la de aplicar salarios variables a fin de remunerar en base a los conocimientos, habilidades y actitudes. Sin embargo, este es uno de los aspectos más controvertidos y discutidos a la hora de llevarlo a la práctica.

Figura 3.3. Proceso de Gestión de Recursos Humanos Basada en Competencias

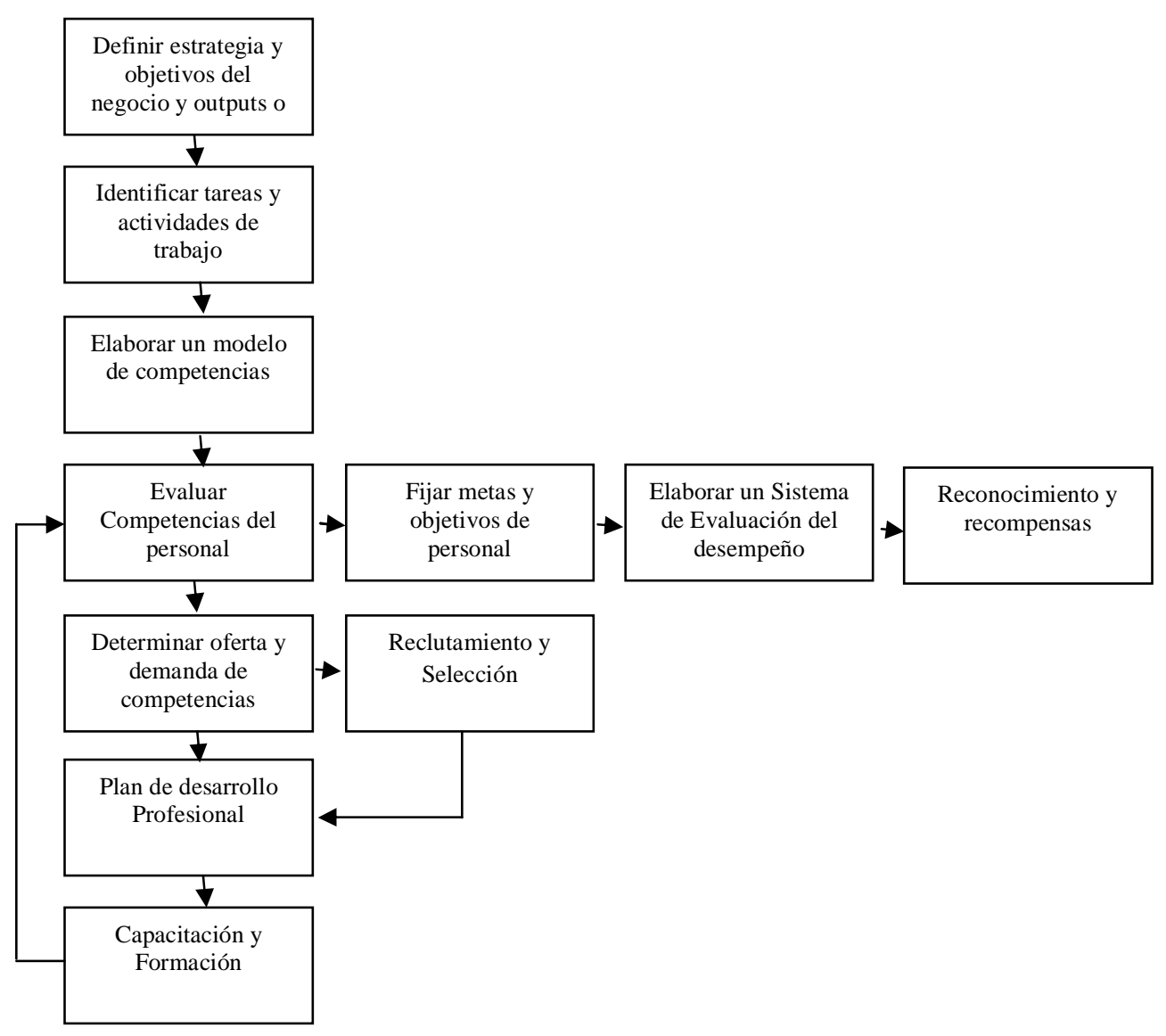

Fuente: Elaboración propia basada en Rothwell y Duboise (2004) 


\section{Capítulo 3 Transferencia de Conocimiento y Desempeño Organizativo}

Bajo este enfoque, la identificación de competencias esenciales, la consolidación de una cultura organizacional que fortalezca la unión entre los empleados, el apoyo de los jefes en el desarrollo del conocimiento y el establecimiento de mecanismos para la promoción y remuneración basada en conocimiento, son elementos fundamentales para una adecuada gestión por competencias.

\subsubsection{El aprendizaje continuo}

Para comprender el aprendizaje continuo y su relación con la transferencia de conocimiento, en esta primera parte se presentará una revisión de los conceptos más extendidos y utilizados en la literatura.

\subsubsection{Niveles de aprendizaje contínuo}

Diversos autores han identificado diferentes niveles de aprendizaje organizativo, relacionado al nivel de radicalidad y profundidad del aprendizaje experimentado por la organización.

Argyris y Shon (1978) identifican dos niveles de aprendizaje organizativo, en "bucle simple" y en "bucle doble". El aprendizaje en bucle simple se da cuando la organización, en respuesta a los cambios internos o externos, adopta medidas correctivas a los errores, sin modificar esencialmente la "teoría en uso organizativa"; por lo cuál, no es radicalmente transformada. El aprendizaje en bucle doble implica un cambio radical de la "teoría en uso organizativa". 


\section{Capítulo 3 Transferencia de Conocimiento y Desempeño Organizativo}

Otros niveles propuestos para el aprendizaje organizativo son el de "tercer ciclo"; este nivel de aprendizaje contribuye a mejorar la actividad organizativa incrementando el grado de eficiencia e impulsa una reestructuración completa, promoviendo el desarrollo de la organización (Swieringa y Wierdsma, 1992).

Estos mismos autores consideran como un nivel superior de aprendizaje a los anteriores, la capacidad de "aprender a aprender" o "metaprendizaje"; este tipo de aprendizaje asegura el máximo grado de proactividad, por lo tanto está orientado a buscar la supervivencia o evolución de la organización.

Por su parte, Probst y Buchel (1997) identifican tres niveles de aprendizaje organizativo: el adaptativo, reconstructivo y de proceso; este último se identifica con la capacidad de aprender a aprender.

La capacidad para aprender o la habilidad para crear y aplicar el nuevo conocimiento, se considera como una de las principales fuentes de ventaja competitiva. De acuerdo al enfoque basado en el conocimiento, las firmas son sistemas abiertos para trabajar con el conocimiento y desarrollar procesos continuos de aprendizaje organizativo (López-Sáez et al., 2010).

Tabla 3.3. Niveles de aprendizaje

\begin{tabular}{||l|l|l||}
\hline \multicolumn{1}{|c||}{ Nivel de aprendizaje } & Área de aprendizaje & \multicolumn{1}{|c|}{$\begin{array}{c}\text { Resultado del } \\
\text { aprendizaje }\end{array}$} \\
\hline "bucle simple"; "adaptativo"; & $\begin{array}{l}\text { Reglas y } \\
\text { procedimientos }\end{array}$ & $\begin{array}{l}\text { Corrección de errores, } \\
\text { mejora }\end{array}$ \\
\hline
\end{tabular}


Capítulo 3 Transferencia de Conocimiento y Desempeño Organizativo

\begin{tabular}{|c|c|c|}
\hline $\begin{array}{l}\text { "bucle doble"; } \\
\text { "reconstructivo"; "doble } \\
\text { ciclo" }\end{array}$ & $\begin{array}{l}\text { Asunciones básicas, } \\
\text { visiones o "teoría en } \\
\text { uso organizativa" }\end{array}$ & Renovación \\
\hline $\begin{array}{l}\text { "aprender a aprender"; } \\
\text { "aprendizaje de proceso"; } \\
\text { "triple ciclo" }\end{array}$ & $\begin{array}{l}\text { Principios esenciales, } \\
\text { identidad, razón de ser }\end{array}$ & Desarrollo \\
\hline "metaprendizaje" & Renovación total & Supervivencia, evolución \\
\hline
\end{tabular}

Fuente: Elaboración propia en base a Swieringa y Wierdsma (1995)

\subsubsection{Conceptualización y proceso de aprendizaje}

Lee y Choi (2003:191) definen al aprendizaje como" la adquisición de nuevo conocimiento por parte de las personas que están dispuestas a aplicar el conocimiento en la toma de decisiones o para influir en otras personas". Adicionalmente, se ha reconocido la correlación positiva entre el tiempo utilizado para aprender y la cantidad de conocimiento adquirido.

Huber (1991) conceptualiza al aprendizaje organizativo como un proceso dinámico que implica el movimiento del conocimiento tanto de ida como de vuelta entre diferentes niveles de la organización, específicamente el individual, el grupal y el organizativo.

Templeton et al. (2002), luego de revisar 78 definiciones de aprendizaje organizativo, lo conceptualizan como "un conjunto de acciones (adquisición de conocimiento, distribución de información, interpretación de información y 


\section{Capítulo 3 Transferencia de Conocimiento y Desempeño Organizativo}

memoria organizacional) dentro de la organización que influye de forma intencional o no en el cambio organizacional positivo".

El aprendizaje organizativo puede ser entendido como la capacidad de una organización para procesar conocimiento (crear, adquirir, transferir e integrar) y modificar su comportamiento para reflejar una nueva situación cognitiva, con el fin de mejorar su desempeño (Jerez-Gómez et al., 2005; Grant, 1996; Fiol y Lyles, 1985).

El proceso de aprendizaje se puede dar a nivel individual, grupal y organizacional. Crossan et al. (1999) identifican cuatro procesos de aprendizaje entre estos niveles: intuición, interpretación, integración e institucionalización.

Figura 3.4. Aprendizaje organizativo como un proceso dinámico

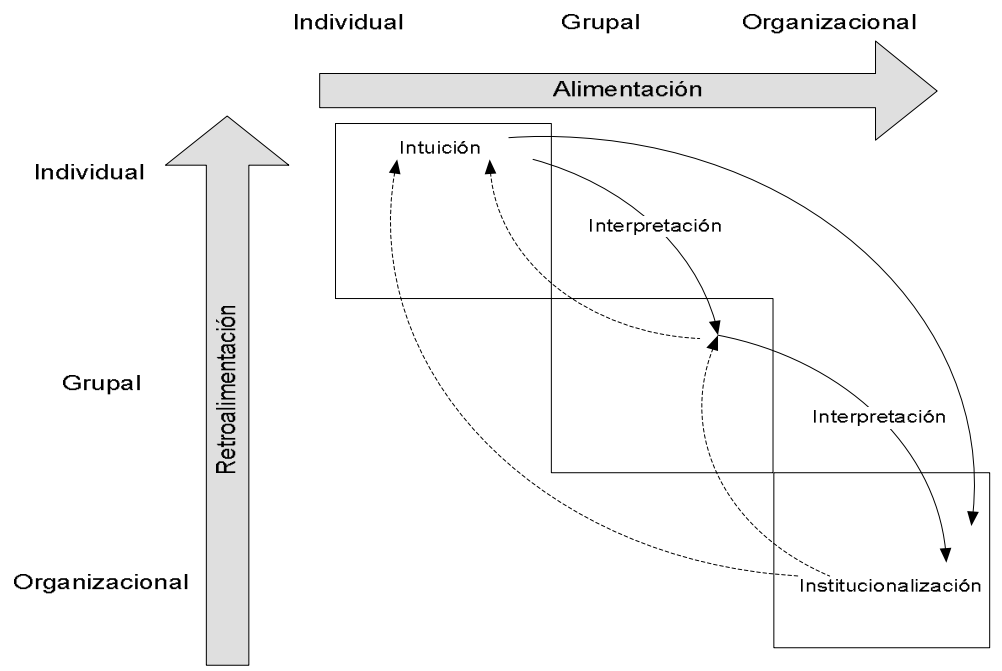

Fuente: Crossan, Lane y White (1999) 
Pawlowsky, Forslin y Reinhardt (2003) indican que los enfoques sobre aprendizaje organizativo pueden clasificarse en 5 grupos: toma de decisiones organizativas y adaptación; de la teoría de sistemas; cognitivo y enfoque de conocimiento; cultural y de acción de aprender.

\section{Figura 3.5. Marco Conceptual para la Gestión del Aprendizaje Organizativo}

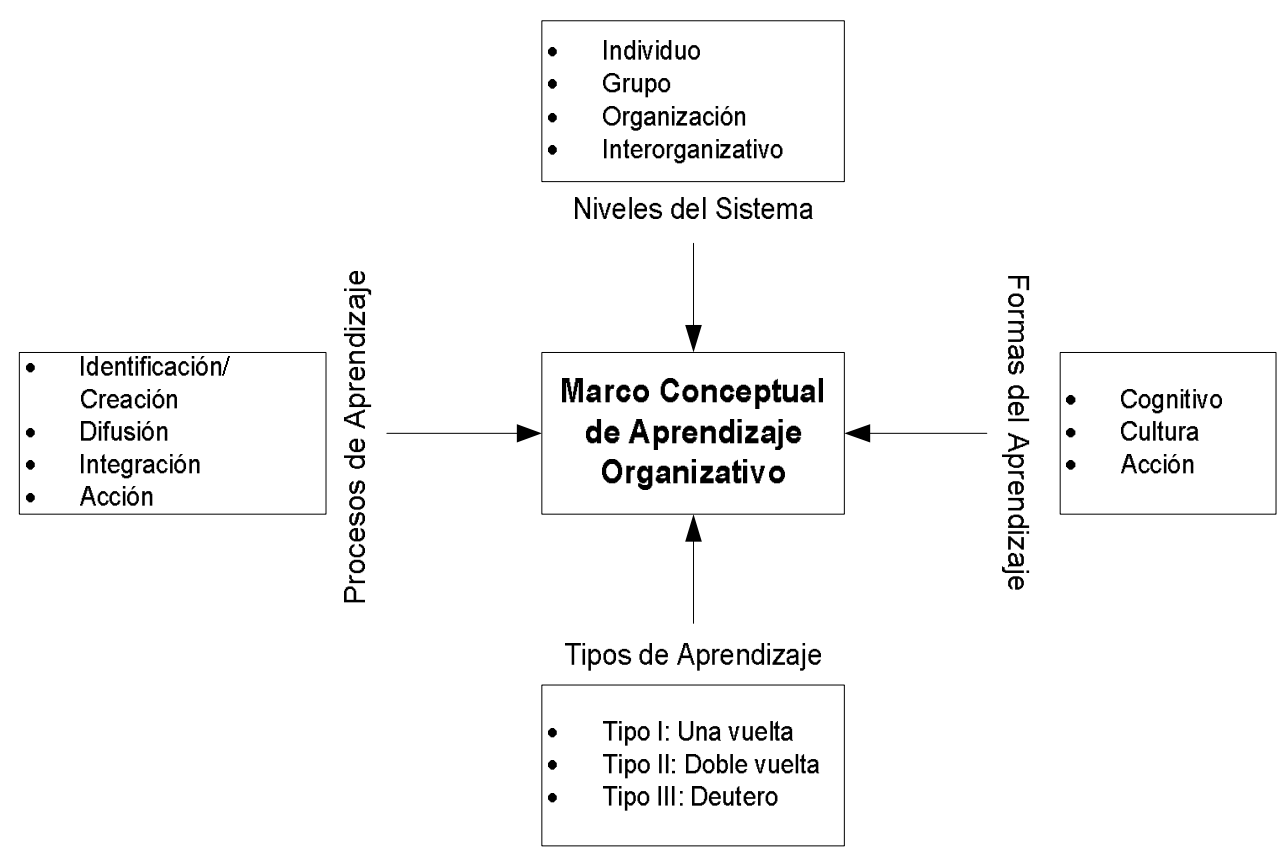

Fuente: Elaboración Propia en base a Pawlowsky et al. (2003)

Brockman y Morgan (2003) han considerado al aprendizaje organizativo como un elemento clave para el desempeño organizativo. Por su parte, Prahalad y Hamel 


\section{Capítulo 3 Transferencia de Conocimiento y Desempeño Organizativo}

(1990) señalaron la importancia del desarrollo de habilidades para la creación de competencias distintivas, siendo estas determinantes para el éxito en las empresas. Los hoteles son vistos como organizaciones que facilitan el conocimiento; ya que los administradores y empleados comparten información y experiencias para crear nuevo conocimiento y herramientas.

En el sector hotelero la mayor parte del personal que atiende a los clientes desarrolla el conocimiento a través de su interacción con los huéspedes, administradores, colegas, proveedores, empleados de la competencia y de otros grupos externos. Durante estas interacciones sociales, los empleados perciben impresiones sobre cómo estos grupos actúan en sus fuentes de trabajo (Hallin y Marnburg, 2008).

El aprendizaje por observación es uno de los mecanismos de transferencia del conocimiento, el cuál es importante para la industria del turismo, dadas las dificultades en patentar el capital intelectual o la concesión de innovaciones (Aldebert, Dang y Longhi, 2011).

\subsubsection{Barreras al aprendizaje organizativo}

Tomando en cuenta los niveles de conocimiento y los procesos propuestos por Crossan et al. (1999), se han identificado ciertas barreras a la transferencia de conocimiento que se presentan en la siguiente tabla: 
Tabla 3.4. Barreras del aprendizaje organizativo

\begin{tabular}{|c|c|c|c|c|}
\hline & Intuición & Interpretación & Integración & Institucionalización \\
\hline 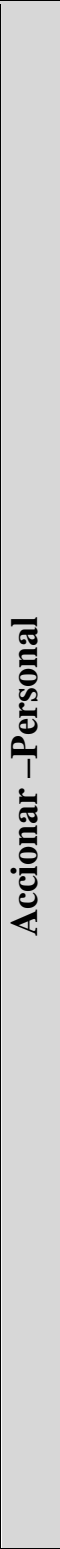 & \begin{tabular}{|l|} 
Sesgos y \\
deficiencias \\
en los \\
empleados en \\
sus funciones \\
como \\
sensores en la \\
organización \\
Aprendizaje \\
supersticioso \\
Falta de \\
conocimiento \\
referido a \\
análisis de \\
falla \\
sistemática \\
Falta de \\
innovación \\
Alto nivel de \\
estrés \\
Identidad \\
profesional \\
caracterizada \\
por solución \\
de problemas \\
de primer \\
orden \\
Miedo a las \\
desventajas \\
Estilo \\
gerencial \\
restrictivo \\
-
\end{tabular} & \begin{tabular}{|l|} 
Miedo de perder \\
el control y \\
propiedad del \\
conocimiento \\
Falta de \\
habilidades \\
sociales y \\
políticas Bajo \\
estatus, \\
confidencia y \\
confianza del \\
innovador \\
Relación \\
conflictiva entre \\
el innovador y el \\
grupo \\
Falta percibida \\
de ventaja \\
relativa de las \\
prácticas \\
existentes \\
Falta de \\
capacidad de \\
absorción o \\
retención de los \\
miembros del \\
grupo \\
Falta de \\
motivación y \\
ansiedad de parte \\
los miembros del \\
grupo
\end{tabular} & \begin{tabular}{|l|} 
Miedo de las \\
desventajas por \\
los beneficios del \\
equipo \\
Falta de \\
reconocimiento \\
por la innovación \\
Falta de la \\
autoridad formal \\
Falta de apoyo \\
de la alta \\
gerencia \\
Sobre confianza \\
de los gerentes \\
en las prácticas \\
existentes \\
Principios, \\
supuestos y \\
valores rígidos \\
Inconsistencias \\
las visiones de \\
empleados y las \\
de la \\
organización \\
Síndrome de no \\
se inventó aquí \\
Falta de \\
participación y \\
comunicación \\
Incompatibilidad \\
percibida de la \\
cultura y \\
estructura de la
\end{tabular} & 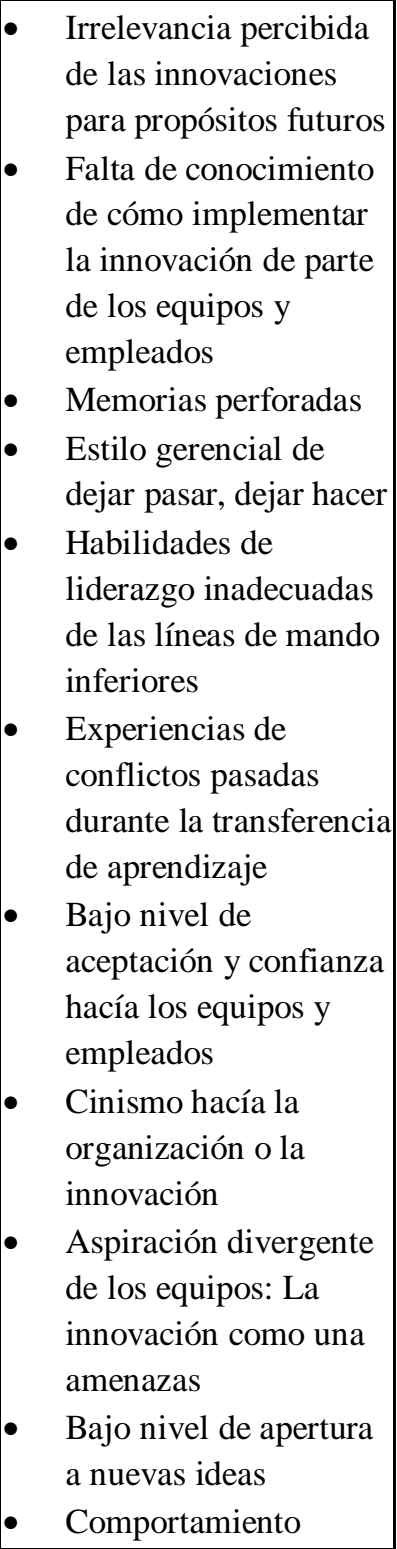 \\
\hline
\end{tabular}


Capítulo 3 Transferencia de Conocimiento y Desempeño Organizativo

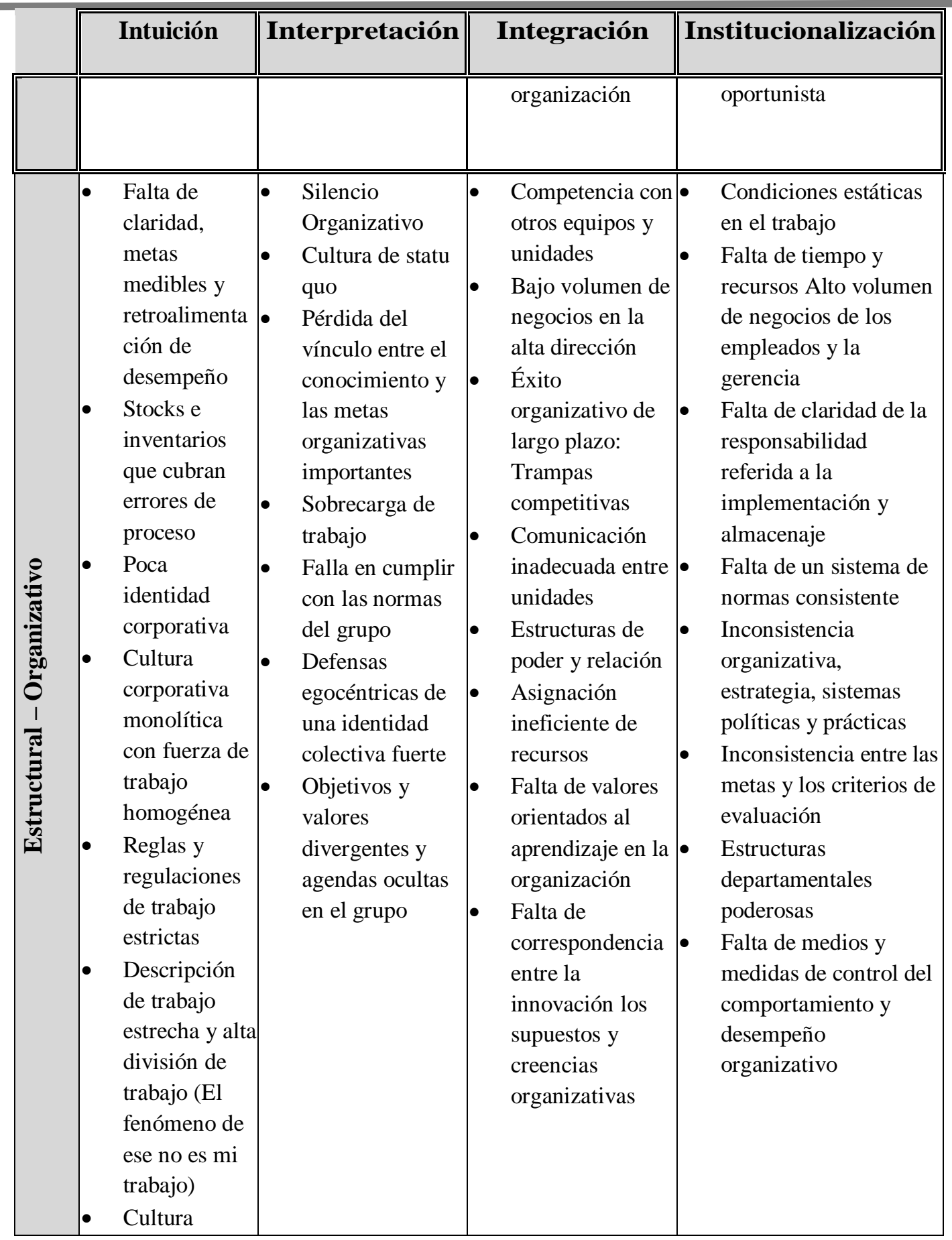


Capítulo 3 Transferencia de Conocimiento y Desempeño Organizativo

\begin{tabular}{|c|c|c|c|c|}
\hline & Intuición & Interpretación & Integración & Institucionalización \\
\hline & $\begin{array}{l}\text { organizaciona } \\
1 \text { de la culpa }\end{array}$ & & & \\
\hline 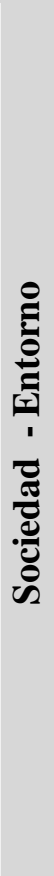 & \begin{tabular}{|l} 
Entornos de \\
mercado \\
complejos, \\
dinámicos y \\
competitivos \\
Distancia \\
cultural y \\
experiencia \\
pobre en la \\
cultura \\
relevante \\
Conocimiento \\
ambiguo, \\
complejo y \\
difícil \\
Conocimiento \\
Relevante \\
pero implícito \\
e inmóvil
\end{tabular} & \begin{tabular}{|l} 
- \\
inconocimiento \\
con mapas \\
mentales \\
existentes
\end{tabular} & \begin{tabular}{|l} 
- \\
industriales en \\
contra de la \\
innovación \\
- Tiempo entre la \\
acción \\
organizativa y la \\
respuesta del \\
entorno
\end{tabular} & 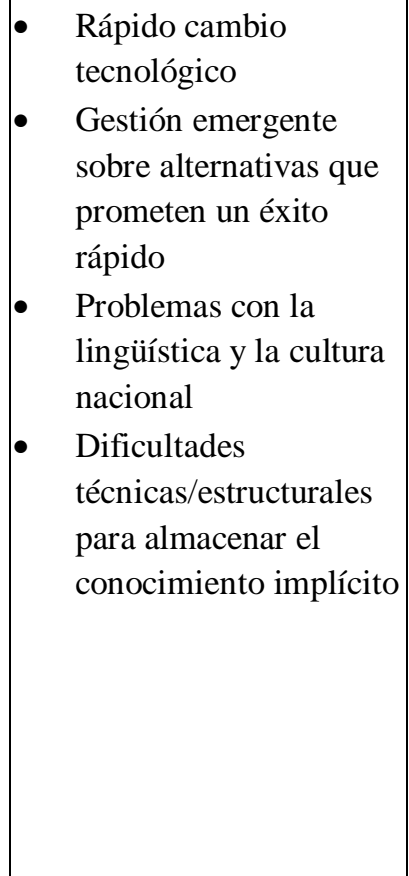 \\
\hline
\end{tabular}

Fuente: Elaboración Propia en base a Schilling y Kluge (2009)

\subsubsection{Dimensiones del aprendizaje contínuo}

Bierly et al. (2000) identifican cuatro dimensiones estratégicas del aprendizaje continuo: interno versus externo, gradual versus radical, velocidad de aprendizaje, grado de profundidad y amplitud de la base de conocimiento. Sobre estas dimensiones diferencian cuatro estrategias genéricas: innovadores, exploradores, explotadores y solitarios. 


\section{Capítulo 3 Transferencia de Conocimiento y Desempeño Organizativo}

Palacios et al. (2010) distinguen cuatro dimensiones para el desarrollo de un sistema continuo de aprendizaje:

- Compromiso de la dirección con el aprendizaje continuo

- Cultura que fomente la innovación y el aprendizaje

- Desarrollo de competencias internas

- Diseño organizativo basado en el aprendizaje.

\subsubsection{Infraestructura técnica de las Tecnologías de Información TI}

Las tecnologías de información han recibido bastante atención por parte de gerentes de empresas así como en el ámbito académico, en razón de que las mismas contribuyen positivamente al desempeño organizativo, así como a la creación y sostenimiento de ventajas competitivas (Nakata et al., 2008; Bharadwaj, 2000; Brynjolfsson y Hitt, 2000; Mata et al., 1995; Barney, 1991).

El rol de las tecnologías de información, al facilitar la transferencia del conocimiento, puede resumirse como un medio para capturar, almacenar y transmitir el conocimiento (Gururajan y Fink, 2010).

De acuerdo a diversos estudios, para lograr una mejora en el desempeño organizativo es necesaria la inversión en tecnologías de información (Brynjolfsson y Hitt, 1996); (Brynjolfsson y Yang, 1996). Sin embargo, esta condición no es suficiente si las personas no la utilizan. En este entendido, Davis et al. (1989) desarrollaron el modelo llamado TAM “Technology Acceptance Model", que mide el nivel de uso de las tecnologías de información. 


\section{Capítulo 3 Transferencia de Conocimiento y Desempeño Organizativo}

Algunos autores argumentan que la relación entre las tecnologías de información y el desempeño empresarial no es directa, ya que es mediada por otras variables. Barua et al. (1995) sugieren que se debe estudiar el impacto de las tecnologías de información en medidas de desempeño funcionales y operativas. Por su parte, Ravichandran y Lertwongsatien (2005) corroboran ésta afirmación, sugiriendo que estas medidas de desempeño intermedias deberían brindar resultados más robustos que las medidas de desempeño empresarial más generales.

Algunas relaciones encontradas en la literatura respecto al las TI son:

- Relación positiva entre TI y productividad (Brynjolfsson y Hitt, 1996).

- El efecto de los recursos y capacidades de los sistemas de información en el desempeño organizativo (Ravichandran y Lertwongsatien, 2005).

- La relación entre la infraestructura de tecnologías de información con los sistemas de información logística y el desempeño empresarial (Byrd et al., 2008).

- La relación de la capacidad tecnológica con el desarrollo de nuevos productos y desempeño organizativo (Wang et al., 2006).

- Las habilidades de TI, tecnologías genéricas, gasto en TI y la flexibilidad de la infraestructura de TI con el desempeño relativo de procesos (Ray et al., 2005). 


\section{Capítulo 3 Transferencia de Conocimiento y Desempeño Organizativo}

\subsubsection{Tecnologías de información (TI) y sistemas de información (SI)}

Un tema recurrente al estudiar las TI ha sido definir el alcance de recursos en Sistemas de Información (SI). Ross et al. (1996) dividen los SI en tres activos de TI: activos humanos (habilidades técnicas, comprensión del negocio, orientación a la resolución de problemas), activos tecnológicos (activos tecnológicos físicos, plataformas técnicas, bases de datos, arquitectura tecnológica) y activos relacionales (relación con otras divisiones, relaciones con clientes, apoyo de la alta gerencia y responsabilidad, así como riesgo compartido).

Por su parte, Bharadwaj (2000) clasifica los recursos de TI en: la parte tangible, que comprende la infraestructura física de TI, los recursos humanos de TI (que tienen las habilidades técnicas y gerenciales de TI). Por otro lado, se identifican los recursos intangibles, siendo estos recursos facilitadores de TI, los cuales incluyen activos de conocimiento, orientación hacía el consumidor y sinergia.

Feeny y Willcocks (1998) definen nueve capacidades de SI agrupadas en: visión de TI y negocios, diseño de la arquitectura de TI y entrega de servicios de SI. Las nueve capacidades identificadas son: liderazgo, pensamiento de sistemas de negocios, construcción de relaciones, planificación de la arquitectura, hacer que la tecnología trabaje, compras informadas, facilitación de contrataciones, monitoreo de contrataciones y desarrollo de aprovisionamiento de servicios TI y SI.

La capacidad de tecnologías de información se define como la habilidad de movilizar y aplicar los recursos de TI en combinación o con la presencia de otros recursos y capacidades (Bharadwaj, 2000). En cambio, Nakata et al. (2008), así 


\section{Capítulo 3 Transferencia de Conocimiento y Desempeño Organizativo}

como Bakos y Treacy (1986), definen la capacidad TI como la habilidad de un sistema computarizado de almacenar, procesar y comunicar información.

\subsubsection{Importancia de las TI y SI en la transferencia de conocimiento y creación de ventajas competitivas}

La relación entre las tecnologías de información y la creación de ventajas competitivas que se reflejen en un desempeño organizativo superior, ha sido abordado por diversos autores (Nakata et al., 2008; Ravichandran y Lertwongsatien, 2005; Wade y Hulland, 2004; Bharadwaj, 2000; Brynjolfsson y Hitt, 2000; Mata et al., 1995).

Lee y Choi (2003) sostienen que la tecnología y sus capacidades permite conectar a las personas con el conocimiento y crear nuevo conocimiento, por lo que contribuye a la gestión del conocimiento de diferentes maneras: en primer lugar la infraestructura tecnológica facilita la rápida recolección, almacenaje e intercambio de conocimiento, facilitando de esta manera el proceso de creación del conocimiento. En segundo lugar, permite integrar flujos fragmentados del conocimiento, eliminando de esta manera las barreras de comunicación entre departamentos dentro de la organización. Finalmente, fortalece todos los modos de creación del conocimiento.

Kulkarni et al. (2007) también mencionaron que las tecnologías de información permiten a los empleados compartir, almacenar y retener documentos y otros objetos del conocimiento que pueden ser utilizados en su trabajo. 


\section{Capítulo 3 Transferencia de Conocimiento y Desempeño Organizativo}

El progreso tecnológico y la industria del turismo han ido de la mano. Desde los años 80 las tecnologías de información y comunicación han transformado esta industria. Estos cambios han permitido incrementar la capacidad y velocidad de las redes, lo que ha influenciado en el número de viajeros alrededor del mundo que utilizan estas tecnologías para planificar y experimentar en sus viajes. Las tecnologías de información y comunicación permiten a los viajeros acceder a información precisa, confiable y a la vez a realizar sus reservaciones en muy corto tiempo, costo y sin inconvenientes (Buhalis y Law, 2008; Zehrer, Crotts y Magnini, 2010).

Esta interacción permite que las organizaciones turísticas se comprometan con los intereses y participación de los consumidores; también permite capturar información acerca de su preferencia y a la vez usar esta información para proveer comunicación y servicios personalizados. Las tecnologías de información empoderan a los consumidores para identificar y comprar productos turísticos, también apoyan a la globalización de la industria, al proveer herramientas efectivas a los proveedores (Doolin, Burgess y Cooper, 2002).

Las tecnologías de información y comunicación también cambiaron radicalmente la eficiencia y efectividad de las organizaciones turísticas, la forma en que los negocios se realizan y la manera en que los consumidores interactúan con la empresa (Buhalis y Law, 2008). La innovación juega un papel importante en la industria del turismo, ya que el turismo se ha convertido en uno de los principales conductores en el uso de internet en la economía, desde el comercio electrónico hasta las relaciones dentro de las firmas o la aplicación de la Web 2.0. La web 2.0 


\section{Capítulo 3 Transferencia de Conocimiento y Desempeño Organizativo}

ha emergido como un medio fundamental por el cual los consumidores adquieren información antes de la compra (Zehrer et al., 2010).

La innovación en el sector turístico es un fenómeno multifacético en términos de las tecnologías de información y comunicación, así mismo debe considerarse que el turismo es una actividad compleja (Aldebert et al., 2011).

Con el avance tecnológico (especialmente del internet) las fuentes de información disponibles para los clientes se han incrementado. Un ejemplo son los “cyber espacios", en el que se exponen los comentarios de los consumidores. Esta información es importante a la hora de seleccionar un producto (Sparks y Browning, 2011).

Como consecuencia del dinamismo del sector turístico y la alta rotación de recursos humanos se pierden activos intangibles, ya que afecta la retención de información. Por ello, se han explorado y planificado diversos tipos de programas y sistemas para minimizar esta pérdida (Yang y Wan, 2004).

Por esta razón, Yang y Wan (2004) sostienen que los hoteles tienen la necesidad de considerar programas que estimulen y permitan que los empleados de todos los niveles compartan lo que saben con otros y almacenen el conocimiento organizacional en depósitos. Compartir el conocimiento busca que se transfieran experiencias y conocimiento individuales para generar el conocimiento organizacional, el mismo que representa un activo intangible significativo. 


\section{Capítulo 3 Transferencia de Conocimiento y Desempeño Organizativo}

Hjalager (2010) de acuerdo a su investigación, menciona que es necesaria una agenda para futuras investigaciones cuantitativas y cualitativas sobre las bases, procesos, implicaciones y políticas de innovación aplicadas al turismo.

\subsection{RELACIONES TEÓRICAS ENTRE LAS VARIABLES}

Como se analizó en el capítulo uno, la evolución de los diferentes enfoques en organización de empresas muestra una transición de la focalización en aspectos internos de la organización hacia una visión holística, que considera a la organización como un sistema abierto que interactúa con su entorno. Por otra parte, es necesario pasar de un enfoque estático a uno dinámico, como una forma de renovación tanto de recursos como de capacidades, a fin de sostener la ventaja competitiva en el tiempo.

La generación de ventajas competitivas sostenibles requiere de un enfoque integral (Sanchez y Heene, 1997), es por ello que para la presente investigación se adopta el Enfoque Basado en Competencias (EBC) y en sus corrientes de pensamiento: el enfoque basado en recursos y capacidades, el enfoque de las capacidades dinámicas, el enfoque basado en el conocimiento y el enfoque basado en el aprendizaje. El EBC permite contar con un enfoque dinámico, sistémico, cognitivo y holístico.

El EBC centra su atención en el desarrollo de competencias como fuente de la ventaja competitiva sostenible. Las competencias distintivas, esenciales o nucleares, como las denominan los distintos autores, juegan un rol fundamental 


\section{Capítulo 3 Transferencia de Conocimiento y Desempeño Organizativo}

para este propósito, ya que la base del desarrollo de este tipo de competencias son los activos estratégicos y en especial el conocimiento.

Palacios et al. (2006) resaltan al conocimiento como un activo estratégico y fuente indiscutible de ventajas competitivas sostenibles para las organizaciones, ya que ayuda a mejorar los procesos y por ende el desempeño en las mismas, a través de la generación de nuevas ideas e innovaciones. En la siguiente figura se presenta la propuesta de un Modelo dinámico de gestión con base en el modelo instrumental BMS descrito en el capítulo dos:

Figura 3.6. Propuesta de modelo dinámico de gestión

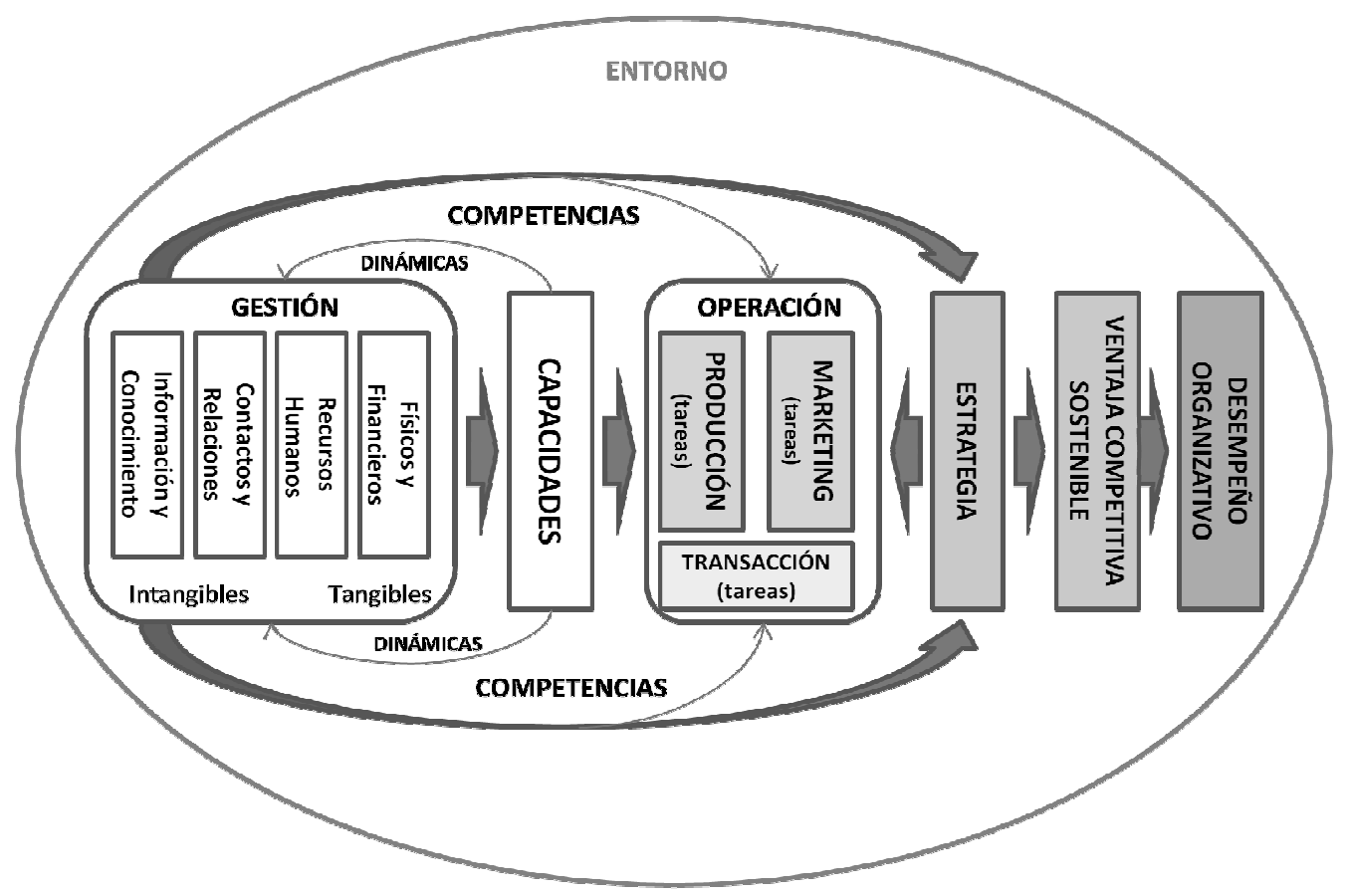

Fuente: Elaboración propia a partir del modelo BMS 


\section{Capítulo 3 Transferencia de Conocimiento y Desempeño Organizativo}

El modelo de referencia permite visualizar las relaciones entre los recursos, capacidades, competencias, la ventaja competitiva sostenible y el desempeño organizativo (Teece, 2007; Palacios, 2002; Teece et al., 1997; Amit y Schoemaker, 1993; Grant, 1991; Prahalad y Hamel, 1990).

En este modelo se resalta la importancia de los activos intangibles, en particular el conocimiento, y su gestión para la generación de ventajas competitivas sostenibles que se reflejen en un mejor desempeño organizativo.

Las ventajas competitivas derivadas del conocimiento dependen, por una parte, de la naturaleza misma de este recurso que lo hace estratégico y, por otra, de su adecuada gestión (Yi, 2009; Girdauskienè y Savanevičienė, 2007; Lee y Choi, 2003; Zack, 1999; Teece, 1998; Spender, 1996; Nonaka y Takeuchi, 1995).

La posesión de conocimiento no asegura la sostenibilidad de las ventajas competitivas, es necesaria la transferencia de conocimiento para que otras unidades de la organización se beneficien del mismo; de ahí la importancia que tiene la transferencia de conocimiento, particularmente a nivel interno de la organización.

Con estas consideraciones, a continuación se presenta el modelo teórico desarrollado para la presente investigación y el planteamiento de las hipótesis a ser contrastadas empíricamente. 


\subsubsection{Modelo teórico y planteamiento de las hipotesis}

Como se ha presentado en los epígrafes anteriores, varios autores corroboran que la transferencia del conocimiento, en particular en el sector turístico, no ha sido explorada suficientemente y por ende existe la necesidad de mayores investigaciones sobre el tema y sus factores antecedentes (Gururajan y Fink, 2010; Shaw y Williams, 2009; Girdauskienè y Savanevičienè, 2007; Segarra, 2006; Lee y Choi, 2003; Foss y Pedersen, 2002).

Tomando en cuenta las dimensiones de la transferencia de conocimiento y elementos analizados en la literatura sobre la gestión de conocimiento, presentados en la Tabla 3.2, para la presente investigación y planteamiento del modelo teórico, se considerarán los siguientes factores antecedentes a la transferencia de conocimiento: visión holística de la organización, gestión por competencias, aprendizaje continuo e infraestructura técnica de las tecnologías de información.

\subsubsection{Visión Holística de la organización}

Como se analizó en el capítulo uno, el Enfoque Basado en Competencias, proporciona un enfoque dinámico, sistémico, cognitivo y holístico, los cuales son necesarios para gestionar la transferencia de conocimiento en las organizaciones.

Como menciona Peter Senge en su libro La Quinta Disciplina, desde pequeños nos enseñan a separar en partes los problemas, a fragementar el mundo, esto con el propósito de que una tarea o tema complejo sea más manejable, sin embargo 


\section{Capítulo 3 Transferencia de Conocimiento y Desempeño Organizativo}

por ello se paga un enorme precio oculto, puesto que se pierde el sentido intrínseco de conexión a un total más grande.

Los enfoques clásicos en organización de empresas han estado limitados por considerar a las organizaciones como sistemas cerrados, por otra parte los enfoques funcionalistas dividen la organización en departamentos y unidades a fin de proporcionales mayor eficiencia, sacrificando en muchos casos la visión de conjunto. Una visión sistémica considera a la organización como un sistema abierto.

En este sentido, los gerentes deben escanear el entorno (competidores, clientes, proveedores), analizarlo y evaluarlo, a fin de identificar brechas estratégicas. Con base en estas, evaluar la composición de stocks y flujos de activos actuales, así como los cambios necesarios para alcanzar las metas empresariales en un entorno competitivo.

Uno de los factores antecedentes para la transferencia de conocimiento, es contar con una visión holística de la organización, que permita alinear los objetivos de la organización con todos sus miembros, de manera que todos estén comprometidos con la gestión del conocimiento (Palacios et al., 2006; DiBella y Nevis, 1998).

La palabra holístico (integral) proviene de la palabra griega "holos" que significa la observación de algo desde el punto de vista funcional a partir de todas sus partes e interrelacionarlas unas con otras como un todo. 


\section{Capítulo 3 Transferencia de Conocimiento y Desempeño Organizativo}

La transferencia de conocimiento es facilitada mediante la consolidación de una cultura organizacional que permita generar una visión compartida en la organización, que considere a los proveedores y clientes (Levy et al., 2010; Joseph, 2009; Girdauskienė y Savanevičienė, 2007;Yang y Wan, 2004; Camisón y Boronat, 2004; Lee y Choi, 2003).

Otros aspectos que facilitan la transferencia de conocimiento son: la actitud entre los compañeros de trabajo, los supervisores, los incentivos proporcionados a aquellos que contribuyen a la creación y uso del conocimiento, el liderazgo organizacional y la dirección (Shaw y Williams, 2009; Yi, 2009; Javidan, 1998; Kulkarni et al., 2007; Lin, 2007; Szulanski, 1996).

La estructura organizacional es un factor que afecta a la transferencia de conocimiento. Una estructura rígida y vertical generará barreras para la comunicación y transferencia de conocimiento. Por otra parte, una excesiva subdivisión del trabajo le quitará la visión de conjunto a la organización (Magnier-Watanabe y Senno, 2010).

El diseño de la organización con base en los procesos, permite visualizar a la organización más alla de las divisiones jerárquicas y funcionales, por ello ha cobrado importancia la utilización de sistemas de planificación de recursos como ser Enterprise Resource Planning (ERP) Systems, que influyen en los resultados de las empresas (Elragal y Al-Serafi, 2011).

Contar con una visión holística es particularmente importante en el sector turístico, puesto que el sector es complejo, debido a que está compuesto por 


\section{Capítulo 3 Transferencia de Conocimiento y Desempeño Organizativo}

actividades heterogéneas de diversa naturaleza que están dispersas en tiempo y espacio, que reúnen a actores que tienen distintos niveles cognitivos y se encuentran en diferentes lugares, de ahí la necesidad de tener una perspectiva interorganizacional (Aldebert et al., 2011; Hallin y Marnburg, 2008; Yang y Wan, 2004).

El interés de la investigación radica en conocer si aquellas empresas que han desarrollado una visión holística de la organización, logran una mejor transferencia de conocimiento. De esta forma se enuncia la primera hipótesis como sigue:

H1: El desarrollo de una Visión Holística de la organización está positiva y significativamente relacionada con la Transferencia de Conocimiento.

\subsubsection{La gestión por competencias}

El desempeño organizativo dependerá de la consistencia de las ventajas competitivas que sostenga la empresa y de las habilidades distintivas para generarlas, protegerlas, potenciarlas y regenerarlas.

Para gestionar el stock de competencias esenciales de una empresa, es necesario desagregar las competencias esenciales en sus componentes, hasta llegar a las personas que poseen un talento específico (Hamel y Prahalad, 1994).

Se ha evidenciado que la ventaja competitiva sostenible es creada a partir de las habilidades individuales de los trabajadores y del conocimiento, que contribuye 


\section{Capítulo 3 Transferencia de Conocimiento y Desempeño Organizativo}

para alcanzar un desempeño más alto en la organización. Por ello, es importante prestar especial atención al recurso humano y su gestión por competencias.

La gestión por competencias implica un cambio filosófico, conceptual y de actuación respecto del tradicional enfoque de la dirección de personal (Pereda et al., 2010).

Las competencias se constituyen en una característica subyacente en un individuo que se relaciona a un estándar de rendimiento superior en un trabajo o situación (Spencer y Spencer, 1993).

La gestión por competencias implica su aplicación a todas las tareas relacionadas con el manejo del recurso humano: reclutamiento y selección, integración, formación, planificación y gestión de carrera, evaluación del desempeño y recompensas (Moreno et al., 2004).

La identificación de competencias esenciales, la consolidación de una cultura organizacional que fortalezca la unión entre los empleados, el apoyo de los jefes en el desarrollo del conocimiento y el establecimiento de mecanismos para la promoción y remuneración basada en conocimiento, son elementos fundamentales para una adecuada gestión por competencias (Rothwell y Duboise, 2004).

Gardner y Wright (2009) examinaron el impacto de las prácticas de recursos humanos en los resultados de la empresa. Prácticas como sistemas de compensación, selección de personal influyen positivamente en los beneficios 


\section{Capítulo 3 Transferencia de Conocimiento y Desempeño Organizativo}

logrados por las empresas. Por otra parte, una adecuada gestión del recurso humano, genera un efecto positivo en la innovación (Laursen y Foss, 2003)

Con estas consideraciones, el enunciado de la segunda hipótesis es el siguiente:

H2: La Gestión por Competencias adoptada por la organización está positiva y significativamente relacionada con la Transferencia de Conocimiento.

\subsubsection{El aprendizaje continuo}

La capacidad para aprender relacionada con la habilidad para crear, transferir y aplicar el nuevo conocimiento, se considera como una de las principales fuentes de ventaja competitiva. En este entendido, las empresas son sistemas abiertos para trabajar con el conocimiento y desarrollar procesos continuos de aprendizaje (López-Sáez et al., 2010; Brockman y Morgan, 2003).

El aprendizaje continuo puede ser entendido como la capacidad de una organización para procesar conocimiento (crear, adquirir, transferir, integrar), con el fin de mejorar su desempeño (Jerez-Gómez et al., 2005; Grant, 1996; Fiol y Lyles, 1985).

El aprendizaje continuo, conceptualizado como un conjunto de acciones relacionadas a la gestión del conocimiento (Templeton et al., 2002), presenta ciertas dificultades y barreras en los diferentes procesos (intuición, interpretación, integración e institucionalización) y niveles de aprendizaje (individual, grupal y organizacional) presentadas en la tabla 3.4 (Schilling y Kluge, 2009; Crossan et al., 1999). 
Palacios et al. (2010) distinguen cuatro dimensiones para el desarrollo de un sistema continuo de aprendizaje: compromiso de la dirección con el aprendizaje continuo; cultura que fomente la innovación y el aprendizaje; desarrollo de competencias internas; diseño organizativo basado en el aprendizaje.

Varios autores han considerado al aprendizaje continuo como un elemento clave para el desempeño organizativo (Jerez-Gómez et al., 2005; Brockman y Morgan, 2003; Prahalad y Hamel, 1990).

Para la industria del turismo, el aprendizaje continuo es importante, dadas las dificultades en patentar el capital intelectual o la concesión de innovaciones (Aldebert et al., 2011).

Uno de los factores que reducen la capacidad para transferir el conocimiento y la permanencia de las iniciativas innovativas en el sector turístico y hotelero es la alta movilidad de los administradores en la industria (Hallin y Marnburg, 2008).

Las altas tasas de entradas y salidas de personas, implica la posibilidad de perder el conocimiento de los empleados por lo que el proceso de creación y retención del conocimiento puede ser inefectivo. Si el conocimiento no es compartido y almacenado, las compañías pueden perder activos intangibles (Yang y Wan, 2004). 


\section{Capítulo 3 Transferencia de Conocimiento y Desempeño Organizativo}

La tercera hipótesis del modelo se enuncia de la siguiente manera:

H3: El Aprendizaje continuo en la Organización está positiva y significativamente relacionado con la Transferencia de Conocimiento.

\subsubsection{La infraestructura técnica de las TI}

El rol de las tecnologías de información al facilitar la transferencia del conocimiento puede resumirse como un medio para capturar, almacenar y transmitir el conocimiento (Gururajan y Fink, 2010), para ello es necesaria la inversión en tecnologías de información como una condición necesaria, así como su utilización por los miembros de la empresa (Brynjolfsson y Hitt, 1996; Brynjolfsson y Yang, 1996; Davis et al., 1989).

Las tecnologías de información contribuyen positivamente al desempeño organizativo y la creación y sostenimiento de ventajas competitivas (Nakata et al., 2008; Bharadwaj, 2000; Brynjolfsson y Hitt, 2000; Mata et al., 1995; Barney, 1991).

La relación entre las tecnologías de información y el desempeño empresarial no es directa, ya que es mediada por otras variables (Ravichandran y Lertwongsatien, 2005; Barua et al., 1995).

Algunas relaciones encontradas en la literatura respecto al a las TI son: relación positiva entre TI y productividad (Brynjolfsson y Hitt, 1996), el efecto de los 


\section{Capítulo 3 Transferencia de Conocimiento y Desempeño Organizativo}

recursos y capacidades de los Sistemas de Información en el desempeño organizativo (Ravichandran y Lertwongsatien, 2005), la relación entre la infraestructura de Tecnologías de información con los sistemas de información logística y el desempeño empresarial (Byrd et al., 2008), la relación de la capacidad tecnológica con el desarrollo de nuevos productos y desempeño organizativo (Wang et al., 2006), las habilidades de TI, tecnologías genéricas, gasto en TI y la flexibilidad de la infraestructura de TI con el desempeño relativo de procesos (Ray et al., 2005).

Las tecnologías de información juegan un papel importante en la industria del turismo, ya que el turismo se ha convertido en uno de los principales conductores en el uso de internet en la economía. (Aldebert et al., 2011; Sparks y Browning, 2011; Hjalager, 2010; Zehrer et al., 2010; Buhalis y Law, 2008; Yang y Wan, 2004; Doolin et al., 2002).

Dos corrientes relacionadas al turismo han emergido en el internet. Por un lado los sitios sociales web, tales como: blogs, comunidades virtuales, wikis, redes sociales, files compartidos en youtube, etc. Por otro lado, el internet interviene en la manera en que los turistas utilizan los sitios sociales para reconstruir y compartir sus viajes (Xiang y Gretzel, 2010).

El enunciado de la cuarta hipótesis, en este sentido, es el siguiente:

H4: La Infraestructura Técnica de las TI está positiva y significativamente relacionada con la Transferencia de Conocimiento. 


\subsubsection{La transferencia de conocimiento y el desempeño organizativo}

Como se ha argumentado en el capítulo dos, la ventaja competitiva sostenible reflejada en un desempeño organizativo superior se basa en los activos intangibles, en particular en el conocimiento. Sin embargo, la posesión de conocimiento no asegura la sostenibilidad de las ventajas competitivas; en este sentido, es necesaria la transferencia para que otras unidades se beneficien del mismo.

Lee y Choi (2003:181) definen al desempeño organizativo como "el grado en el cual las compañías alcanzan sus objetivos empresariales, que puede ser medido en términos de aprendizaje continuo, beneficios u otros beneficios financieros". Estos autores, también especifican que la medición del desempeño organizativo puede ser realizada por medio de medidas financieras, capital intelectual, beneficios tangibles e intangibles y el balanced scorecard.

Conner y Prahalad (1996) indicaron que el desempeño en las organizaciones está determinado por la existencia de asimetrías en el conocimiento y por su asociación a las competencias y capacidades inherentes de cada organización.

La transferencia de conocimiento es un proceso conducido por procesos de comunicación y flujos de información (Szulanski, 1996); por lo que la transferencia de conocimiento estará influenciada por las características del conocimiento transferido, de la unidad receptora, unidad fuente y el contexto en el que se realiza la transferencia (Segarra, 2006). 


\section{Capítulo 3 Transferencia de Conocimiento y Desempeño Organizativo}

El conocimiento posee un carácter multidimensional que influye en su transferencia:

- tácito - explícito (Lubit, 2001; Schulz y Jobe, 2001; Teece, 2000; Zander y Kogut, 1995; Nonaka, 1991; Nelson y Winter, 1982).

- complejo - simple (McEvily y Chakravarthy, 2002; Simonin, 1999; Hansen, 1999; Zander y Kogut, 1995; Simon, 1961).

- específico - general (Brown y Duguid, 1998; Grant, 1996; Williamson, 1991; Demsetz, 1991).

- dependiente o sistémico - independiente o autónomo (Hansen, 1999)

Existen numerosos estudios que confirman la utilidad de la transferencia interna de conocimiento traducida en beneficios económicos, particularmente en casos de empresas multinacionales, sin embargo para la transferencia de conocimiento se presentan dificultades o barreras (Foss y Pedersen, 2002; Becker, 2001; Lee y Yang, 2000; Davenport y Prusak, 1998; O' Dell y Grayson, 1998).

Con base en estas consideraciones y lo argumentado en el presente capítulo, el enunciado de la quinta hipótesis es el siguiente:

H5: Existe una relación significativa y positiva entre la Transferencia de Conocimiento y el Desempeño Organizativo.

\subsubsection{El papel mediador de la transferencia de conocimiento}

Desde el Enfoque Basado en Competencias y la jerarquía propuesta por Javidan (1998), referido a los recursos, capacidades, competencias y competencias 


\section{Capítulo 3 Transferencia de Conocimiento y Desempeño Organizativo}

nucleares; la gestión del conocimiento y en particular su transferencia se relaciona con el desempeño organizativo de forma indirecta.

Por su parte Davenport (1999) relaciona la forma en la que las actividades de Gestión de conocimiento son capaces de influir en una serie de actividades intermedias como la gestión del capital humano, que sí tienen una incidencia directa sobre los resultados financieros

Wiig (1999) representa un diagrama que muestra los efectos y beneficios intermedios, tanto internos como externos, generados por actividades de gestión del conocimiento, reforzando con ello el carácter mediador de la transferencia de conocimiento con el desempeño organizativo.

Como se ha analizado en los epígrafes anteriores, la transferencia de conocimiento está relacionada con un conjunto de factores antecedentes, que se constituyen en las variables de las hipótesis 1, 2, 3 y 4 del modelo teórico. Por otra parte, la transferencia de conocimiento facilita el desarrollo de competencias distintivas y las mismas están relacionadas con el desarrollo de ventajas competitivas sostenibles.

Por ello, la sexta hipótesis señala que:

H6: La Transferencia de Conocimiento juega un papel mediador entre los factores antecedentes y el desempeño organizativo. 


\subsubsection{El modelo teórico}

En la siguiente figura se presenta el modelo teórico que representa el conjunto de variables y sus relaciones:

Figura 3.7. Modelo Teórico

Factores antecedentes

Procesos de

Resultado

Gestión de Conocimiento

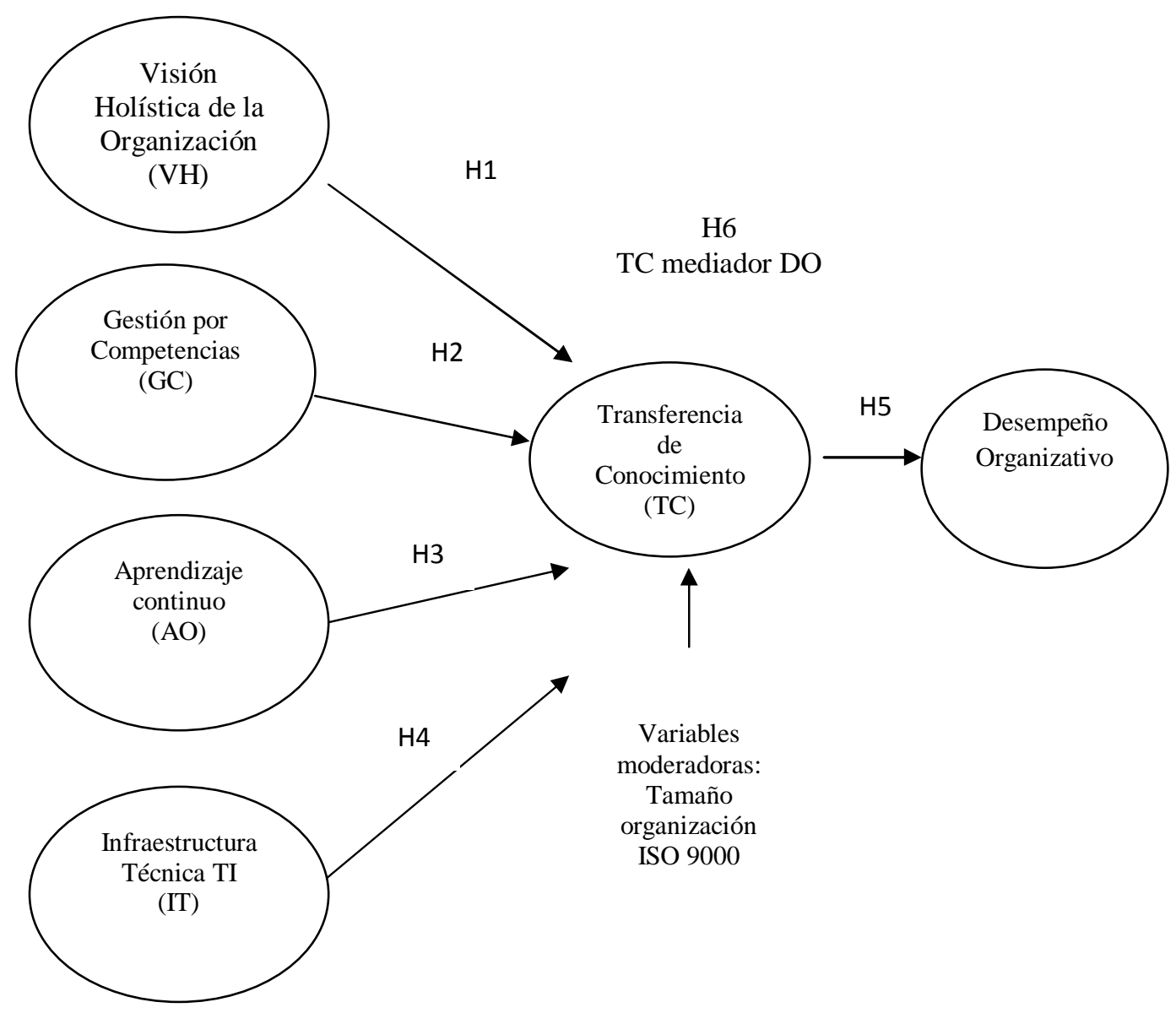


Una vez enunciado el conjunto de hipótesis que se contrastarán empíricamente, se concluye el presente capítulo.

La investigación se ha orientado, por una parte a la identificación y planteamiento de un conjunto de factores antecedentes que influyen en la transferencia de conocimiento y por otra parte, a la relación existente entre la transferencia de conocimiento con el desempeño organizativo. 


\section{Capítulo 4}

\section{Caracterización del Sector de}

\section{Estudio e Instrumento de \\ Medida}




\section{CAPÍTULO 4}

\subsection{INTRODUCCIÓN Y OBJETIVOS DEL CAPÍTULO}

En los tres primeros capítulos se ha desarrollado el marco teórico de la presente investigación.

Con base en la revisión de los principales enfoques en organización de empresas, realizado en el primer capítulo, se ha adoptado el posicionamiento teórico de la investigación. En el capítulo dos se han analizado las implicaciones de la gestión del conocimiento en la ventaja competitiva. En el capítulo tres se desarrolló el modelo teórico, que explica las relaciones entre las variables antecedentes, la transferencia de conocimiento y el desempeño organizativo.

El objetivo del presente capítulo se centra en presentar los datos más relevantes de la industria del turismo y del sector hotelero en España, analizar la transferencia de conocimiento en este sector y desarrollar el instrumento de medición para la contrastación empírica del modelo teórico de la investigación.

En la primera parte del capítulo se analiza el sector turístico en general y su importancia; luego se presenta la información más relevante de este sector en España así como sus implicaciones económicas y sociales; y finalmente se analiza el sector hotelero en particular. 


\section{Capítulo 4 Caracterización del Sector de Estudio e Instrumento de Medida}

En la segunda parte se presenta la importancia de la transferencia de conocimiento en el sector turístico, en particular en el hotelero y el instrumento de medida de las variables del modelo teórico presentado en el capítulo tres.

\subsection{EL SECTOR TURÍSTICO Y SU IMPORTANCIA}

El turismo se constituye en la mayor actividad económica del mundo. Según la Organización Mundial del Turismo ${ }^{3}$ (2011) el volumen de negocios de la industria del turismo iguala o supera las exportaciones de petróleo, productos alimenticios y automóviles. El sector turismo representa aproximadamente el $5 \%$ de la actividad económica mundial y absorbe entre el 6 al $7 \%$ del empleo tanto directo como indirecto.

Desde 1950 el crecimiento del sector turismo ha sido sostenido, la tasa de crecimiento de llegadas internacionales de viajeros ha crecido a una tasa del 6,5\% anual, en consecuencia se ha pasado de 25 millones de turistas en 1950 a 806 millones en el 2005.

\footnotetext{
${ }^{3}$ http://unwto.org/en/about/tourism
} 


\section{Capítulo 4 Caracterización del Sector de Estudio e Instrumento de Medida}

\section{Figura 4.1. Crecimiento del turismo entre los años de 1950 y el 2005}

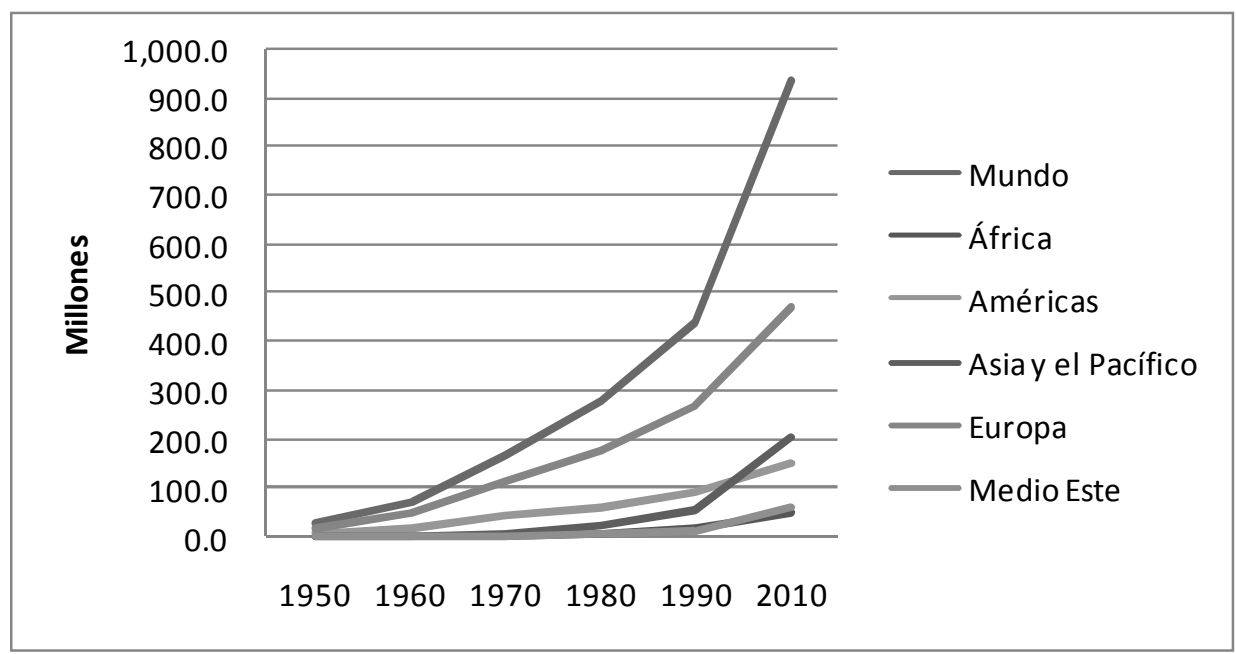

Fuente: Elaboración propia con datos de la Organización Mundial del Turismo

Como se puede apreciar en el gráfico anterior, la región de Europa es la que presenta mayor volumen de llegadas internacionales así como el mayor crecimiento; resalta el crecimiento experimentado por la región del Asía y Pacífico a partir de los años 80.

De acuerdo a las cifras actuales y proyectadas por la Organización Mundial de Turismo, el año 2009 el turismo internacional generó 852 billones de dólares americanos en ingresos de exportación, constituyéndose en uno de los más importantes sectores que aportan a la economía. 


\section{Capítulo 4 Caracterización del Sector de Estudio e Instrumento de Medida}

Asia y el Pacífico tuvieron las tasas más rápidas de crecimiento el 2010, pero actualmente ha disminuido su tasa a un $6 \%$ a pesar del desempeño del año anterior. Los resultados para Europa fueron mejor de los esperados $(+6 \%)$, impulsados por la recuperación de Europa central y del este, así como la distribución temporal de destinos del Sur y el Mediterráneo. Las Américas tuvieron un crecimiento en línea con el promedio mundial $+5 \%$, con los resultados más fuertes de Sud América y el Caribe, pero un poco menor en Norte y Centro América.

De acuerdo al Barómetro Mundial del Turismo de la Organización Mundial del Turismo 2011, se estima que para el año 2010 el número internacional de llegadas de turistas alcanzó los 935 millones en el mundo, 58 millones más alto $(6,7 \%)$ que el 2009 con 877 millones y 22 millones más (2.4\%) que el pico más alto del 2008 (913 millones) antes de la crisis.

Figura 4.2. Crecimiento de llegadas internacionales de turismo (Millones)

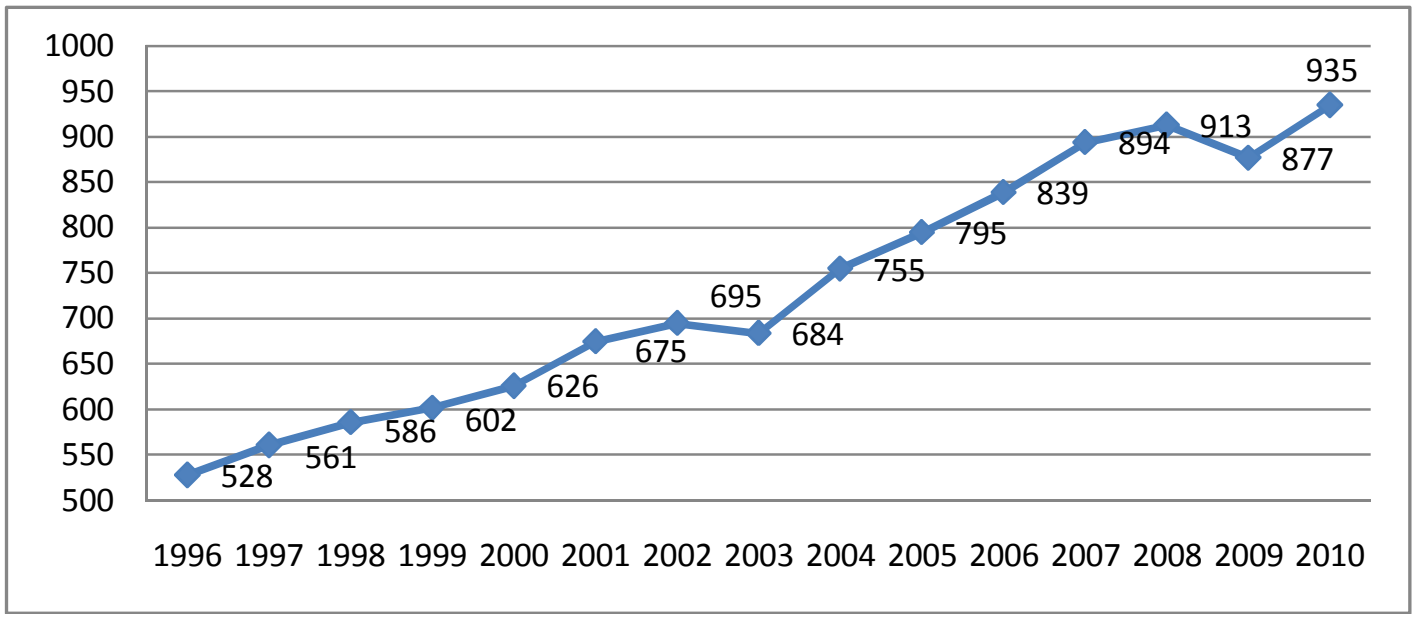




\section{Capítulo 4 Caracterización del Sector de Estudio e Instrumento de Medida}

Fuente: Elaboración propia con base en los datos del Barómetro Mundial del Turismo, OMT.

La industria del turismo tuvo una fuerte recuperación el 2010, después de la recesión y la crisis financiera global. La llegada de turistas se incremento en un 7\%, equivalente a 935 millones, después de la excepcional caída del 4\% el 2009. La recuperación principalmente se debe a economías emergentes.

En el siguiente gráfico se puede apreciar el crecimiento en los últimos cinco años por regiones, en el que se aprecia un crecimiento positivo en todas ellas.

Figura 4.3. Llegadas internacionales por regiones entre 2005 y 2010

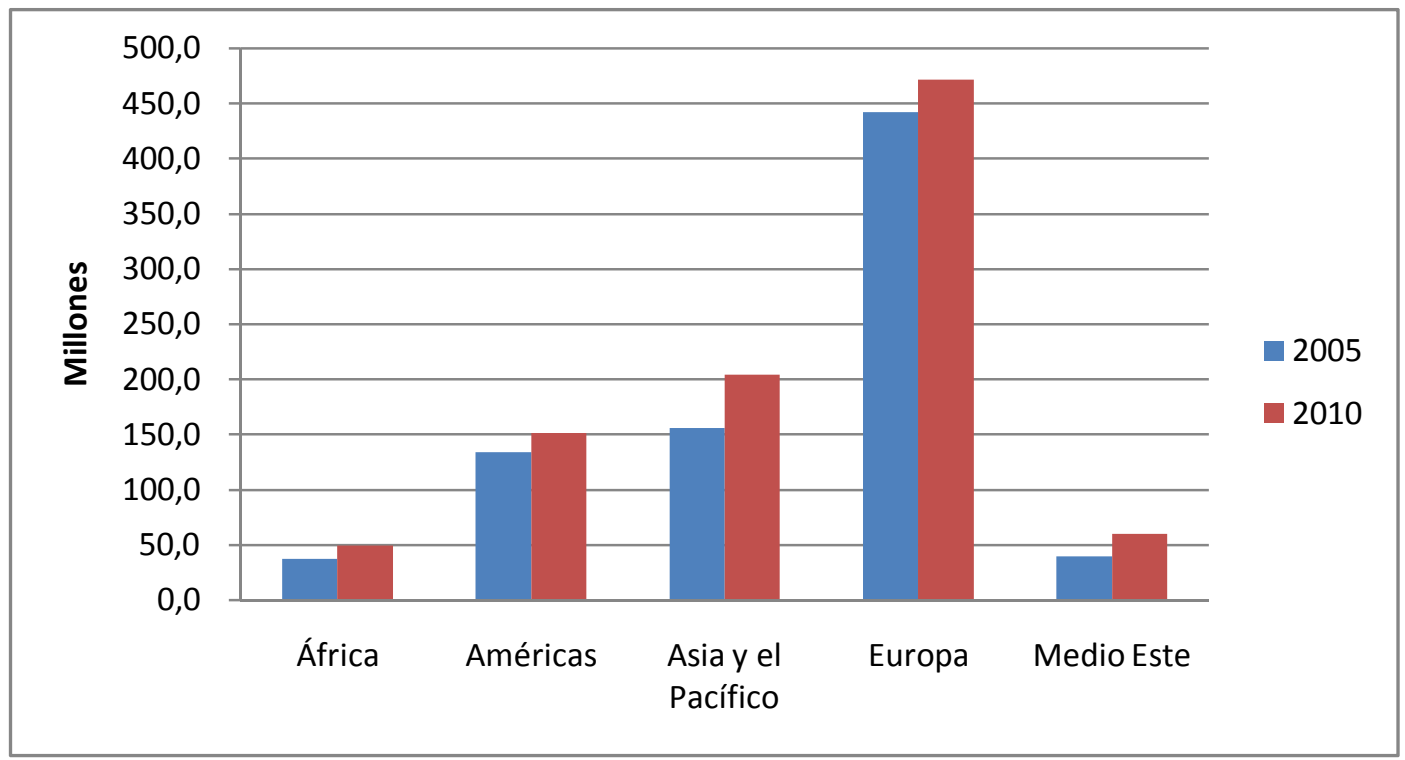

Fuente: Elaboración propia con base en los datos del Barómetro Mundial del Turismo, OMT. 


\section{Capítulo 4 Caracterización del Sector de Estudio e Instrumento de Medida}

Si bien el crecimiento del turismo es positivo en todas las regiones, algunas presentan mayores niveles de crecimiento que otras.

En el siguiente gráfico se puede apreciar que la región de Europa ha bajado su participación del $55 \%$ en el 2005 al $50 \%$ en el 2010, mientras que la región de Asia y el Pacífico han incrementado del 19\% en el 2005 al $22 \%$ en el 2010.

Figura 4.4. Participación porcentual por regiones entre 2005 y 2010

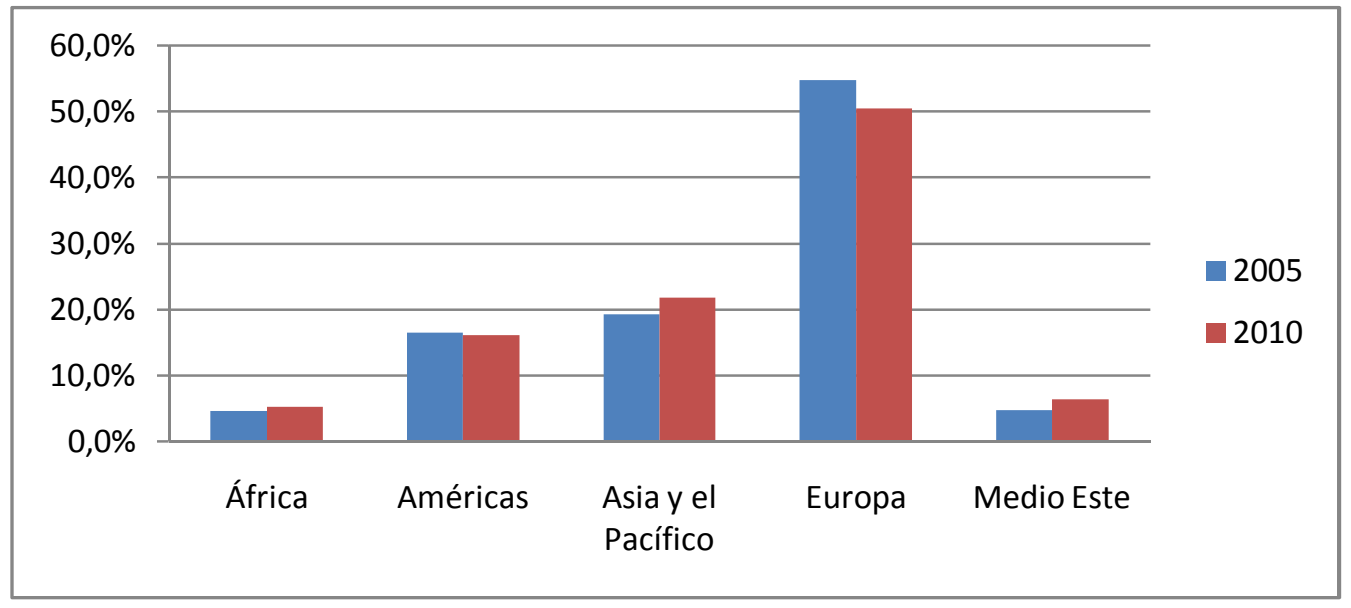

Fuente: Elaboración propia con base en los datos del Barómetro Mundial del Turismo, OMT.

La participación de la región de Europa es importante en el contexto mundial. Sin embargo, el crecimiento de las regiones de Asia y el Pacífico, así como otros destinos turísticos, han modificado la composición en los últimos años. 


\section{Capítulo 4 Caracterización del Sector de Estudio e Instrumento de Medida}

Figura 4.5. Participación por regiones 2010

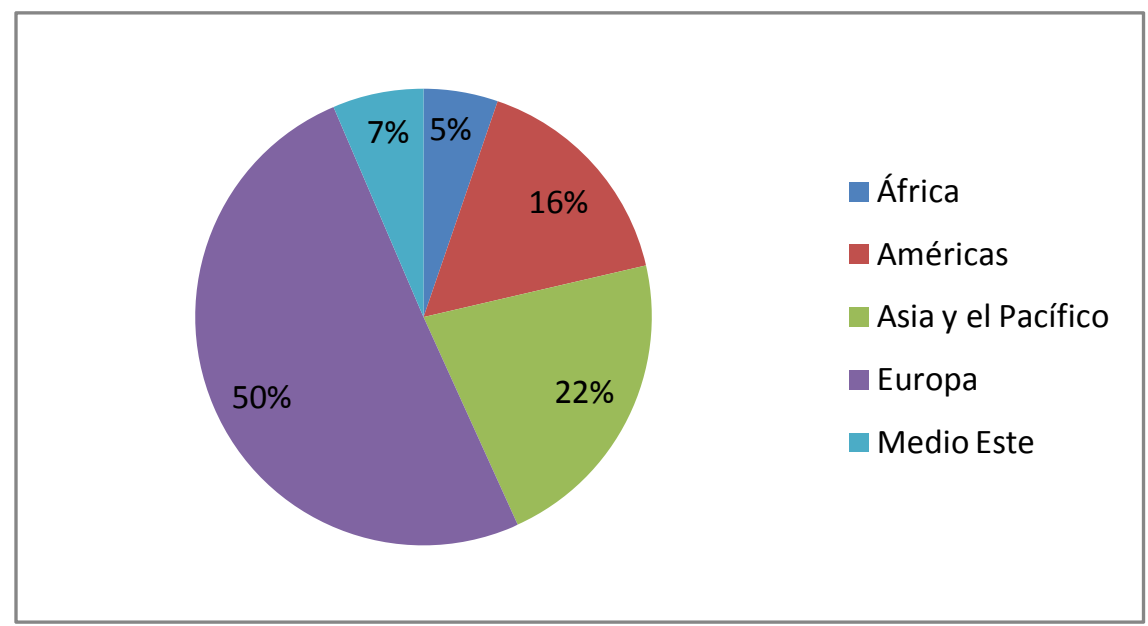

Fuente: Elaboración propia con base en los datos del Barómetro Mundial del Turismo, OMT.

En 1950 los quince destinos más importantes absorbían el 88\% de las llegadas, en 1970 ésta proporción cae al 75\% y en el 2005 al 57\%. Estos datos reflejan la aparición de nuevos destinos, muchos de ellos en países en desarrollo. En 1950 la participación de la región de Europa era del 66 \% y de la región de Asia y el Pacífico del 0,2\%.

Entre los 20 países con más llegadas de turismo internacional se encuentra España, ocupando la posición 4 el año 2010, siendo Francia el país con mayor cantidad de visitantes en el mundo.

En la tabla siguiente se presenta un resumen histórico de los 20 países con más llegadas internacionales. 
Capítulo 4 Caracterización del Sector de Estudio e Instrumento de Medida

Tabla 4.1.Países con mayor cantidad de llegadas de turismo internacional (Millones)

\begin{tabular}{|c|c|c|c|c|c|c|}
\hline Posición & País & 2000 & 2005 & 2008 & 2009 & 2010 \\
\hline 1 & Francia & 77.2 & 75.0 & 79.2 & 76.8 & .. \\
\hline 2 & Estados Unidos & 51.2 & 49.2 & 57.9 & 54.9 & .. \\
\hline 3 & China & 31.2 & 46.8 & 53.0 & 50.9 & 55.7 \\
\hline 4 & España & 46.4 & 55.9 & 57.2 & 52.2 & 52.7 \\
\hline 5 & Italia & 41.2 & 36.5 & 42.7 & 43.2 & .. \\
\hline 6 & Reino Unido & 23.2 & 28.0 & 30.1 & 28.2 &. \\
\hline 7 & Turquía & 9.6 & 20.3 & 25.0 & 25.5 & 27.0 \\
\hline 8 & Alemania & 19.0 & 21.5 & 24.9 & 24.2 & 26.9 \\
\hline 9 & Malasia & 10.2 & 16.4 & 22.1 & 23.6 & 24.6 \\
\hline 10 & México & 20.6 & 21.9 & 22.6 & 21.5 & 22.4 \\
\hline 11 & Austria & 18.0 & 20.0 & 21.9 & 21.4 & 22.0 \\
\hline 12 & Ucrania & 6.4 & 17.6 & 25.4 & 20.8 & 21.2 \\
\hline 13 & Hong Kong (China) & 8.8 & 14.8 & 17.3 & 16.9 & 20.1 \\
\hline 14 & Federación Rusa & 19.2 & 19.9 & 21.6 & 19.4 & ... \\
\hline 15 & Canadá & 19.6 & 18.8 & 17.1 & 15.7 & 16.1 \\
\hline 16 & Tailandia & 9.6 & 11.6 & 14.6 & 14.1 & 15.8 \\
\hline 17 & Grecia & 13.1 & 14.8 & 15.9 & 14.9 & . \\
\hline
\end{tabular}


Capítulo 4 Caracterización del Sector de Estudio e Instrumento de Medida

\begin{tabular}{||c|l|l|l|l|l|l||}
\hline 18 & Egipto & 5.1 & 8.2 & 12.3 & 11.9 & 14.1 \\
\hline 19 & Polonia & 17.4 & 15.2 & 13.0 & 11.9 &.. \\
\hline 20 & Arabia Saudita & 6.6 & 8.0 & 14.8 & 10.9 &.. \\
\hline
\end{tabular}

Fuente: Elaboración propia con base en los datos del Barómetro Mundial del Turismo, OMT

\subsection{EL SECTOR TURÍSTICO EN ESPAÑA}

España ha pasado del segundo destino turístico del mundo en el año 2005 al cuarto en el 2010. El primer lugar lo mantiene Francia, seguido por Estados Unidos. China ha desplazado a España del tercer lugar al cuarto el año 2010.

Figura 4.6. Llegadas de turismo internacional

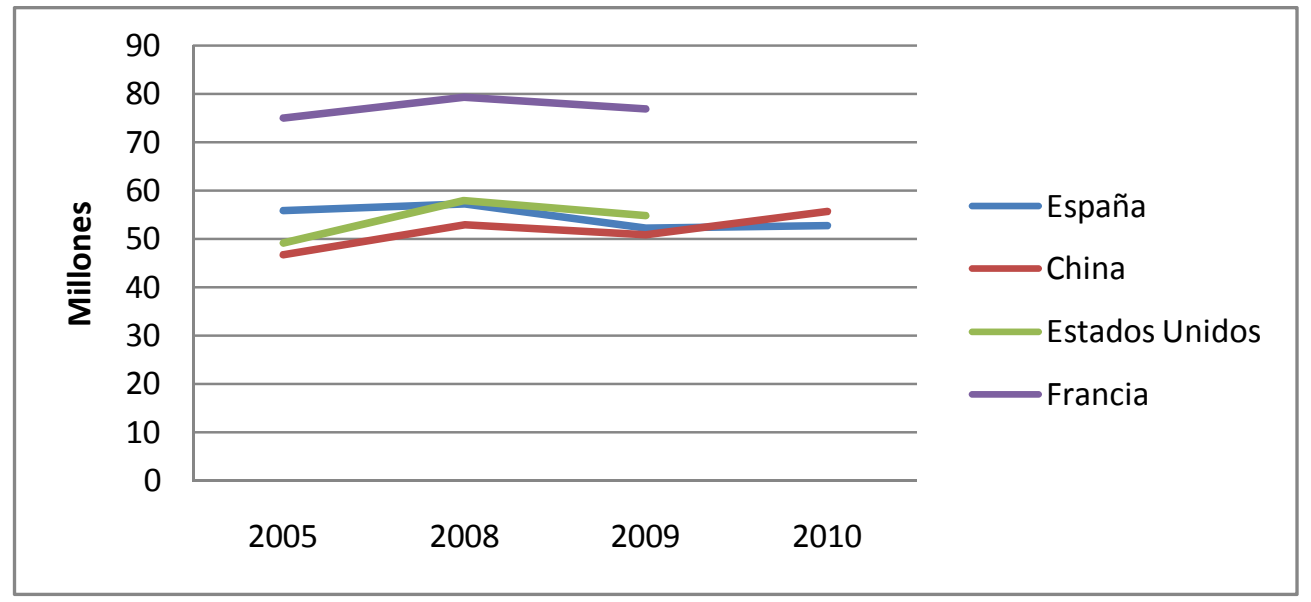

Fuente: Elaboración propia con base en los datos del Barómetro Mundial del Turismo, OMT 


\section{Capítulo 4 Caracterización del Sector de Estudio e Instrumento de Medida}

En el siguiente gráfico se presenta el Índice de Tendencia de Competitividad Turística (ITCT) que se elabora a partir de la evolución de los precios de la oferta española en relación a otros países y de la variación relativa de las tasas de cambio nominales que encontrará el turista cuando llegue a España (Balance del Turismo, 2010).

Figura 4.7. Evolución del ITCT - España

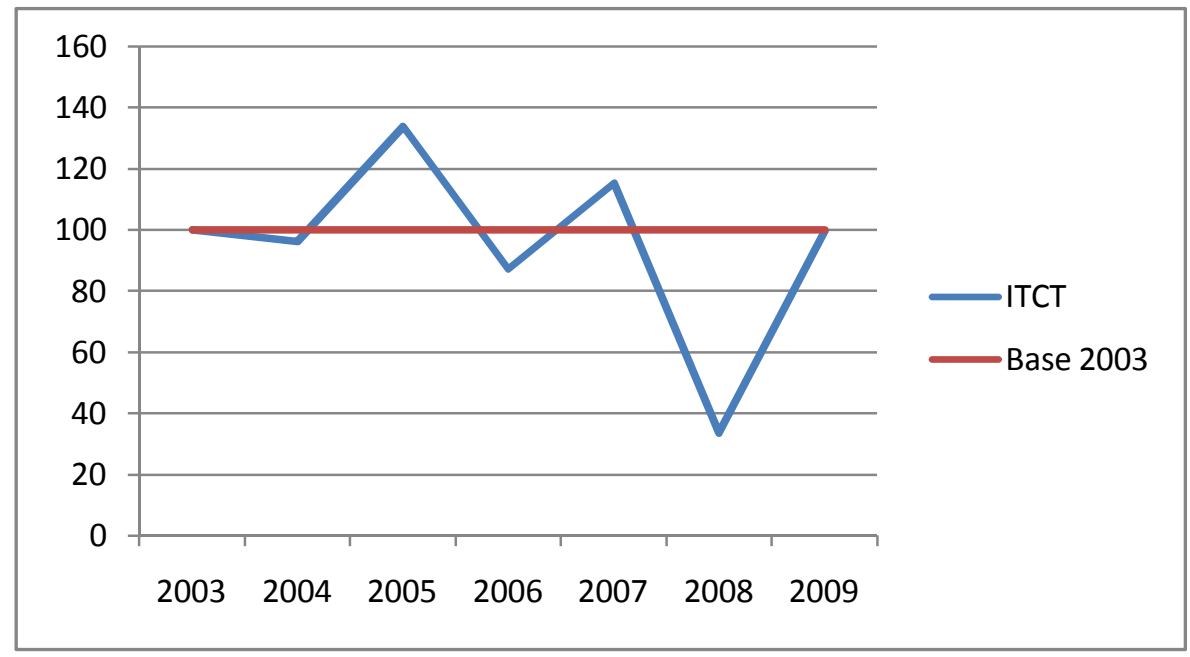

Aumento ITCT $=$ Pérdida competitiva

Disminución ITCT= Mejora competitiva

Fuente: Elaboración propia con base en los datos del Balance del Turismo, 2010

España ha disminuido su competitividad en el 2009, este resultado viene precedido de una pérdida del nivel de competitividad en los años 2005 y 2007 así como mejoras competitivas el 2003, 2006 y el 2008. 


\section{Capítulo 4 Caracterización del Sector de Estudio e Instrumento de Medida}

Entre los principales competidores mediterráneos de España, destacan Portugal, Croacia y Turquía, con incrementos del $6,0 \%, 4,8 \%$ y $5,9 \%$ respectivamente. Italia exhibe un ligero incremento del 0,9\%, al igual que Grecia con un 1,5\%.

\subsubsection{Implicaciones económicas y sociales del turismo en España}

El sector Turismo en España es muy importante por su aporte a la economía así como por su capacidad en la generación de empleo. La diferencia entre el turismo receptor y emisor es positiva, contribuyendo con ello a la balanza de pagos y al PIB con un $10 \%$ en el 2010.

Respecto a la generación de empleo, el 11,5 \% de los ocupados en la economía española lo están en alguna actividad turística ${ }^{4}$, cifra que llega a un $25 \%$ del empleo en algunas regiones (Balance del Turismo, 2011).

\footnotetext{
${ }^{4}$ Siguiendo las recomendaciones internacionales se consideran actividades características del turismo a las siguientes ramas de actividad de la CNAE 2009: 55 y 56 Hostelería, 491 Transporte interurbano de pasajeros por ferrocarril, 493 Otro transporte terrestre de pasajeros, 501 Transporte marítimo de pasajeros, 503 Transporte de pasajeros por vías navegables interiores, 511 Transporte aéreo de pasajeros, 522 Actividades anexas al transporte, 791 Actividades de agencias de viajes y operadores turísticos, 771 Alquiler de vehículos de motor, 773 Alquiler de otra maquinaria, equipos y bienes tangibles, 799 Otros servicios de reservas, 900 Actividades de creación, artísticas y espectáculos, 910 Actividades de bibliotecas, archivos, museos y otras actividades culturales, 931 Actividades deportivas, 932 Actividades recreativas y de entretenimiento. Esta aproximación constituye una infraestimación, al no considerar otras actividades económicas que en parte pueden contribuir a la actividad del sector turístico, y al tiempo, una sobreestimación en la medida en que las ramas consideradas no desarrollan su actividad exclusivamente para el sector turístico.
} 


\section{Capítulo 4 Caracterización del Sector de Estudio e Instrumento de Medida}

\subsubsection{Aporte a la economía del sector turismo}

El aporte al Producto Interno Bruto el año 2000 fue del orden del 11.6 \%. Si bien en términos absolutos ha ido creciendo hasta el año 2008, la participación porcentual en el contexto general de la economía ha ido disminuyendo, como se muestra en el siguiente gráfico.

\section{Figura 4.8. Aporte porcentual del Turismo al PIB}

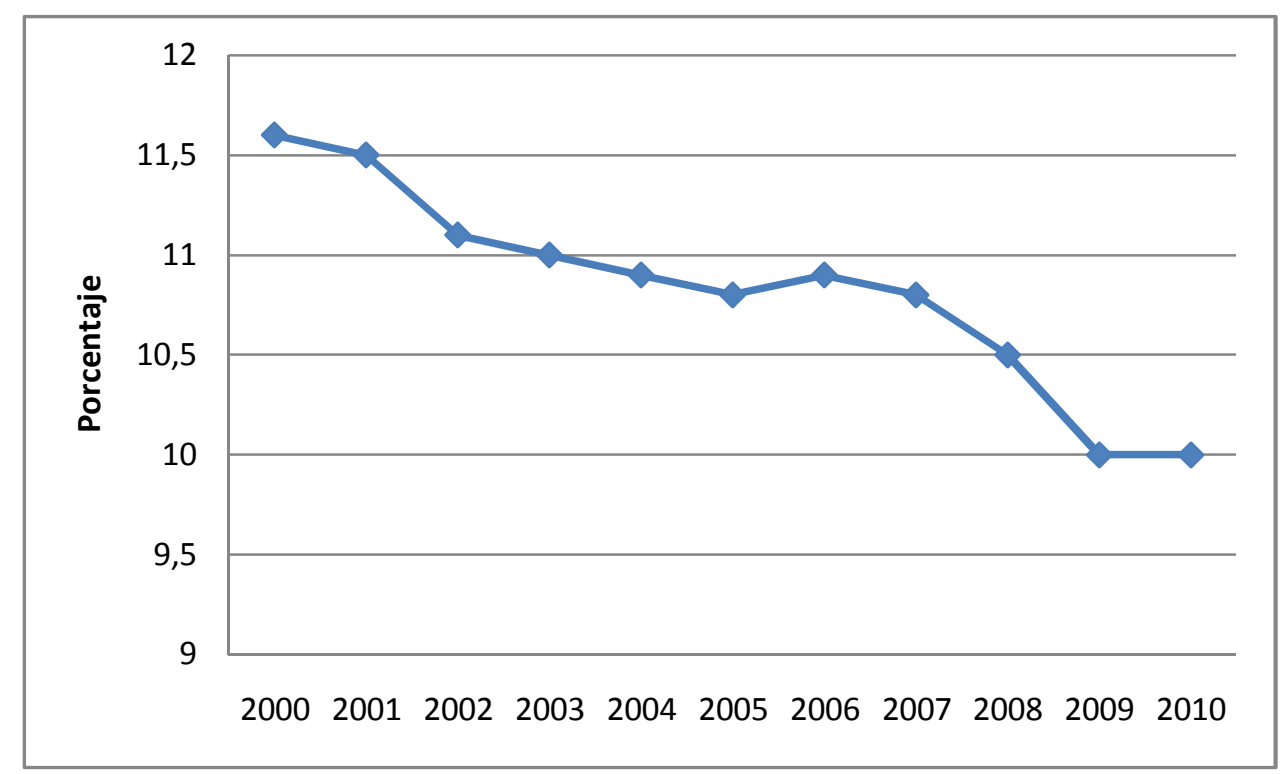

Fuente: Elaboración propia con base en datos del INE

Si bien la tendencia porcentual es decreciente, el aporte del Turismo en millones de euros presenta una tendencia creciente, tal como se puede apreciar en el siguiente gráfico. 
Capítulo 4 Caracterización del Sector de Estudio e Instrumento de Medida

Figura 4.9. Contribución del Turismo al PIB

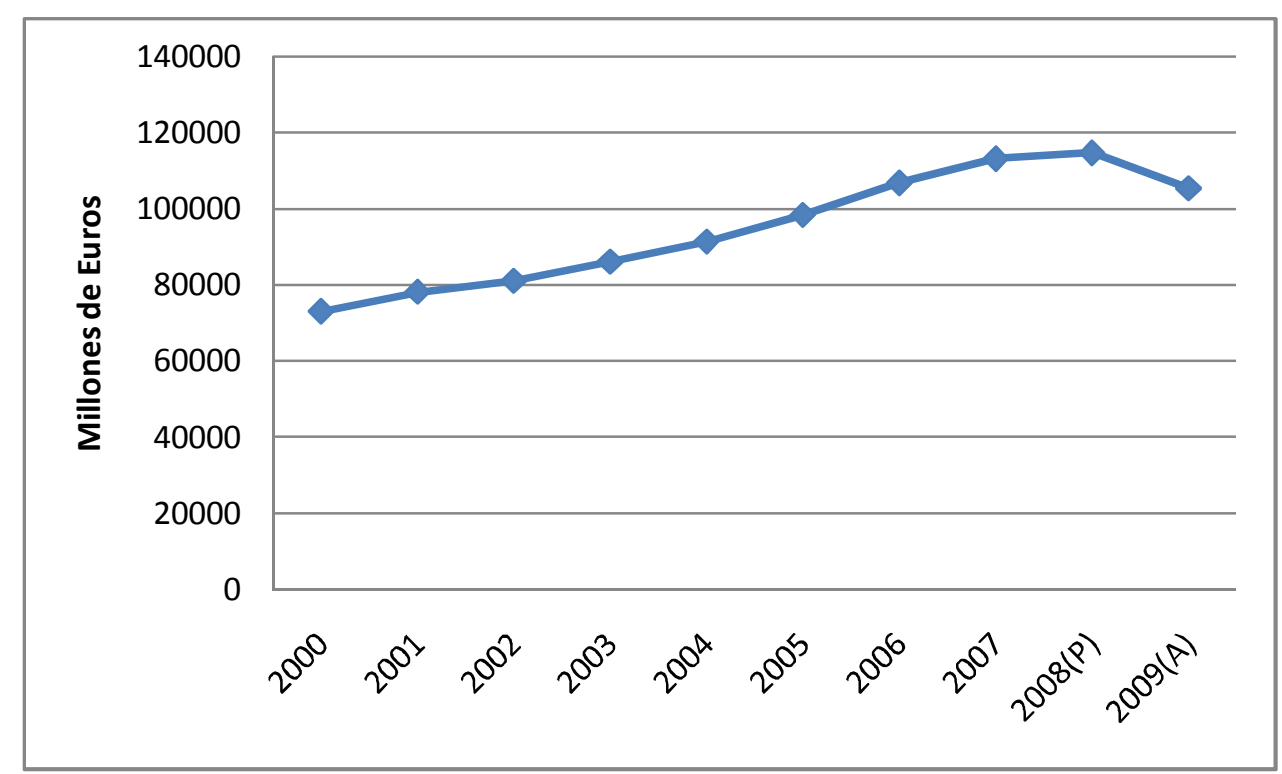

Fuente: Elaboración propia con base en datos del INE

Si se analiza la contribución por componentes, el aporte del Turismo Receptor ha disminuido frente a los otros competentes del turismo, tanto en términos porcentuales como en términos absolutos en millones de euros. 
Capítulo 4 Caracterización del Sector de Estudio e Instrumento de Medida

Tabla 4.2. Aporte de la industria del Turismo al PIB

\begin{tabular}{|c|c|c|c|c|c|c|c|c|c|c|}
\hline & \multicolumn{10}{|c|}{ Millones de Euros } \\
\hline & 2000 & 2001 & 2002 & 2003 & 2004 & 2005 & 2006 & 2007 & $\begin{array}{c}2008 \\
(\mathbf{P})\end{array}$ & $\begin{array}{c}2009 \\
\text { (A) }\end{array}$ \\
\hline $\begin{array}{l}\text { Turismo } \\
\text { receptor }\end{array}$ & 36415 & 38573 & 38261 & 39683 & 41432 & 44155 & 47122 & 49230 & 49937 & 43966 \\
\hline $\begin{array}{l}\text { Otros } \\
\text { compo- } \\
\text { nentes del } \\
\text { turismo }\end{array}$ & 36574 & 39499 & 42751 & 46370 & 49964 & 54236 & 59707 & 63982 & 64800 & 61428 \\
\hline \multirow[t]{2}{*}{ Total } & 72988 & 78072 & 81012 & 86053 & 91396 & 98390 & 106829 & 113212 & 114737 & 105394 \\
\hline & \multicolumn{10}{|c|}{ 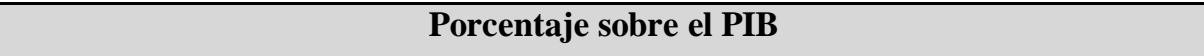 } \\
\hline $\begin{array}{l}\text { Turismo } \\
\text { receptor }\end{array}$ & 5,8 & 5,7 & 5,2 & 5,1 & 4,9 & 4,9 & 4,8 & 4,7 & 4,6 & 4,2 \\
\hline $\begin{array}{l}\text { Otros } \\
\text { compo- } \\
\text { nentes } \\
\text { del } \\
\text { turismo }\end{array}$ & 5,8 & 5,8 & 5,9 & 5,9 & 5,9 & 6 & 6,1 & 6,1 & 6 & 5,8 \\
\hline Total & 11,6 & 11,5 & 11,1 & 11 & 10,9 & 10,8 & 10,9 & 10,8 & 10,5 & 10 \\
\hline
\end{tabular}

(P): Estimación provisional (A): Estimación avance

Fuente: Elaboración Propia con base en datos del INE 


\section{Capítulo 4 Caracterización del Sector de Estudio e Instrumento de Medida}

Como se aprecia en el siguiente gráfico, en el año 2000 el aporte del turismo receptor y otros componentes del turismo era similar en términos porcentuales (5.8\%) y absolutos. El año 2009 el turismo receptor bajo su participación al 4.2 $\%$.

Figura 4.10. Turismo Receptor Vs. otros componentes del Turismo

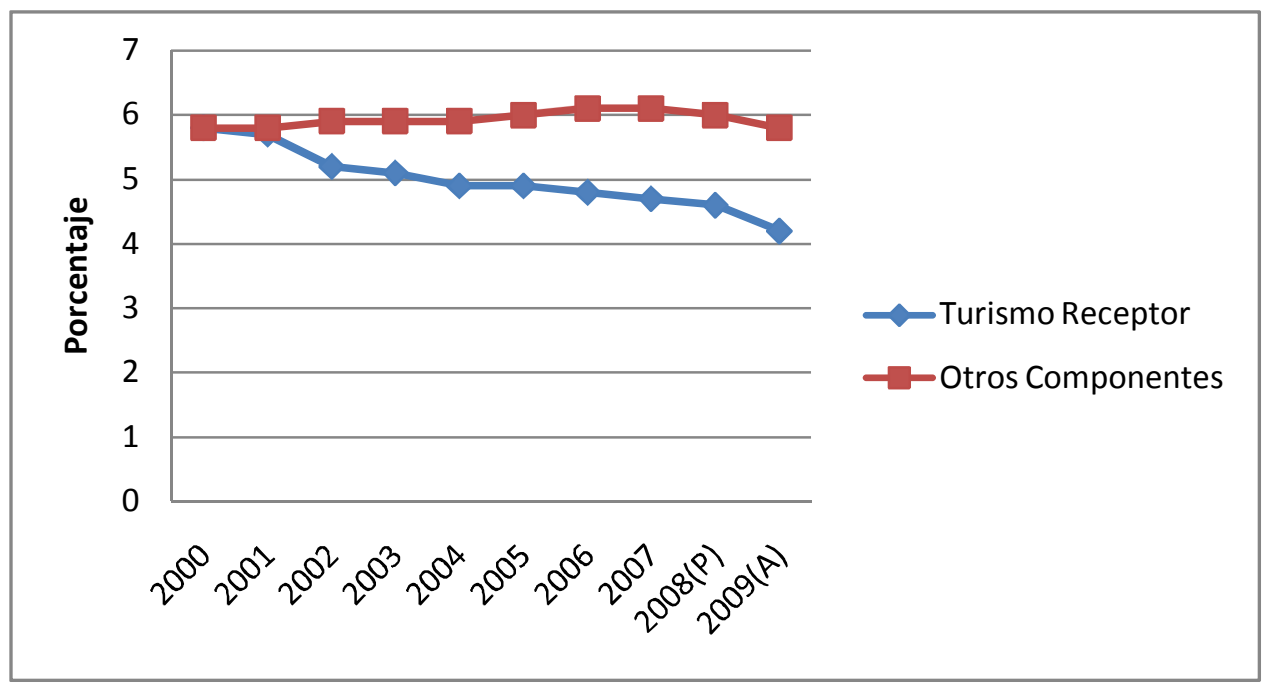

Fuente: Elaboración Propia con base en datos del INE

\subsubsection{Aporte del sector turismo a la generación de empleo}

En España el turismo es un sector estratégico y vital para la economía y la sociedad. En el 2010 los trabajadores activos en el sector del turismo fueron 2.488.525, equivalente a un $10,8 \%$ de los 23,1 millones de trabajadores. De este total, 14.8 millones pertenecen al sector servicios, por lo que el aporte del turismo en este sector representa el $16,8 \%$. 


\section{Capítulo 4 Caracterización del Sector de Estudio e Instrumento de Medida}

Los ocupados en turismo descendieron en un 1,1\% entre el 2009 al 2010, esto debido a la caída en servicios de comidas y bebidas $(-4,7 \%)$.

En el siguiente gráfico se presenta el aporte porcentual de la industria del turismo por ramas de actividad en la generación de empleo.

Figura 4.11. Empleo en el sector Turismo por ramas de actividad

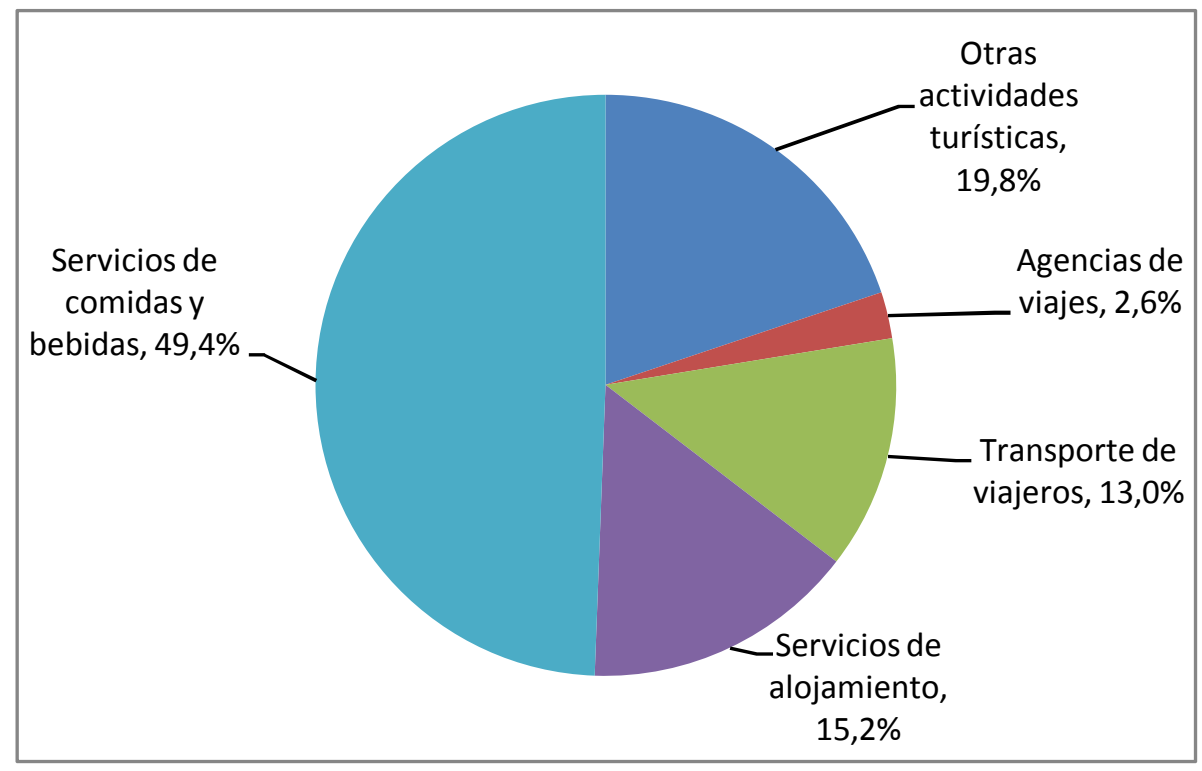

Fuente: Elaboración Propia con base en datos de la EPA 2010

Como se aprecia en el gráfico anterior, cerca a dos terceras partes del empleo en el sector turismo se concentra en las actividades de comidas y bebidas (49.4\%) y alojamiento (15.2\%). 


\section{Capítulo 4 Caracterización del Sector de Estudio e Instrumento de Medida}

Un aspecto importante para el análisis del empleo del sector turismo, es la relación entre los trabajadores asalariados y autónomos. Los asalariados representan el $78.2 \%$ del total de ocupados en las actividades turísticas. De acuerdo a los datos del Balance en Turismo los asalariados el año 2010 fueron 1.657.526, registrándose un descenso del $1.7 \%$ respecto al año anterior.

Figura 4.12. Relación asalariados Vs. cuenta propia

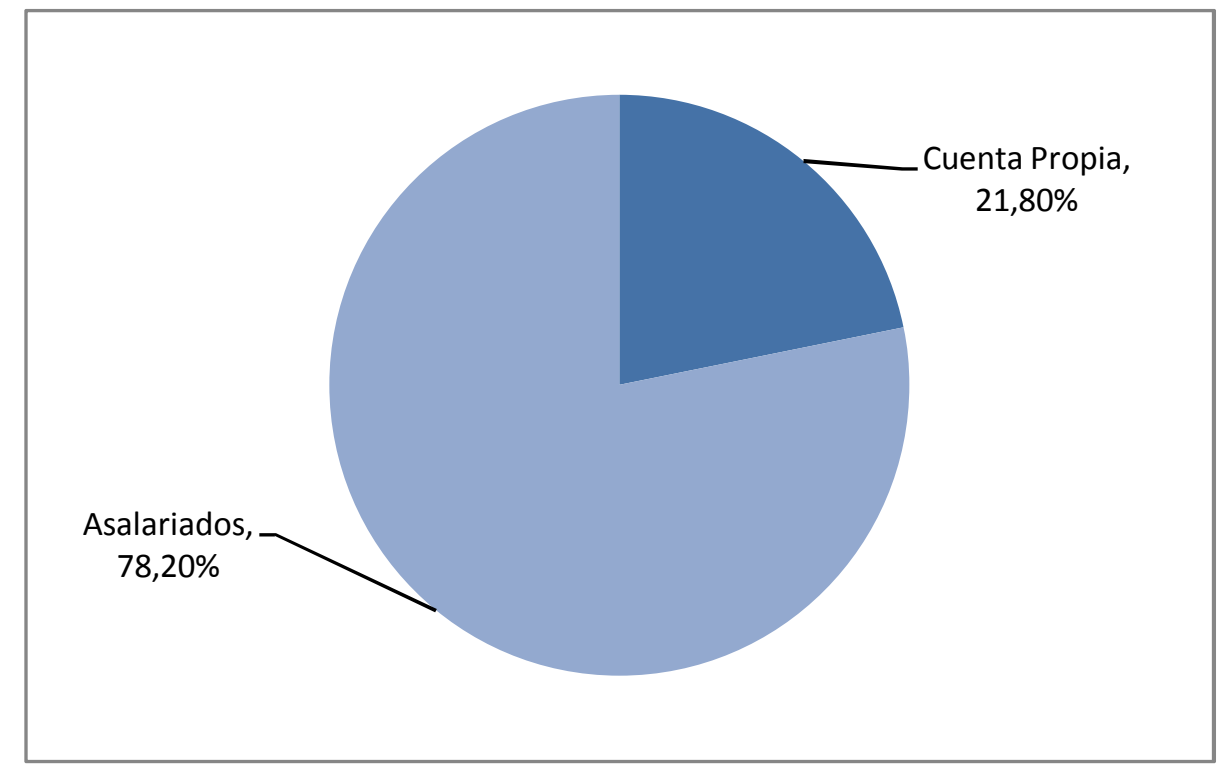

Fuente: Elaboración Propia con base en datos de la EPA, 2010

En la rama de servicios de alojamiento, el número de trabajadores asalariados se incremento en un 2,5\% el año 2010. El empleo asalariado es el más prevalente, sobre todo en los servicios de alojamiento, llegando al 93,9\%, mientras que otras 


\section{Capítulo 4 Caracterización del Sector de Estudio e Instrumento de Medida}

ramas del sector, como en el de los servicios de comidas y bebidas, el porcentaje de asalariados es del 70,5\%.

De acuerdo a los datos de la Seguridad Social en España del año 2010, la distribución porcentual de los afiliados en el sector turístico está concentrado principalmente en la rama de la hostelería, con un $66,1 \%$ del total de afiliados en la industria del turismo.

Figura 4.13. Afiliados en el sector turístico por ramas de actividad

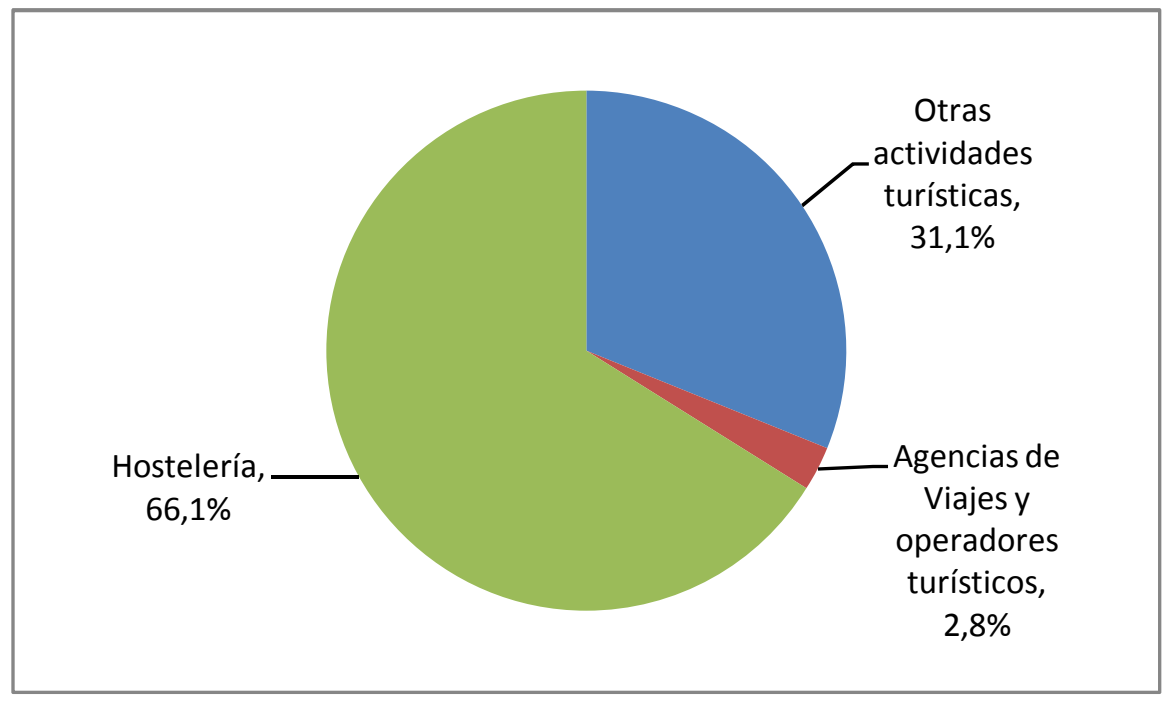

Fuente: Elaboración propia del IET a partir datos de Seguridad Social (MTIN) 


\subsection{EL SECTOR HOTELERO}

Como se ha presentado en el segundo epígrafe, la región de Europa ha sido el destino elegido por gran parte del turismo mundial. Sin embargo, los cambios experimentados en las comunicaciones, el transporte (en especial el aéreo), han propiciado la aparición y expansión de nuevos destinos turísticos en América, Asia y El Pacífico.

Los nuevos destinos turísticos han generado un incremento en la capacidad hotelera, particularmente en Sudamérica, el este y sur de Asia y Oriente Próximo. En consecuencia, la región de Europa ha perdido cuota en el mercado mundial (Rincón, 2006).

El desempeño del sector hotelero puede ser medido mediante la tasa de ocupación ${ }^{5}$. En este sentido, el año 2010 el sector a nivel mundial presentó un alza en la tasa de ocupación; destacan las regiones de Asia y el Pacífico, con una variación porcentual del 6,6\% con relación al 2009, seguido de África del Norte $(6,2 \%)$ y América Central y del Sur (5.4\%). Las regiones que bajaron su tasa de ocupación fueron África Austral y Oriente Medio, con tasas del -2.2\% y -1.1\% respectivamente.

\footnotetext{
${ }^{5}$ Tasa de Ocupación Hotelera: Es el cociente entre el número de pernoctaciones producidas en un período de referencia y el número total de plazas disponibles por día en ese mismo período. De esta definición se puede obtener una tasa de ocupación superior al 100\%, debido a la existencia de camas supletorias o convertibles, ya que el ocupante de una de estas plazas, produce una pernoctación, pero no ocupa una plaza. Por el contrario, también puede ocurrir que un establecimiento no tuviese habitaciones libres con una tasa de ocupación inferior al 100\%, al estar algunas habitaciones o apartamentos ocupados por menos personas que las que le corresponden.
} 
Capítulo 4 Caracterización del Sector de Estudio e Instrumento de Medida

Tabla 4.3. Tasa de ocupación por regiones

\begin{tabular}{|l|c|c|c||}
\hline Regiones & $\mathbf{2 0 1 0}$ & $\mathbf{2 0 0 9}$ & $\begin{array}{c}\text { Variación } \\
(\mathbf{\%})\end{array}$ \\
\hline Europa & 57 & 54 & 2,3 \\
\hline África del Norte & 70 & 64 & 6,2 \\
\hline África Austral & 57 & 59 & $-2,2$ \\
\hline Oriente Medio & 64 & 65 & $-1,1$ \\
\hline Asia y el Pacífico & 64 & 57 & 6,6 \\
\hline América del Norte & 54 & 52 & 1,5 \\
\hline América Central y del Sur & 63 & 57 & 5,4 \\
\hline Total & $\mathbf{6 1}$ & $\mathbf{5 8}$ & $\mathbf{2 , 7}$ \\
\hline
\end{tabular}

Fuente: Elaboración propia con datos de la Organización Mundial del Turismo

Haciendo un análisis por países y ciudades, Francia presenta la tasa de ocupación más alta, con un 77,1\%. Resaltan el alza de Israel, con 11,7\% y Turquía, con 9,2\% en relación al 2009. Los países que registraron una baja en la tasa de ocupación fueron Grecia, Islandia y Noruega.

Entre los 10 países con las tasas de ocupación más altas, se encuentra España. De las dos ciudades españolas para las cuales se calcula la tasa de ocupación, Barcelona ocupa la novena posición y Madrid la posición 20, con tasas de ocupación del 69,1\% y 64,2\% respectivamente. 
Capítulo 4 Caracterización del Sector de Estudio e Instrumento de Medida

Tabla 4.4. Tasa de ocupación por ciudades

\begin{tabular}{|c|c|c|c|c|c|}
\hline Posición & País & $\overline{\text { Ciudad }}$ & 2010 & 2009 & $\begin{array}{c}\text { Cambio } \\
\%\end{array}$ \\
\hline 1 & Francia & Paris & 77,1 & 74,2 & 3 \\
\hline 2 & Israel & Tel Aviv & 76,4 & 64,7 & 11,7 \\
\hline 3 & Países Bajos & Amsterdam & 75,2 & 67,3 & $\overline{7,9}$ \\
\hline 4 & Turquía & Estambul & 73,8 & 64,5 & 9,2 \\
\hline 5 & Suiza & Zurich & 73,6 & 69 & 4,6 \\
\hline 6 & Austria & Viena & 73 & 65,3 & 7,7 \\
\hline 7 & Suecia & Estocolmo & 70,6 & 68,3 & 2,3 \\
\hline 8 & Alemania & Berlin & 70,2 & 68,4 & 1,8 \\
\hline 9 & España & Barcelona & 69,1 & 63,9 & 5,2 \\
\hline 10 & Luxembourg & Luxembourg & 68,7 & 63,8 & 4,9 \\
\hline 11 & Italia & Roma & 68 & 62,6 & 5,4 \\
\hline 12 & Irlanda & Dublín & 67,7 & 64,4 & $\overline{3,4}$ \\
\hline 13 & Finlandia & Helsinki & 67,3 & 60,8 & 6,5 \\
\hline 14 & Bélgica & Bruselas & 67,3 & 63,5 & 3,8 \\
\hline 15 & Polonia & Varsovia & 67,3 & 61,1 & 6,2 \\
\hline 16 & Suiza & Ginebra & 66,5 & 62,4 & 4 \\
\hline 17 & Alemania & Frankfurt & 66,1 & 58,3 & 7,8 \\
\hline 18 & Portugal & Lisboa & 65,7 & 60 & 5,7 \\
\hline
\end{tabular}


Capítulo 4 Caracterización del Sector de Estudio e Instrumento de Medida

\begin{tabular}{||c|l|c|c|c|r||}
\hline \hline Posición & \multicolumn{1}{|c|}{ País } & Ciudad & $\mathbf{2 0 1 0}$ & $\mathbf{2 0 0 9}$ & $\begin{array}{c}\text { Cambio } \\
\text { \% }\end{array}$ \\
\hline 19 & Dinamarca & Copenhagen & 65,6 & 63,3 & 2,4 \\
\hline 20 & España & Madrid & 64,2 & 57,6 & 6,6 \\
\hline 21 & $\begin{array}{l}\text { República } \\
\text { Checa }\end{array}$ & Praga & 63 & 57,1 & 5,9 \\
\hline 22 & $\begin{array}{l}\text { Federación } \\
\text { Rusa }\end{array}$ & Moscow & 62,9 & 57,3 & 5,6 \\
\hline 23 & Noruega & Oslo & 62,3 & 63,8 & $-1,6$ \\
\hline 24 & Italia & Milan & 62,1 & 57,6 & 4,5 \\
\hline 25 & Grecia & Atenas & 59,3 & 62 & $-2,8$ \\
\hline 26 & Hungría & Budapest & 59,1 & 54,1 & 5 \\
\hline 27 & Reino Unido & Londres & 56,9 & 53,5 & 3,4 \\
\hline 28 & Estonia & Tallin & 55,4 & 48,1 & 7,3 \\
\hline 29 & Islandia & Reykjavik & 54,8 & 59 & $-4,3$ \\
\hline 30 & Eslovaquia & Bratislava & 42,9 & 42,5 & 0,5 \\
\hline & & & & & 5 \\
\hline
\end{tabular}

Fuente: Elaboración propia con datos de la Organización Mundial del Turismo 


\section{Capítulo 4 Caracterización del Sector de Estudio e Instrumento de Medida}

\subsubsection{El sector hotelero en España}

El número de hoteles y establecimientos similares españoles, en el año 2000 representaba el $7.8 \%$ del total de la Unión Europea. Como se puede apreciar en la figura siguiente, el porcentaje de participación de España se ha ido incrementando llegando al $9 \%$ en el año 2009.

\section{Figura 4.14. Relación porcentual del Sector Hotelero Español dentro de la} Unión Europea

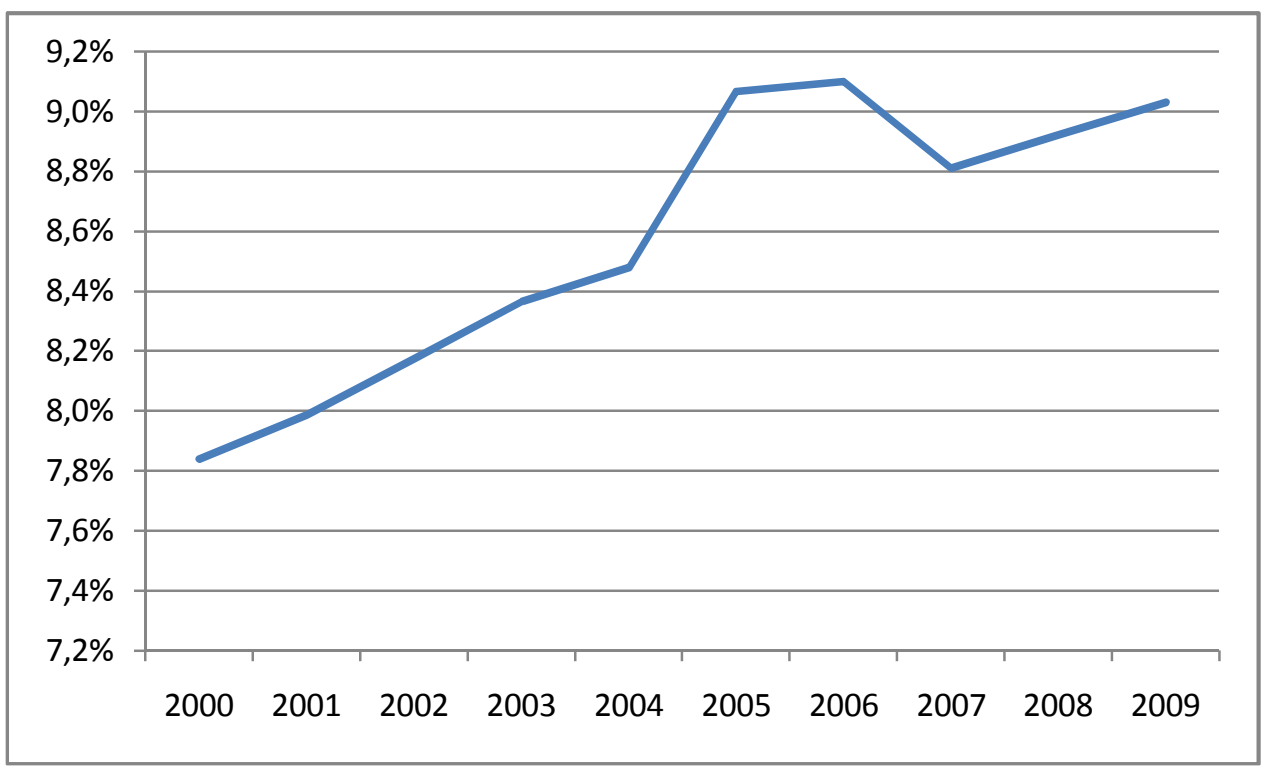

Fuente: Elaboración propia con base en los datos de Eurostat 2011 


\section{Capítulo 4 Caracterización del Sector de Estudio e Instrumento de Medida}

Respecto a las plazas en hoteles y establecimientos similares, el año 2000 España representaba el 12,4 \% respecto a la Unión Europea. El porcentaje de participación se ha incrementado llegando al $14.1 \%$ el año 2009.

Figura 4.15. Número de plazas en España dentro de la Unión Europea

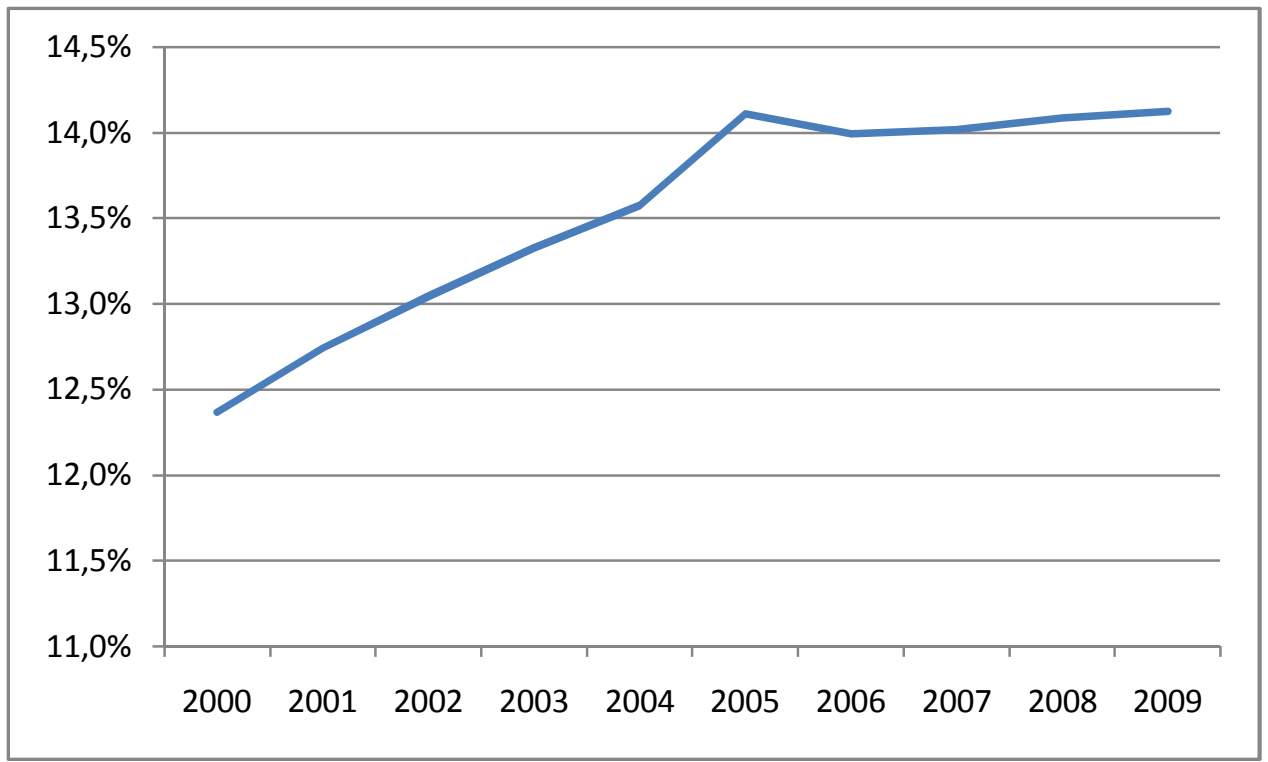

Fuente: Elaboración propia con base en los datos de Eurostat 2011

\subsubsection{Clasificación de Hoteles}

No existe una clasificación estandar de los hoteles, la misma puede variar de un país a otro en función al grado de confort, posicionamiento y nivel de servicios que ofrecen. 


\section{Capítulo 4 Caracterización del Sector de Estudio e Instrumento de Medida}

En España, cada Gobierno Autónomo tiene su propia legislación sobre la clasificación de hoteles, de acuerdo a la Confederación Española de Hoteles y Alojamientos Turísticos (CEHAT) ${ }^{6}$. En la práctica, las diferencias en las legislaciones de los Gobiernos Autónomos son mínimas, debiendo los establecimientos cumplir con requerimientos básicos por categoría:

- UNA ESTRELLA: Habitación doble de $12 \mathrm{~m}^{2}$ mínimo, habitación individual de $7 \mathrm{~m}^{2}$ mínimo, cuarto de baño (baño ó ducha) de $3,5 \mathrm{~m}^{2}$ mínimo, calefacción y ascensor.

- DOS ESTRELLAS: Habitación doble de $14 \mathrm{~m}^{2}$ mínimo, habitación individual de $7 \mathrm{~m}^{2}$ mínimo, cuarto de baño (baño ó ducha) de $3,5 \mathrm{~m}^{2}$ mínimo, teléfono en habitación, calefacción, ascensor y servicio de caja de seguridad.

- TRES ESTRELLAS: Habitación doble de $15 \mathrm{~m}^{2}$ mínimo, habitación individual de $8 \mathrm{~m}^{2}$ mínimo, cuarto de baño (baño o ducha) de $4 \mathrm{~m}^{2}$ mínimo, teléfono en habitación, calefacción, aire acondicionado en zonas comunes, ascensor, bar y servicio de caja de seguridad.

- CUATRO ESTRELLAS: Habitación doble de $16 \mathrm{~m}^{2}$ mínimo, habitación individual de $9 \mathrm{~m}^{2}$ mínimo, cuarto de baño (baño y ducha) de $4,5 \mathrm{~m}^{2}$ mínimo, teléfono en habitación, calefacción, aire acondicionado en habitación, ascensor, bar y caja fuerte en habitación.

- CINCO ESTRELLAS: Habitación doble de $17 \mathrm{~m}^{2}$ mínimo, habitación individual de $10 \mathrm{~m}^{2}$ mínimo, cuarto de baño (baño y ducha) de $5 \mathrm{~m}^{2}$

\footnotetext{
${ }^{6}$ www.cehat.com
} 


\section{Capítulo 4 Caracterización del Sector de Estudio e Instrumento de Medida}

mínimo, teléfono en habitación, calefacción, aire acondicionado en habitación, ascensor, bar y caja fuerte en habitación.

\subsubsection{Crecimiento y distribución de Hoteles}

En el período de 1999 al 2009, el número de establecimientos se ha incrementado. El año 1999 se tenían registradas en el Directorio Central de Empresas, 12.531 empresas clasificadas como hoteles de acuerdo a su actividad principal. Esta cifra, 10 años más tarde, alcanza a 14.960 empresas.

\section{Figura 4.16. Crecimiento del número de Hoteles}

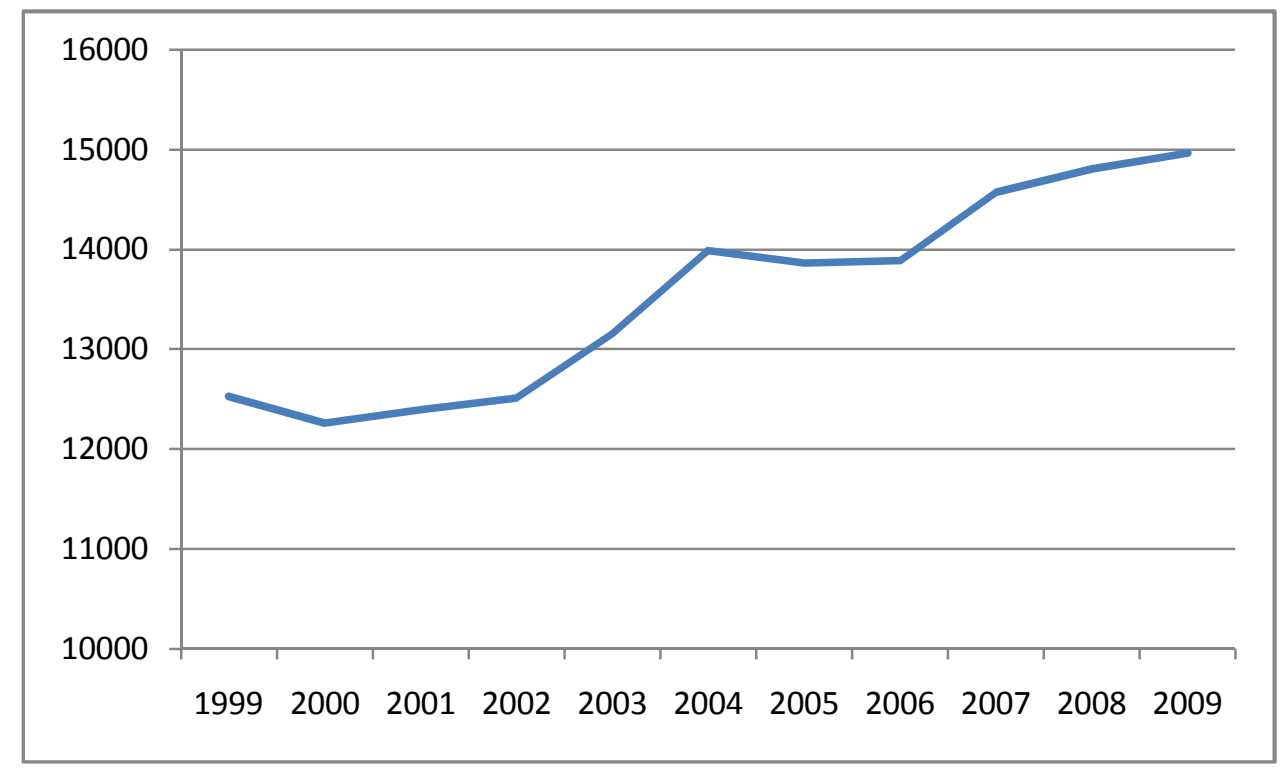

Fuente: Elaboración propia con base en los datos del Directorio Central de Empresas, INE 


\section{Capítulo 4 Caracterización del Sector de Estudio e Instrumento de Medida}

\subsubsection{Número de Hoteles por Comunidades Autónomas}

Al año 2009 más del $30 \%$ del total de empresas se encontraban concentradas en las comunidades de Cataluña (2044), Andalucía (1836) y la Comunidad de Madrid (1180).

Figura 4.17. Hoteles por Comunidades Autónomas en el 2009

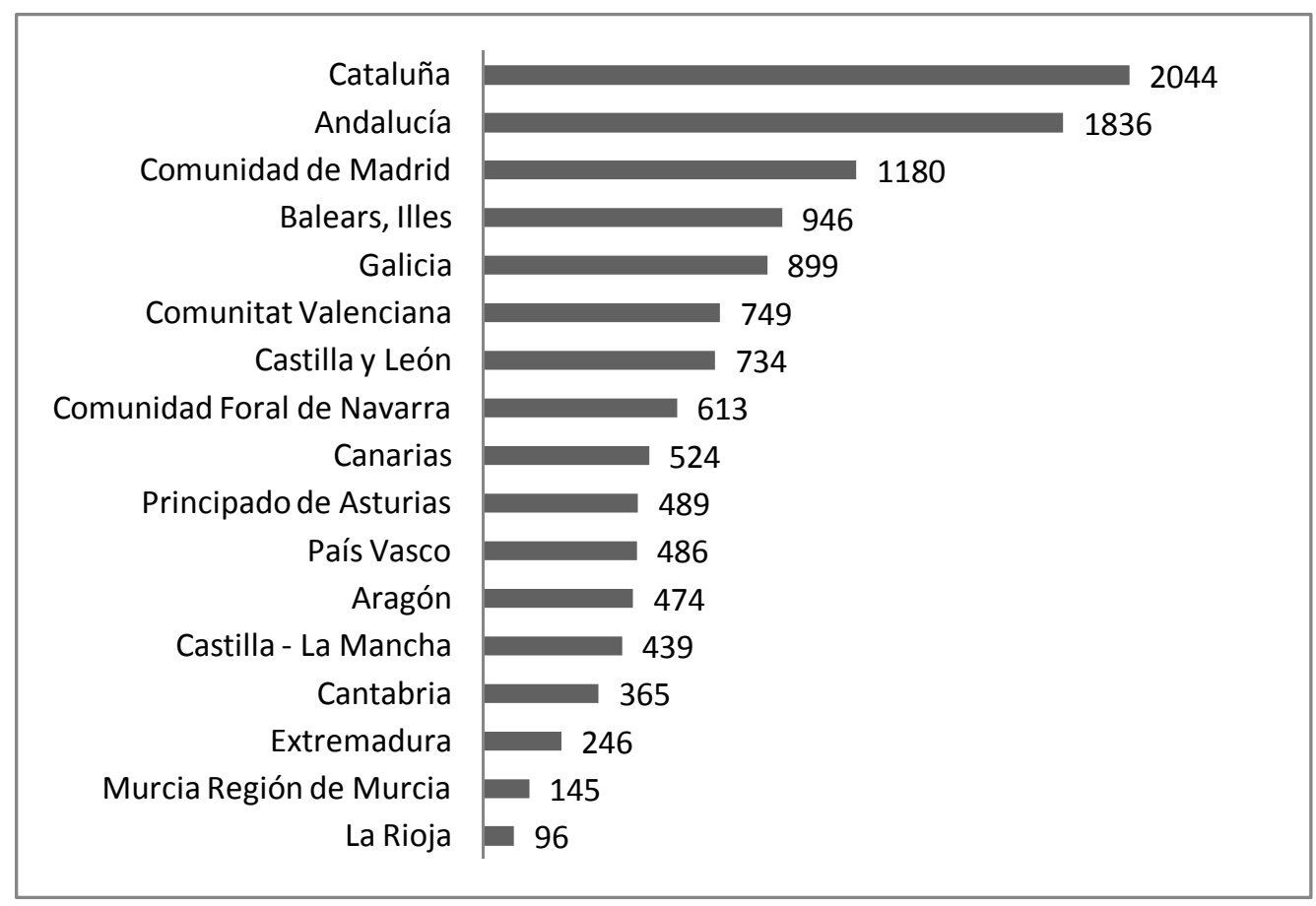

Fuente: Elaboración propia con base en los datos del Directorio Central de Empresas, INE

La mayor parte de hoteles corresponden a la categoría de tres estrellas (33\%), seguido de los hoteles de dos y cuatro estrellas. 


\section{Capítulo 4 Caracterización del Sector de Estudio e Instrumento de Medida}

Figura 4.18. Hoteles por Categoría en el 2010

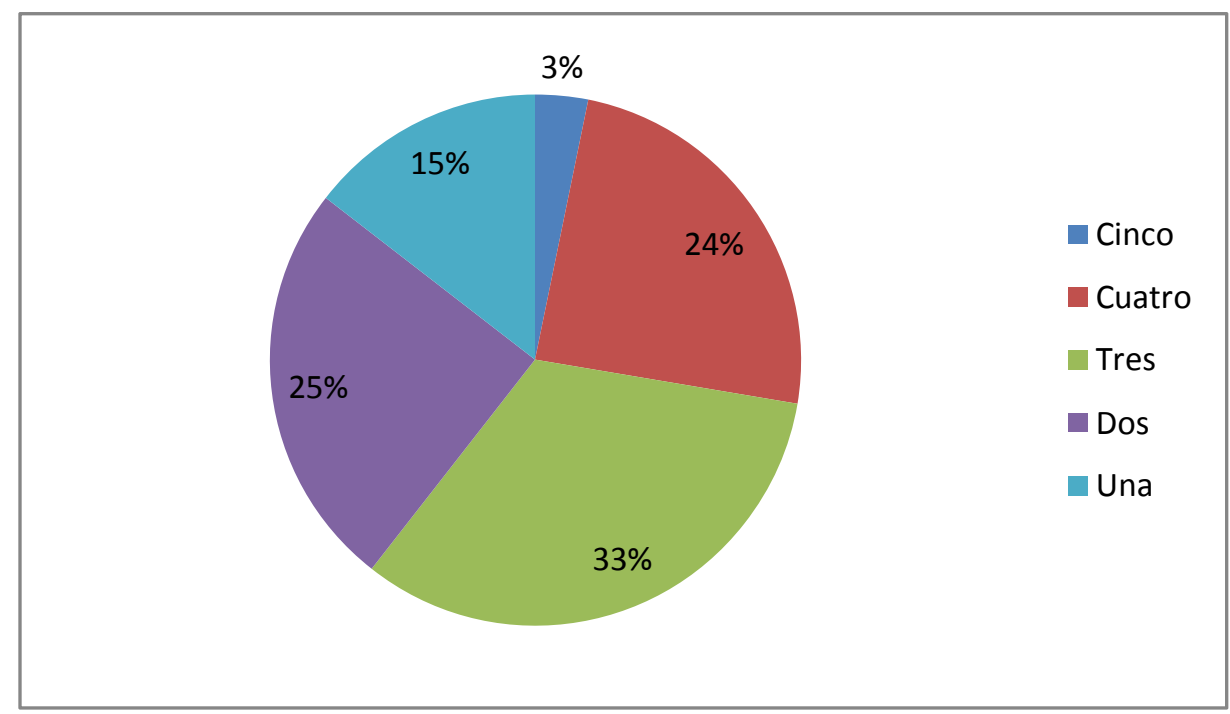

Fuente: Elaboración propia con base en los datos de la Encuesta de Ocupación Hotelera, INE

Los hoteles de 5 estrellas, en cantidad de establecimientos, representan el 3\%, y tienen en promedio 334 plazas $^{7}$, seguido de los hoteles de cuatro estrellas, con 298 plazas y los hoteles de tres, con 172 plazas.

Tabla 4.5. Oferta por categorías 2010

\begin{tabular}{||l|c|c|c|c|c||}
\hline Categorías & $\begin{array}{c}\text { Número } \\
\text { de Hoteles }\end{array}$ & $\begin{array}{c}\text { \% Número } \\
\text { de Hoteles }\end{array}$ & $\begin{array}{c}\text { Número de } \\
\text { Plazas }\end{array}$ & $\begin{array}{c}\text { \% Número } \\
\text { de Plazas }\end{array}$ & $\begin{array}{c}\text { Promedio de } \\
\text { plazas por Hotel }\end{array}$ \\
\hline Cinco & 239 & $3 \%$ & 79.588 & $7 \%$ & 334 \\
\hline Cuatro & 1.832 & $24 \%$ & 546.001 & $45 \%$ & 298 \\
\hline
\end{tabular}

\footnotetext{
${ }^{7}$ El número de plazas promedio se ha calculado como la media entre el número de plazas, sobre el número de establecimientos por categoría.
} 
Capítulo 4 Caracterización del Sector de Estudio e Instrumento de Medida

\begin{tabular}{||l|c|c|c|c|c||}
\hline Tres & 2.467 & $33 \%$ & 423.180 & $35 \%$ & 172 \\
\hline Dos & 1.863 & $25 \%$ & 116.013 & $10 \%$ & 62 \\
\hline Una & 1.087 & $15 \%$ & 52.051 & $4 \%$ & 48 \\
\hline & $\mathbf{7 4 8 8 , 1 7}$ & $\mathbf{1 0 0 \%}$ & $\mathbf{1 . 2 1 6 . 8 3 2}$ & $\mathbf{1 0 0 \%}$ & \multicolumn{1}{|l}{} \\
\cline { 2 - 5 } & & & & & \\
\hline
\end{tabular}

Fuente: Elaboración propia con base en los datos de la Encuesta de Ocupación Hotelera, INE

El $80 \%$ de la oferta de plazas se concentra en los hoteles cuatro y tres estrellas, como se muestra en la siguiente figura.

Figura 4.19. Porcentaje de Hoteles y Plazas - 2010

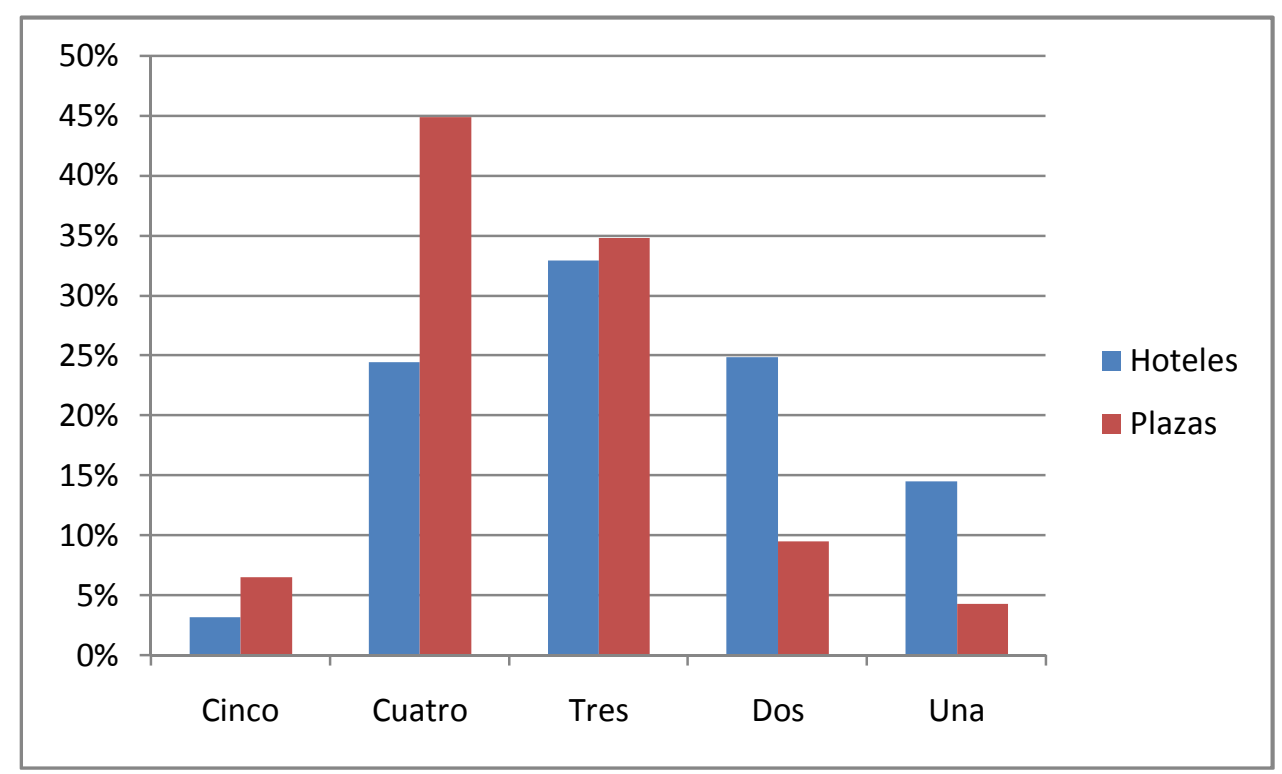

Fuente: Elaboración propia con base en los datos de la Encuesta de Ocupación Hotelera, INE 


\section{Capítulo 4 Caracterización del Sector de Estudio e Instrumento de Medida}

\subsubsection{Desempeño del sector hotelero}

Los indicadores utilizados para medir el desempeño en el sector hotelero son el Average Daily Rate o Tarifa Media Diaria ADR, el Revenue per Available Room o Ingresos por Habitación Disponible RevPAR y el grado de ocupación. El ADR son los ingresos medios diarios obtenidos por habitación ocupada y el RevPAR son los ingresos medios por habitación disponible.

En ambas definiciones los ingresos hacen referencia a aquellos percibidos por los hoteleros por la prestación del servicio de alojamiento, sin incluir otro tipo de servicios, como pueden ser servicios de restauración, minibar, Spa, gimnasio, organización de reuniones o eventos.

Entre ambos indicadores existe la siguiente relación ${ }^{8}$ :

$$
R e v P A R \cong A D R * \text { Grado de ocupación por habitaciones }
$$

\footnotetext{
${ }^{8}$ La igualdad no es exacta debido a que el grado de ocupación por habitaciones se calcula según criterios de la Encuesta de Ocupación Hotelera, no siendo exactamente iguales en la estimación del ADR y RevPAR por razones metodológicas.
} 
Capítulo 4 Caracterización del Sector de Estudio e Instrumento de Medida

Figura 4.20. Tasa Media Diaria (ADR) por categorías de Hoteles 2010

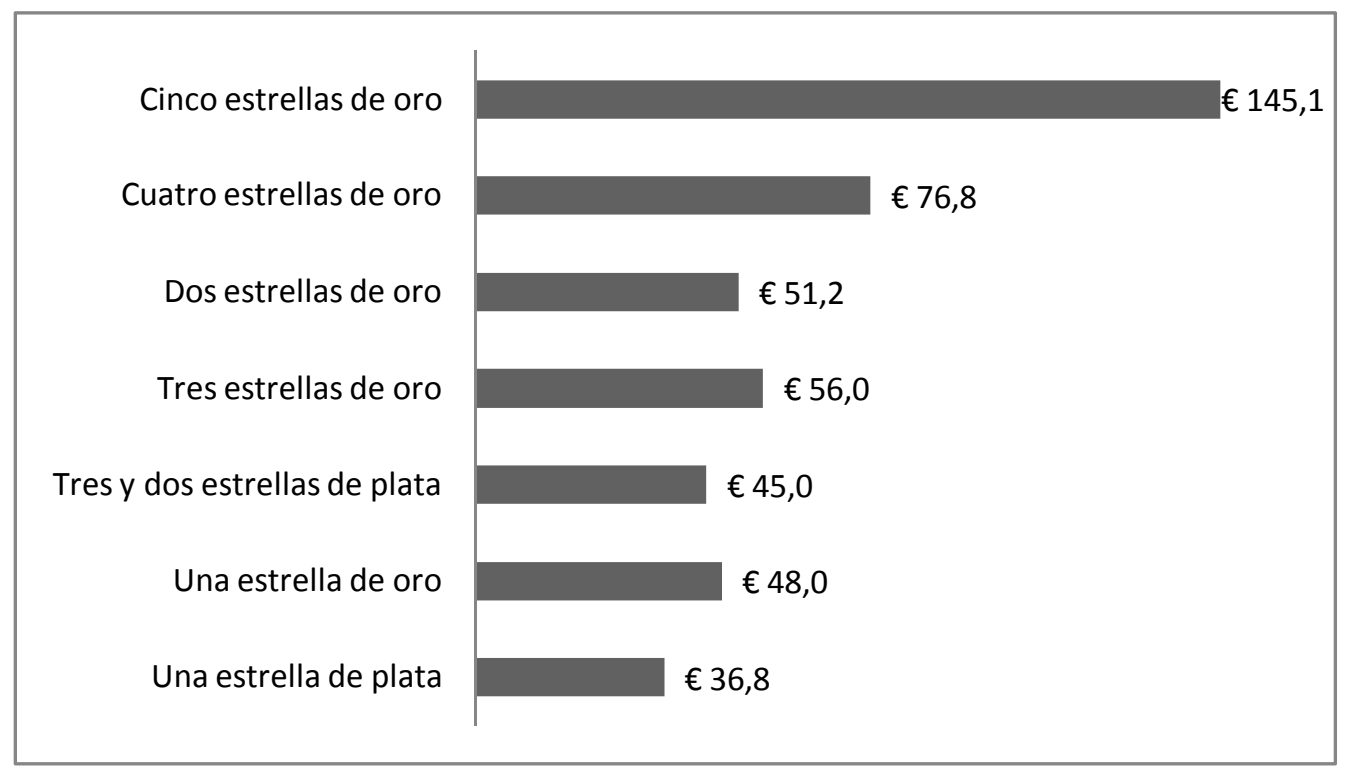

Fuente: Elaboración propia con base en la encuesta de ocupación hotelera del INE

Los hoteles de 5 y 4 estrellas presentan mayor estabilidad de acuerdo a la tasa media diaria (ADR). La tasa de la categoría de hoteles de cinco estrellas de oro, es en promedio un $111 \%$ más alta que el promedio del sector. En el caso de los hoteles de 4 estrellas, están muy cercanas al promedio del sector. 
Capítulo 4 Caracterización del Sector de Estudio e Instrumento de Medida

Figura 4.21. Tasa Media Diaria (ADR)

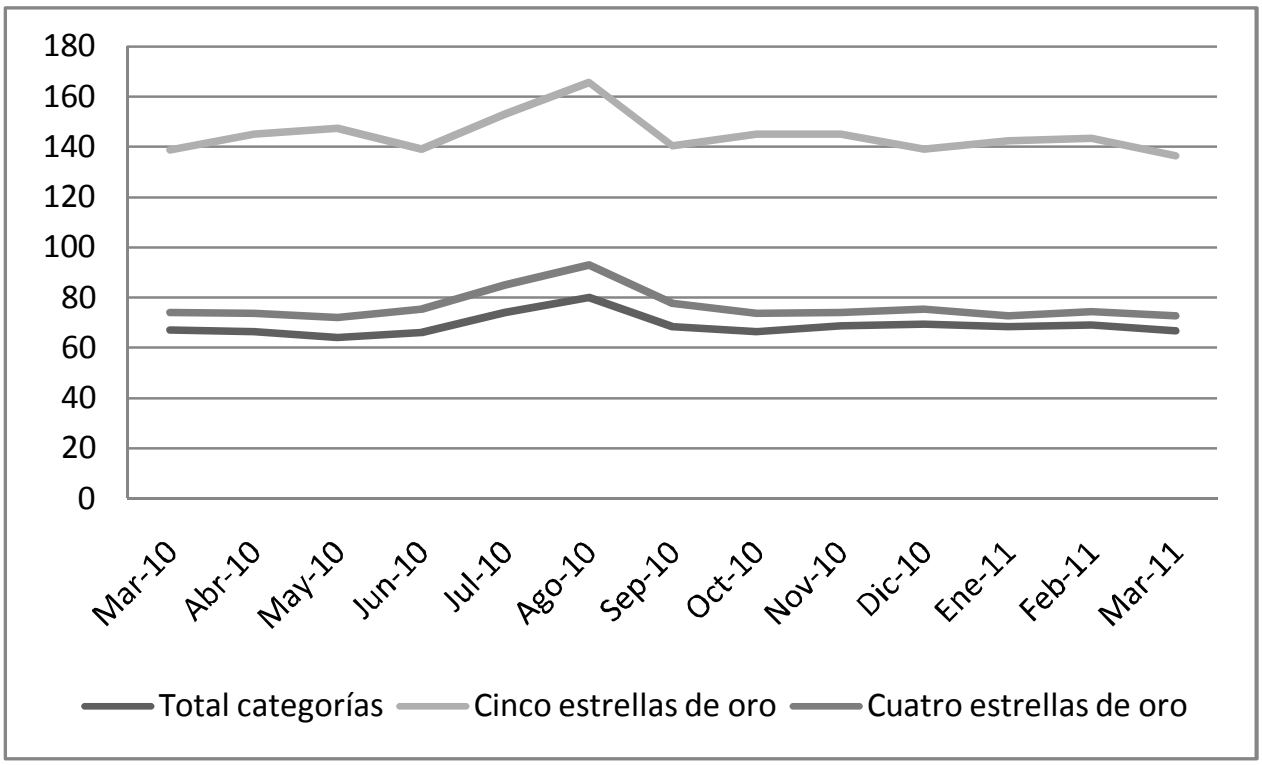

Fuente: Elaboración propia con base en la encuesta de ocupación hotelera del INE

Los ingresos promedios por habitación disponible (RevPAR) del año 2010, se presentan en la siguiente tabla.

Tabla 4.6. Ingresos promedios por habitación disponible (RevPAR) en el 2010

\begin{tabular}{||l||c||}
\hline \hline Desglose por categorías & $\begin{array}{c}\text { Ingresos por habitación } \\
\text { disponible (RevPAR) }\end{array}$ \\
\hline \hline Total categorías & $€ 36,9$ \\
\hline Cinco estrellas de oro & $€ 78,9$ \\
\hline Cuatro estrellas de oro & $€ 47,8$ \\
\hline
\end{tabular}


Capítulo 4 Caracterización del Sector de Estudio e Instrumento de Medida

\begin{tabular}{||l|c||}
\hline Tres estrellas de oro & $€ 32,9$ \\
\hline Dos estrellas de oro & $€ 22,3$ \\
\hline Una estrella de oro & $€ 16,8$ \\
\hline Tres y dos estrellas de plata & $€ 14,9$ \\
\hline Una estrella de plata & $€ 11,0$ \\
\hline
\end{tabular}

Fuente: Elaboración propia con base en la encuesta de ocupación hotelera del INE

Figura 4.22. Ingresos promedios por habitación disponible (RevPAR)

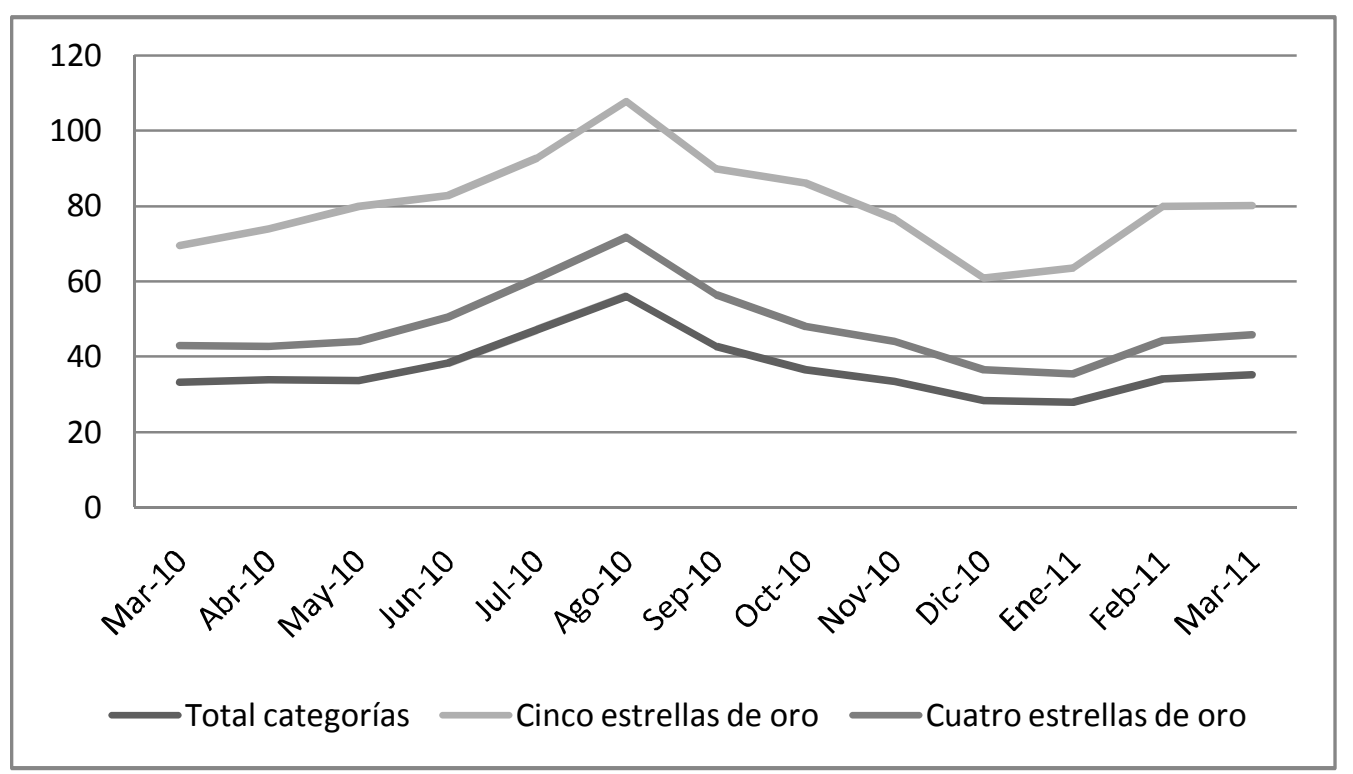

Fuente: Elaboración propia con base en la encuesta de ocupación hotelera del INE

Los ingresos de los hoteles de cinco estrellas son aproximadamente $61 \%$ más altos respecto a los hoteles de 4 estrellas y más del doble que el promedio entre categorías. 


\subsubsection{Grado de ocupación por categorías}

El grado de ocupación promedio el año 2010 fue de 49,5\%. La categoría con mayor grado de ocupación por plazas, de acuerdo a los datos anuales de la Encuesta de Ocupación Hotelera 2010, son los hoteles de 3 estrellas, con 57,43\%, seguidos muy de cerca por los hoteles de 4 estrellas con 57,43\%. Los hoteles con menor ocupación son los de una estrella, con una media anual del grado de ocupación del $32,97 \%$.

La categoría de 4 estrellas tiene una mayor cantidad de personal ocupado (83.537) y los hoteles de una estrella la menor (4.570). Por otra parte, los grados de ocupación por plazas en fin de semana, cambian ligeramente, siendo la categoría de los hoteles de 4 estrellas la que registra el mayor grado de ocupación $(63,41)$, seguida por la categoría de hoteles de 3 estrellas, con un grado de ocupación del $62,92 \%$.

Tabla 4.7. Grado de ocupación por categorías

\begin{tabular}{||c|c|c|c||}
\hline Categoría & $\begin{array}{c}\text { Grado de } \\
\text { ocupación por } \\
\text { plazas** }\end{array}$ & $\begin{array}{c}\text { Grado de ocupación } \\
\text { por plazas en fin } \\
\text { de semana** }\end{array}$ & Personal ocupado* \\
\hline Cinco & 48,43 & 54,63 & 22.879 \\
\hline Cuatro & 57,43 & 63,41 & 83.537 \\
\hline Tres & 58,26 & 62,92 & 52.329 \\
\hline Dos & 40,99 & 47,23 & 11.221 \\
\hline Una & 32,97 & 38,43 & 4.570 \\
\hline
\end{tabular}

* Media anual

** Grado de ocupación ponderado por plazas

Fuente: Elaboración propia con base en la encuesta de ocupación hotelera del INE 


\subsection{LA TRANSFERENCIA DE CONOCIMIENTO Y EL SECTOR TURÍSTICO}

El sector turístico es complejo, debido a que está compuesto por actividades heterogéneas de diversa naturaleza que están dispersas en tiempo y espacio. Esta característica requiere que las distintas actividades sean combinadas creando paquetes de productos y servicios interrelacionados (transporte, acomodación, servicios, alquileres de automóviles, entre otros) y gestionadas de forma dinámica, puesto que reúnen a actores que tienen distintos niveles cognitivos y se encuentran en diferentes lugares (Aldebert et al., 2011).

Un aspecto importante en el sector turístico es la innovación, que implica la interacción de actores tradicionales del turismo con nuevos entrantes o líderes, para la aplicación de diversas innovaciones que requieren el involucramiento de profesionales en el turismo. De acuerdo a Aldebert et al. (2011) un sistema sectorial de innovación y producción debe considerar los siguientes atributos:

a. Estar basado en el conocimiento y un proceso de aprendizaje

b. Considerar la heterogeneidad de los actores y redes.

c. Considerar la demanda, puesto que los productos turísticos son esencialmente bienes experimentados, cuya utilidad y calidad es incierta y solo puede ser conocida de manera ex post.

Los conceptos de la gestión del conocimiento en la literatura han sido desarrollados mayormente desde una perspectiva manufacturera y multinacional, por lo que no toman en cuenta las muchas facetas de los servicios turísticos, los 


\section{Capítulo 4 Caracterización del Sector de Estudio e Instrumento de Medida}

mismo que están basados en redes y en la necesidad de tener una perspectiva inter organizacional (Hallin y Marnburg, 2008).

Por otra parte, estos autores mencionan que dos factores reducen la capacidad para transferir el conocimiento y la permanencia de las iniciativas innovativas en el sector turístico y hotelero, que son:

a) La alta movilidad de los administradores en la industria

b) Las altas tasas de consolidación a través de uniones, alianzas y adquisiciones.

El proceso de transferencia de conocimiento en el sector turístico requiere de canales tanto directos como indirectos. Los canales indirectos están más orientados a la difusión de conocimiento mediante seminarios, publicaciones de prensa, actividades en las asociaciones de gremios y la movilidad del personal. En cambio, los canales directos se orientan más a los procesos de transferencia de conocimiento, siendo algunos de sus mecanismos la franquicia, Joint ventures, sistemas de entrenamiento, entre otros (Hjalager, 2010).

Las características del sector turístico y en especial del hotelero, requiere que se tenga una visión holística hacia afuera de la organización, que considere la interrelación con actores diferentes, los cuales representan un complejo sistema de proveedores y clientes; así como una visión holística al interior de la propia organización, que permita alinear los objetivos y acciones de todo el personal. En 


\section{Capítulo 4 Caracterización del Sector de Estudio e Instrumento de Medida}

este sentido, es importante gestionar las diferentes redes, tanto internas como externas. Hjalager (2010) identifica cuatro tipos de redes en el sector turístico:

1. Redes verticales de distribución entre firmas turísticas y sus distribuidores (operadores turísticos)

2. Relaciones de entrada vertical entre firmas turísticas y sus proveedores

3. Relaciones competitivas horizontales o cadenas de relación entre firmas turísticas similares (hoteles que ofrecen productos similares)

4. Firmas turísticas, tales como las que ofrecen atracciones turísticas y establecimiento de alojamiento.

Hallin y Marnburg (2008) mencionan que las cadenas de hoteles se están esforzando por incorporar prácticas de gestión del conocimiento en sus instituciones, puesto que deben entregar servicios de calidad estandarizados.

Según el análisis realizado en el tercer capítulo de la presente investigación, se ha evidenciado que la ventaja competitiva sostenible es creada a partir de las habilidades individuales de los trabajadores y del conocimiento, que contribuye para alcanzar un desempeño más alto en la organización. Por ello, es importante prestar especial atención al recurso humano y su gestión por competencias.

En la industria hotelera las altas tasas de entradas y salidas de personas, implican tres grandes problemas: 


\section{Capítulo 4 Caracterización del Sector de Estudio e Instrumento de Medida}

1. La posibilidad de perder el conocimiento de los empleados, puesto que las personas no compartirán vertical u horizontalmente lo que saben antes de irse.

2. Si los empleados no transfieren el conocimiento importante antes de que dejen la empresa, el proceso de creación y retención del conocimiento puede ser inefectivo. Este proceso incluye los programas de orientación, inducción y de entrenamiento.

3. El conocimiento compartido necesita ser almacenado, de otra manera, el conocimiento puede perderse cuando los empleados dejan el trabajo. En otras palabras, si el conocimiento no es compartido y almacenado, las compañías pueden perder activos intangibles (Yang y Wan, 2004).

Dado que la industria turística está basada en el contacto con los clientes, esta característica se convierte en una fuente crucial de conocimiento acerca de los mercados y la satisfacción de los clientes. Por ello, es importante generar mecanismos para el aprendizaje continuo en la organización e impulsar la transferencia de conocimiento con prácticas, por ejemplo, el establecimiento de comunidades de práctica.

El sector turístico y su interrelación con las tecnologías de información y comunicación, permite que los consumidores interactúen directamente con el contenido, por ejemplo de los sitios webs. Esta interacción permite que las organizaciones turísticas se comprometan con los intereses y participación de los consumidores, también permite capturar información acerca de su preferencia y a la vez usar esta información para proveer comunicación y servicios personalizados (Doolin et al., 2002). 
Las fronteras entre la competición y la cooperación han evolucionado con el uso del internet, cuyo resultado es la reorganización de los mercados y la industria del turismo. El internet abrió la posibilidad a los turistas de acceder a información sobre los productos turísticos y crear paquetes, lo cual en un sentido los pone a competir contra las agencias de viaje. Los cambios tecnológicos y los que se dan en el sector turismo son casi simultáneos, la evolución tecnológica confirma la llegada secuencial de nuevas bases del conocimiento en el sector (Aldebert et al., 2011).

De acuerdo a Buhalis y Law (2008) las organizaciones turísticas, tales como hoteles, compañías aéreas, agencias de viaje, han adoptado tecnologías de internet como parte de sus estrategias de marketing y de comunicación.

El internet ha cambiado la forma en que la información relacionada al turismo se distribuye y la manera en que las personas planifican los viajes. Dos corrientes han emergido en el internet. Por un lado los sitios sociales web, tales como: blogs, comunidades virtuales, wikis, redes sociales, files compartidos en youtube, etc. Por otro lado, el internet interviene en la manera en que los turistas utilizan los sitios sociales para reconstruir y compartir sus viajes (Xiang y Gretzel, 2010).

En la siguiente tabla se puede apreciar la importancia de las tecnologías de información y comunicación en el sector turístico, en especial en los servicios de alojamiento. 
Capítulo 4 Caracterización del Sector de Estudio e Instrumento de Medida

Tabla 4.8. Variables de uso de TIC, en el sector de servicios de alojamiento, 2010

\begin{tabular}{||l|c||}
\hline \multicolumn{1}{||c|}{ Variables } & Porcentaje \\
\hline Empresas que disponen de conexión a Internet & 99,2 \\
\hline \begin{tabular}{l} 
Empresas que disponen de correo electrónico (e-mail) \\
\hline $\begin{array}{l}\text { Empresas con conexión a Internet que, como usuarios de servicios de } \\
\text { internet, lo utilizan para: observar el comportamiento del mercado(1) }\end{array}$
\end{tabular} & 69,5 \\
\hline $\begin{array}{l}\text { Motivo de interacción: Presentar una propuesta comercial a licitación } \\
\text { pública (eprocurement)(1) }\end{array}$ & 6,7 \\
\hline \begin{tabular}{l} 
Empresas con conexión a Internet y sitio/página web(1) \\
\hline $\begin{array}{l}\text { Empresas con conexión a Internet y página web para: Presentación de } \\
\text { la empresa(2) }\end{array}$
\end{tabular} & 98,1 \\
\hline $\begin{array}{l}\text { Empresas con conexión a Internet y página web para: Realización de } \\
\text { pedidos o reservas online(2) }\end{array}$ & 74 \\
\hline $\begin{array}{l}\text { Empresas con conexión a Internet y página web para: Anuncios de } \\
\text { ofertas de trabajo o recepción de solicitudes de trabajo online(2) }\end{array}$ & 25,7 \\
\hline $\begin{array}{l}\text { Empresas que disponen de alguna aplicación informática para } \\
\text { gestionar información de clientes ( herramientas CRM ) }\end{array}$ & 32,1 \\
\hline $\begin{array}{l}\text { Empresas que disponen de herramientas CRM para: Capturar, } \\
\text { almacenar y compartir información sobre clientes }\end{array}$ & 32,1 \\
$\begin{array}{l}\text { Empresas que disponen de herramientas CRM para: Analizar la } \\
\text { información disponible acerca de los clientes con fines comerciales y } \\
\text { de marketing }\end{array}$ & 25,7 \\
\hline
\end{tabular}

(1)Porcentaje sobre el total de empresas con conexión a Internet

(2) Porcentaje sobre el total de empresas con conexión a Internet y página web

Fuente: Elaboración propia con base en los datos del INE

Para el 40,8\% de las empresas, la solución tecnológica que más impacto ha tenido en el sector Hotelero en el 2009 ha sido la gestión de reservas, seguida de las herramientas de marketing social $(22,1 \%)$, en línea con la explosión de las redes 


\section{Capítulo 4 Caracterización del Sector de Estudio e Instrumento de Medida}

sociales. Los blogs turísticos se han convertido también en una herramienta muy útil tanto para la promoción del hotel como para conocer la opinión de los clientes.

Figura 4.23. Tecnologías con mayor impacto en el 2009

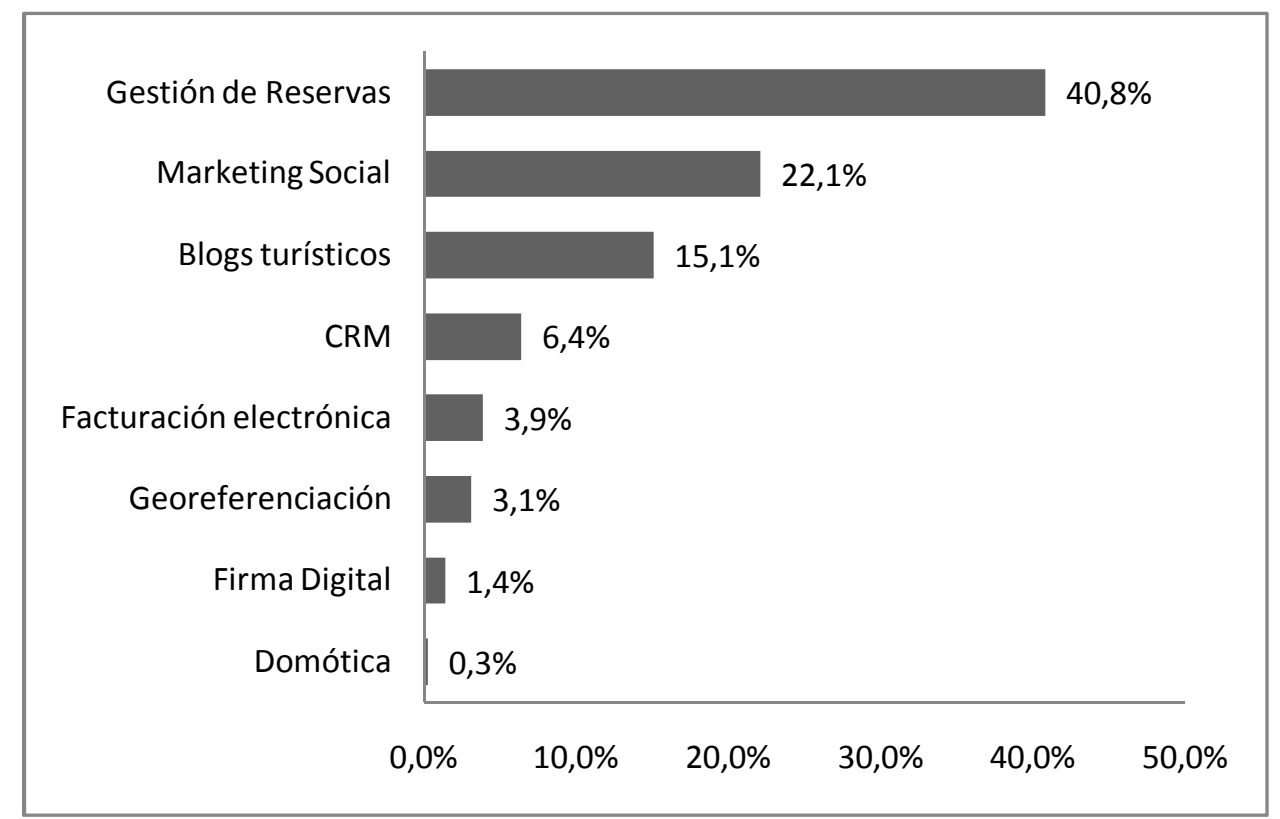

Fuente: Elaboración propia con base en el Informe Pyme09, 2010 


\subsection{DISEÑO DEL INSTRUMENTO DE MEDICIÓN}

El objetivo de la tesis es determinar la incidencia de la transferencia de conocimiento en el desempeño organizativo a través de la visión holística, gestión por competencias, aprendizaje continuo e infraestructura tecnológica de las TI.

La industria seleccionada para realizar el estudio fue la del Turismo, específicamente el sector Hotelero, debido a su importancia económica y social en España y dado que es un sector que ha comenzado a implementar prácticas de gestión de conocimiento y en particular transferencia de conocimiento tanto interna como externa, con el propósito de mejorar sus niveles de competitividad.

Para desarrollar las escalas de medición se ha realizado una revisión bibliográfica a fin de seleccionar los instrumentos para medir cada una de las variables del modelo presentado.

Tabla 4.9. Bibliografía relevante para el desarrollo de los instrumentos de medición

\begin{tabular}{|c|c|}
\hline VARIABLES & BIBLIOGRAFÍA CONSULTADA \\
\hline Visión holística de la organización & $\begin{array}{ll} & \text { Elragal y Al-Serafi (2011) } \\
\text { - } & \text { Joseph (2009) } \\
\text { - } & \text { Palacios y Garrigós (2006) } \\
\text { - } & \text { Senge (1990) }\end{array}$ \\
\hline Gestión por competencias & $\begin{array}{ll}\text { - } & \text { Gardner y Wright (2009) } \\
\text { - } & \text { Palacios y Garrigós (2006) } \\
\text { - } & \text { Steyn y Kahn (2008) }\end{array}$ \\
\hline
\end{tabular}


Capítulo 4 Caracterización del Sector de Estudio e Instrumento de Medida

\begin{tabular}{|c|c|}
\hline & - $\quad$ Laursen y Foss (2003) \\
\hline Aprendizaje Contínuo & $\begin{array}{ll}\text { - } & \text { Palacios y Garrigós (2006) } \\
\text { - } & \text { Jerez-Gómez et al. (2005) } \\
\text { - } & \text { Templeton et al. (2002) } \\
\text { - } & \text { Fiol y Lyles (1985) }\end{array}$ \\
\hline Infraestructura tecnológica de las TI & $\begin{array}{ll}\text { - } & \text { Byrd et al. (2008) } \\
\text { - } & \text { Albadvi } \text { et al. (2007) } \\
\text { - } & \text { Tallon (2007) } \\
\text { - } & \text { Zhang y Tansuhaj (2007) } \\
\text { - } & \text { Lewis y Byrd (2003) } \\
\text { - } & \text { Byrd y Turner (2000) }\end{array}$ \\
\hline Transferencia de conocimiento & $\begin{array}{ll}\text { - } & \text { Yi (2009) } \\
\text { - } & \text { Lin (2007) } \\
\text { - } & \text { Zaim et al. (2007) } \\
\text { - } & \text { Jantunen (2005) } \\
\text { - } & \text { Sabherwal y Becerra-Fernandez } \\
& (2003) \\
\text { - } & \text { Lee y Choi (2003) }\end{array}$ \\
\hline Desempeño Empresarial & $\begin{array}{ll}\text { - } & \text { Nakata } \text { et al. }(2008) \\
\text { - } & \text { Eskildsen } \text { et al. }(2003) \\
\text { - } & \text { Kearns y Lederer (2003) } \\
\text { - } & \text { Brady y Cronin (2001) } \\
\text { - } & \text { Chan (2000) }\end{array}$ \\
\hline
\end{tabular}

Fuente: Elaboración Propia

Con base en la revisión de la líteratura se ha seleccionado un conjunto de escalas para medir cada una de las variables del modelo, a continuación se detallan los items de las escalas de medición por variables: 


\subsubsection{Visión holística de la organización}

La escala de medición utilizada fue la de Palacios y Garrigós (2006), cuyos items son:

1. La estrategia y la política de gestión del conocimiento afectan a toda la organización y repercuten en la forma de concebir y gestionar la empresa

2. No es posible la elaboración de políticas y estrategias sin tener en cuenta a toda la organización, incluyendo proveedores y clientes

3. Una implantación efectiva de una estrategia requiere que el control se consiga gracias a los valores y la visión compartida por todos los miembros de la empresa

4. No es posible gestionar la empresa sin identificar los procesos de la organización y sus interrelaciones

5. Existe un sistema definido de distribución de información al personal, clientes y proveedores de acuerdo a las necesidades detectadas

6. La empresa dispone de sistemas de captación y tratamiento integral de la información sobre los procesos (tipo sistemas ERP “Enterprise resource planning”)

7. La empresa desarrolla proyectos que cruzan las barreras entre departamentos

8. Existen incentivos para el cumplimiento de los objetivos globales de la organización 


\section{Capítulo 4 Caracterización del Sector de Estudio e Instrumento de Medida}

\subsubsection{Gestión por Competencias}

Los items para medir la gestión por competencias, se basan en la escala de medición de Palacios y Garrigós (2006):

1. Las habilidades y competencias de cada empleado deben ser valoradas para el desarrollo de su carrera profesional

2. Los compañeros deben ayudar en la mejora de las competencias y habilidades de cada empleado

3. Un cometido de los jefes y supervisores es el de apoyar a sus subordinados en el desarrollo de nuevas competencias

4. La empresa debe implantar un sistema de gestión por competencias que permita a cada empleado recibir un salario acorde con las competencias desarrolladas

5. La organización dispone de sistemas para medir las competencias de sus empleados

6. Los sistemas de remuneración y promoción de los empleados influyen en el desarrollo de competencias, ideas y conocimientos de los empleados

7. La empresa emplea técnicas de benchmarking para la mejora de las competencias de sus empleados

\subsubsection{Aprendizaje Continuo}

La escala utilizada para medir el aprendizaje continuo fue la de Palacios y Garrigós (2006), cuyos items son: 


\section{Capítulo 4 Caracterización del Sector de Estudio e Instrumento de Medida}

1. En la empresa se ha de fomentar la reflexión, la crítica y el cambio para la mejora continua

2. Las nuevas ideas deben ser muy valoradas, independientemente del empleado que las formule

3. En una organización se debe esperar de todos, no sólo de los directivos, que resuelvan los problemas y ofrezcan sugerencias

4. Los empleados deben ver su trabajo en la empresa como un proceso de aprendizaje que nunca termina

5. La empresa posee un plan de carrera que incentiva a sus empleados al aprendizaje continuo

6. Los empleados reciben formación generalista que posteriormente aplican a sus tareas habituales

7. Existe un sistema de mejora continua que permite mejorar los procesos que hayan alcanzado los estándares de calidad fijados

\subsubsection{Infraestructura Técnica de las TI}

Para medir la infraestructura técnica de las tecnologías de información se utilizaron los items de la escala de Byrd y Turner (2000):

1. Nuestra empresa tiene lo último en sistemas y conexiones de Tecnología Informática, TI, disponibles (Ej. ADSL, VDSL, ATM, SDV)

2. Nuestra empresa ha tratado formalmente el tema de la seguridad de los datos con diversos protocolos (Ej. Kerberos, V.5, MIME, PGP, S-HTTP).

3. Todas las oficinas y sucursales remotas están conectadas a la oficina central 


\section{Capítulo 4 Caracterización del Sector de Estudio e Instrumento de Medida}

4. Nuestra empresa utiliza mecanismos de red de sistemas abiertos para estimular la conectividad

5. En nuestra empresa no existen cuellos de botella en la comunicación

6. Nuestra empresa utiliza una red virtual o VLAN para conectarse a los usuarios finales

7. Los módulos de software reusables son ampliamente utilizados en el desarrollo de nuevos sistemas

8. Se utilizan herramientas orientadas a objetos para crear las aplicaciones de los usuarios finales en colaboración con éstos.

9. El personal de TI utiliza tecnologías orientadas a objetos para minimizar el tiempo de desarrollo de las aplicaciones.

10. Los sistemas heredados en nuestra organización no limitan el desarrollo de nuevas aplicaciones

11. Apenas se utilizan funciones programadas para otras aplicaciones en el desarrollo de nuevas aplicaciones

12. Las oficinas remotas tienen que realizar pasos adicionales o procedimientos para acceder a la oficina central

13. Los usuarios finales utilizan un sistema operativo común en toda la organización (Ej. UNIX, LINUX, OS/2)

14. Las aplicaciones de software pueden ser fácilmente transportadas y usadas en múltiples plataformas

15. Nuestra empresa ofrece una amplia variedad de tipos de información a los usuarios finales (multimedia)

16. Los interfaces de nuestros usuarios proporcionan un acceso transparente a todas las plataformas y aplicaciones 


\section{Capítulo 4 Caracterización del Sector de Estudio e Instrumento de Medida}

17. Nuestra empresa proporciona múltiples interfaces o puntos de entrada (Ej. Acceso web) para los usuarios externos

18. La conexión con la oficina central es inmediata desde cualquier terminal de la empresa

19. Nuestra base de datos corporativa es capaz de comunicarse a través de varios protocolos (Ej. SQL, ODBC)

20. Los empleados que trabajan fuera de la oficina tienen acceso rápido a los mismos datos utilizados en los PC de la oficina

21. Existen dificultades para adaptarse a los estándares y protocolos de bases de datos de algunos proveedores

22. Los datos capturados en cualquier parte de nuestra empresa están inmediatamente disponibles en la base de datos.

\subsubsection{Transferencia de Conocimiento}

Para medir la transferencia de conocimiento se utilizó la escala sugerida por Yi (2009), cuyos items son:

1. Presentar regularmente documentos e informes

2. Publicar artículos en revistas de la empresa, revistas especializadas o boletines de noticias

3. Compartir la documentación de los archivos personales relacionados con el trabajo actual

4. Contribuir con ideas y pensamientos a la empresa mediante bases de datos en línea 


\section{Capítulo 4 Caracterización del Sector de Estudio e Instrumento de Medida}

5. Mantener a otros empleados al día con información importante de la empresa a través de foros de discusión en línea

6. Expresar ideas y pensamientos en las reuniones de la empresa

7. Participar plenamente en sesiones de lluvia de ideas ("brainstorming")

8. Proponer sugerencias para resolver problemas en las reuniones de equipo

9. Responder a las preguntas de los demás en reuniones de equipo

10. Hacer preguntas que puedan provocar la discusión y análisis en las reuniones de equipo

11. Compartir historias de éxito que pueden beneficiar a la empresa en las reuniones de organización

12. Compartir los fracasos relacionados con el trabajo, para ayudar a otros a evitar la repetición de estas en las reuniones de la empresa

13. Hacer presentaciones en las reuniones de la empresa

14. Apoyar a los empleados con menos experiencia durante el tiempo de trabajo personal

15. Participar en las acciones de entrenamiento a largo plazo de los empleados más jóvenes

16. Pasar tiempo en conversaciones personales (por ejemplo, la discusión en el pasillo, durante el almuerzo, a través del teléfono) con otros, para ayudarles a resolver problemas del trabajo.

17. Mantener a otros empleados al día con información importante de la empresa a través de una conversación personal

18. Compartir la pasión y la emoción de algunos temas específicos con los demás mediante la conversación personal

19. Compartir experiencias que pueden ayudar a otros a evitar riesgos y problemas mediante la conversación personal. 


\section{Capítulo 4 Caracterización del Sector de Estudio e Instrumento de Medida}

20. Tener charlas en línea con otros empleados para ayudarles con sus problemas relacionados con el trabajo.

21. Pasar tiempo en la comunicación por email con otros empleados para ayudarlos con sus problemas relacionados con el trabajo

22. Reuniones de la "Comunidad" para crear soluciones innovadoras a los problemas del trabajo

23. Reuniones de la "Comunidad" para compartir la propia experiencia y la práctica sobre temas específicos de común interés.

24. Reuniones de la "Comunidad" para compartir el éxito y malos resultados y sobre temas específicos de común interés.

25. Reuniones de la "Comunidad" para fomentar la excelencia en el trabajo

26. Apoyo personal de desarrollo de nuevas "Comunidades"

27. Enviar información relacionada a los miembros de la "Comunidad" a través lista de correo electrónico

28. Compartir ideas y pensamientos sobre temas específicos a los miembros de la "Comunidad" utilizando los sistemas en línea

\subsubsection{Desempeño Organizativo}

Para medir la capacidad de innovación se utilizaron los items de la escala de Nakata et al. (2008):

1. La calidad del producto o servicio

2. El éxito de nuevos productos o servicios

3. La tasa de retención de clientes

4. El nivel de ventas

5. El retorno sobre capital 
6. El margen bruto de utilidad

7. El retorno sobre inversión

\subsection{MODELOS DE ECUACIONES ESTRUCTURALES}

Los fenómenos que se presentan en las ciencias sociales son complejos, en las que intervienen un número considerable de variables. Esta complejidad implica el análisis simultáneo de un conjunto de variables.

Para el tratamiento de estos conjuntos de variables, se han desarrollado métodos y técnicas multivariantes. El desarrollo de los ordenadores y paquetes de software ha facilitado los complejos y numerosos cálculos que requieren estas técnicas.

Entre los métodos y técnicas multivariantes se encuentran: la regresión múltiple, el análisis factorial, el análisis multivariante de la varianza, el análisis discriminante. Una limitación de estas técnicas, es que solo pueden examinar una relación al mismo tiempo.

De acuerdo a Kisch (1975) las variables utilizadas en el diseño de una investigación pueden clasificarse en: Variables explicativas, que se consituyen en aquellas que se quieren investigar; Variables controladas, que son las que están auténticamente controladas; Variables no controlas con relaciones funcionales con las variables independientes; y Variables no controladas que guardan relaciones funcionales tanto con las variables independientes como con las dependientes. 


\section{Capítulo 4 Caracterización del Sector de Estudio e Instrumento de Medida}

Los modelos de ecuaciones estructurales, incluyen una familia de modelos como: de la estructura de la covarianza, análisis de variable latente, análisis factorial confirmatorio, análisis LISREL.

Los modelos de ecuaciones estructurales se caracterizan por realizar estimaciones de relaciones de dependencias múltiples y cruzadas así como por la capacidad de representar conceptos no observados en estas relaciones y tener en cuenta el error de medida en el proceso de estimación.

De acuerdo a Bollen (1989) los modelos de ecuaciones estructurales buscan minimizar la diferencia entre las covarianzas de la muestra y las covarianzas que predice el modelo. Esto con el fin de que si las ecuaciones estructurales que plantea al modelo propuesto son correctas y se conocen dichos parámetros, la matriz de covarianzas poblacional puede ser reproducida exactamente o con un nivel elevado de aproximación.

Las ecuaciones estructurales se componen de dos elementos básicos: el submodelo de medida que representa la relación existente entre las variables latentes y las variables observables, que ayuda a determinar la fiabilidad y validez de los indicadores como medidas de las variables latentes; y el modelo estructural, que describe cómos se relacionan las variables latentes con el fin de de confirmar la medida en que las relaciones causales que especifica el modelo propuesto son consistentes con los datos disponibles (Hair et al., 1999; Bollen, 1989).

Las etapas a seguir en la construcción de modelos de ecuaciones estructurales son: la especificación, identificación, estimación y evaluación (Hair et al., 1999). 
La fase de especificación consiste en el planteamiento de un modelo teórico que concrete la forma de medición de las variables y la relación que existe entre dichas variables.

En esta fase, con base en los conocimientos teóricos se plantean las ecuaciones matemáticas relativas a los efectos causales de las variables latentes y las expresiones que las relacionan con los indicadores o variables observables. Se formulan los enunciados sobre el conjunto de parámetros (decidiendo entre los que serán "libres" para ser estimados o "fijos" a los que se les asigna normalmente un valor de 0). Se especifícan los supuestos estadísticos sobre las fuentes de variación y distribución conjunta (mayormente se considera la normalidad multivariante) y finalmente el comportamiento de las variables no incluidas en el modelo, cuyo efecto se determina en los términos de error de medida o perturbación.

Los modelos de ecuaciones estructurales se plantean mediante diagramas así como de forma matricial, que proponen un sistema de ecuaciones simultáneas.

A continuación a modo de ejemplo se presenta un diagrama general de un modelo de relaciones causales: 
Figura 4.24 Diagrama general de relaciones causales

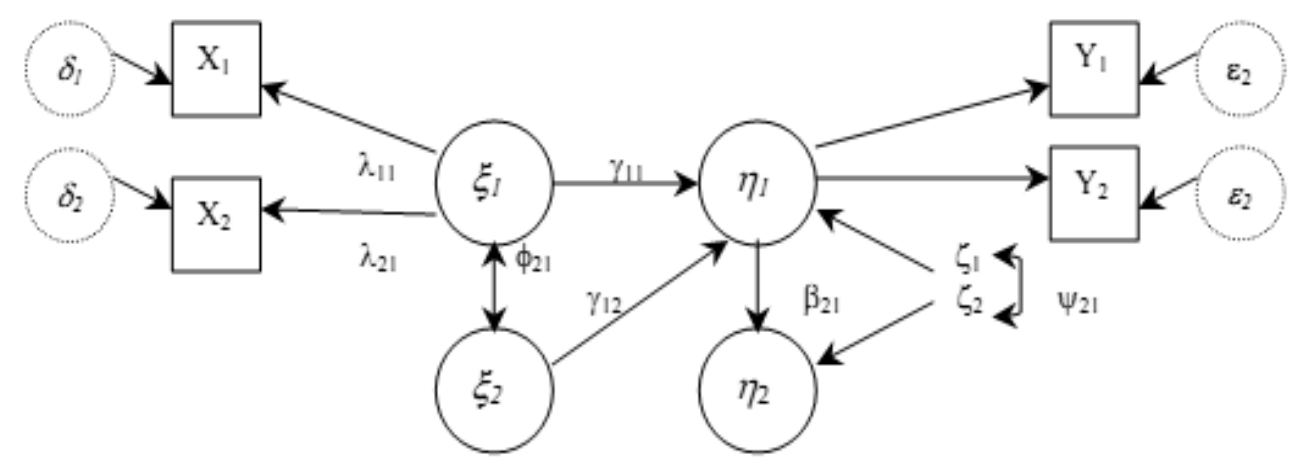

- Variables latentes: endógenas $\eta$, exógenas $\xi$

- Variables observadas: endógenas Y, exógenas X.

- Errores de medida: variables observadas endógenas $\varepsilon$, variables observadas exógenas $\delta$.

- Término de perturbación: $\zeta$, que incluye los efectos de las variables omitidas, los errores de medida y la aleatoriedad del proceso especificado. La variación en el término de perturbación se simboliza por $\psi$ y la covariación entre los términos de perturbación i-ésimo y j-ésimo se denota por $\psi \mathrm{i} \mathrm{j}$

- Coeficiente de regresión: $\lambda$, que relaciona las variables latentes con los indicadores.

- Coeficientes de regresión $\gamma, \beta, \varphi$ que relacionan las variables latentes entre sí, y las variables observadas entre sí.

La fase de identificación consiste en determinar si existe una única solución para cada parámetro estimado, para ello se analiza si las covarianzas entre las variables 


\section{Capítulo 4 Caracterización del Sector de Estudio e Instrumento de Medida}

proporcionan suficiente información para estimar los parámetros del modelo (Batista y Coenders, 2000).

Entre las principales reglas para identificar un modelo estan: la de los "grados de libertad", que son obtenidos como la diferencia entre el número de varianzas y covarianzas y el número de parámetros a estimar. Esta se constituye en una condición necesaria pero no suficiente. Cuando las $\mathrm{g}<0$, se dice que el modelo está infraidentificado, cuando $\mathrm{g}=0$ el modelo es posiblemente identificado $\mathrm{y}$ cuando g>0 el modelo está sobreidentificado. Otra regla es; si el modelo es recursivo (es decir si entre sus variables se presentan efectos circulares o recíprocos), el modelo esté identificado.

En la fase de estimación se obtienen los coeficientes que representan las relaciones del modelo y se ajustan los datos.

Con base en la fase anterior, si el modelo está identificado, cada uno de los parámetros tendrá un valor único. Para la estimación del modelo se obtienen los valores $p$ de los parámetros $\pi$ que se ajusten lo mejor posible a la matriz observada, por la que aquellos reproducen. La estimación de los coeficientes se realiza mediante procedimientos iterativos de minimización de desviaciones, bajo la hipótesis de que el modelo es correcto. Los tests de bondad del ajuste, permitirán decidir si la falta de identidad entre la matriz de varianzas y covarianzas y covarianzas muestral y la generada por el modelo, se debe al azar o la inadecuación del modelo. 


\section{Capítulo 4 Caracterización del Sector de Estudio e Instrumento de Medida}

Finalmente en la fase de evaluación se comprueba la adecuación de los distintos parámetros estimados y el grado de ajuste del modelo.

A contiuación se presenta una síntesis de los indicadores que serán utilizados para la comprobación de las características de las escalas de medición del modelo: la dimensionalidad, la fiabilidad y la validez; así como el contraste de las hipótesis.

Tabla 4.10 Medidas absolutas de ajuste

\begin{tabular}{||c|c||}
\hline $\begin{array}{c}\text { MEDIDAS ABSOLUTAS DE } \\
\text { AJUSTE }\end{array}$ & $\begin{array}{c}\text { NIVELES DE ACEPTACIÓN } \\
\text { RECOMENDADOS }\end{array}$ \\
\hline $\begin{array}{c}\chi 2 \text { Satorra-Bentler y nivel de } \\
\text { significación }\end{array}$ & Nivel de significación mayor de 0,05 \\
\hline GFI & Valores superiores a 0,90 \\
\hline RMSR & Valores inferiores a 0,08 \\
\hline RMSEA & Valores inferiores a 0,08 \\
\hline Medidas incrementales de ajuste & \\
\hline AGFI & Valores superiores a 0,90 \\
\hline BB NFI & Valores superiores a 0,90 \\
\hline BB NNFI & Valores superiores a 0,90 \\
\hline IFI & Valores próximos a 1 \\
\hline Medidas de ajuste de & \\
\hline
\end{tabular}


Capítulo 4 Caracterización del Sector de Estudio e Instrumento de Medida

\begin{tabular}{|c|c||}
\hline \hline $\begin{array}{c}\text { MEDIDAS ABSOLUTAS DE } \\
\text { AJUSTE }\end{array}$ & $\begin{array}{c}\text { NIVELES DE ACEPTACIÓN } \\
\text { RECOMENDADOS }\end{array}$ \\
\hline parsimonia & $\begin{array}{l}\text { Valores entre 1 y 2, llegando a 5 con } \\
\text { menos exigencia }\end{array}$ \\
\hline NC & Valores reducidos \\
\hline AIC & \\
\hline
\end{tabular}

Fuente: Barrio y Luque (2000) 


\section{Capítulo 5}

\section{Resultados del estudio empírico}




\section{CAPÍtULLO 5}

\subsection{INTRODUCCIÓN Y OBJETIVOS DEL CAPÍTULO}

En este capítulo se determinó si los instrumentos utilizados para medir los constructos teóricos fueron adecuados o no y por otra parte si las hipótesis que se han desarrollado en el modelo teórico se cumplen o no en la muestra de estudio. Con este fin, el capítulo se estructura de la siguiente manera:

En primer lugar es necesario asegurar que los instrumentos de medida elaborados en el capítulo 4 son fiables y válidos para la investigación científica (DeVellis, 1991:10). Así, en el apartado 5.2 se analizaron las propiedades de las escalas de medida de los constructos tratados en el modelo teórico (Visión holística de la organización, Gestión por competencias, Aprendizaje continuo, Infraestructura técnica de las TI, Transferencia de Conocimiento y Desempeño organizativo).

En la segunda parte del capítulo se contrastaron las hipótesis teóricas planteadas en el capítulo 3, siguiendo el mismo orden en el que las mismas fueran presentadas. En el apartado 5.3 se desarrollaron los modelos estructurales para cada una de las hipótesis, analizando los resultados y el ajuste de los diferentes modelos.

La investigación se realizó en el sector hoteleo de cuatro y cinco estrellas a nivel nacional, mediante un cuestionario estructurado enviado por correo, como se muestra en la ficha técnica del estudio empírico. 
Capítulo 5 Resultados del estudio empírico

Tabla 5.1. Ficha técnica del estudio empírico

\begin{tabular}{||l|l||}
\hline Universo: & Hoteles de cuatro y cinco estrellas \\
\hline Ámbito de la investigación: & Nacional \\
\hline Tipo de entrevista: & Por correo, mediante cuestionario estructurado \\
\hline Tamaño muestral: & 244 empresas \\
\hline Margen de error estadístico: & $\begin{array}{l} \pm 6 \% \text { (para un nivel de confianza del } 95 \% \text { para } \\
\text { el caso más desfavorable } \mathrm{p}=\mathrm{q}=50 \%)\end{array}$ \\
\hline Fecha del trabajo de campo: & Enero 2010 - Julio 2010 \\
\hline
\end{tabular}

\subsection{ANÁLISIS DE LAS PROPIEDADES DE LAS ESCALAS DE MEDIDA}

Previamente a la utilización de las escalas de medición, se ha procedido a su evaluación, con el fin de asegurar que recogen la información del constructo que se pretende medir, y además, que esta información se obtenga por el procedimiento más exacto y fiable.

\subsubsection{Evaluación de la Escala de medida de la Visión Holística de la Organización}

En el trabajo se ha utilizado la escala de Palacios y Garrigós (2006), ya que cumple con todas las propiedades sociométricas que se le exigen a las escalas de medición en ciencias sociales. Para evaluar esta escala de medida en el estudio empírico se comprobaron tres características: a) la dimensionalidad; b) la fiabilidad; c) la validez (de contenido, convergente y discriminante). 


\section{a) Dimensionalidad}

Para comprobar la unidimensionalidad de cada una de las dimensiones propuestas se realizó un análisis factorial confirmatorio sobre cada una de las dimensiones del modelo inicial.

A continuación se muestran los resultados obtenidos para cada una de las dimensiones:

Tabla 5.2. Índices de ajuste de las dimensiones individuales

\begin{tabular}{|c|c|c|c|c|c|c|c|}
\hline DIMENSIONES & g.l. & $\mathbf{p}$ & $\begin{array}{c}\text { Chi }^{2} \\
\text { Satorra-Bentler }\end{array}$ & RMSR & BB NNFI & IFI & $\mathrm{NC}$ \\
\hline DE1 & 2 & 0,545 & 1,21 & 0,011 & 0,992 & 0,997 & 1,4 \\
\hline DE2 & 2 & 0,565 & 1,13 & 0,007 & 0,01 & 1,004 & 0,49 \\
\hline DE3 & 2 & 0,017 & 8,14 & 0,024 & 0,874 & 0,959 & 5,59 \\
\hline DE4 & 2 & 0,274 & 2,58 & 0,015 & 0,994 & 0,998 & 1,26 \\
\hline DE5 & 2 & 0,969 & 0,06 & 0,003 & 1,02 & 1,007 & 0,03 \\
\hline DE6 & 2 & 0,025 & 7,87 & 0,031 & 0,935 & 0,978 & 4,24 \\
\hline
\end{tabular}

Una vez comprobado que se cumple la unidimensionalidad de los factores de primer orden, se analizó el ajuste del modelo factorial de segundo orden. 
Tabla 5.3. Índices de ajuste del modelo medida de la visión holística

\begin{tabular}{||c|c|c|c|c|c|c||}
\hline g.l. & $\mathbf{P}$ & Satorra-Bentler & RMSR & BB NNFI & IFI & NC \\
\hline 52 & 0,0443 & 70,55 & 0,03 & 0,941 & 0,954 & 2,28 \\
\hline
\end{tabular}

En la siguiente tabla se presenta los estadísticos descriptivos de la variable.

Tabla 5.4. Media y desviación típica de los ítems de la escala visión holística de la organización

\begin{tabular}{|c|c|c|}
\hline Item & $\mathbf{m}$ & $\Sigma$ \\
\hline $\begin{array}{l}\text { V1: La estrategia y la política de gestión del } \\
\text { conocimiento afectan a toda la organización y } \\
\text { repercuten en la forma de concebir y gestionar la } \\
\text { empresa. }\end{array}$ & 5,67 & 0,93 \\
\hline $\begin{array}{l}\text { V2: No es posible la elaboración de políticas y } \\
\text { estrategias sin tener en cuenta a toda la } \\
\text { organización incluyendo proveedores y clientes. }\end{array}$ & 6,38 & 0,34 \\
\hline $\begin{array}{l}\text { V3: Una implantación efectiva de una estrategia } \\
\text { requiere que el control se consiga gracias a los } \\
\text { valores y la visión compartida por todos los } \\
\text { miembros de la empresa. }\end{array}$ & $5,5,81$ & 0,87 \\
\hline $\begin{array}{l}\text { V4: No es posible gestionar la empresa sin } \\
\text { identificar los procesos de la organización y sus }\end{array}$ & 6,43 & 1,08 \\
\hline
\end{tabular}




\begin{tabular}{|l||c||c||}
\hline interrelaciones. & & \\
\hline \hline $\begin{array}{l}\text { V5: Existe un sistema definido de distribución de } \\
\text { información al personal, clientes y proveedores de } \\
\text { acuerdo a las necesidades detectadas. }\end{array}$ & 4,24 & 1,15 \\
\hline $\begin{array}{l}\text { V6: La empresa dispone de sistemas de captación y } \\
\text { tratamiento integral de la información sobre los } \\
\text { procesos (tipo sistemas ERP “Enterprise resource } \\
\text { planning”). }\end{array}$ & 5,97 & 0,85 \\
\hline $\begin{array}{l}\text { V7: La empresa desarrolla proyectos que cruzan las } \\
\text { barreras entre departamentos. }\end{array}$ & 6,14 & 0,88 \\
\hline \hline $\begin{array}{l}\text { V8: Existen incentivos por el cumplimiento de los } \\
\text { objetivos globales de la organización. }\end{array}$ & 4,71 & 1,09 \\
\hline
\end{tabular}

\section{b) Fiabilidad}

Los valores de las cargas, errores de medida y perturbaciones se muestran en la siguiente tabla.

Tabla 5.5. Cargas factoriales estandarizadas y errores de medida

\begin{tabular}{|c|l|c|c|}
\hline $\mathbf{N}^{\mathbf{0}}$ & \multicolumn{1}{|c|}{ Ítem } & $\boldsymbol{\lambda}$ & Error \\
\hline V1 & $\begin{array}{l}\text { La estrategia y la política de gestión del } \\
\text { conocimiento afectan a toda la organización y } \\
\text { repercuten en la forma de concebir y gestionar la } \\
\text { empresa. }\end{array}$ & $0,864^{*}$ & 0,504 \\
\hline V2 & $\begin{array}{l}\text { No es posible la elaboración de políticas y } \\
\text { estrategias sin tener en cuenta a toda la } \\
\text { organización incluyendo proveedores y clientes. }\end{array}$ & 0,822 & 0,570 \\
\hline
\end{tabular}




\begin{tabular}{|c|l|l|l|l||}
\hline V3 & $\begin{array}{l}\text { Una implantación efectiva de una estrategia } \\
\text { requiere que el control se consiga gracias a los } \\
\text { valores y la visión compartida por todos los } \\
\text { miembros de la empresa. }\end{array}$ & 0,778 & 0,628 \\
\hline V4 & $\begin{array}{l}\text { No es posible gestionar la empresa sin identificar } \\
\text { los procesos de la organización y sus } \\
\text { interrelaciones. }\end{array}$ & 0,617 & 0,787 \\
\hline V5 & $\begin{array}{l}\text { Existe un sistema definido de distribución de } \\
\text { información al personal, clientes y proveedores } \\
\text { de acuerdo a las necesidades detectadas. }\end{array}$ & 0,880 & 0,475 \\
\hline V6 & $\begin{array}{l}\text { La empresa dispone de sistemas de captación y } \\
\text { tratamiento integral de la información sobre los } \\
\text { procesos (tipo sistemas ERP “Enterprise } \\
\text { resource planning”). }\end{array}$ & 0,530 & 0,848 \\
\hline V7 & $\begin{array}{l}\text { La empresa desarrolla proyectos que cruzan las } \\
\text { barreras entre departamentos. }\end{array}$ & 0,902 & 0,431 \\
\hline V8 & $\begin{array}{l}\text { Existen incentivos por el cumplimiento de los } \\
\text { objetivos globales de la organización. }\end{array}$ & 0,638 & 0,770 \\
\hline \hline
\end{tabular}

Los parámetros señalados con * se han igualado a 1 con el fin de fijar la escala de la variable latente. Todos los parámetros estimados son estadísticamente significativos al $95 \%(\mathrm{t}>1,96)$.

Por lo que respecta a la fiabilidad individual de los indicadores, aunque algunos no llegan al valor mínimo recomendado para la $\mathrm{R}^{2}$, se entiende que no es necesario eliminarlos del modelo, ya que pueden recoger mejor el contenido de la dimensión, requisito necesario para demostrar la validez de contenido. La fiabilidad compuesta es excelente, ya que presenta un valor de 0,75 y ello 
significa que el conjunto de ítems explica una parte de la variación del factor mucho más grande que la explicada por el error de medida.

\section{c) Validez}

\section{- Validez de contenido}

En general se considera que una escala de medida tiene validez de contenido si cumple dos condiciones. La primera es que la generación de los ítems que la forman se basen en argumentaciones teóricas, escalas y estudios empíricos previos existentes en la literatura. La escala original cumple con el criterio anterior, de hecho existe un artículo que íntegramente argumenta como se ha confeccionado la escala, por lo que se puede considerar que la escala cumple la primera condición.

La segunda condición es que la escala haya sido elaborada de acuerdo con procedimientos aceptados en literatura. El proceso de generación cumple los requisitos marcados por Churchill (1979), por lo que se puede considerar que existe validez de contenido.

\section{- Validez convergente}

A partir de los datos de bondad del indicador BB-NNFI $(0,863)$ y la magnitud de las cargas factoriales (ver tabla 5.5), se asegura la validez convergente de la escala de medida. 
Capítulo 5 Resultados del estudio empírico

Tabla 5.6. Índices de ajuste del modelo de medida

\begin{tabular}{|c|c|c|c|c|c|c|c||}
\hline g.l. & Chi2 & P & BB NNFI & RCFI & GFI & RMR & NC \\
\hline 131 & 158,27 & 0,0525 & 0,863 & 0,981 & 0,826 & 0,052 & 1,21 \\
\hline
\end{tabular}

Las medidas absolutas de ajuste presentan valores excelentes para el caso del índice RMR y de la significatividad del estadístico chi-cuadrado; el índice GFI por el contrario, se sitúa ligeramente por debajo del umbral de aceptación. En cuanto a las medidas incrementales de ajuste, el RCFI obtiene un valor excelente mientras que el BBNFI roza el mínimo recomendado. Por último, la medida de ajuste de parsimonia, la NC, muestra un índice muy bueno.

\section{- Validez discriminante}

La validez discriminante es evaluada mediante la matriz de correlaciones. Dado que todos los valores son menores que 0,9 y estadísticamente significativos, se puede asegurar la validez discriminante de la escala. 
Capítulo 5 Resultados del estudio empírico

Tabla 5.7. Matriz de correlaciones entre dimensiones de la visión holística

\begin{tabular}{|l|r|r|r|r|r|r||}
\hline \hline DIMENSIÓN & \multicolumn{1}{|c|}{ DE1 } & DE2 & DE3 & DE4 & DE5 & DE6 \\
\hline DE1 & 1 & & & & & \\
\hline DE2 & 0,857 & 1 & & & & \\
\hline DE3 & 0,825 & 0,816 & 1 & & & \\
\hline DE4 & 0,814 & 0,789 & 0,855 & 1 & & \\
\hline DE5 & 0,874 & 0,810 & 0,799 & 0,802 & 1 & \\
\hline DE6 & 0,798 & 0,832 & 0,784 & 0,832 & 0,815 & 1 \\
\hline \hline
\end{tabular}

Todos los coeficientes de correlación son estadísticamente significativos $(\mathrm{p} \leq 0,01)$

Una vez comprobada la dimensionalidad, fiabilidad y validez de la escala propuesta, se concluye que cumple todas las propiedades sociométricas que se les exigen a las escalas de medición en las ciencias sociales.

\subsubsection{Evaluación de la Escala de Medida de la Gestión por Competencias}

Como en el caso anterior, se ha utilizado la escala de Palacios y Garrigós (2006), ya que cumple con todas las propiedades sociométricas que se le exigen a las escalas de medición en ciencias sociales. Para evaluar esta escala de medida en el estudio empírico se comprueban tres características: a) la dimensionalidad; b) la fiabilidad; c) la validez (de contenido, convergente y discriminante). 


\section{a) Dimensionalidad}

Para comprobar la unidimensionalidad de cada una de las dimensiones propuestas se realiza un análisis factorial confirmatorio sobre cada una de las dimensiones del modelo inicial. A continuación se muestran los resultados obtenidos para cada una de las dimensiones:

Tabla 5.8. Índices de ajuste de los modelos de las seis dimensiones individuales

\begin{tabular}{|c|c|c|c|c|c|c|c|c||}
\hline Modelo & g.l. & Chi2 & p & BB NNFI RCFI & GFI & RMR & NC \\
\hline D1 & 2 & 0,847 & 0,241 & 0,969 & 0,997 & 0,972 & 0,034 & 1,42 \\
\hline D2 & 5 & 18,801 & 0,002 & 0,910 & 0,954 & 0,894 & 0,054 & 3,76 \\
\hline D3 & 2 & 2,732 & 0,255 & 0,986 & 0,998 & 0,975 & 0,027 & 1,37 \\
\hline D4 & 2 & 1,794 & 0,407 & 0,940 & 1 & 0,982 & 0,040 & 0,89 \\
\hline D5 & 1 & 0,907 & 0,341 & 0,998 & 1 & 0,997 & 0,004 & 0,91 \\
\hline D6 & 5 & 2,129 & 0,831 & 0,988 & 1 & 0,987 & 0,021 & 0,46 \\
\hline \hline
\end{tabular}

El siguiente paso consistió en analizar el ajuste del modelo de segundo orden, entendiendo el concepto formado por seis dimensiones.

Tabla 5.9. Índices de ajuste del modelo de segundo orden

\begin{tabular}{||c|c|c|c|c|c|c|c||}
\hline g.l. & Chi2 & p & BB NNFI & RCFI & GFI & RMR & NC \\
\hline 9 & 10,779 & 0,291 & 0,954 & 0,995 & 0,943 & 0,034 & 1,20 \\
\hline
\end{tabular}


En la siguiente tabla se muestran los estadísticos descriptivos de la variable.

Tabla 5.10. Media y desviación típica de los ítems de la escala gestión por competencias

\begin{tabular}{||l|c|c||}
\hline \multicolumn{1}{|c||}{ Item } & $\mathbf{~}$ & $\mathbf{2}$ \\
\hline $\begin{array}{l}\text { C1: Las habilidades y competencias de cada } \\
\text { empleado deben ser valoradas para el desarrollo } \\
\text { de su carrera profesional. }\end{array}$ & 6,34 & 0,58 \\
\hline $\begin{array}{l}\text { C2: Los compañeros deben ayudar en la mejora } \\
\text { de las competencias y habilidades de cada } \\
\text { empleado. }\end{array}$ & 6,17 & 0,98 \\
\hline $\begin{array}{l}\text { C3: Un cometido de los jefes y supervisores es el } \\
\text { de apoyar a sus subordinados en el desarrollo de } \\
\text { nuevas competencias. }\end{array}$ & 6,24 & 0,68 \\
\hline $\begin{array}{l}\text { C4: La empresa debe implantar un sistema de } \\
\text { gestión por competencias que permita a cada } \\
\text { empleado recibir un salario acorde con las } \\
\text { competencias desarrolladas. }\end{array}$ & 5,77 & 1,03 \\
\hline $\begin{array}{l}\text { C5: La organización dispone de sistemas para } \\
\text { medir las competencias de sus empleados. }\end{array}$ & 4,17 & 1,24 \\
\hline $\begin{array}{l}\text { C6: Los sistemas de remuneración y promoción } \\
\text { de los empleados influyen en el desarrollo de } \\
\text { competencias, ideas y conocimientos por los } \\
\text { empleados. }\end{array}$ & 5,83 & 0,92 \\
\hline $\begin{array}{l}\text { C7: La empresa emplea técnicas de } \\
\text { benchmarking para la mejora de las } \\
\text { competencias de sus empleados. }\end{array}$ & 4,33 & 0,96 \\
\hline
\end{tabular}




\section{b) Fiabilidad}

En la siguiente tabla se presentan los valores de las cargas, errores de medida y perturbaciones. Los ítems que no aparecen en la tabla se han eliminado por no tener cargas estadísticas significativas.

Tabla 5.11. Cargas factoriales estandarizadas y errores de medida

\begin{tabular}{|c|l|c|c||}
\hline $\mathbf{N}^{\mathbf{0}}$ & \multicolumn{1}{|c|}{ Ítem } & $\boldsymbol{1}$ & Error \\
\hline $\mathrm{C} 1$ & $\begin{array}{l}\text { Las habilidades y competencias de cada } \\
\text { empleado deben ser valoradas para el } \\
\text { desarrollo de su carrera profesional. }\end{array}$ & $0,899 *$ & 0,438 \\
\hline $\mathrm{C} 2$ & $\begin{array}{l}\text { Los compañeros deben ayudar en la mejora } \\
\text { de las competencias y habilidades de cada } \\
\text { empleado. }\end{array}$ & 0,881 & 0,474 \\
\hline $\mathrm{C} 3$ & $\begin{array}{l}\text { Un cometido de los jefes y supervisores es } \\
\text { el de apoyar a sus subordinados en el } \\
\text { desarrollo de nuevas competencias. }\end{array}$ & 0,785 & 0,620 \\
\hline $\mathrm{C} 4$ & $\begin{array}{l}\text { La empresa debe implantar un sistema de } \\
\text { gestión por competencias que permita a } \\
\text { cada empleado recibir un salario acorde con } \\
\text { las competencias desarrolladas. }\end{array}$ & 0,640 & 0,769 \\
\hline C7 & $\begin{array}{l}\text { La empresa emplea técnicas de } \\
\text { benchmarking para la mejora de las } \\
\text { competencias de sus empleados. }\end{array}$ & 0,760 \\
\hline
\end{tabular}

Los parámetros señalados con * se han igualado a 1 con el fin de fijar la escala de la variable latente. Todos los parámetros estimados son estadísticamente 
significativos al 95\% ( $>1$ 1,96). El valor que presentan las cargas factoriales estandarizadas es elevado, ya que son superiores a 0,6 y en todo caso superiores a 0,4 que es el mínimo sugerido por Hair et al. (1999).

Por lo que respecta a la fiabilidad individual de los indicadores, aunque algunos no llegan al valor mínimo recomendado para la $\mathrm{R}^{2}$, se entiende que no es necesario eliminarlos del modelo ya que pueden recoger mejor el contenido de la dimensión, requisito necesario para demostrar la validez de contenido. La fiabilidad compuesta supera el mínimo exigido, ya que presenta un valor de 0,82 .

\section{c) Validez}

\section{- Validez de contenido}

La escala de medida cumple con los dos criterios que se le exigen para tener validez de contenido. La primera es que la generación de los ítems que la forman se basen en argumentaciones teóricas, escalas y estudios empíricos previos existentes en la literatura. La escala original cumple con el criterio anterior, por lo que se puede considerar que la escala cumple la primera condición.

La segunda condición es que la escala haya sido elaborada de acuerdo con procedimientos aceptados en la literatura. El proceso de generación cumple los requisitos marcados por Churchill (1979), por lo que se puede considerar que existe validez de contenido. 


\section{- Validez convergente}

A partir de los datos de bondad del indicador BB-NNFI $(0,941)$ y la magnitud de las cargas factoriales (ver tabla 5.11), se asegura la validez convergente de la escala de medida.

Tabla 5.12. Índices de ajuste del modelo de medida

\begin{tabular}{||c|c|c|c|c|c|c|c||}
\hline \hline g.l. & Chi2 & P & BB NNFI & RCFI & GFI & RMR & NC \\
\hline 5 & 9,441 & 0,0927 & 0,941 & 0,976 & 0,946 & 0,057 & 1,89 \\
\hline
\end{tabular}

Como se puede apreciar en la tabla anterior, las medidas de ajuste, las medidas de ajuste incremental y las de ajuste de parsimonia presentan un ajuste excelente.

\section{- Validez discriminante}

De las correlaciones bivariadas se obtienen coeficientes que no alcanzan el valor de 0,9 ; ya que cada ítem mide aspectos diferentes del concepto de gestión por competencias, por lo que se puede deducir que esta escala cumple la propiedad de la validez discriminante.

En la siguiente tabla se presenta el valor de las correlaciones: 
Capítulo 5 Resultados del estudio empírico

Tabla 5.13. Matriz de correlaciones entre dimensiones de la gestión por competencias

\begin{tabular}{||l|r|r|r|r|r|r||}
\hline \hline DIMENSIÓN & \multicolumn{1}{|c|}{ DE1 } & DE2 & DE3 & DE4 & DE5 & DE6 \\
\hline DE1 & 1 & & & & & \\
\hline DE2 & 0,843 & 1 & & & & \\
\hline DE3 & 0,822 & 0,818 & 1 & & & \\
\hline DE4 & 0,823 & 0,791 & 0,842 & 1 & & \\
\hline DE5 & 0,853 & 0,808 & 0,748 & 0,805 & 1 & \\
\hline DE6 & 0,788 & 0,829 & 0,785 & 0,822 & 0,807 & 1 \\
\hline
\end{tabular}

Todos los coeficientes de correlación son estadísticamente significativos $(\mathrm{p} \leq 0,01)$

Por tanto, esta escala, al igual que la anterior, también cumple con todas las propiedades sociométricas que se les exigen a las escalas de medición en las ciencias sociales.

\subsubsection{Evaluación de la Escala de Medida de Aprendizaje continuo}

Debido a que cumple con todas las propiedades sociométricas que se le exigen a las escalas de medición en ciencias sociales, se ha utilizado la escala de Palacios y Garrigós (2006), como en el caso anterior. Para evaluar esta escala de medida en el estudio empírico se han comprobado tres características: a) la dimensionalidad; b) la fiabilidad; c) la validez (de contenido, convergente y discriminante). 


\section{a) Dimensionalidad}

Para comprobar la unidimensionalidad de cada una de las dimensiones propuestas se realizó un análisis factorial confirmatorio sobre cada una de las dimensiones del modelo inicial.

A continuación se muestran los resultados obtenidos para cada una de las dimensiones:

Tabla 5.14. Índices de ajuste de las subdimensiones del aprendizaje continuo

\begin{tabular}{|c|c|c|c|c|c|c|c||}
\hline \hline SUBDIMENSIÓN & g.l. & $\mathbf{p}$ & $\begin{array}{c}\text { Chi }^{2} \\
\text { Satorra- } \\
\text { Bentler }^{2}\end{array}$ & RMSR & BB NNFI & IFI & NC \\
\hline DE1 & 2 & 0,453 & 8,82 & 0,032 & 0,989 & 0,994 & 1,34 \\
\hline DE2 & 2 & 0,025 & 7,87 & 0,031 & 0,935 & 0,978 & 4,24 \\
\hline DE3 & 2 & 0,263 & 6,59 & 0,028 & 0,993 & 0,996 & 1,24 \\
\hline DE4 & 2 & 0,969 & 0,061 & 0,003 & 1,02 & 1,007 & 0,03 \\
\hline DE5 & 2 & 0,712 & 6,2761 & 0,025 & 0,993 & 0,996 & 1,27 \\
\hline DE6 & 20 & 0,130 & 27,19 & 0,031 & 0,978 & 0,978 & 1,62 \\
\hline
\end{tabular}

Respecto al modelo factorial del segundo orden se ha obtenido igualmente unos índices de ajuste perfectos. La siguiente tabla muestra los valores obtenidos: 
Capítulo 5 Resultados del estudio empírico

Tabla 5.15. Índices de ajuste del modelo de segundo orden del aprendizaje continuo

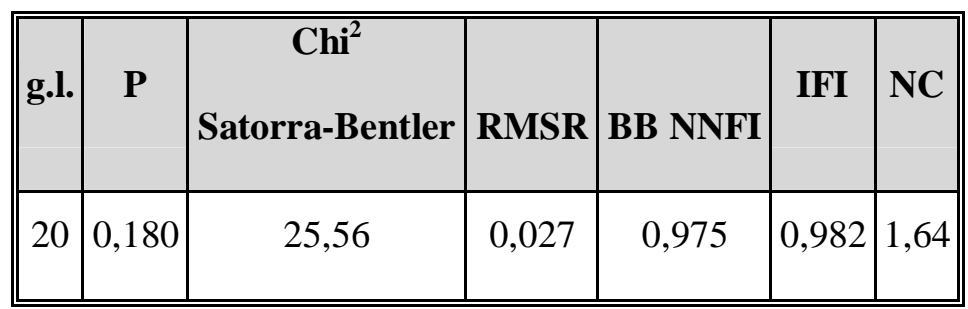

En la siguiente tabla se presenta los estadísticos descriptivos de la variable.

Tabla 5.16. Media y desviación típica de los ítems de la escala aprendizaje continuo

\begin{tabular}{||l|c|c||}
\hline \multicolumn{1}{|c|}{ Item } & M & $\boldsymbol{\Sigma}$ \\
\hline $\begin{array}{l}\text { A1: En la empresa se ha de fomentar la } \\
\text { reflexión, la crítica y el cambio para la } \\
\text { mejora continua }\end{array}$ & 6,34 & 0,58 \\
\hline $\begin{array}{l}\text { A2: Las nuevas ideas deben ser muy } \\
\text { valoradas, independientemente del } \\
\text { empleado que las formule }\end{array}$ & 6,17 & 0,98 \\
\hline $\begin{array}{l}\text { A3: En una organización se debe esperar } \\
\text { de todos, no sólo de los directivos, que } \\
\text { resuelvan los problemas y ofrezcan } \\
\text { sugerencias }\end{array}$ & & \\
\hline $\begin{array}{l}\text { A4: Los empleados deben ver su trabajo } \\
\text { en la empresa como un proceso de } \\
\text { aprendizaje que nunca termina }\end{array}$ & 5,77 & 1,03 \\
\hline $\begin{array}{l}\text { A5: La empresa posee un plan de carrera } \\
\text { que incentiva a sus empleados al }\end{array}$ & 4,17 & 1,24 \\
\hline
\end{tabular}


Capítulo 5 Resultados del estudio empírico

\begin{tabular}{||l|c|c||}
\hline \hline aprendizaje continuo & & \\
\hline $\begin{array}{l}\text { A6: Los empleados reciben formación } \\
\text { generalista que posteriormente aplican a } \\
\text { sus tareas habituales }\end{array}$ & 5,83 & 0,92 \\
\hline $\begin{array}{l}\text { A7: Existe un sistema de mejora } \\
\text { continua que permite mejorar los } \\
\text { procesos que hayan alcanzado los } \\
\text { estándares de calidad fijados }\end{array}$ & 4,33 & 0,96 \\
\hline
\end{tabular}

\section{b) Fiabilidad}

En la siguiente tabla se muestran los valores de las cargas, errores de medida y perturbaciones. Los ítems que no aparecen en la tabla se han eliminado por no tener cargas estadísticas significativas.

Tabla 5.17. Cargas factoriales estandarizadas y errores de medida

\begin{tabular}{|c|l|c|c|c|}
\hline $\mathbf{N}^{\mathbf{0}}$ & \multicolumn{1}{|c|}{ Ítem } & $\boldsymbol{1}$ & Error \\
\hline A1 & $\begin{array}{l}\text { En la empresa se ha de fomentar la } \\
\text { reflexión, la crítica y el cambio para la } \\
\text { mejora continua }\end{array}$ & $0,814^{*}$ & 0,582 \\
\hline A2 & $\begin{array}{l}\text { Las nuevas ideas deben ser muy valoradas, } \\
\text { independientemente del empleado que las } \\
\text { formule }\end{array}$ & 0,880 & 0,474 \\
\hline A3 & $\begin{array}{l}\text { En una organización se debe esperar de } \\
\text { todos, no sólo de los directivos, que } \\
\text { resuelvan los problemas y ofrezcan } \\
\text { sugerencias }\end{array}$ & 0,933 & 0,360 \\
\hline
\end{tabular}




\begin{tabular}{||l|l|c|c||}
\hline A4 & $\begin{array}{l}\text { Los empleados deben ver su trabajo en la } \\
\text { empresa como un proceso de aprendizaje } \\
\text { que nunca termina }\end{array}$ & 0,841 & 0,541 \\
\hline A5 & $\begin{array}{l}\text { La empresa posee un plan de carrera que } \\
\text { incentiva a sus empleados al aprendizaje } \\
\text { continuo }\end{array}$ & 0,581 & 0,814 \\
\hline A6 & $\begin{array}{l}\text { Los empleados reciben formación } \\
\text { generalista que posteriormente aplican a sus } \\
\text { tareas habituales }\end{array}$ & 0,638 & 0,770 \\
\hline A7 & $\begin{array}{l}\text { Existe un sistema de mejora continua que } \\
\text { permite mejorar los procesos que hayan } \\
\text { alcanzado los estándares de calidad fijados }\end{array}$ & 0,775 & 0,632 \\
\hline
\end{tabular}

Los parámetros señalados con * se han igualado a 1 con el fin de fijar la escala de la variable latente. Todos los parámetros estimados son estadísticamente significativos al 95\% ( $>1,96)$. El valor que presentan las cargas factoriales estandarizadas es elevado, ya que son superiores a 0,58 y en todo caso superiores a 0,4 que es el mínimo sugerido por Hair et al. (1999).

En lo que respecta a la fiabilidad individual de los indicadores, aunque algunos no llegan al valor mínimo recomendado para la $\mathrm{R}^{2}$, se entiende que no es necesario eliminarlos del modelo, ya que pueden recoger mejor el contenido de la dimensión, requisito necesario para demostrar la validez de contenido. La fiabilidad compuesta supera el mínimo exigido, ya que presenta un valor de 0,84 . 


\section{c) Validez}

\section{- Validez de contenido}

La escala de medida cumple con los dos criterios que se le exigen para tener validez de contenido. La primera es que la generación de los ítems que la forman se basen en argumentaciones teóricas, escalas y estudios empíricos previos existentes en la literatura. La escala original cumple con el criterio anterior, por lo que se puede considerar que la escala cumple la primera condición.

La escala ha sido elaborada de acuerdo con procedimientos aceptados en la literatura, en este caso por Churchill (1979), por lo que cumple esta segunda condición y se puede considerar que existe validez de contenido.

\section{- Validez convergente}

A partir de los datos de bondad del indicador BB-NNFI $(0,969)$ y la magnitud de las cargas factoriales (ver tabla 5.17), se asegura la validez convergente de la escala de medida.

Tabla 5.18. Índices de ajuste del modelo de medida

\begin{tabular}{||c|c|c|c|c|c|c|c||}
\hline g.l. & Chi2 & p & BB NNFI & RCFI & GFI & RMR & NC \\
\hline 2 & 2,847 & 0,241 & 0,969 & 0,997 & 0,972 & 0,034 & 1,42 \\
\hline
\end{tabular}

Como se puede apreciar en la tabla anterior, las medidas de ajuste, las medidas de ajuste incremental y las de ajuste de parsimonia presentan un ajuste excelente. 


\section{- Validez discriminante}

De las correlaciones bivariadas se obtienen coeficientes que no alcanzan el valor de 0,9; ya que cada ítem mide aspectos diferentes del concepto de aprendizaje continuo. Por ello que se puede deducir que esta escala cumple la propiedad de la validez discriminante.

En la siguiente tabla se presenta el valor de las correlaciones:

Tabla 5.19. Matriz de correlaciones entre dimensiones del aprendizaje continuo

\begin{tabular}{||l|r|r|r|r|r|r||}
\hline \hline DIMENSIÓN & \multicolumn{1}{|c|}{ DE1 } & DE2 & DE3 & DE4 & DE5 & DE6 \\
\hline DE1 & 1 & & & & & \\
\hline DE2 & 0,825 & 1 & & & & \\
\hline DE3 & 0,843 & 0,824 & 1 & & & \\
\hline DE4 & 0,817 & 0,724 & 0,836 & 1 & & \\
\hline DE5 & 0,849 & 0,803 & 0,768 & 0,802 & 1 & \\
\hline DE6 & 0,796 & 0,817 & 0,765 & 0,828 & 0,824 & 1 \\
\hline
\end{tabular}

Todos los coeficientes de correlación son estadísticamente significativos

$$
(\mathrm{p} \leq 0,01)
$$


Por tanto, esta escala al igual que la anterior también cumple con todas las propiedades sociométricas que se les exigen a las escalas de medición en las ciencias sociales.

\subsubsection{Evaluación de la Escala de Medida de Infraestructura Técnica de las TI}

En este caso se utilizó la escala de Byrd y Turner (2000). Como en los casos anteriores, para evaluar esta escala de medida en el estudio empírico, se han comprobado tres características: a) la dimensionalidad; b) la fiabilidad; c) la validez (de contenido, convergente y discriminante).

\section{a) Dimensionalidad}

En primer lugar se comprueba la unidimensionalidad de cada una de las dimensiones propuestas realizando un análisis factorial confirmatorio sobre cada una de las dimensiones del modelo inicial.

A continuación se muestran los resultados obtenidos para cada una de las dimensiones: 
Capítulo 5 Resultados del estudio empírico

Tabla 5.20. Índices de ajuste de las dimensiones de la infraestructura técnica de las TI

\begin{tabular}{||c|c|c|c|c|c|c|c||}
\hline DIMENSIÓN & g.l. & $\mathbf{p}$ & Chi $^{2}$ & RMSR & BB NNFI & IFI & NC \\
\hline D1 & 54 & 0,067 & 70,28 & 0,028 & 0,977 & 0,981 & 1,43 \\
\hline D2 & 14 & 0,112 & 20,57 & 0,025 & 0,975 & 0,984 & 1,8 \\
\hline D3 & 27 & 0,471 & 26,85 & 0,024 & 0,990 & 0,993 & 1,24 \\
\hline D4 & 5 & 0,068 & 10,28 & 0,045 & 0,928 & 0,964 & 3,89 \\
\hline
\end{tabular}

Los resultados son excelentes para todas las dimensiones en todos los aspectos. Todos los modelos están sobreidentificados (g.l. mayores que cero), las $\mathrm{Chi}^{2}$ son estadísticamente significativas y las medidas de ajuste alcanzan o están muy próximos a los valores estipulados como buenos. Los resultados de ajuste incremental y absoluto son excelentes.

La siguiente tabla muestra como se ajusta el modelo de segundo orden. Los valores que se obtienen están dentro de los rangos adecuados. 
Tabla 5.21. Índices de ajuste del modelo medida de la infraestructura técnica en TI

\begin{tabular}{||c|c|c|c|c|c|c||}
\hline \hline g.l. & $\mathbf{P}$ & $\begin{array}{c}\mathbf{C h i}^{2} \\
\text { Satorra-Bentler }\end{array}$ & RMSR & BB NNFI & IFI & NC \\
\hline 49 & 0,0947 & 563,81 & 0,039 & 0,974 & 0,976 & 1,19 \\
\hline
\end{tabular}

En la siguiente tabla se presentan los estadísticos descriptivos de la variable infraestructura técnica de las TI.

Tabla 5.22. Media y desviación típica de los ítems de la escala infraestructura técnica de las TI

\begin{tabular}{||l|c|c||}
\hline \multicolumn{1}{|c||}{ Item } & M & $\mathbf{\Sigma}$ \\
\hline $\begin{array}{l}\text { I1: Nuestra empresa tiene lo último en } \\
\text { sistemas y conexiones de Tecnología } \\
\text { Informática, TI, disponibles (ej. ADSL, } \\
\text { VDSL, ATM, SDV) }\end{array}$ & 4,67 & 0,68 \\
\hline $\begin{array}{l}\text { I2: Nuestra empresa ha tratado formalmente el } \\
\text { tema de la seguridad de los datos con diversos } \\
\text { protocolos (ej. Kerberos, V.5, MIME, PGP, S- } \\
\text { HTTP) }\end{array}$ & 4,29 & 0,92 \\
\hline $\begin{array}{l}\text { I3: Todas las oficinas y sucursales remotas } \\
\text { están conectadas a la oficina central }\end{array}$ & 4,44 & 0,71 \\
\hline $\begin{array}{l}\text { I4: Nuestra empresa utiliza mecanismos de } \\
\text { red de sistemas abiertos para estimular la }\end{array}$ & 4,10 & 1,13 \\
\hline
\end{tabular}


Capítulo 5 Resultados del estudio empírico

\begin{tabular}{|l|c|c||}
\hline \multicolumn{1}{|c||}{ Item } & $\mathbf{M}$ & \\
\hline conectividad & & \\
\hline $\begin{array}{l}\text { I5: En nuestra empresa no existen cuellos de } \\
\text { botella en la comunicación }\end{array}$ & 3,86 & 1,25 \\
\hline $\begin{array}{l}\text { I6: Nuestra empresa utiliza una red virtual o } \\
\text { VLAN para conectarse a los usuarios finales }\end{array}$ & 3,78 & 0,93 \\
\hline $\begin{array}{l}\text { I7: Los módulos de software reusables son } \\
\text { ampliamente utilizados en el desarrollo de } \\
\text { nuevos sistemas }\end{array}$ & 3,02 & 0,33 \\
\hline $\begin{array}{l}\text { I8: Se utilizan herramientas orientadas a } \\
\text { objetos para crear las aplicaciones de los } \\
\text { usuarios finales en colaboración con éstos }\end{array}$ & 4,47 & 1,47 \\
\hline $\begin{array}{l}\text { I9: El personal de TI utiliza tecnologías } \\
\text { orientadas a objetos para minimizar el tiempo } \\
\text { de desarrollo de las aplicaciones }\end{array}$ & 4,12 & 1,05 \\
\hline $\begin{array}{l}\text { I10: Los sistemas heredados en nuestra } \\
\text { organización no limitan el desarrollo de } \\
\text { nuevas aplicaciones }\end{array}$ & 3,08 & 0,67 \\
\hline $\begin{array}{l}\text { I11: Apenas se utilizan funciones } \\
\text { programadas para otras aplicaciones en el } \\
\text { desarrollo de nuevas aplicaciones }\end{array}$ & 4,05 & 1,65 \\
\hline $\begin{array}{l}\text { I12: Las oficinas remotas tienen que realizar } \\
\text { pasos adicionales o procedimientos para } \\
\text { acceder a la oficina central }\end{array}$ & & \\
\hline $\begin{array}{l}\text { I13: Los usuarios finales utilizan un sistema } \\
\text { operativo común en toda la organización (ej. } \\
\text { UNIX, LINUX, OS/2 }\end{array}$ & & \\
\hline \hline
\end{tabular}


Capítulo 5 Resultados del estudio empírico

\begin{tabular}{|l|c|c||}
\hline \multicolumn{1}{|c||}{ Item } & $\mathbf{M}$ & $\mathbf{\Sigma}$ \\
\hline $\begin{array}{l}\text { I14: Las aplicaciones de software pueden ser } \\
\text { fácilmente transportadas ysadas en múltiples } \\
\text { plataformas }\end{array}$ & 4,37 & 0,95 \\
\hline $\begin{array}{l}\text { I15: Nuestra empresa ofrece una amplia } \\
\text { variedad de tipos de información a los } \\
\text { usuarios finales (multimedia) }\end{array}$ & 2,87 & 1,64 \\
\hline $\begin{array}{l}\text { I16: Los interfaces de nuestros usuarios } \\
\text { proporcionan un acceso transparente a todas } \\
\text { las plataformas y aplicaciones }\end{array}$ & 3,69 & 1,08 \\
\hline $\begin{array}{l}\text { I17: Nuestra empresa proporciona múltiples } \\
\text { interfaces o puntos de entrada (ej. Acceso } \\
\text { web) para los usuarios externos }\end{array}$ & 3,57 & 1,44 \\
\hline $\begin{array}{l}\text { I18: La conexión con la oficina central es } \\
\text { inmediata desde cualquier terminal de la } \\
\text { empresa }\end{array}$ & 3,95 & 1,17 \\
\hline $\begin{array}{l}\text { I19: Nuestra base de datos corporativa es } \\
\text { capaz de comunicarse a través de varios } \\
\text { protocolos (ej. SQL, ODBC) }\end{array}$ & 4,42 & 0,94 \\
\hline $\begin{array}{l}\text { I20: Los empleados que trabajan fuera de la } \\
\text { oficina tienen acceso rápido a los mismos } \\
\text { datos utilizados en los PC de la oficina }\end{array}$ & 2,74 & 1,04 \\
\hline $\begin{array}{l}\text { I21: Existen dificultades para adaptarse a los } \\
\text { estándares y protocolos de bases de datos de } \\
\text { algunos proveedores }\end{array}$ & 4,34 & 0,84 \\
\hline $\begin{array}{l}\text { I22: Los datos capturados en cualquier parte } \\
\text { de nuestra empresa están inmediatamente } \\
\text { disponibles en la base de datos }\end{array}$ & 4,05 & 0,67 \\
\hline
\end{tabular}




\section{b) Fiabilidad}

En la siguiente tabla se muestran los valores de las cargas, errores de medida y perturbaciones. Los ítems que no aparecen en la tabla se han eliminado por no tener cargas estadísticas significativas.

Tabla 5.23. Cargas factoriales estandarizadas y errores de medida

\begin{tabular}{|c|c|c|c|}
\hline $\mathbf{N}^{\mathbf{0}}$ & Ítem & $\lambda$ & Error \\
\hline I1 & 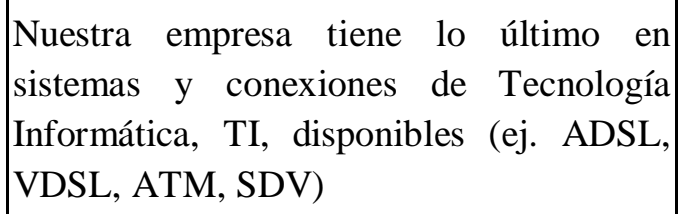 & $0,864 *$ & 0,504 \\
\hline I4 & $\begin{array}{l}\text { Nuestra empresa utiliza mecanismos de } \\
\text { red de sistemas abiertos para estimular la } \\
\text { conectividad }\end{array}$ & 0,822 & 0,570 \\
\hline I8 & $\begin{array}{l}\text { Se utilizan herramientas orientadas a } \\
\text { objetos para crear las aplicaciones de los } \\
\text { usuarios finales en colaboración con éstos }\end{array}$ & 0,778 & 0,628 \\
\hline I14 & $\begin{array}{l}\text { Las aplicaciones de software pueden ser } \\
\text { fácilmente transportadas y usadas en } \\
\text { múltiples plataformas }\end{array}$ & 0,792 & 0,611 \\
\hline I16 & $\begin{array}{l}\text { Los interfaces de nuestros usuarios } \\
\text { proporcionan un acceso transparente a } \\
\text { todas las plataformas y aplicaciones }\end{array}$ & 0,763 & 0,646 \\
\hline I19 & $\begin{array}{l}\text { Nuestra base de datos corporativa es capaz } \\
\text { de comunicarse a través de varios }\end{array}$ & 0,897 & 0,442 \\
\hline
\end{tabular}


Capítulo 5 Resultados del estudio empírico

\begin{tabular}{|l|l|c|c|}
\hline I22 & $\begin{array}{l}\text { protocolos (ej. SQL, ODBC) } \\
\text { nuestra empresa están inmediatamente } \\
\text { disponibles en la base de datos }\end{array}$ & 0,778 & 0,629 \\
\hline
\end{tabular}

Los parámetros señalados con * se han igualado a 1 con el fin de fijar la escala de la variable latente. Todos los parámetros estimados son estadísticamente significativos al 95\% ( $\mathrm{t}>1,96)$. El valor que presentan las cargas factoriales estandarizadas es elevado, ya que son superiores a 0,7 y en todo caso superiores a 0,4 que es el mínimo sugerido por Hair et al. (1999).

En lo que respecta a la fiabilidad individual de los indicadores, aunque algunos no llegan al valor mínimo recomendado para la $\mathrm{R}^{2}$. Sin embargo, no es recomendable eliminarlos del modelo porque pueden recoger mejor el contenido de la dimensión, requisito necesario para demostrar la validez de contenido. La fiabilidad compuesta supera el mínimo exigido, ya que presenta un valor de 0,78.

\section{c) Validez}

\section{- Validez de contenido}

La escala de medida cumple con los dos criterios que se le exigen para tener validez de contenido. La primera es que la generación de los ítems que la forman se basen en argumentaciones teóricas, escalas y estudios empíricos previos existentes en la literatura. La escala original cumple con el criterio anterior, por lo que se puede considerar que la escala cumple la primera condición. 
La segunda condición es que la escala haya sido elaborada de acuerdo con procedimientos aceptados en la literatura. El proceso de generación cumple los requisitos marcados por Churchill (1979), por lo que se puede considerar que existe validez de contenido.

\section{- Validez convergente}

A partir de los datos de bondad del indicador BB-NNFI $(0,910)$ y la magnitud de las cargas factoriales (ver tabla 5.23), se asegura la validez convergente de la escala de medida.

Tabla 5.24. Índices de ajuste del modelo de medida

\begin{tabular}{||c|c|c|c|c|c|c|c||}
\hline \hline g.l. & Chi2 & P & BB NNFI & RCFI & GFI & RMR & NC \\
\hline 5 & 18,801 & 0,002 & 0,910 & 0,954 & 0,894 & 0,054 & 3,76 \\
\hline
\end{tabular}

Como se puede ver en la tabla anterior, las medidas de ajuste, las medidas de ajuste incremental y las de ajuste de parsimonia presentan un ajuste excelente.

\section{- Validez discriminante}

De las correlaciones bivariadas se obtienen coeficientes que no alcanzan el valor de 0,9 , por lo que cada ítem mide aspectos diferentes del concepto de infraestructura técnica de las TI, por lo que se puede deducir que esta escala cumple la propiedad de la validez discriminante. 
Se verá en la siguiente tabla el valor de las correlaciones:

Tabla 5.25. Matriz de correlaciones entre dimensiones de la infraestructura técnica de las TI

\begin{tabular}{||c|r|r|r|r||}
\hline DIMENSIÓN & \multicolumn{1}{|c|}{ DE1 } & DE2 & DE3 & DE4 \\
\hline DE1 & 1 & & & \\
\hline DE2 & 0,795 & 1 & & \\
\hline DE3 & 0,835 & 0,741 & 1 & \\
\hline DE4 & 0,816 & 0,804 & 0,799 & 1 \\
\hline
\end{tabular}

Todos los coeficientes de correlación son estadísticamente significativos ( $\mathrm{p} \leq$ $0,01)$

Por tanto, esta escala al igual que las anteriores también cumple con todas las propiedades sociométricas que se les exigen a las escalas de medición en las ciencias sociales.

\subsubsection{Evaluación de la Escala de Medida de Transferencia de Conocimiento}

En este caso se utilizó la escala de Yi (2009). Para evaluar esta escala de medida en el estudio empírico se verificaron tres características: a) la dimensionalidad; b) la fiabilidad; c) la validez (de contenido, convergente y discriminante). 


\section{a) Dimensionalidad}

En primer lugar se comprueba la unidimensionalidad de cada una de las dimensiones propuestas realizando un análisis factorial confirmatorio sobre cada una de las dimensiones del modelo inicial.

A continuación se muestran los resultados obtenidos para cada una de las dimensiones:

Tabla 5.26. Índices de ajuste de los modelos de las dimensiones individuales para la transferencia de conocimiento

\begin{tabular}{||c|c|c|c|c|c|c|c|c||}
\hline \hline & G.L. & Chi $^{2}$ & P & BB NFI & IFI & GFI & AGFI & PGFI \\
\hline D1 & 2 & 0,0289 & 0,8595 & 0,9972 & 0,999 & 0,9952 & 0,9762 & 0,9856 \\
\hline D2 & 2 & 0,856 & 0,6523 & 0,9740 & 0,9795 & 0,9625 & 0,9478 & 0,9785 \\
\hline D3 & 2 & 0,965 & 0,5263 & 0,9553 & 0,9584 & 0,9377 & 0,9101 & 0,9562 \\
\hline D4 & 2 & 0,0365 & 0,8462 & 0,9947 & 0,9976 & 0,9917 & 0,9744 & 0,9832 \\
\hline
\end{tabular}


El segundo paso es ajustar el modelo de segundo orden de la escala.

Tabla 5.27. Modelo de segundo orden de la variable transferencia de conocimiento

\begin{tabular}{||c|c|c|c|c|c|c|c|c||}
\hline \hline & G.L. & Chi $^{\mathbf{2}}$ & P & BB NFI & IFI & GFI & AGFI & PGFI \\
\hline D1 & 5 & 7,98 & 0,4356 & 0,9425 & 0,9452 & 0,9536 & 0,9296 & 0,9523 \\
\hline
\end{tabular}

En la siguiente tabla se presentan los estadísticos descriptivos de la variable transferencia de conocimiento.

Tabla 5.28. Media y desviación típica de los ítems de la escala transferencia de conocimiento

\begin{tabular}{||l|c|c||}
\hline \multicolumn{1}{|c|}{ Item } & $\mathbf{M}$ & $\mathbf{\Sigma}$ \\
\hline T1: Presentar regularmente documentos e informes & 4,35 & 0,72 \\
\hline $\begin{array}{l}\text { T2: Publicar artículos en revistas de la empresa, revistas } \\
\text { especializadas o boletines de noticias }\end{array}$ & 4,15 & 0,95 \\
\hline $\begin{array}{l}\text { T3: Compartir la documentación de los archivos } \\
\text { personales relacionados con el trabajo actual }\end{array}$ & 4,07 & 1,05 \\
\hline $\begin{array}{l}\text { T4: Contribuir con ideas y pensamientos a la empresa } \\
\text { mediante bases de datos en línea }\end{array}$ & 3,78 & 1,34 \\
\hline $\begin{array}{l}\text { T5: Mantener a otros empleados al día con información } \\
\text { importante de la empresa a través de foros de discusión en } \\
\text { línea }\end{array}$ & 3,92 & 1,43 \\
\hline
\end{tabular}




\section{Capítulo 5 Resultados del estudio empírico}

\begin{tabular}{|l|c|c||}
\hline \multicolumn{1}{|c||}{ Item } & M & $\mathbf{\Sigma}$ \\
\hline $\begin{array}{l}\text { T6: Expresar ideas y pensamientos en las reuniones de la } \\
\text { empresa }\end{array}$ & 4,09 & 0,91 \\
\hline $\begin{array}{l}\text { T7: Participar plenamente en sesiones de lluvia de ideas } \\
\text { (“brainstorming”) }\end{array}$ & 4,12 & 0,84 \\
\hline $\begin{array}{l}\text { T8: Proponer sugerencias para resolver problemas en las } \\
\text { reuniones de equipo en colaboración con éstos }\end{array}$ & 4,24 & 1,25 \\
\hline $\begin{array}{l}\text { T9: Responder a las preguntas de los demás en reuniones } \\
\text { de equipo }\end{array}$ & 3,98 & 1,03 \\
\hline $\begin{array}{l}\text { T10: Hacer preguntas que puedan provocar la discusión y } \\
\text { análisis en las reuniones de equipo }\end{array}$ & 4,39 & 0,71 \\
\hline $\begin{array}{l}\text { T11: Compartir historias de éxito que pueden beneficiar a } \\
\text { la empresa en las reuniones de organización }\end{array}$ & 4,23 & 1,33 \\
\hline $\begin{array}{l}\text { T12: Compartir los fracasos relacionados con el trabajo, } \\
\text { para ayudar a otros a evitar la repetición de estas en las } \\
\text { reuniones de la empresa }\end{array}$ & 4,73 & 1,24 \\
\hline $\begin{array}{l}\text { T13: Hacer presentaciones en las reuniones de la empresa } \\
\text { p14: Apoyar a los empleados con menos experiencia } \\
\text { durante el tiempo de trabajo personal }\end{array}$ & 4,22 & 0,91 \\
\hline $\begin{array}{l}\text { T15: Participar en las acciones de entrenamiento a largo } \\
\text { plazo de los empleados más jóvenes }\end{array}$ & 3,58 & 1,49 \\
\hline $\begin{array}{l}\text { T16: Pasar tiempo en conversaciones personales (por } \\
\text { ejemplo, la discusión en el pasillo, durante el almuerzo, a } \\
\text { través del teléfono) con otros, para ayudarles a resolver } \\
\text { problemas del trabajo }\end{array}$ & 4,83 & 0,21 \\
\hline $\begin{array}{l}\text { T17: Mantener a otros empleados al día con información } \\
\text { importante de la empresa a través de una conversación }\end{array}$ & 4,11 & 1,65 \\
\hline \hline
\end{tabular}


Capítulo 5 Resultados del estudio empírico

\begin{tabular}{|l|c|c||}
\hline \hline \multicolumn{1}{|c||}{ Item } & $\mathbf{\Sigma}$ \\
\hline personal & & \\
\hline $\begin{array}{l}\text { T18: Compartir la pasión y la emoción de algunos temas } \\
\text { específicos con los demás mediante la conversación } \\
\text { personal }\end{array}$ & 4,25 & 1,49 \\
\hline $\begin{array}{l}\text { T19: Compartir experiencias que pueden ayudar a otros a } \\
\text { evitar riesgos y problemas mediante la conversación } \\
\text { personal }\end{array}$ & 4,77 & 0,73 \\
\hline $\begin{array}{l}\text { T20: Tener charlas en línea con otros empleados para } \\
\text { ayudarles con sus problemas relacionados con el trabajo }\end{array}$ & 4,03 & 1,47 \\
\hline $\begin{array}{l}\text { T21: Pasar tiempo en la comunicación por email con otros } \\
\text { empleados para } \text { ayudarlos con sus problemas } \\
\text { relacionados con el trabajo }\end{array}$ & 4,16 & 0,93 \\
\hline $\begin{array}{l}\text { T22: Reuniones de la "Comunidad" para crear soluciones } \\
\text { innovadoras a los problemas del trabajo }\end{array}$ & 4,44 & 1,06 \\
\hline $\begin{array}{l}\text { T23: Reuniones de la "Comunidad" para compartir la } \\
\text { propia experiencia y la práctica sobre temas específicos de } \\
\text { común interés }\end{array}$ & 4,27 & 1,62 \\
\hline $\begin{array}{l}\text { T24: Reuniones de la "Comunidad" para compartir el éxito } \\
\text { y malos resultados y sobre temas específicos de común } \\
\text { interés }\end{array}$ & 4,39 & 1,08 \\
\hline $\begin{array}{l}\text { T25: Reuniones de la "Comunidad" para fomentar la } \\
\text { excelencia en el trabajo }\end{array}$ & 4,26 & 0,96 \\
\hline $\begin{array}{l}\text { T26: Apoyo personal de desarrollo de nuevas } \\
\text { "Comunidades" }\end{array}$ & 4,08 & 1,44 \\
\hline $\begin{array}{l}\text { T27: Enviar información relacionada a los miembros de la } \\
\text { "Comunidad" a través lista de correo electrónico }\end{array}$ & 3,78 & \\
\hline \hline
\end{tabular}




\section{Capítulo 5 Resultados del estudio empírico}

\begin{tabular}{||l|c|c||}
\hline \hline \multicolumn{1}{|c|}{ Item } & M & $\mathbf{\Sigma}$ \\
\hline $\begin{array}{l}\text { T28: Compartir ideas y pensamientos sobre temas } \\
\text { específicos a los miembros de la "Comunidad" utilizando } \\
\text { los sistemas en línea }\end{array}$ & 3,55 & 1,22 \\
\hline
\end{tabular}

\section{b) Fiabilidad}

Los valores de las cargas, errores de medida y perturbaciones se muestran en la siguiente tabla. Los ítems que no aparecen en la tabla se han eliminado por no tener cargas estadísticas significativas.

Tabla 5.29. Cargas factoriales estandarizadas y errores de medida

\begin{tabular}{|c|l|c|c|}
\hline \hline $\mathbf{N}^{\mathbf{0}}$ & \multicolumn{1}{|c|}{ Ítem } & \multicolumn{1}{|c|}{$\boldsymbol{1}$} & Error \\
\hline T1 & Presentar regularmente documentos e informes & $0,640^{*}$ & 0,769 \\
\hline T3 & $\begin{array}{l}\text { Compartir la documentación de los archivos } \\
\text { personales relacionados con el trabajo actual }\end{array}$ & 0,756 & 0,655 \\
\hline T6 & $\begin{array}{l}\text { Expresar ideas y pensamientos en las reuniones de la } \\
\text { empresa }\end{array}$ & 0,760 & 0,650 \\
\hline T8 & $\begin{array}{l}\text { Proponer sugerencias para resolver problemas en las } \\
\text { reuniones de equipo en colaboración con éstos }\end{array}$ & 0,783 & 0,622 \\
\hline T10 & $\begin{array}{l}\text { Hacer preguntas que puedan provocar la discusión y } \\
\text { análisis en las reuniones de equipo }\end{array}$ & 0,777 & 0,629 \\
\hline T11 & Compartir historias de éxito que pueden beneficiar a & 0,785 & 0,620 \\
\hline
\end{tabular}




\section{Capítulo 5 Resultados del estudio empírico}

\begin{tabular}{|c|c|c|c|}
\hline & la empresa en las reuniones de organización & & \\
\hline $\mathrm{T} 12$ & $\begin{array}{l}\text { Compartir los fracasos relacionados con el trabajo, } \\
\text { para ayudar a otros a evitar la repetición de estas en } \\
\text { las reuniones de la empresa }\end{array}$ & 0,881 & 0,474 \\
\hline $\mathrm{T} 14$ & $\begin{array}{l}\text { Apoyar a los empleados con menos experiencia } \\
\text { durante el tiempo de trabajo personal }\end{array}$ & 0,749 & 0,662 \\
\hline T16 & $\begin{array}{l}\text { Pasar tiempo en conversaciones personales (por } \\
\text { ejemplo, la discusión en el pasillo, durante el } \\
\text { almuerzo, a través del teléfono) con otros, para } \\
\text { ayudarles a resolver problemas del trabajo }\end{array}$ & 0,917 & 0,399 \\
\hline $\mathrm{T} 17$ & $\begin{array}{l}\text { Mantener a otros empleados al día con información } \\
\text { importante de la empresa a través de una } \\
\text { conversación personal }\end{array}$ & 0,768 & 0,640 \\
\hline $\mathrm{T} 18$ & $\begin{array}{l}\text { Compartir la pasión y la emoción de algunos temas } \\
\text { específicos con los demás mediante la conversación } \\
\text { personal }\end{array}$ & 0,638 & 0,770 \\
\hline $\mathrm{T} 19$ & $\begin{array}{l}\text { Compartir experiencias que pueden ayudar a otros a } \\
\text { evitar riesgos y problemas mediante la conversación } \\
\text { personal }\end{array}$ & 0,801 & 0,599 \\
\hline T24 & $\begin{array}{l}\text { Reuniones de la "Comunidad" para compartir el éxito } \\
\text { y malos resultados y sobre temas específicos de } \\
\text { común interés }\end{array}$ & 0,825 & 0,565 \\
\hline T25 & $\begin{array}{l}\text { Reuniones de la "Comunidad" para fomentar la } \\
\text { excelencia en el trabajo }\end{array}$ & 0,880 & 0,474 \\
\hline
\end{tabular}


Los parámetros señalados con * se han igualado a 1 con el fin de fijar la escala de la variable latente. Todos los parámetros estimados son estadísticamente significativos al 95\% ( $\mathrm{t}>1,96)$. El valor que presentan las cargas factoriales estandarizadas es elevado, ya que son superiores a 0,6 y en todo caso superiores a 0,4 que es el mínimo sugerido por Hair et al. (1999).

En lo que respecta a la fiabilidad individual de los indicadores, aunque algunos no llegan al valor mínimo recomendado para la $\mathrm{R}^{2}$, se entiende que no es necesario eliminarlos del modelo, ya que pueden recoger mejor el contenido de la dimensión, requisito necesario para demostrar la validez de contenido. La fiabilidad compuesta supera el mínimo exigido, ya que presenta un valor de 0,87 .

\section{c) Validez}

\section{- Validez de contenido}

La escala de medida cumple el primer criterio que se le exige para tener validez de contenido, ya que la generación de los ítems que la forman se basa en argumentaciones teóricas, escalas y estudios empíricos previos existentes en la literatura.

También cumple la segunda condición, ya que la escala ha sido elaborada de acuerdo con procedimientos aceptados en la literatura, en este caso los requisitos marcados por Churchill (1979), por lo que se puede considerar que existe validez de contenido. 


\section{- Validez convergente}

A partir de los datos de bondad del indicador BB-NNFI $(0,986)$ y la magnitud de las cargas factoriales (ver tabla 5.29), se asegura la validez convergente de la escala de medida.

Tabla 5.30. Índices de ajuste del modelo de medida

\begin{tabular}{||c|c|c|c|c|c|c|c||}
\hline \hline g.l. & Chi2 & p & BB NNFI & RCFI & GFI & RMR & NC \\
\hline 2 & 2,732 & 0,255 & 0,986 & 0,998 & 0,975 & 0,027 & 1,37 \\
\hline
\end{tabular}

Como se puede apreciar en la tabla anterior, las medidas de ajuste, las medidas de ajuste incremental y las de ajuste de parsimonia presentan un ajuste excelente.

\section{- Validez discriminante}

De las correlaciones bivariadas se obtienen coeficientes que no alcanzan el valor de 0,9 ; ya que cada ítem mide aspectos diferentes del concepto de infraestructura técnica de las TI, por lo que se puede deducir que esta escala cumple la propiedad de la validez discriminante. 
En la siguiente tabla se presenta el valor de las correlaciones:

Tabla 5.31. Matriz de correlaciones entre dimensiones de la transferencia de conocimiento

\begin{tabular}{||c|r|r|r|r|}
\hline DIMENSIÓN & \multicolumn{1}{|c|}{ DE1 } & DE2 & DE3 & DE4 \\
\hline DE1 & 1 & & & \\
\hline DE2 & 0,822 & 1 & & \\
\hline DE3 & 0,688 & 0,804 & 1 & \\
\hline DE4 & 0,745 & 0,748 & 0,834 & 1 \\
\hline
\end{tabular}

Todos los coeficientes de correlación son estadísticamente significativos ( $\mathrm{p} \leq$ $0,01)$

Por tanto, esta escala al igual que las anteriores también cumple con todas las propiedades sociométricas que se les exigen a las escalas de medición en las ciencias sociales.

\subsubsection{Evaluación de la Escala de Medida de Desempeño Organizativo}

Para evaluar la escala de medida de Nakata (2008), en el estudio empírico se comprobaron tres características: a) la dimensionalidad; b) la fiabilidad; c) la validez (de contenido, convergente). 


\section{a) Dimensionalidad}

Esta escala no tiene dimensiones. En la siguiente tabla se presentan los estadísticos descriptivos de la variable desempeño organizativo.

Tabla 5.32. Media y desviación típica de los ítems de la escala desempeño organizativo

\begin{tabular}{||l|c|c||}
\hline \multicolumn{1}{|c|}{ Item } & M & $\mathbf{\Sigma}$ \\
\hline D1: La calidad del producto o servicio & 4,24 & 0,89 \\
\hline D2: El éxito de nuevos productos o servicios & 3,95 & 1,24 \\
\hline D3: La tasa de retención de clientes & 3,87 & 0,96 \\
\hline D4: El nivel de ventas & 3,67 & 1,04 \\
\hline D5: El retorno sobre capital & 4,05 & 0,77 \\
\hline D6: El margen bruto de utilidad & 3,42 & 0,87 \\
\hline D7: El retorno sobre inversión & 4,12 & 1,05 \\
\hline
\end{tabular}

\section{b) Fiabilidad}

En la siguiente tabla se presentan los valores de las cargas, errores de medida y perturbaciones. 
Capítulo 5 Resultados del estudio empírico

Tabla 5.33. Cargas factoriales estandarizadas y errores de medida

\begin{tabular}{|c|l|c|c||}
\hline $\mathbf{N}^{\mathbf{0}}$ & \multicolumn{1}{|c|}{ Ítem } & $\boldsymbol{\lambda}$ & Error \\
\hline D1 & La calidad del producto o servicio & $0,933^{*}$ & 0,360 \\
\hline D2 & El éxito de nuevos productos o servicios & 0,895 & 0,447 \\
\hline D3 & La tasa de retención de clientes & 0,638 & 0,770 \\
\hline D4 & El nivel de ventas & 0,747 & 0,665 \\
\hline D5 & El retorno sobre capital & 0,749 & 0,662 \\
\hline D6 & El margen bruto de utilidad & 0,814 & 0,582 \\
\hline D7 & El retorno sobre inversión & 0,863 & 0,505 \\
\hline
\end{tabular}

El parámetro señalado con * se han igualado a 1 con el fin de fijar la escala de la variable latente. Todos los parámetros estimados son estadísticamente significativos al $95 \%(\mathrm{t}>1,96)$. El valor que presentan las cargas factoriales estandarizadas es elevado, ya que son superiores a 0,6 y en todo caso superiores a 0,4 que es el mínimo sugerido por Hair et al. (1999).

Por lo que respecta a la fiabilidad individual de los indicadores, aunque algunos no llegan al valor mínimo recomendado para la $\mathrm{R}^{2}$, no es necesario eliminarlos del modelo, ya que pueden recoger mejor el contenido de la dimensión, requisito necesario para demostrar la validez de contenido. La fiabilidad compuesta supera el mínimo exigido, ya que presenta un valor de 0,88 . 


\section{c) Validez}

\section{- Validez de contenido}

La escala de medida cumple con los dos criterios que se le exigen para tener validez de contenido. La primera es que la generación de los ítems que la forman se basa en argumentaciones teóricas, escalas y estudios empíricos previos existentes en la literatura. La escala original cumple con el criterio anterior, por lo que se puede considerar que la escala cumple la primera condición.

La segunda condición es que la escala haya sido elaborada de acuerdo con procedimientos aceptados en la literatura. El proceso de generación cumple los requisitos marcados por Churchill (1979), por lo que se puede considerar que existe validez de contenido.

\section{- Validez convergente}

A partir de los datos de bondad del indicador BB-NNFI $(0,956)$ y la magnitud de las cargas factoriales (ver tabla 5.33), se asegura la validez convergente de la escala de medida.

Tabla 5.34. Índices de ajuste del modelo de medida

\begin{tabular}{||c|c|c|c|c|c|c|c||}
\hline g.l. & Chi2 & p & BB NNFI & RCFI & GFI & RMR & NC \\
\hline 2 & 1,985 & 0,370 & 0,956 & 1 & 0,956 & 0,041 & 0,99 \\
\hline
\end{tabular}


Como se puede apreciar en la tabla anterior, las medidas de ajuste, las medidas de ajuste incremental y las de ajuste de parsimonia presentan un ajuste excelente.

Por tanto, esta escala al igual que las anteriores también cumple con todas las propiedades sociométricas que se les exigen a las escalas de medición en las ciencias sociales.

\subsection{CONTRASTE DE HIPÓTESIS MEDIANTE LA UTILIZACIÓN DE MODELOS DE ECUACIONES ESTRUCTURALES}

En este epígrafe se comprueban las relaciones entre los conceptos teóricos utilizando y los modelos de ecuaciones estructurales. A continuación se explican las etapas a seguir en la construcción de modelos de ecuaciones estructurales:

Las etapas a seguir en la construcción de modelos de ecuaciones estructurales son: la especificación, identificación, estimación y evaluación (Hair et al., 1999).

La fase de especificación consiste en el planteamiento de un modelo teórico que concrete la forma de medición de las variables y la relación que existe entre dichas variables.

La fase de identificación consiste en determinar si existe una única solución para cada parámetro, para ello se analiza si las covarianzas entre las variables proporcionan suficiente información para estimar los parámetros del modelo (Batista y Coenders, 2000). 
En la fase de estimación se obtienen los coeficientes que representan las relaciones del modelo y se ajustan los datos.

Finalmente en la fase de evaluación se comprueba la adecuación de los distintos parámetros estimados y el grado de ajuste del modelo.

En el capítulo 3 se han enunciado el conjunto de hipótesis que comprenden el modelo teórico, cuyos resultados se presentan a continuación.

\subsubsection{Primera Hipótesis: Estudio de la Relación entre Visión Holística de la Organización y la Transferencia de Conocimiento}

Esta primera hipótesis se ha formulado previamente en el epígrafe 3.5.1 y supone que existe una relación positiva y significativa entre estas dos variables. Para proceder al contraste de esta hipótesis, en primer lugar, se debe especificar el modelo y sus relaciones estructurales.

El modelo estructural está formado por una variable latente exógena (visión holística de la organización) que tiene a su vez seis dimensiones y una variable latente endógena (transferencia de conocimiento) que está formada por cuatro dimensiones.

\subsubsection{Ajuste global del modelo}

La siguiente tabla muestra los índices de ajuste global del modelo. Del valor de los estadísticos se puede deducir que el modelo está sobreidentificado, es decir, 
que el número de grados de libertad es positivo, de manera parsimoniosa (el NC se encuentra entre 1 y 2 ).

El resto de medidas de ajuste también reflejan medidas excelentes. El estadístico chi-cuadrado es estadísticamente significativo, el índice GFI es superior a 0,9 y el RMR roza el nivel de 0, lo cual indica un buen ajuste en términos absolutos. Igualmente el BBNFI y el RCFI rebasan los niveles mínimos de aceptación.

Tabla 5.35. Índices del ajuste global del modelo

\begin{tabular}{||c|c|c|c|c|c|c|c||}
\hline g.l. & Chi2 & P & BB NNFI RCFI GFI & RMR & NC \\
\hline 18 & 28,782 & 0,051 & 0,950 & 0,991 & 0,904 & 0,024 & 1,6 \\
\hline
\end{tabular}

\subsubsection{Ajuste del modelo de medida}

La evaluación de este ajuste sirve para asegurarse de que las variables latentes están bien medidas mediante las variables observables consideradas. La revisión del ajuste del modelo de medida se realizó a través del examen de la significación estadística de cada carga obtenida entre el indicador y la variable latente $(t \geq 1,96)$. A continuación, se comprueba la fiabilidad compuesta de la variable latente.

La siguiente tabla muestra las cargas factoriales tanto para el modelo exógeno como para el modelo endógeno. Se observa que todas las cargas presentan niveles correctos y son estadísticamente significativas, por lo que el primer requisito para el ajuste del modelo de medida queda comprobado. 
Tabla 5.36. Parámetros estimados en el modelo de medida exógeno y endógeno

\begin{tabular}{||c|c|c||}
\hline $\mathbf{N}^{\mathbf{0}}$ & $\boldsymbol{\lambda}$ & Error \\
\hline VH -D1 & $0,862^{*}$ & 0,506 \\
\hline VH-D2 & 0,916 & 0,401 \\
\hline VH-D3 & 0,844 & 0,536 \\
\hline VH-D4 & 0,924 & 0,383 \\
\hline VH-D5 & 0,822 & 0,570 \\
\hline VH-D6 & 0,778 & 0,628 \\
\hline TC-D1 & $0,931^{*}$ & 0,365 \\
\hline TC-D2 & 0,933 & 0,359 \\
\hline TC-D3 & 0,890 & 0,456 \\
\hline TC-D4 & 0,876 & 0,482 \\
\hline
\end{tabular}

Los parámetros señalados con * se han igualado a 1 con el fin de fijar la escala de la variable latente. Todos los parámetros estimados son estadísticamente significativos al 95\% ( $\mathrm{t}>1,96)$. La fiabilidad compuesta para el modelo exógeno es de 0,76 y de 0,87 para el modelo endógeno, por lo que superan el nivel mínimo de 0,7 . 


\subsubsection{Ajuste del modelo estructural}

El ajuste del modelo estructural implica el análisis de la significación alcanzada por los coeficientes estimados (para un nivel de significación de 0,05 el valor de t ha de alcanzar el valor de 1,96). Un parámetro no significativo indicaría que no hay un efecto sustancial sobre la relación propuesta.

\section{Tabla 5.37. Parámetro estimado e índice de fiabilidad en el modelo estructural de la primera hipótesis}

\begin{tabular}{||c|c|c||}
\hline \hline MODELO & $\begin{array}{c}\text { Coeficiente } \gamma \\
\text { en la ecuación }\end{array}$ & Fiabilidad \\
\hline VH $\rightarrow$ TC & 0,996 & 0,991 \\
\hline
\end{tabular}

El parámetro estimado es estadísticamente significativo al 95\% ( $\mathrm{t}=15,019 \geq 1,96)$. La tabla anterior muestra un ajuste correcto del modelo estructural. Por lo tanto, queda probada la primera hipótesis: existe una relación positiva y estadísticamente significativa entre el enfoque holístico de la organización y la transferencia de conocimiento. Este resultado está acorde con la revisión de la literatura sintetizada en el epígrafe 3.5.1. 


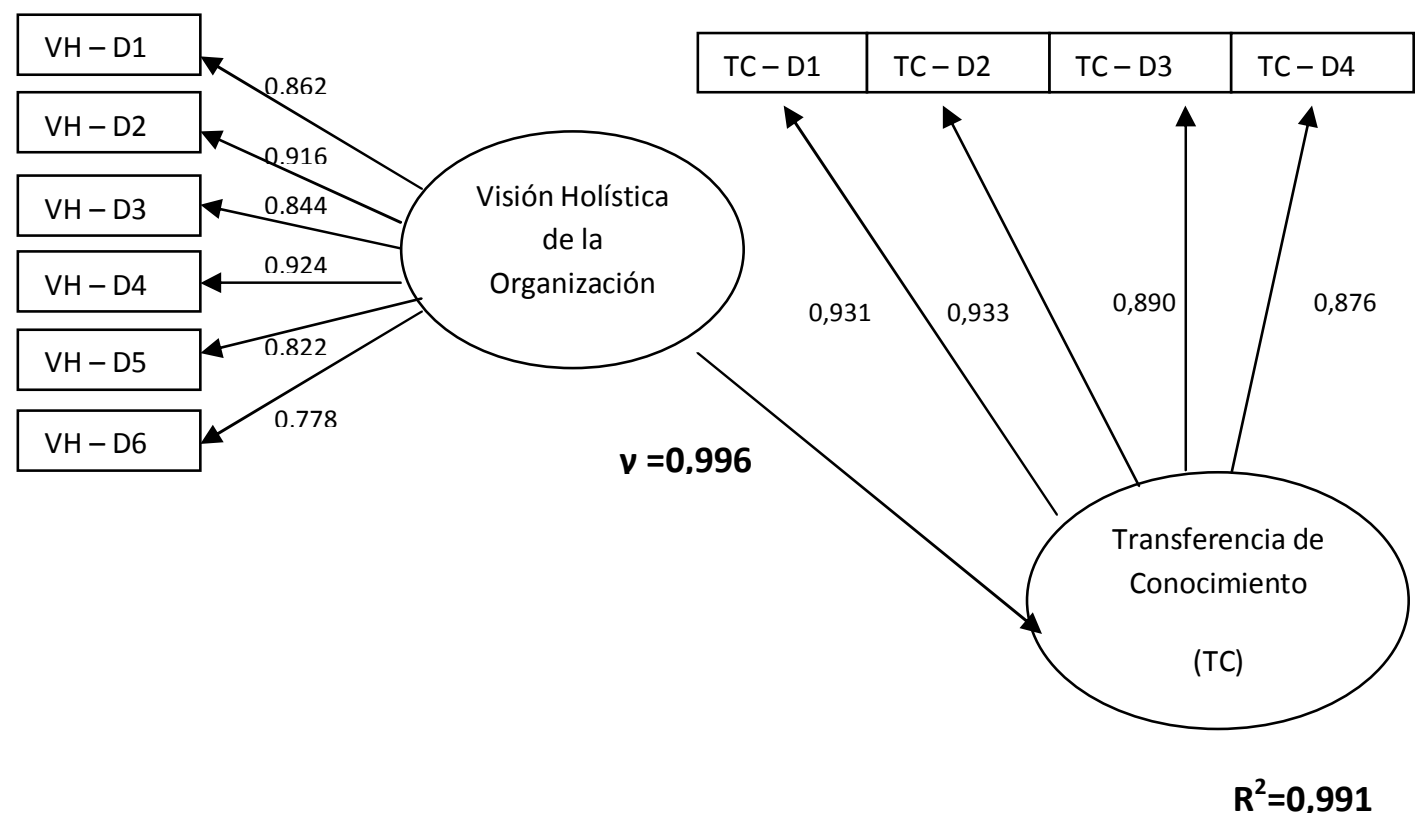

\subsubsection{Segunda Hipótesis: Estudio de la Relación entre la Gestión por Competencias y la Transferencia de Conocimiento}

Esta segunda hipótesis se ha formulado previamente en el epígrafe 3.5.1 y supone que existe una relación positiva y significativa entre estas dos variables. Para proceder al contraste de esta hipótesis, en primer lugar, se debe especificar el modelo y sus relaciones estructurales. El modelo estructural está formado por una variable latente exógena (gestión por competencias) que tiene a su vez seis dimensiones y una variable latente endógena (transferencia de conocimiento) que está formada por cuatro dimensiones. 


\subsubsection{Ajuste global del modelo}

La siguiente tabla muestra los índices de ajuste global del modelo. Del valor de los estadísticos se puede deducir que el modelo está sobreidentificado, es decir, que el número de grados de libertad es positivo, de manera parsimoniosa (el NC se encuentra entre 1 y 2 ).

El resto de medidas de ajuste también reflejan medidas excelentes. El estadístico chi-cuadrado es estadísticamente significativo, el índice GFI es superior a 0,9 y el RMR roza el nivel de 0, lo cual indica un buen ajuste en términos absolutos. Igualmente el BBNFI y el RCFI rebasan los niveles mínimos de aceptación.

Tabla 5.38. Índices del ajuste global del modelo

\begin{tabular}{|c|c|c|c|c|c|c|c||}
\hline \hline g.l. & Chi2 & P & BB NNFI & RCFI & GFI & RMR & NC \\
\hline 8 & 10,5842 & 0,2264 & 0,956 & 0,996 & 0,923 & 0,022 & 1,32 \\
\hline
\end{tabular}

\subsubsection{Ajuste del modelo de medida}

La evaluación de este ajuste sirve para asegurarse de que las variables latentes están bien medidas mediante las variables observables consideradas. La revisión del ajuste del modelo de medida se realizó a través del examen de la significación estadística de cada carga obtenida entre el indicador y la variable latente $(t \geq 1,96)$. A continuación, se comprueba la fiabilidad compuesta de la variable latente. 
La siguiente tabla muestra las cargas factoriales tanto para el modelo exógeno como para el modelo endógeno. Se observa que todas las cargas presentan niveles correctos y son estadísticamente significativas, por lo que el primer requisito para el ajuste del modelo de medida queda comprobado.

Tabla 5.39. Parámetros estimados en el modelo de medida exógeno y endógeno

\begin{tabular}{||c|c|c||}
\hline $\mathbf{N}^{\mathbf{o}}$ & $\boldsymbol{\lambda}$ & Error \\
\hline GC -D1 & $0,846^{*}$ & 0,533 \\
\hline GC-D2 & 0,895 & 0,447 \\
\hline GC-D3 & 0,857 & 0,516 \\
\hline GC-D4 & 0,903 & 0,430 \\
\hline GC-D5 & $0,949^{*}$ & 0,317 \\
\hline GC-D6 & 0,871 & 0,758 \\
\hline TC-D1 & $0,931^{*}$ & 0,365 \\
\hline TC-D2 & 0,933 & 0,359 \\
\hline TC-D3 & 0,890 & 0,456 \\
\hline TC-D4 & 0,876 & 0,482 \\
\hline \hline
\end{tabular}

Los parámetros señalados con * se han igualado a 1 con el fin de fijar la escala de la variable latente. Todos los parámetros estimados son estadísticamente significativos al 95\% ( $\mathrm{t}>1,96)$. La fiabilidad compuesta para el modelo exógeno es 
de 0,84 y de 0,87 para el modelo endógeno, por lo que superan el nivel mínimo de 0,7 .

\subsubsection{Ajuste del modelo estructural}

El ajuste del modelo estructural implica el análisis de la significación alcanzada por los coeficientes estimados (para un nivel de significación de 0,05 el valor de t ha de alcanzar el valor de 1,96). Un parámetro no significativo indicaría que no hay un efecto sustancial sobre la relación propuesta.

\section{Tabla 5.40. Parámetro estimado e índice de fiabilidad en el modelo estructural de la segunda hipótesis}

\begin{tabular}{||r|c|c||}
\hline MODELO & $\begin{array}{c}\text { Coeficiente } \boldsymbol{\gamma} \\
\text { en la ecuación }\end{array}$ & Fiabilidad \\
\hline GC $\rightarrow$ TC & 0,908 & 0,943 \\
\hline
\end{tabular}

El parámetro estimado es estadísticamente significativo al 95\% ( $\mathrm{t}=13,413 \geq 1,96)$. La tabla anterior muestra un ajuste correcto del modelo estructural. Por lo tanto, queda probada la segunda hipótesis: existe una relación positiva y estadísticamente significativa entre la gestión por competencias y la transferencia de conocimiento. Este resultado, además concuerda con la literatura sintetizada en el epígrafe 3.5.1. 
Figura 5.2. Parámetros de la segunda hipótesis

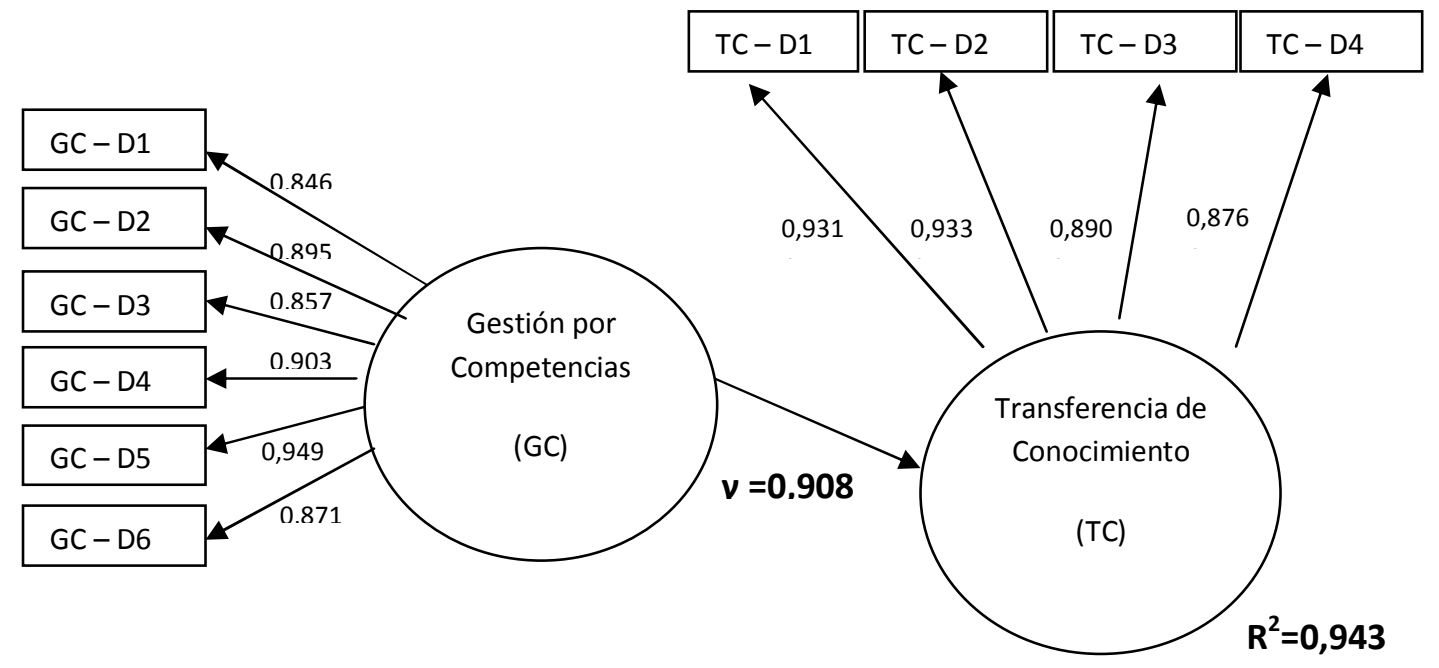

5.3.3 Tercera Hipótesis: Estudio de la Relación entre el Aprendizaje continuo y la Transferencia de Conocimiento

El epígrafe 3.5.1 se ha formulado esta tercera hipótesis y supone que existe una relación positiva y significativa entre estas dos variables. Para proceder al contraste de esta hipótesis, al igual que en los casos anteriores, se debe especificar el modelo y sus relaciones estructurales. El modelo estructural está formado por una variable latente exógena (aprendizaje continuo) que tiene a su vez seis dimensiones y una variable latente endógena (transferencia de conocimiento) que está formada por cuatro dimensiones. 


\subsubsection{Ajuste global del modelo}

La siguiente tabla muestra los índices de ajuste global del modelo. Del valor de los estadísticos se puede deducir que el modelo está sobreidentificado, es decir, que el número de grados de libertad es positivo, de manera parsimoniosa (el NC se encuentra entre 1 y 2 ).

El resto de medidas de ajuste también reflejan medidas excelentes. El estadístico chi-cuadrado es estadísticamente significativo, el índice GFI es superior a 0,9 y el RMR roza el nivel de 0, lo cual indica un buen ajuste en términos absolutos. Igualmente el BBNFI y el RCFI rebasan los niveles mínimos de aceptación.

Tabla 5.41. Índices del ajuste global del modelo

\begin{tabular}{|c|c|c|c|c|c|c|c||}
\hline g.l. & Chi2 & P & BB NNFI RCFI GFI & RMR & NC \\
\hline 8 & 11,851 & 0,158 & 0,983 & 0,996 & 0,960 & 0,010 & 1,48 \\
\hline
\end{tabular}

\subsubsection{Ajuste del modelo de medida}

La evaluación de este ajuste sirve para asegurarse de que las variables latentes están bien medidas mediante las variables observables consideradas. La revisión del ajuste del modelo de medida se realiza a través del examen de la significación estadística de cada carga obtenida entre el indicador y la variable latente $(t \geq 1,96)$. A continuación, se comprueba la fiabilidad compuesta de la variable latente. 
La siguiente tabla muestra las cargas factoriales tanto para el modelo exógeno como para el modelo endógeno. Se observa que todas las cargas presentan niveles correctos y son estadísticamente significativas, por lo que el primer requisito para el ajuste del modelo de medida queda comprobado.

Tabla 5.42. Parámetros estimados en el modelo de medida exógeno y endógeno

\begin{tabular}{||c|c|c||}
\hline $\mathbf{N}^{\mathbf{o}}$ & $\boldsymbol{\lambda}$ & Error \\
\hline AO -D1 & $0,925^{*}$ & 0,979 \\
\hline AO-D2 & 0,916 & 0,401 \\
\hline AO-D3 & 0,872 & 0,489 \\
\hline AO-D4 & 0,924 & 0,383 \\
\hline AO-D5 & 0,975 & 0,222 \\
\hline AO-D6 & 0,851 & 0,525 \\
\hline TC-D1 & $0,931^{*}$ & 0,365 \\
\hline TC-D2 & 0,933 & 0,359 \\
\hline TC-D3 & 0,890 & 0,456 \\
\hline TC-D4 & 0,876 & 0,482 \\
\hline \hline
\end{tabular}

Los parámetros señalados con * se han igualado a 1 con el fin de fijar la escala de la variable latente. Todos los parámetros estimados son estadísticamente significativos al 95\% ( $\mathrm{t}>1,96)$. La fiabilidad compuesta para el modelo exógeno es 
de 0,84 y de 0,87 para el modelo endógeno, por lo que superan el nivel mínimo de 0,7 .

\subsubsection{Ajuste del modelo estructural}

El ajuste del modelo estructural implica el análisis de la significación alcanzada por los coeficientes estimados (para un nivel de significación de 0,05 el valor de t ha de alcanzar el valor de 1,96). Un parámetro no significativo indicaría que no hay un efecto sustancial sobre la relación propuesta.

\section{Tabla 5.43. Parámetro estimado e índice de fiabilidad en el modelo estructural de la tercera hipótesis}

\begin{tabular}{|l|c|c|}
\hline MODELO & $\begin{array}{c}\text { Coeficiente } \gamma \\
\text { en la ecuación }\end{array}$ & Fiabilidad \\
\hline $\mathrm{AO} \rightarrow \mathrm{TC}$ & 0,974 & 0,486 \\
\hline
\end{tabular}

El parámetro estimado es estadísticamente significativo al 95\% ( $\mathrm{t}=24,533 \geq 1,96)$. La tabla anterior muestra un ajuste correcto del modelo estructural. Por lo tanto, queda probada la tercera hipótesis: existe una relación positiva y estadísticamente significativa entre el aprendizaje continuo y la transferencia de conocimiento. Este resultado concuerda con la revisión de la literatura sintetizada en el epígrafe 3.5.1. 


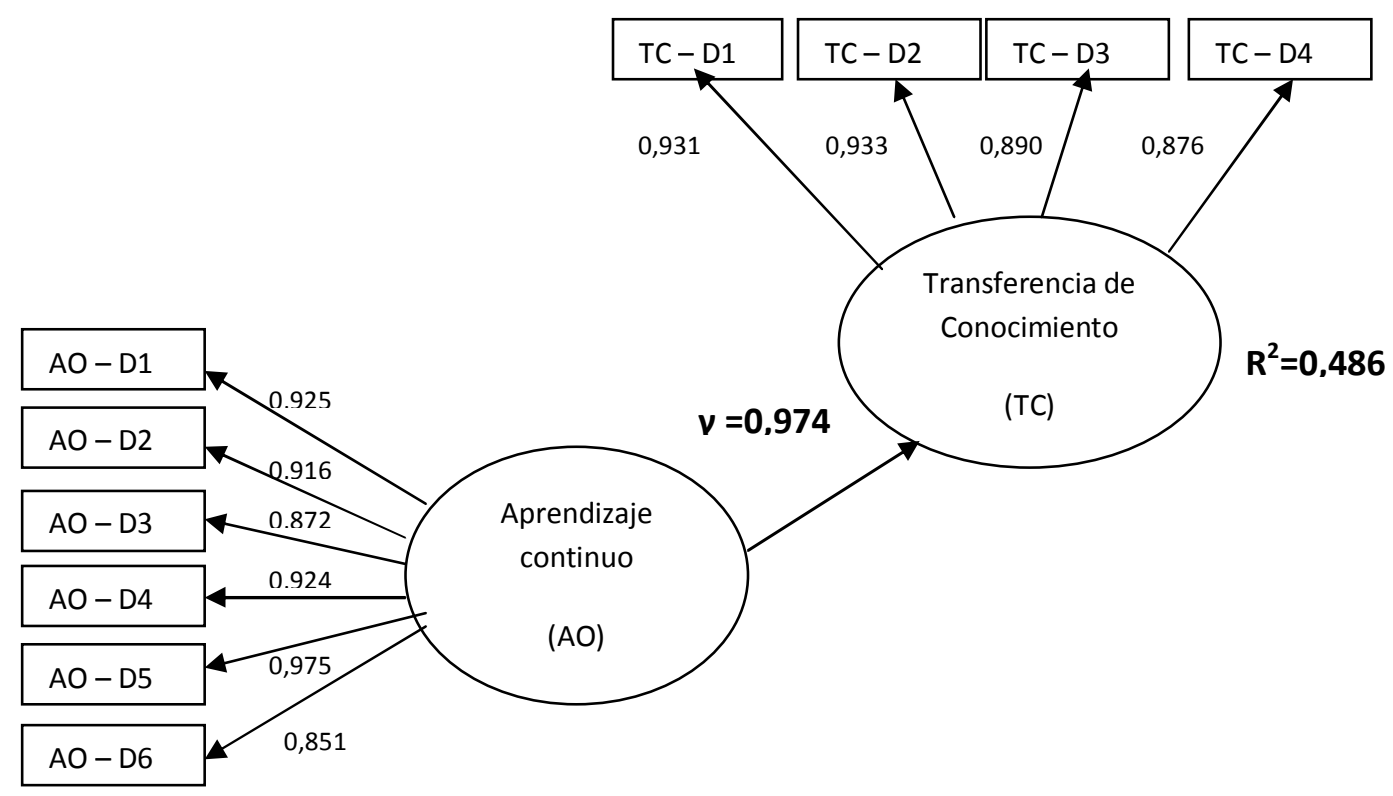

5.3.4 Cuarta Hipótesis: Estudio de la Relación entre la Infraestructura Técnica de la TI y la Transferencia de Conocimiento

Esta hipótesis se ha formulado en el epígrafe 3.5.1 y supone una relación positiva y significativa entre estas dos variables. Se especifica, en primer lugar, el modelo y sus relaciones estructurales; para proceder al contraste de esta hipótesis. El modelo estructural está formado por una variable latente exógena (infraestructura técnica de las TI) que tiene a su vez seis dimensiones y una variable latente endógena (transferencia de conocimiento) que está formada por cuatro dimensiones. 


\subsubsection{Ajuste global del modelo}

La siguiente tabla muestra los índices de ajuste global del modelo. Del valor de los estadísticos se puede deducir que el modelo está sobreidentificado, es decir, que el número de grados de libertad es positivo, de manera parsimoniosa (el NC se encuentra entre 1 y 2 ).

El resto de medidas de ajuste también reflejan medidas excelentes. El estadístico chi-cuadrado es estadísticamente significativo, el índice GFI es superior a 0,9 y el RMR roza el nivel de 0, lo cual indica un buen ajuste en términos absolutos. Igualmente el BBNFI y el RCFI rebasan los niveles mínimos de aceptación.

Tabla 5.44. Índices del ajuste global del modelo

\begin{tabular}{|c|c|c|c|c|c|c|c||}
\hline g.l. & Chi2 & p & BB NNFI RCFI & GFI & RMR & NC \\
\hline 20 & 25,761 & 0,174 & 0,951 & 0,990 & 0,937 & 0,030 & 1,29 \\
\hline
\end{tabular}

\subsubsection{Ajuste del modelo de medida}

La evaluación de este ajuste sirve para asegurarse de que las variables latentes están bien medidas mediante las variables observables consideradas. La revisión del ajuste del modelo de medida se realiza a través del examen de la significación estadística de cada carga obtenida entre el indicador y la variable latente $(t \geq 1,96)$. A continuación, se comprueba la fiabilidad compuesta de la variable latente. 
La siguiente tabla muestra las cargas factoriales tanto para el modelo exógeno como para el modelo endógeno. Se observa que todas las cargas presentan niveles correctos y son estadísticamente significativas, por lo que el primer requisito para el ajuste del modelo de medida queda comprobado.

Tabla 5.45. Parámetros estimados en el modelo de medida exógeno y endógeno

\begin{tabular}{||c|c|c||}
\hline $\mathbf{N}^{\mathbf{0}}$ & $\boldsymbol{\lambda}$ & Error \\
\hline IT -D1 & $0,881^{*}$ & 0,474 \\
\hline IT-D2 & 0,899 & 0,438 \\
\hline IT-D3 & 0,785 & 0,620 \\
\hline IT-D4 & 0,777 & 0,629 \\
\hline TC-D1 & $0,931^{*}$ & 0,365 \\
\hline TC-D2 & 0,933 & 0,359 \\
\hline TC-D3 & 0,890 & 0,456 \\
\hline TC-D4 & 0,876 & 0,482 \\
\hline
\end{tabular}

Los parámetros señalados con * se han igualado a 1 con el fin de fijar la escala de la variable latente. Todos los parámetros estimados son estadísticamente significativos al 95\% ( $\mathrm{t}>1,96)$. La fiabilidad compuesta para el modelo exógeno es de 0,86 y de 0,87 para el modelo endógeno, por lo que superan el nivel mínimo de 0,7 . 


\subsubsection{Ajuste del modelo estructural}

El ajuste del modelo estructural implica el análisis de la significación alcanzada por los coeficientes estimados (para un nivel de significación de 0,05 el valor de t ha de alcanzar el valor de 1,96$)$. Un parámetro no significativo indicaría que no hay un efecto sustancial sobre la relación propuesta.

\section{Tabla 5.46. Parámetro estimado e índice de fiabilidad en el modelo estructural de la cuarta hipótesis}

\begin{tabular}{|l|c|c||}
\hline \hline MODELO & $\begin{array}{c}\text { Coeficiente } \gamma \\
\text { en la ecuación }\end{array}$ & Fiabilidad \\
\hline IT $\rightarrow$ TC & 0,845 & 0,521 \\
\hline
\end{tabular}

El parámetro estimado es estadísticamente significativo al 95\% ( $\mathrm{t}=13,942 \geq 1,96)$. La tabla anterior muestra un ajuste correcto del modelo estructural. Por ello, queda probada la cuarta hipótesis: existe una relación positiva y estadísticamente significativa entre la infraestructura de las TI y la transferencia de conocimiento; resultado que se ajusta a la revisión de la literatura sintetizada en el epígrafe 3.5.1. 


\section{Figura 5.4. Parámetros de la cuarta hipótesis}

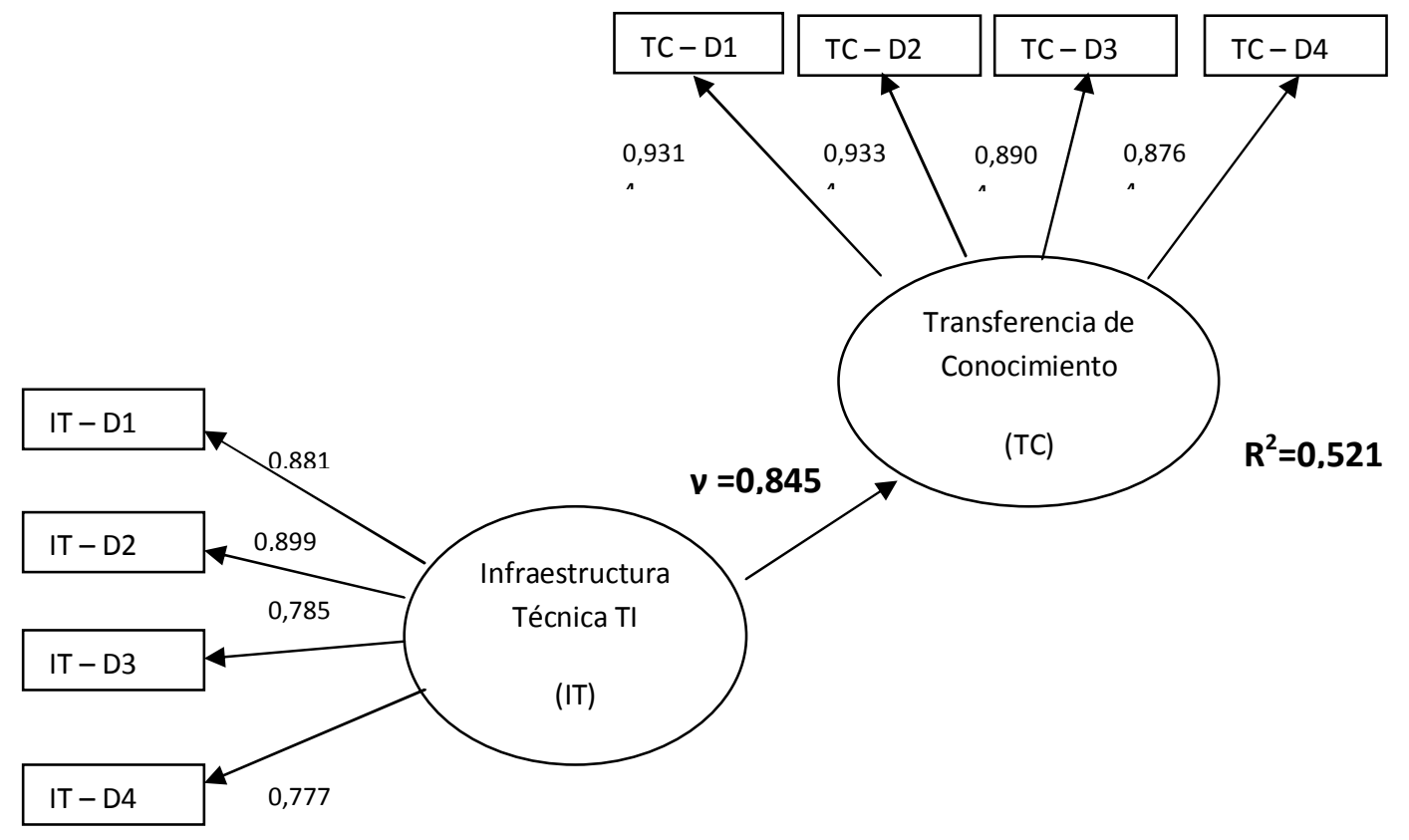

5.3.5 Quinta Hipótesis: Estudio de la Relación entre la Transferencia de Conocimiento y el Desempeño Organizativo

En el epígrafe 3.5.1 se ha presentado la quinta hipótesis, que supone que existe una relación positiva y significativa entre estas dos variables. Para proceder al contraste de la misma, inicialmente se especificó el modelo y sus relaciones estructurales. El modelo estructural está formado por una variable latente exógena (transferencia de conocimiento) que tiene a su vez cuatro dimensiones y una variable latente endógena (desempeño organizativo). 


\subsubsection{Ajuste global del modelo}

La siguiente tabla muestra los índices de ajuste global del modelo. Del valor de los estadísticos se puede deducir que el modelo está sobreidentificado, es decir, que el número de grados de libertad es positivo, de manera parsimoniosa (el NC se encuentra entre 1 y 2 ).

El resto de medidas de ajuste también reflejan medidas excelentes. El estadístico chi-cuadrado es estadísticamente significativo, el índice GFI es superior a 0,9 y el RMR roza el nivel de 0, lo cual indica un buen ajuste en términos absolutos. Igualmente el BBNFI y el RCFI rebasan los niveles mínimos de aceptación.

Tabla 5.47. Índices del ajuste global del modelo

\begin{tabular}{|c|c|c|c|c|c|c|c||}
\hline g.l. & Chi2 & P & BB NNFI RCFI & GFI & RMR & NC \\
\hline 35 & 26,022 & 0,025 & 0,924 & 0,973 & 0,918 & 0,044 & 1,86 \\
\hline
\end{tabular}

\subsubsection{Ajuste del modelo de medida}

La evaluación de este ajuste sirve para asegurarse de que las variables latentes están bien medidas mediante las variables observables consideradas. La revisión del ajuste del modelo de medida se realiza a través del examen de la significación estadística de cada carga obtenida entre el indicador y la variable latente $(t \geq 1,96)$. La fiabilidad compuesta de la variable latente se comprueba a continuación. 
La siguiente tabla muestra las cargas factoriales tanto para el modelo exógeno como para el modelo endógeno. Se observa que todas las cargas presentan niveles correctos y son estadísticamente significativas, por lo que el primer requisito para el ajuste del modelo de medida queda comprobado.

Tabla 5.48. Parámetros estimados en el modelo de medida exógeno y endógeno

\begin{tabular}{||c|c|c||}
\hline $\mathbf{N}^{\mathbf{0}}$ & $\boldsymbol{\lambda}$ & Error \\
\hline TC-D1 & $0,864^{*}$ & 0,504 \\
\hline TC-D2 & 0,897 & 0,442 \\
\hline TC-D3 & 0,945 & 0,328 \\
\hline TC-D4 & 0,890 & 0,457 \\
\hline DO & 0,880 & 0,475 \\
\hline
\end{tabular}

Los parámetros señalados con * se han igualado a 1 con el fin de fijar la escala de la variable latente. Todos los parámetros estimados son estadísticamente significativos al 95\% ( $>1$ 1,96). La fiabilidad compuesta para el modelo exógeno es de 0,87 y de 0,86 para el modelo endógeno, por lo que superan el nivel mínimo de 0,7 .

\subsubsection{Ajuste del modelo estructural}

El ajuste del modelo estructural implica el análisis de la significación alcanzada por los coeficientes estimados (para un nivel de significación de 0,05, el valor de t 
ha de alcanzar el valor de 1,96). Un parámetro no significativo indicaría que no hay un efecto sustancial sobre la relación propuesta.

Tabla 5.49. Parámetro estimado e índice de fiabilidad en el modelo estructural de la quinta hipótesis

\begin{tabular}{||c|c|c||}
\hline MODELO & $\begin{array}{c}\text { Coeficiente } \gamma \\
\text { en la ecuación }\end{array}$ & Fiabilidad \\
\hline TC $\rightarrow$ DO & 0,985 & 0,495 \\
\hline
\end{tabular}

El parámetro estimado es estadísticamente significativo al 95\% ( $\mathrm{t}=16,965 \geq 1,96)$. La tabla anterior muestra un ajuste correcto del modelo estructural. Por lo tanto, damos por probada la primera hipótesis: existe una relación positiva y estadísticamente significativa entre la transferencia de conocimiento y el desempeño organizativo. Este resultado está acorde con la revisión de la literatura sintetizada en el epígrafe 3.5.1.

Figura 5.5. Parámetros de la quinta hipótesis

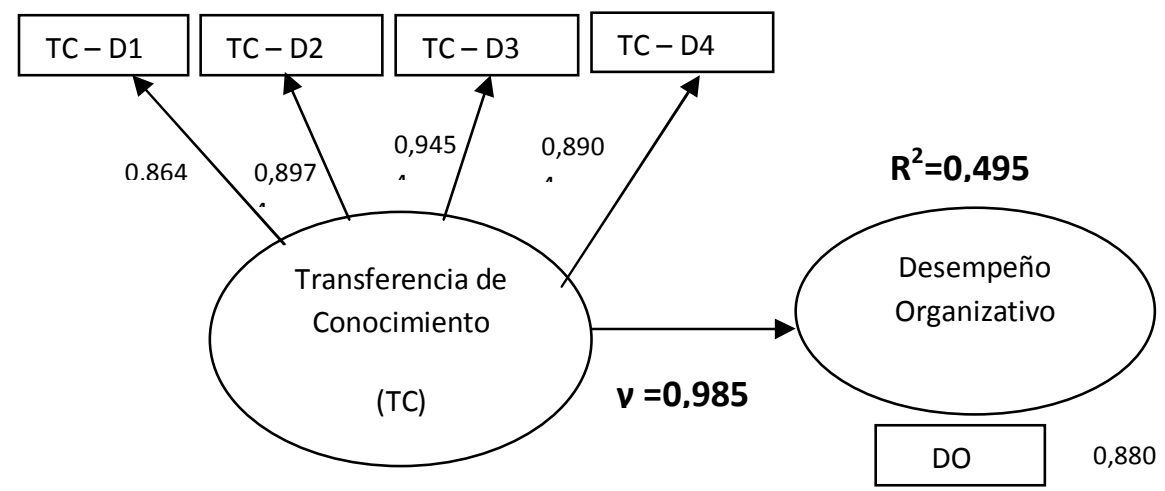


Capítulo 5 Resultados del estudio empírico

\subsubsection{Sexta Hipótesis: Análisis del papel mediador de la Transferencia de Conocimiento en el Desempeño Organizativo}

En las primeras cinco hipótesis se ha verificado la relación positiva existente entre las variables explicativas de la transferencia del conocimiento,; estas variables explicativas se caracterizan por generar prácticas que fomentan que la generación y transferencia de conocimiento en el interior de la empresa.

Sin embargo, hasta el momento no se ha demostrado que la transferencia del conocimiento es una variable mediadora entre los cuatro constructos teóricos que le anteceden (Visión holística de la organización, Gestión por competencias, Aprendizaje continuo, Infraestructura Técnica de las TI) y el desempeño organizativo. Esta sexta hipótesis es la que va a determinar si existe o no ese efecto mediador, tal se había predicho en el modelo teórico y tal como se ha argumentado teóricamente.

A continuación, siguiendo la metodología de los modelos de ecuaciones estructurales, se analiza el ajuste del modelo en sus tres dimensiones: ajuste global, ajuste del modelo de medida y ajuste del modelo estructural.

\subsubsection{Ajuste global del modelo}

La siguiente tabla muestra los índices de ajuste global del modelo. Del valor de los estadísticos se puede deducir que el modelo está sobreidentificado, es decir, que el número de grados de libertad es positivo, de manera parsimoniosa (el NC se encuentra entre 1 y 2 ). 


\section{Capítulo 5 Resultados del estudio empírico}

El resto de medidas de ajuste también reflejan medidas excelentes. El estadístico chi-cuadrado es estadísticamente significativo, el índice GFI está muy próximo a 0,9 y el RMR roza el nivel de 0, lo cual indica un buen ajuste en términos absolutos. Igualmente el BBNFI y el RCFI rebasan los niveles mínimos de aceptación.

Tabla 5.50. Índices del ajuste global del modelo

\begin{tabular}{|c|c|c|c|c|c|c|c||}
\hline g.l. & Chi2 & P & BB NNFI RCFI & GFI & RMR & NC \\
\hline 27 & 39,145 & 0,061 & 0,946 & 0,992 & 0,877 & 0,022 & 1,45 \\
\hline
\end{tabular}

\subsubsection{Ajuste del modelo de medida}

Ya se ha comprobado el ajuste de los modelos de medida en los epígrafes anteriores. Todos los ajustes estudiados han sido sobradamente satisfactorios, por lo tanto, se los considera igualmente satisfactorios en este nuevo análisis.

\subsubsection{Ajuste del modelo estructural}

En la siguiente tabla se puede comprobar el ajuste de los modelos estructurales de la sexta hipótesis. La fiabilidad en ambos modelos es elevada, por lo que se da la condición de fiabilidad. Los coeficientes $\gamma$ y $\alpha$ de las ecuaciones estructurales son estadísticamente significativos. El coeficiente $\beta$, en cambio, no lo es, ya que su valor $\mathrm{t}$ asociado es inferior a 1,96. En conjunto, se considera el ajuste aceptable. 
Capítulo 5 Resultados del estudio empírico

Tabla 5.51. Parámetros estimados e índices de fiabilidad en los modelos estructurales de la sexta hipótesis

\begin{tabular}{|c|c|c|}
\hline \multicolumn{1}{|c|}{ MODELO } & Coeficiente $\gamma$ en la ecuación & $\begin{array}{c}\text { Fiabilidad de la ecuación } \\
\text { estructural }\end{array}$ \\
\hline $\mathrm{VA} \rightarrow \mathrm{TC} \rightarrow \mathrm{DO}$ & $\begin{array}{c}\mathrm{DO}=\gamma \mathrm{TC}+\beta \mathrm{VA}+\mathrm{D} \\
\beta=0,882(\mathrm{t}=22,152) ;\end{array}$ & 0,521 \\
\hline $\mathrm{VA} \rightarrow \mathrm{TC}$ & $\mathrm{TC}=\alpha \mathrm{VA}+\mathrm{D}=0,952)$ & 0,385 \\
\hline
\end{tabular}

En la siguiente tabla se presenta el efecto total desagregado en el efecto indirecto y directo del modelo.

Tabla 5.52. Efecto directo e indirecto de las variables antecedentes sobre el desempeño organizativo

\begin{tabular}{||c|c|c|c||}
\hline MODELO & Efecto Indirecto & Efecto Directo & Efecto Total \\
\hline $\mathrm{VA} \rightarrow \mathrm{TC} \rightarrow$ DO & $\alpha \gamma=0,862$ & $\beta=0,101$ & 0,963 \\
& & no significativo $(\mathrm{t}=0,952)$ & \\
\hline
\end{tabular}

En la tabla anterior se descompone el efecto directo e indirecto de los constructos teóricos (Visión holística de la organización, Gestión por competencias, 


\section{Capítulo 5 Resultados del estudio empírico}

Aprendizaje continuo, Infraestructura Técnica de las TI) sobre el desempeño organizativo. Se puede comprobar que el efecto indirecto es mucho mayor que el directo. Además, el efecto directo no es estadísticamente significativo, mientras que el indirecto sí que lo es.

Si se introducen las variables de control en el modelo (tamaño de la organización y normas de calidad ISO 9000) se puede concluir que la relación sigue siendo positiva, aunque estas variables moderadoras resultan no ser significativas. La varianza explicada por el modelo es de un $17 \%$ y con el uso de variables de control no mejora.

Con el contraste de esta sexta hipótesis se verifica que los constructos teóricos Visión holística de la organización, Gestión por competencias, Aprendizaje continuo e Infraestructura Técnica de las TI tienen un efecto importante sobre el Desempeño Organizativo. Los resultados del contraste de esta sexta hipótesis evidencian que la influencia de estas cuatro variables sobre el desempeño organizativo se produce, de forma mayoritaria y consistente, de manera indirecta a través de la transferencia de conocimiento.

La transferencia de conocimiento actúa como variable intermedia y su inclusión en el modelo explicativo contribuye a un mejor entendimiento de las relaciones entre sus variables antecedentes y el desempeño organizativo. Este resultado, además concuerda con la revisión de la literatura sintetizada en el epígrafe 3.5.1. 
Figura 5.6. Contraste de hipótesis del modelo completo

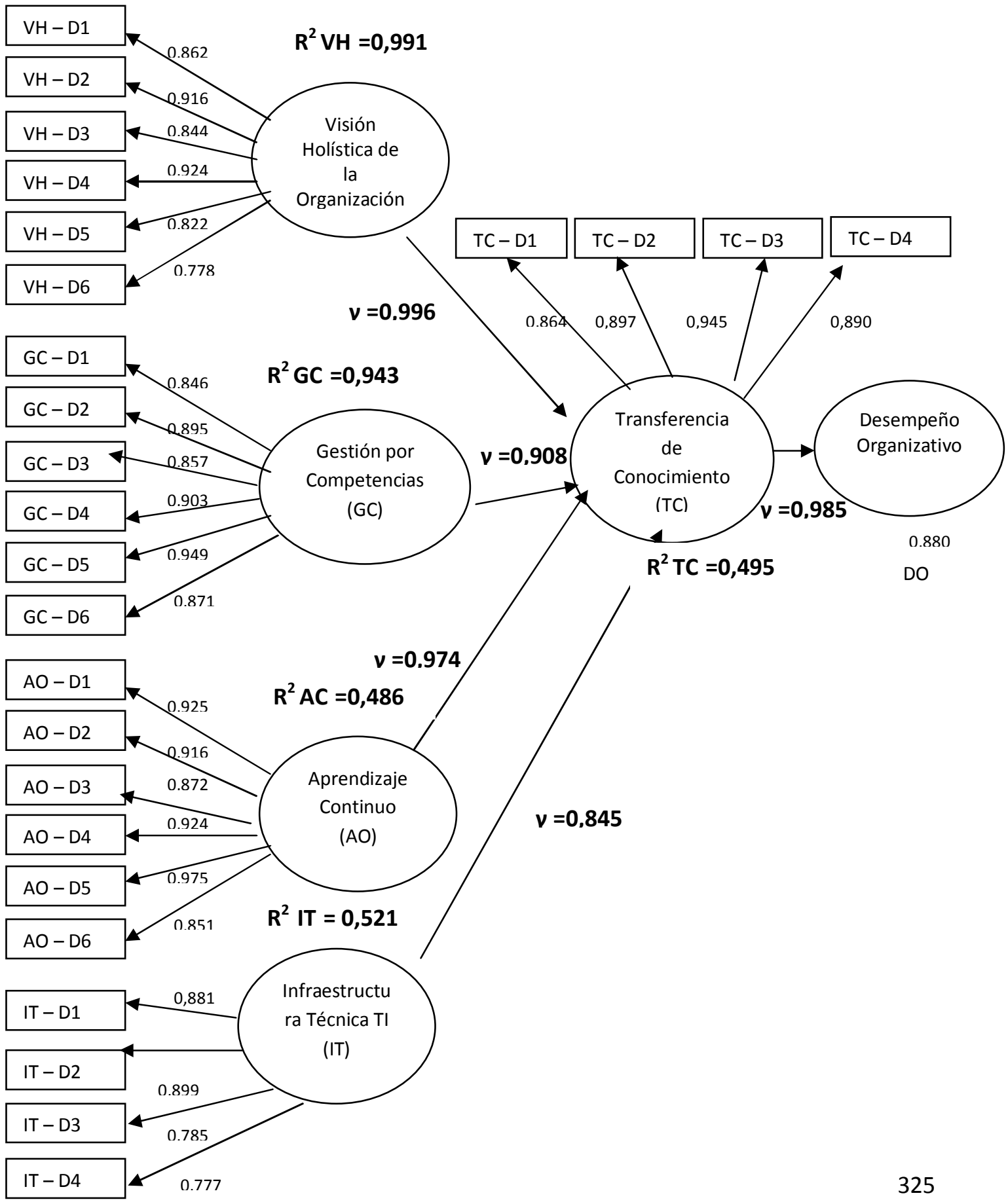




\section{Capítulo 6}

\section{Conclusiones, limitaciones}

\section{del estudio y futuras investigaciones}




\subsection{CONCLUSIONES}

Las conclusiones se presentan siguiendo el esquema expositivo que se ha planteado a lo largo del trabajo y en el mismo orden sobre los principales puntos de interés que se han planteado en los objetivos.

\subsubsection{Conclusiones sobre la primera parte del trabajo: Aspectos teóricos}

La primera parte del estudio, de naturaleza teórica, comprendió los tres primeros capítulos, cuyos objetivos fueron los siguientes:

- Revisar los principales enfoques en organización de empresas y análisis de aquellos que tienen mayor relevancia para la gestión del conocimiento.

- Analizar el efecto de la transferencia de conocimiento en el desempeño organizativo, así como los factores antecedentes en la transferencia de conocimiento.

- Crear un modelo teórico en el que se introduzcan las variables comentadas anteriormente, analizando sus posibilidades de relaciones tanto directas como indirectas. 


\section{Conclusiones respecto a la revisión de los principales enfoques en} organización de empresas

La revisión de los diferentes enfoques en organización de empresas presenta una complementariedad desde el abordaje de las diferentes ciencias (economía, psicología, sociología). En este sentido es necesario considerar la complejidad del ser humano y no su reduccionismo a uno u otro ámbito (Grandío, 1997).

Como se presentó en la tabla 1.2, cada uno de los enfoques ha aportado al entendimiento y gestión de las empresas en la búsqueda de mejores resultados organizativos, sin embargo dichos enfoques también presentan limitaciones y críticas.

Como menciona Grant (1991), con el paso del tiempo resurgió el interés en el rol de los recursos organizacionales como fuente de las ventajas competitivas, en este entendido la empresa es caracterizada como un sistema de activos tangibles e intangibles, entre ellos el conocimiento, organizados de una manera estratégicamente lógica para alcanzar sus metas (Sanchez et al., 1996).

Las diferentes perspectivas y enfoques en organización de empresas y la gestión de la complejidad en entornos cambiantes, confluye en la necesidad de contar con un enfoque dinámico, sistémico, cognitivo y holístico, los cuales se encuentran integrados en el Enfoque Basado en Competencias (EBC).

Los cuatro enfoques que conforman el EBC considerados para este estudio, definen a las empresas como entidades heterogéneas que contienen conocimiento; 
por lo cual las empresas ya no son vistas solamente en el sentido contractual, sino como depósitos de conocimiento productivo distintivo (tecnológico y organizacional) y como entidades que pueden aprender y crecer con base en ese conocimiento (Foss y Knudsen, 1996).

El EBC se ajusta a la complejidad actual del turismo y en particular al sector hotelero, cuyo desarrollo y crecimiento se encuentra entre los dos de los sectores de más rápido crecimiento en la economía global. El sector hotelero requiere de una rápida adaptación al mercado y generación de ventajas competitivas sostenibles.

En este sentido, adicionalmente a los recursos físicos y financieros con los que cuenta el sector, es de vital importancia el conocimiento tácito que se encuentra en las personas (recurso humano) y a la vez, la gestión del conocimiento y desarrollo del capital relacional por la constante interacción con otras empresas que forman parte de la cadena de valor del sector hotelero.

Por otro lado, debido al dinamismo de este sector se resalta la importancia de los factores antecedentes para la transferencia interna de conocimiento.

\section{Conclusiones respecto a la gestión del conocimiento y ventaja competitiva}

En la literatura sobre dirección estratégica no se encuentra un consenso sobre las diferentes perspectivas respecto a los factores que explican el éxito empresarial. 
Camisón y Boronat (2004), agrupan los factores causantes de la heterogeneidad en el logro del éxito empresarial en: el efecto país, el efecto industria, el efecto corporación y el efecto empresa.

La ventaja competitiva ha sido abordada desde distintas perspectivas y enfoques. Por un lado se tiene los enfoques estáticos, que consideran las características del sector (economía industrial) en el que compiten y la posición estratégica que la empresa decide adoptar, o el énfasis en la posesión de activos valiosos y escasos que le permiten en un momento dado formular una estrategia que ningún otro competidor puede implementar. Por otro lado, los enfoques dinámicos, que se centran en los procesos de acumulación y renovación de recursos, así como competencias, en respuesta a los cambios en un entorno altamente cambiante.

El EBC centra su atención en el desarrollo de competencias como fuente de la ventaja competitiva sostenible. Las competencias distintivas, esenciales o nucleares juegan un rol fundamental para este propósito, la base del desarrollo de este tipo de competencias son los activos estratégicos y en especial el conocimiento.

Frente a la necesidad de gestionar la complejidad y adoptar un enfoque integrado basado en una visión sistémica, dinámica, cognitiva y holística, se requiere la aplicación de modelos conceptuales e instrumentales, entre ellos el Business Management System (BMS), que integren la estrategia con la operación y se facilite el diseño organizacional orientado a impulsar la gestión del conocimiento. 
Como un aporte del presente trabajo se presentó una propuesta de reconfiguración del modelo instrumental BMS, la misma que ha sido presentada al "International Trade Center" con sede en Ginebra, siendo esta validada y prevista su aplicación para el nuevo programa de formación de facilitadores y capacitadores. Por otra parte se ha previsto incorporar una línea de trabajo en el área de gestión del conocimiento y realizar adecuaciones del modelo a organizaciones de servicios y sectores específicos.

El conocimiento y su gestión han suscitado el interés tanto de académicos, investigadores así como de empresarios; puesto que ha transformado las antiguas reglas sobre estrategia y competencia (Lee y Choi, 2003), el conocimiento se constituye en un factor clave para generar y sostener ventajas competitivas en las organizaciones (Palacios et al., 2010).

De acuerdo a la revisión de la literatura, la gestión del conocimiento se puede agrupar en: la creación y adquisición del conocimiento; su almacenamiento, retención y recuperación; la transferencia e intercambio; y su aplicación (Girdauskienè y Savanevičienè, 2007; Argote et al., 2003; Chakravarthy et al., 2003; Alavi y Leidner, 2001). El presente trabajo se centra en la transferencia de conocimiento.

Como se mencionó en la anterior conclusión, la interacción con las diferentes empresas que componen la cadena de valor del sector hotelero se ha intensificado, por ello cobra particular importancia la gestión del conocimiento y el desarrollo del capital relacional para la generación de ventajas competitivas sostenibles. 
El conocimiento creado y transferido al interior del sector hotelero debe permitir que el personal pueda responder a las diferentes actividades primarias del negocio, así como la asistencia posterior a la venta de los servicios. Entre estas actividades primarias se encuentran aquellas relacionadas a la creación, puesta en marcha de los servicios (producción) y la promoción, publicidad y venta (marketing). Por otra parte el conocimiento se constituye en un recurso valioso para el ciclo de la estrategia.

\section{Conclusiones relacionadas al Modelo teórico}

Las ventajas competitivas derivadas del conocimiento, dependen por una parte de la naturaleza misma de este recurso que lo hace estratégico y por otra parte de su adecuada gestión.

La gestión del conocimiento es posible gracias a los siguientes procesos cognitivos sociales e individuales que no siempre ocurren de manera secuencial: creación, almacenaje y retiro, transferencia y aplicación del conocimiento (Alavi y Leidner, 2001).

La posesión de conocimiento no asegura la sostenibilidad de las ventajas competitivas, es necesaria la transferencia de conocimiento para que otras unidades de la organización se beneficien del mismo. De ahí la importancia que tiene la transferencia de conocimiento, particularmente a nivel interno de la organización. 
Con base en las dimensiones de la transferencia de conocimiento planteadas por Segarra (2006) y la revisión de la literatura, se han identificado cuatro factores que influyen en la transferencia de conocimiento: la visión holística de la organización, la gestión por competencias, el aprendizaje continuo y la infraestructura técnica de las tecnologías de información.

Dados los objetivos marcados en la investigación y el enfoque seguido, a partir del modelo teórico elaborado podemos obtener las siguientes conclusiones:

1) Existe una relación causal positiva entre los factores: visión holística de la organización; gestión por competencias; aprendizaje continuo e infraestructura técnica de las TI con la transferencia de conocimiento.

2) La transferencia de conocimiento tiene un efecto positivo en el desempeño organizativo

3) La transferencia de conocimiento juega un papel mediador entre los factores antecedentes y el desempeño organizativo.

La transferencia de conocimiento por sí misma no es capaz de mejorar los resultados organizativos, sino que ejerce una influencia previa en la creación y renovación de capacidades y competencias, principalmente las distintivas o nucleares y estas en la mejora mejores niveles de desempeño. 
Estas conclusiones coinciden con lo expuesto por Davenport (1999), que relaciona la forma en la que las actividades de Gestión de conocimiento son capaces de influir en una serie de actividades intermedias y por Wiig (1999) que muestra los efectos y beneficios intermedios, tanto internos como externos, generados por actividades de gestión del conocimiento.

\subsubsection{Conclusiones sobre la segunda parte del trabajo: Resultados empíricos}

Los objetivos de la segunda parte del trabajo fueron:

- Contrastar el modelo teórico desarrollado con el estudio empírico, llevado a cabo en el sector hotelero español; utilizando para ello la metodología de análisis de los modelos de ecuaciones estructurales, que permiten corroborar todas las propiedades sociométricas exigibles a las escalas de medición en ciencias sociales para cada una de las variables del estudio, además de determinar la existencia de relaciones causales entre los constructos teóricos.

- Proporcionar al gerente un conjunto de prácticas que le permita gestionar de manera eficiente la transferencia de conocimiento tanto a nivel interno como externo a la organización y analizar la repercusión que ello podría tener en los resultados empresariales. 
La Transferencia de conocimiento se concibe como un factor de tercer orden, se han identificado un conjunto de factores de segundo orden que tienen una relación causal positiva con la transferencia de conocimiento.

Las escalas que se han utilizado para medir cada una de las variables, cumplen con las propiedades sociométricas exigibles a las escalas de medición en las ciencias sociales, es decir, dimensionalidad, fiabilidad y validez.

El modelo teórico planteado se ha traducido en seis hipótesis. Las cuatro primeras se refieren a los factores de segundo orden que influyen positivamente en la transferencia de conocimiento, la quinta hipótesis hace referencia al efecto de la transferencia de conocimiento en el desempeño organizativo y la sexta hipótesis se refiere al papel mediador de la transferencia de conocimiento entre los factores antecedentes y el desempeño organizativo.

Con base en el modelo y los resultados del estudio empírico, se ha elaborado dos artículos, los mismos que han sido aceptados y publicados en la revista "International Entrepreneurship and Management Journal” (ISSN: 15551938): "Learning for sharing: an empirical analysis of organizational learning and knowledge sharing” y "Do market oriented firms adopt Web 2.0 technologies? An empirical study in hospitality firms"en septiembre de 2011.

\section{Conclusiones sobre los resultados empíricos del estudio}

- El resultado de la primera hipótesis muestra un coeficiente de la ecuación de 0.996 y una fiabilidad de 0.991 , que comprueba que existe un efecto 
positivo y significativo entre la visión holística de la organización y la transferencia de conocimiento.

Contar con una visión holística de la organización, basada en principios y prácticas proporciona el contexto adecuado para la transferencia de conocimiento. El papel de la cultura organizacional y el alineamiento del personal mediante una visión compartida y sistémica que considere a los clientes y proveedores, facilita el diseño de la organización con base en procesos y la implantación de prácticas que trascienden las divisiones departamentales y jerárquicas.

La visión holística es particularmente importante en el sector turístico, puesto que el sector es complejo, debido a que está compuesto por actividades heterogéneas de diversa naturaleza que están dispersas en tiempo y espacio, que reúnen a actores que tienen distintos niveles cognitivos y se encuentran en diferentes lugares (Aldebert et al., 2011; Hallin y Marnburg, 2008; Yang y Wan (2004).

En el caso particular del sector hotelero se encuentran compañías relacionadas al transporte, restaurantes, agencias de viaje, alquiler de autos, promotoras de eventos entre otras. Esta compleja interacción, requiere el establecimiento de sólidos sistemas de información como instrumento "estratégico" para mejorar la competitividad de los hoteles. La utilización de estos sistemas, les permitirá establecer una ventaja competitiva ya que podrán compartir información y conocimiento interno y con sus asociados y al mismo tiempo permitirá que los consumidores interactúen directamente con los proveedores turísticos. 
En este sentido, es imprescindible que los gerentes tengan una visión holística de la organización, ya que las áreas que conforma un hotel son diversas: contabilidad, gestión de almacenes, gestión del personal, gestión de fiscalía, manejo base de datos de clientes, entre otros, y la interacción con diversas organizaciones independientes es cada vez más intensa.

- La segunda hipótesis muestra un coeficiente de la ecuación de 0.908 y una fiabilidad de 0.943, que comprueba que existe un efecto positivo y significativo entre la gestión por competencias y la transferencia de conocimiento.

Coincidentemente con Hamel y Prahalad (1994) es necesario desagregar las competencias esenciales en sus componentes, hasta llegar a las personas que poseen un talento específico.

La gestión por competencias implica un cambio filosófico, conceptual y de actuación respecto del tradicional enfoque de la dirección de personal (Pereda et al., 2010).

La complejidad creciente del sector hotelero, que va más allá de brindar solamente un servicio de hospedaje, se ve reflejado en estructuras organizacionales matriciales o funcionales que comprenden los departamentos de: Alojamiento (recepción, reservas, mostrador, mano corriente y caja, conserjería, pisos, lencería y lavandería), Alimentos y bebidas (restaurante, bar, cocina, economato, bodega), Mantenimiento y Servicios Técnicos y de Seguridad, Comercial, Financiero (administración, contabilidad, financiación, Recursos humanos. Ello implica 
contar con recursos humanos con diversas competencias que respondan a los requerimientos de un entorno cada vez más dinámico y competitivo.

Considerando el dinamismo y competitividad requerida en el sector hotelero se requiere cada vez mayores competencias en el personal, mismas que deben estar acorde a las necesidades de los diversos tipos de clientes, como son los clientes comerciales, vacacionales, clientes asistentes a conferencias o convenciones y residentes.

Estas competencias deben permitir brindar no solo el servicio de hospedaje, si no también ofrecer otro tipo de servicios como los relacionados al área de alimentos y bebidas, mantenimiento y servicios técnicos, comerciales y financieros.

En este contexto, la gestión por competencias puede ser de gran utilidad frente a este desafío, ya que implica un cambio filosófico, conceptual y de actuación respecto del tradicional enfoque de la dirección de personal, que comprende todas las tareas relacionadas con el manejo del recurso humano: reclutamiento y selección, integración, formación, planificación y gestión de carrera, evaluación del desempeño y recompensas.

- El resultado de la tercera hipótesis muestra un coeficiente de la ecuación de 0.974 y una fiabilidad de 0.486 , que comprueba que existe un efecto positivo y significativo entre el aprendizaje organizativo y la transferencia de conocimiento. 
La rapidez con la que se está transformado el mercado y los retos que enfrenta el sector hotelero (nuevos destinos competidores, cambios en el modelo de negocio, nuevos hábitos y costumbres de los clientes, nuevas tecnologías, entre otros), sumados a las altas tasas de entradas y salidas de personal y las dificultades en patentar el capital intelectual o la concesión de innovaciones, hace necesario que las empresas hoteleras tengan que realizar una continua adaptación, orientando la organización hacia el aprendizaje continuo.

El sector hotelero debe desarrollar la capacidad de responder a los nuevos cambios en el modelo de negocio, que requiere de intensa información para que los clientes realicen fácilmente la búsqueda de tarifas, horarios, ofertas de viajes, disponibilidad de hoteles y nuevos destinos competidores; al mismo tiempo que puedan realizar transacciones ya sea desde sus oficinas o desde sus domicilios, las 24 horas del días y los 365 días al año.

- La cuarta hipótesis muestra un coeficiente de la ecuación de 0.845 y una fiabilidad de 0.521, que comprueba que existe un efecto positivo y significativo entre la infraestructura técnica de las TI y la transferencia de conocimiento.

El resultado de esta variable, confirma la necesidad de invertir en tecnologías de información para facilitar la transferencia de conocimiento. Sin embargo, esta condición no es suficiente para sostener las ventajas competitivas, si los miembros de la empresa no tienen los conocimientos, habilidades y actitudes para utilizarlas. 
El desarrollo de las tecnologías de información y comunicación, así como la nueva generación de "Nativos Digitales", obliga a las empresas hoteleras a contar con una infraestructura técnica de las TI.

En este aspecto se destaca el impacto del internet sobre los cambios en los hábitos de consumo de los clientes, generando una menor fidelización de los mismos, reducción de la estancia, incremento de los viajes de larga distancia y descenso en la antelación de las reservas y un aumento de la competencia de alojamientos extra-hoteleros y nuevos destinos turísticos alternativos a los tradicionales.

Entre las tecnologías de información y comunicación más utilizadas y que se convirtieron en factores de competitividad se encuentran: el internet y algunos programas (software) especializados como ser el: PMS (Property Management System), CRM (Costumer Relationship Management), CRS (Central de Reservas), ERP (Enterprice Relatioship Process), Herramientas de revenue and yield management, Software para la gestión del mantenimiento de las infraestructuras hoteleras y Soluciones de movilidad.

- El resultado de la quinta hipótesis muestra un coeficiente de la ecuación de 0.985 y una fiabilidad de 0.495 , que comprueba que existe un efecto positivo y significativo entre la transferencia de conocimiento y el desempeño organizativo

En las primeras cinco hipótesis han verificado la relación positiva existente entre las variables explicativas de la transferencia del conocimiento; estas variables 
explicativas se caracterizan por generar prácticas que fomentan que la generación y transferencia de conocimiento en el interior de la empresa.

Al descomponer el efecto directo e indirecto de los constructos teóricos (visión holística de la organización, gestión por competencias, aprendizaje continuo, infraestructura técnica de las $\mathrm{TI}$ ) de la transferencia de conocimiento sobre el desempeño organizativo, en la sexta hipótesis se ha comprobado que el efecto indirecto $(0,862)$ es mucho mayor que el directo (0.101). Además, el efecto directo no es estadísticamente significativo, mientras que el indirecto sí lo es.

La importancia de la gestión del conocimiento y en particular de la transferencia de conocimiento para la generación de capacidades y competencias radica en que el conocimiento se constituye en un recurso estratégico para la ejecución de complejas tareas y actividades realizadas en diferentes departamentos de un hotel. Por otro lado, la generación de capacidades y competencias se traducen en un mejor desempeño organizativo.

\subsection{LIMITACIONES}

Tal como se ha presentado en la parte teórica el trabajo, la jerarquía propuesta por Javidan (1998): recursos, capacidades, competencias y competencias nucleares, sitúa a las competencias en el tercer nivel de la jerarquía y las define como la integración funcional y la coordinación de capacidades. Las competencias nucleares son fuente de las ventajas competitivas sostenibles y estas de un desempeño organizativo superior. 
El presente trabajo se ha limitado a explicar los efectos de la transferencia de conocimiento en el desempeño organizativo, el modelo no ha considerado los efectos de la Transferencia de Conocimiento sobre las capacidades y competencias. La constatación empírica ha demostrado que el efecto indirecto de la transferencia de conocimiento en el desempeño organizativo es mucho mayor y estadísticamente significativo que el directo.

El Enfoque Basado en Competencias, en sus líneas de pensamiento contempla al Enfoque Basado en Capacidades Dinámicas, en este entendido, las empresas deben recomponer sus recursos y capacidades en respuesta a entornos altamente cambiantes. Para poder analizar estos cambios es necesario un estudio longitudinal que recoja datos en diferentes periodos temporales.

El presente trabajo se ha realizado en un periodo de tiempo determinado, debido a limitaciones de tiempo y coste, así como a la limitación de respuesta del encuestado en la situación que no fuera capaz de discernir el contenido de un ítem para diferentes momentos temporales.

Debido a la multiplicidad de variables que intervienen en la transferencia de conocimiento, el presente trabajo se ha centrado en la Transferencia Interna de Conocimiento. 


\subsection{FUTURAS INVESTIGACIONES}

En resumen, la presente investigación supone una contribución importante en el estudio de las relaciones entre la transferencia de conocimiento y el desempeño organizativo.

El conocimiento de las relaciones que se establecen entre ambos constructos nos ha permitido desvelar la importancia que tiene la transferencia de conocimiento en la mejora del desempeño organizativo y los factores antecedentes. No obstante, la investigación aquí iniciada debe seguir mejorándose incluyendo nuevos elementos que expliquen mejor la relación entre la transferencia de conocimiento y el desempeño organizativo.

A continuación y siguiendo el orden de las limitaciones del presente trabajo, se sugieren las siguientes futuras investigaciones:

1. Analizar los Efectos de la Transferencia de Conocimiento en diferentes tipos de capacidades y competencias

2. Efectuar un estudio longitudinal a fin de evaluar la recomposición de recursos y capacidades frente a cambios del entorno

3. Dadas las características del sector turístico, realizar un estudio sobre la transferencia externa de conocimiento.

4. Adecuar el modelo BMS al sector de servicios en particual al hotelero 
Alavi, M. y Leidner, D. (2001). "Review: Knowledge management and knowledge management systems: Conceptual foundations and research issues". MIS Quarterly: 1, 107-136.

Al-Adaileh, Raid. M., y Muawad S. Al-Atawi. (2011). "Organizational culture impact on knowledge exchange: Saudi Telecom context". Journal of Knowledge Management 15 (2), 212-230.

Aldebert, B., Rani Dang, R., y Longhi, C. (2011). "Innovation in the tourism industry: The case of Tourism". Tourism Management 32(2011), 12041213.

Albadvi, A., A. Keramati, y J. Razmi. (2007). "Assessing the impact of information technology on firm performance considering the role of intervening variables: organizational infrastructures and business processes reengineering". International Journal of Production Research 45, 12(6), 2697-2734.

Almeida, P., Phene, A., y Grant, R.M.. (2003). "Innovation and knowledge management: scanning, sourcing, and integration”, en M. Easterby-Smith y M.A. Lyles (eds.), Handbook of Organizational Learning and Knowledge Management, Blackwell Publishing, pp. 356 - 371.

Alvesson, M., y Karreman, D. (2001). "Odd Couple: Making Sense of the Curious Concept of Knowledge Management”. Journal of Management Studies 38 (7), 995-1018.

Amit, R. y Schoemaker, P. (1993). "Strategic Assets and Organizational Rent". Strategic Management Journal 14(1), 33-46.

Argote, L., e Ingram, P. (2000). "Knowledge Transfer: A Basis for Competitive Advantage in Firms". Organizational Behavior and Human Decision Processes 82(1), 150 - 169

Argote, L., McEvily, B.,y Reagans, R. (2003). "Managing Knowledge in Organizations: An Integrative Framework and Review of Emerging Themes". Management Science 49 (4), 571-582.

Argyris, C. y Shon, D. (1978). "Organizational learning: A theory of action perspective". Reading, M.A.: Addisori-Wesley. 77-78 (97), 345-348

Argyris, C. (1957). Personality and organization: the conflict between system and the individual.

Arling, P. A., y Mark W.S. Chun. (2011). "Facilitating new knowledge creation and obtaining KM maturity". Journal of Knowledge Management 15 (2), 231-250.

Asensio, R.A., Bono, E., y García, E. (2000). La Sostenibilidad del desarrollo: el caso valenciano. Universitat de València. 
Atac, O. (2002). Businees Mangement System. International Trade Center.

Banón, A., y A. Aragón. (2007). Análisis de los efectos empresa e industria en las PYME murcianas. Cuadernos de Ciencias Económicas y Empresariales, 53, 83-105.

Bakos, J., y Treacy, M. (1986). Information Technology and Corporate Strategy: A Research Perspective. MIS Quarterly 10(2), 107-119.

Barney, J. B. (1986). "Types of Competition and the Theory of Strategy: Toward an Integrative Framework". Academy of Management Review 11(4), 791800.

Barney, J. B. (1991). "Firm Resources and Sustained Competitive Advantage". Journal of Management 17(1), 99 - 120.

Bartol, K. M., y Srivastava, A.. (2002). "Encouraging Knowledge Sharing: The Role of Organizational Reward Systems". Journal of Leadership and Organizational Studies 9, 64-76.

Barrio, S. y Luque, T. (2000). Análisis de ecuaciones estructurales. En Luque, T. (coord): Técnicas de análisis de datos en investigación de mercados. Pirámide, Madrid.

Batista, J. M., y Coenders, G. (2000). Modelos de ecuaciones estructurales. Madrid, Hesperides.

Barua, Anitesh, Charles H. Kriebel, y Tridas Mukhopadhyay. (1995). "Information Technologies and Business Value: An Analytic and Empirical Investigation". Information Systems Research 6 (1), 3.

Bharadwaj, A.S. (2000). "A Resource - Based Perspective on Information Technology Capability and Firm Performance: An empirical Investigation". MIS Quarterly 24 (1), 169-196.

Brady, M. K., y J. J. Cronin. (2001). "Customer Orientation: Effects on Customer Service Perceptions and Outcome Behaviors". Journal of Service Research 3 (3), 241-251.

Becker, M.C. (2001). "Managing Dispersed Knowledge: Organizational Problems, Managerial Strategies, and Their Effectiveness". Journal of Management Studies 38 (7), 1037-1051.

Bertalanffy, Ludwig von. (2006). Teoría General de Los Sistemas: Fundamentos, Desarrollo, Aplicaciones. Fondo de Cultura Económica, Agosto 28.

Bierly III, P.E., Kessler, E.H. y Christensen, E.W. (2000). "Organizational learning, knowledge and wisdom". Journal of Organizational Change Management 13, (6), 595. 
Byrd, T. A., y Turner, D.E. (2000). "Measuring the Flexibility of Information Technology Infrastructure: Exploratory Analysis of a Construct". Journal of Management Information Systems 17 (1), 167-208.

Bock, G.W. y Kim, Young-Gul. (2002). "Breaking the Myths of Rewards: An Exploratory Study of Attitudes about Knowledge Sharing". Information Resources Management Journal 15 (2), 14.

Bollen, K.A. (1989). Structural equations with latent variables. John Wiley \& Son, New York.

Brynjolfsson, E., y S. Yang. (1996). "Information Technology and Productivity: A Review of the Literature". Advances in Computers 43, 179-214.

Brynjolfsson, E., y Lorin Hitt. (1996). "Paradox Lost? Firm-Level Evidence on the Returns to Information Systems Spending". Management Science 42 (4), 541-558.

Brynjolfsson, E., y Lorin M. Hitt. (2000). "Beyond Computation: Information Technology, Organizational Transformation and Business Performance". Journal of Economic Perspectives 14 (4), 23-48.

Brockman, B. K., y Morgan, R. M.. (2003). "The Role of Existing Knowledge in New Product Innovativeness and Performance". Decision Sciences 34, 385-419.

Brown, J., y Duguid, P.. (1998)." Organizing Knowledge”. California Management Review 40 (3), 90-111.

Blumentritt, R., y Johnston, R. (1999). "Towards a Strategy for Knowledge Management." Technology Analysis \& Strategic Management 11 (3), 287300 .

Bontis, N. (1999). "Managing an Organizational Learning System by Aligning Stocks and Flows of Knowledge". Academy of Management Proceedings \& Membership Directory: J1-J2.

Bueno, E. y Morcillo, P. (2006). Dirección Estratégica: Nuevas Perspectivas Teóricas. Piramide Ediciones Sa.

Bueno, E. (1998). "El capital intangible como clave estratégica en la competencia actual". Boletin de Estudios Económicos 53 (164), 207 - 229.

Buhalis, D., y R. Law. (2008). Progress in information technology and tourism management: 20 years on and 10 years after the Internet-The state of Tourism research. Tourism Management 29 (4), 609-623.

Burns, T., y Stalker, G.M. (1961). Tom Burns and G. M. Stalker. The management of innovation.... Tavistock publications.

Buzell, Robert D., y B. T. Gale. (1987). The PIMS Principles. Free Press. http://libraries.ou.edu/access.aspx?url=http://search.ebscohost.com/login.a 
$\underline{\text { spx?direct }=\text { true } \& \mathrm{db}=\text { edsref } \& A N=A B J J A C A \& \text { site }=\text { eds-live. }}$.

Byrd, T.A., Pitts, JP., Adrian, A.M. y Davidson, N.W. (2008). Examination of a Path Model Relating Information Technology Infrastructure with Firm Performance. Journal of Business Logistics 29 (2), 161-187.

Byrd, T.A., y Turner, D.E. (2000). Measuring the Flexibility of Information Technology Infrastructure: Exploratory Analysis of a Construct. Journal of Management Information Systems 17 (1), 167-208.

Camisón, C. (2002). Una propuesta de conceptualización del patrimonio de competencias distintivas de una organización. Grupo de investigación de estrategias en gestión del conocimiento y aprendizaje organizativo. Documento de trabajo 3/02. Universidad Jaume I, Catellón, España.

Camisón, C. y Boronat, M. (2004). "Factores determinantes del desempeño organizativo: efecto industria, incertidumbre y competencias distintivas". Investigaciones europeas de dirección y economía de la empresa 10 (3), 127-143.

Cañibano, L., y Sanchez, P.. (1998). Measuring intangibles to understand and improve innovation management. A Research Proposal to the TSER Programme. Autonomous University of Madrid.

Carrión, M.J. (2007). Estrategia: de la visión a la acción. ESIC Editorial.

Chan, Y.E. (2000). "IT Value: The Great Divide Between Qualitative and Quantitative and Individual and Organizational Measures". Journal of Management Information Systems 16 (4), 225-261.

Coase, R. H. (1937). The Nature of the Firm. Económica 4(16): 386-405.

Collis, D. J., y Montgomery, C. (1995). "Competing on Resources: Strategy in the 1990s". Harvard Business Review 73(4), 118-128.

Conner, K. R, y Prahalad, C. K. (1996). "A resource-based theory of the firm: Knowledge versus opportunism". Organization science: 477-501.

CCoyne, K. (1986). "Sustainable competitive advantage - What it is, what it isn't”. Business Horizons 29 (1), 54-61.

Crossan, M.M, Lane, H.W., y White, R.E. (1999). "An Organizational Learning Framework: From Intuition to Institution”. Academy of Management Review 24(3), 522-537.

Chakravarthy, B., Mcevily, S., Doz,Y. y Devaki, R. (2003). "Knowledge management and competitive advantage", en M. Easterby-Smith y M.A. Lyles (eds.), Handbook of Organizational Learning and Knowledge Management, Blackwell Publishing, pp. 305 - 323.

Chiavenato, I. (2006). Introducción a la teoría general de la administración. McGraw-Hill. 
Chrisman, J.J., Hofer, C.W. y Boulton, W.B. (1988). "Toward a System for Classifying Business Strategies". Academy of Management Review 13(3), 413-428.

Churchill, G.A. (1979). "A Paradigm for Developing Better Measures of Marketing Constructs”. Journal of Marketing Research, 16 (1), 64-73.

Davenport, T. H., y Prusak, L. (1998). Working knowledge: how organizations manage what they know. HarvardBusiness School Press: Boston, MA.

Davenport, T. O. (1999). "Human Capital". Management Review 88(11), 37.

Davis, F.D., Bagozzi, R.P. y Warshaw, P.R.. (1989). "User Acceptance of Computer Technology: A comparison of Two Theoretical Models". Management Science 35(8), 982-1003.

Demsetz, H. (1991). "The Theory of the Firm Revisited", en O.E. Williamson y $\mathrm{S}$. Winter (eds.). The nature of the firm: Origins, evolution, and development, New York: Oxford University Press. 159-178.

DeVellis, R. F. (1991). Scale development: theory and applications. Sage Publications, Newbury Park, California.

DiBella, A.J., y Nevis, E. (1998). How organizations learn $\square$ : an integrated strategy for building learning capability. Jossey Bass Publishers, San Francisco.

Dierickx, I. y Cool, K. (1989). “Asset Stock Accumulation and Sustainability of Competitive Advantage". Management Science 35, (12), 1504-1511.

DiMaggio, P.J., y Powell, W.W. (1983). "The Iron Cage Revisited: Institutional Isomorphism and Collective Rationality in Organizational Fields". American Sociological Review 48(2), 147-160.

Doolin, Bill, Lois Burgess, y Joan Cooper. (2002). "Evaluating the use of the Webfor tourism marketing: a case study from New Zealand". Tourism Management.

Dyer, J. H., y Nobeoka, K. (2000). "Creating and Managing a High-Performance Knowledge-Sharing Network: The Toyota Case". Strategic Management Journal 21(3), 345-367.

Dosi, G., Nelson, R. y Winter, S.G.. (2000). Introduction: The Nature and Dynamics of Organizational Capabilities. Oxford University Press, Inc. New York..

Elragal, A. A, y A. M Al-Serafi. (2011). Communications of the IBIMA The Effect of ERP System Implementation on Business Performance: an Exploratory Case-Study. IBIMA Publishing, Article ID 670212, 19 pages.

Eisenhardt, K. M. (1989). "Agency Theory: An Assessment and Review". Academy of Management Review 14(1), 57-74. 
Eisenhardt, K.M., y Martin, J.K. (2000). "Dynamic Capabilities: What are they?".Strategic Management Journal 21(10/11), 1105.

Eskildsen, J.H. Anders, W. y Kai, K. (2003). "The predictive power of intangibles". Measuring Business Excellence 7 (2), 46-54.

Fayol, Henri. (1916). Administration industrielle et générale: prévoyance, organisation, commandement, coordination, controle. H. Dunod et E. Pinat.

Feeny, D. F., y Willcocks, L.P. (1998). Core IS Capabilities for Exploiting Information Technology. Sloan Management Review 39(3), 9-21.

Fiol, M.C., y Lyles, M.A. (1985)."Organizational Learning”. Academy of Management Review 10 (4), 803-813.

Foss, N.J., y Knudsen, C. (1996). Towards a competence theory of the firm. Routledge.

Foss, N.J., y Pedersen, T. (2002). "Transferring knowledge in MNCs: The role of sources of subsidiary knowledge and organizational context". Journal of International Management 8 (1), 49.

Gantt, H. L. (1919). Organizing for work. Harcourt, Brace and Howe.

Gardner, T. y Wright, P. (2009). "Implicit human resource management theory: a potential threat to the internal validity of human resource practice measures". The International Journal of Human Resource Management 20 (1), 57-74.

Gilbreth, F.B., y Moller, L. (1920). Motion study for the handicapped. Hive Pub. Co.

Girdauskienė, L., y Savanevičienė, A. (2007). "Influence of knowledge culture on effective knowledge transfer". Engineering economics 54, (4), 36-43.

Grant, R.M. (1991). "The Resource-Based Theory of Competitive Advantage: Implications for Strategy Formulation”. California Management Review 33 (3), 114-135.

Grant, R.M. (1996). "Towards a Knowledge-Based Theory of the Firm". Strategic Management Journal 17, 109-122.

Gupta, A. K., y Govindarajan, V. (2000). "Knowledge Management's Social Dimension: Lessons From Nucor Steel”. Sloan Management Review 42, 71-80.

Gurteen, D. (1998). "Knowledge, creativity and innovation". Journal of Knowledge Management 2 (1), 5-13.

Gururajan, V., y D. Fink. (2010). "Attitudes towards knowledge transfer in an environment to perform". Journal of Knowledge Management 14 (6), 828840. 
Gutiérrez, A. Osvaldo W. (2008). "Epistemología de las ciencias económicas y empresariales". Documentos de reflexión académica N58 - Junio 2008, Universidad Mayor de San Simón - PROMEC

Hall, R.H. (1993). "A Framework Linking Intangible Resources and Capabilities to Sustainable Competitive Advantage". Strategic Management Journal 14(8), 607-618.

Hair, J., Anderson, R., Tatham, R. y Black W., (1999).Análisis Multivariable. Prentice Hall, Madrid.

Hallin, C. A, y Marnburg, E. (2008). "Knowledge management in the hospitality industry: A review of empirical research". Tourism Management 29 (2), 366-381.

Hamel, G., y Prahalad, C. K.. (1994). Competing for the future. Harvard Business School Press, Boston, MA

Handzic, M. (2011). "Integrated socio-technical knowledge management model: an empirical evaluation". Journal of Knowledge Management 15 (2), 198211.

Hansen, G.S., y Wernerfelt, B. (1989). "Determinants of Firm Performance: The relative Importance of Economic and Organizational Factors". Strategic Management Journal 10 (5), 399-411.

Hansen, M.T. (1999). "The Search-Transfer Problem: The Role of Weak Ties in Sharing Knowledge across Organization Subunits". Administrative Science Quarterly 44 (1), 82-111.

Hansen, M.T., Nohria, N. y Tierney, T. (1999). "What's your strategy for managing knowledge?". Harvard Business Review 77 (2), 106-116.

Hair, J.R., Anderson, R.E., Tatham, R.L. y Black, W. (1999). Analisis Multivariable. Prentice Hall, Madrid.

Hjalager, A. M. (2010). "A review of innovation research in tourism". Tourism Management 31 (1), 1-12.

Helfat, C., y Peteraf, M. (2003). "The Dynamic Resource - Based View: Capability Lifecycles". Strategic Management Journal 24 (10), 997-1010.

Herzberg. (1999). Frederick Herzberg: the hygiene-motivation theory: An article from: Thinkers. Chartered Management Institute, Diciembre 1.

Hislop, D. (2003). "Linking human resource management and knowledge management via commitment: A review and research agenda". Employee Relations 25 (2), 182-202.

Hjalager, A. M. (2010). "A review of innovation research in tourism". Tourism Management 31 (1), 1-12. 
Hofstede, G. (1991). Cultures and Organizations: Software of the Mind. McGraw-Hill, London.

Huber, G. P. (1991). "Organizational learning: The contributing processes and the literatures". Organization science 2 (1), 88-115.

Huysman, M. y de Wit, D. (2002). Knowledge sharing in practice. Ed. Kluwer Academic Publishers. AA Dordrecht - The Netherlands.

Jantunen, A. (2005). "Knowledge-processing capabilities and innovative performance: an empirical study". European Journal of Innovation Management 8 (3), 336-349.

Javidan, M. (1998). "Core Competence: What does it mean in Practice?". Long Range Planning 31 (1), 60-71.

Jeon, S., Kim, Y.G. y Koh, J. (2011). "An integrative model for knowledge sharing in communities-of-practice". Journal of Knowledge Management $15(2), 251-269$.

Jerez-Gómez, P., Céspedes-Lorente， J., y Valle-Cabrera， R. (2005). "Organizational learning capability: a proposal of measurement". Journal of Business Research 58(6), 715-725.

Joseph, K. (2009). "The Influence of Organizational Culture on Organizational Learning, Worker Involvement and Worker Productivity". International Journal of Business and Management 4(9), 243.

Kannan, G., y Aulbur, W. G.. (2004). "Intellectual capital: Measurement effectiveness". Journal of Intellectual Capital 5 (3), 389-413.

Kast, F.E., y Rosenzweig, J.E. 1969. Organization and management: a systems approach. McGraw - Hill series in Management. Michigan.

Kearns, G. S, y Lederer, A. L. (2003). "A resource-based view of strategic IT alignment: How knowledge sharing creates competitive advantage". Decision Sciences 34 (1), 1-29.

Kisch, L. (1975). "Representation, randomization and Control". Quantitative International Sociology. Academic Press.

Kogut, B. y Zander, U. (1992). "Knowledge of the Firm, Combinative Capabilities and Replication of Technology". Organization Science 3 (3), 383-397.

Kogut, B. y Zander, U. (1996). "What Firms Do? Coordination, Identity, and Learning". Organization Science 7 (5), 502-518.

Koontz, H., O'Donnell, C. y Weihrich, H. (1980). Management. McGraw-Hill.

Kotler, P., y Keller, K.L. (2009). Direccion de Marketing. Pearson Educación, Marzo 29. 
Krone, K.J., Jablin, F.M. y Putnam, L.L. (1987). “Communication theory and organizational communication: Multiple perspectives". en F.M. Jablin, L.L. Putnam, K.M. Robert, y L.W. Porter (Eds.), Handbook of organizational communication: An interdisciplinary perspective., pp. 1840. Newbury Park, CA: Sage.

Kubo, I., Saka, A., y Pam, S. (2001). "Behind the scenes of knowledge sharing in a Japanese bank". Human Resource Development International 4 (4), 465-485.

Kulkarni, U.R., Ravindran, S. y Freeze, R. (2007). "A Knowledge Management Success Model: Theoretical Development and Empirical Validation". Journal of Management Information Systems 23 (3)(1), 309-347. .

Käser, P., y Miles, R. 2001. Knowledge Activists: The culmination of motivation and trust properties of knowledge sharing relationships. En Academy of Management Proceedings \& Membership Directory, D1-D6. Academy of Management. doi:Conference Paper. http://libraries.ou.edu/access.aspx?url=http://search.ebscohost.com/login.a spx?direct $=$ true $\& d b=$ buh $\& A N=6133693 \&$ site $=$ eds-live.

Lambe, P. (2011). "The unacknowledged parentage of knowledge management". Journal of Knowledge Management 15 (2), 175-197.

Laursen, K., y Foss, N.J. (2003). „New human resource management practices, complementarities and the impact on innovation performance". Cambridge Journal of Economics, 27, 243-263.

Lave, J. y Wenger, E. (1991). Situated learning: legitimate peripheral participation. Cambridge University Press.

Lee, C.C. y Yang, J. (2000). "Knowledge value chain". Journal of Management Development 19 (9), 783-794.

Lee, H. y Choi, B. (2003). "Knowledge Management Enablers, Processes, and Organizational Performance: An Integrative View and Empirical Examination". Journal of Management Information Systems 20 (1), 179228.

Leonard-Barton, D., y Deschamps, I. (1988). "Managerial Influence in the Implementation of New Technology". Management Science 34 (10), 12521265.

Levy, M., Hadar, I., Greenspan, S. y Hadar, E. (2010). "Uncovering cultural perceptions and barriers during knowledge audit". Journal of Knowledge Management 14 (1), 114-127.

Lewin, K. (1935). A dynamic theory of personality: selected papers by Kurt Lewin... McGraw-Hill. 
Lewis, B. R, y Byrd, T. A. (2003). "Development of a measure for the information technology infrastructure construct". European Journal of Information Systems 12 (2), 93-109.

Likert, R. 1932. A technique for the measurement of attitudes. s.n.

Lin, H. F. (2007). "Knowledge sharing and firm innovation capability: an empirical study". International Journal of Manpower 28 (3/4), 315-332.

Llonch, J. y Belbeze, M.P. (2004). "La relación entre la orientación al mercado y los resultados y el efecto moderador de la estrategia genérica en dicha relación". Cuadernos de Economia y Dirección de Empresas 21, 65 - 88.

Lubit, R. (2001). "Tacit Knowledge and Knowledge Management: The Keys to Sustainable Competitive Advantage”. Organizational Dynamics 29 (3): 164.

López-Sáez, P., Navas-López, J. E, Martín-de-Castro, G., y Cruz-González, J. (2010). "External knowledge acquisition processes in knowledge-intensive clusters". Journal of Knowledge Management 14 (5), 690-707.

MacNeil, C.M. (2003). "Line managers: facilitators of knowledge sharing in teams”. Employee Relations 25 (3), 294-307.

Magnier-Watanabe, R., y Senno, D. (2010). "Shaping knowledge management: organization and national culture". Journal of Knowledge Management 14 (2), 214-227.

Makadok, R.P. (2001). "Toward a Synthesis of the Resource - Based and Dynamic - Capability views of rent creation". Strategic Management Journal 22 (5), 387.

Mahoney, J.T., y Rajendran J. (1992). "The Resource-Based View Within the Conversation of Strategic Management”. Strategic Management Journal 13 (5), 363-380.

Mata, F.J., Fuerst, W.L. y Barney, J.B. (1995). "Information Technology and Sustained Competitive Advantage: A Resource-Based Analysis". MIS Quarterly 19 (4), 487-505.

Mata y Rodríguez, G. (2010). El análisis estructural de los sectores de actividad: crítica del modelo de las cinco fuerzas del M.E. Porter. Text.Serial Journal. Direccion y Organizacion 40, 40 - 59.

McEvily, S.K., y Chakravarthy, B. (2002). "The Persistence of KnowledgeBased Advantage: An Empirical Test for Product Performance and Technological Knowledge". Strategic Management Journal 23 (4), 285305. 
McGrath, J.E., y Argote, L. (2004). "Group Processes in Organizational Contexts”, en M.A. Hogg y Tindale, R.S. (Eds.), Blackwell handbook of social psychology, Oxford, UK: Blackwell.

Maslow, A. H. (1943). Organizaciones tema 4: la motivación en el trabajo. Uniandes, Fac. Administración. http://books.google.es/books?id=b3_CPgAACAAJ.

Mayo, E. (1933). The human problems of an industrial civilization. The Macmillan company.

McGregor, D. (1960). The human side of enterprise. Ed. McGraw - Hill. University of Michigan.http://libraries.ou.edu/access.aspx?url=http://search.ebscohost.co $\mathrm{m} / \operatorname{login}$. asp $\mathrm{x}$.direct $=$ true $\& \mathrm{db}=$ cat $00057 \mathrm{a} \& \mathrm{AN}=$ uok. $\mathrm{a} 240989 \&$ site $=$ edslive.

McGregor, D., y Cutcher-Gershenfeld, J. (2006). The human side of enterprise. McGraw-Hill Professional.

Metcalf, H.C., y Urwick, L. (2003). Early Sociology of Management and Organizations: Dynamic Administration: The Collected Papers of Mary Parker Follett. Reprint. Routledge, Noviembre 19.

Miles, R.E., Snow, C.C., Meyer, A.D. y Coleman, J.r. (1978). "Organizational Strategy, Structure, and Process". Academy of Management Review 3 (3), 546-562.

Mills, A.M., y Smith, T.A. (2011). "Knowledge management and organizational performance: a decomposed view". Journal of Knowledge Management 15 (1), 156-171.

Mintzberg, H., Ahlstrand, B., y Lampel, J. (1999). Safari a la estrategia. Ediciones Granica S.A., Octubre.

Mintzberg, H., Quinn, J.B., y Voyer, J. (1997). El proceso estratégico: conceptos, contextos y casos. Pearson Educación, Febrero 1.

Montresor, S. (2004). "Resources, Capabilities, Competences and the Theory of the Firm". Journal of Economic Studies 31, (5-6), 409-434.

Moreno, M. J., Pelayo, Y., y Vargas, A. (2004). "La Gestión por Competencias como herramienta para la dirección estratégica de los recursos humanos en la sociedad del conocimiento". Revista de Empresa 10, 56-72.

Nakata, C., Zhu, Z. y Kraimer, M.L. (2008). "The Complex Contribution of Information Technology Capability to Business Performance". Journal of Managerial Issues 20 (4), 485-506.

Nelson, R., y Winter, S. (1982). An evolutionary theory of economic change. Harvard University Press, Cambridge, MA. 
Neumann, J.Von, y Morgenstern, O. (1947). Theory of games and economic behavior. Princeton Univ. Press.

Niu, Kuei-Hsien. (2010). "Organizational trust and knowledge obtaining in industrial clusters". Journal of Knowledge Management 14 (1), 141-155.

Nonaka, I. (1991). "The Knowledge-Creating Company". Harvard Business Review 69 (6), 96-104.

Nonaka, I. (1994). A Dynamic Theory of Organizational Knowledge Creation. Organization Science 5 (1), 14-37.

Nonaka, I. (2003). "The knowledge-creating theory revisited: knowledge creation as a synthesizing process". Knowledge Management Research \& Practice $1(1), 2$.

Nonaka, I. y Takeuchi, H. 1995. "The knowledge-creating company : how Japanese companies create the dynamics of innovation". Oxford University Press: Oxford.

O’ Dell, C., y J. Grayson. 1998. "If only we knew what we know: identification and transfer of best practices". California Management Review 40(3), 183 $-197$

Palacios, D., Garrigos, F.J. y Devece, C.C. (2006). "The Effect of Innovation on Intellectual Capital: An empirical evaluation in the Biotechnology and Telecommunications Industries". International Journal of Innovation Management 10 (1), 89-112.

Palacios, D., Garrigos, F.J., y Pechuan, I.G.. (2010). Relación entre el aprendizaje organizativo y el desempeño empresarial en las empresas hoteleras españolas. (With English summary.). Economía Industrial 375, 77-87.

Palacios, D. (2002). La creación de competencias distintivas dinámicas mediante la gestión del conocimiento y su efecto sobre el desempeño: análisis empírico en las industrias de biotecnología y telecomunicaciones. Tesis Doctoral, Universidad: Jaume I de Castellón, España.

Palacios, D. y Garrigós, F. (2006). "Propuesta de una Escala de Medida de la Gestión del Conocimiento en las Industrias de Biotecnología y Telecomunicaciones". Investigaciones Europeas de Dirección y Economía de la Empresa 12 (1).

Palacios-Marques, D., y F. J Garrigos-Simon. (2005). "A measurement scale for knowledge management in the biotechnology and telecommunications industries". International Journal of Technology Management 31(3), 358374. 
Pawlowsky, P., J. Forslin, y R. Reinhardt. 2003. Practices and tools of organizational learning. Oxford University Press. http://libraries.ou.edu/access.aspx?url=http://search.ebscohost.com/login.a spx?direct $=$ true $\& d b=$ edsref $\& A N=H O L K . P A W L O W S K Y . O X F O R D U N I$ VERSITYPRESS.BJJC.GEE\&site=eds-live.

Penrose, E. y Pitelis, C. (2009). The Theory of the Growth of the Firm. Oxford University Press, Octubre 21.

Pereda, S., Berrocal, F., y López, M. (2010). Gestión de recursos humanos por competencias y gestión del conocimiento. Dirección y organización (28).

Peteraf, M.A. (1993). "The Cornerstones of Competitive Advantage: A Resource - Based View". Strategic Management Journal 14, no. 3 (Marzo): 179191.

Peteraf, M.A., y Barney, J.B. (2003). "Unraveling the Resource-Based Tangle". Managerial and Decision Economics 24 (4), 309-323.

Polanyi, M. 1966. The tacit dimension. London: Routledge \& KeganPau.

Porter, M.E. (1980). Competitive strategy: techniques for analyzing industries and competitors: with a new introduction. The Free Press, New York.

Porter, M.E. (1985). Competitive advantage: creating and sustaining superior performance: with a new introduction. The Free Press, New York.

Prahalad, C.K., y Hamel, G. (1990). "The Core Competence of the Corporation". Harvard Business Review 68 (3): 79-91.

Probst, Gilbert J. B., y Bettina Buchel. (1997). Organizational Learning: The Competitive Advantage of the Future. Prentice Hall, Septiembre.

Ravichandran, T., y Lertwongsatien, C. (2005). "Effect of Information Systems Resources and Capabilities on Firm Performance: A Resource-Based Perspective". Journal of Managent Information Systems 21 (4), 237-276.

Ray, G., Muhanna, W.A. y Barney, J.B. (2005). "Information Technology and Performance of the Customer Service Process. A Resource - Based Analysis". MIS Quarterly 29 (4), 625-652.

Reagans, Ray, y McEvily, Bill. (2003). "Network Structure and Knowledge Transfer: The Effects of Cohesion and Range". Administrative Science Quarterly 48 (2), 240-267.

Reid, D., Bussiere, D. y Greenaway, K. (2001). "Alliance formation issues for knowledge-based enterprises". International Journal of Management Reviews 3 (1), 79.

Reed, R., y DeFillippi, R.J. (1990). "Causal Ambiguity, Barriers to Imitation, and Sustainable Competitive Advantage". Academy of Management Review 15 (1), 88-102. 
Ricardo, D. (2011). On the Principles of Political Economy, and Taxation by David Ricardo. Optimal, Enero 28.

Rincón, M. J.. (2006). "El sector hotelero español". Boletín económico de ICE, Información Comercial Español a. 2884: 11-24.

Rivas, Tovar Luís Arturo. (2009). "Evolución de la teoría de la Organización". Universidad y Empresa.

Ross, J.W., Mathis, C. y Goodhue, D. (1996). "Develop Long-Term Competitiveness through IT Assets". Sloan Management Review 38 (1), 31-42.

Rothwell, W.J., y Duboise, D.D. (2004). Competency-Based Human Resource Management. Nicholas Brealey Publishing, Enero 20.

Rumelt, R. P. (1984). "Towards a Strategic Theory of the Firm" en R. Lamb (ed), Competitive Strategic Management. Englewood Cliffs: Prentice-Hall, Inc., pp. $556-570$.

Rumelt, R.P. (1991). "How Much Does Industry Matter?". Strategic Management Journal 12, (3): 167-185.

Sabherwal, R., y Becerra-Fernandez, I. (2003). "An empirical study of the effect of knowledge management processes at individual, group, and organizational levels". Decision Sciences 34 (2), 225-260.

Saint-Onge, H., y Wallace, D. (2003). Leveraging communities of practice for strategic advantage. Butterworth-Heinemann.

Sanchez, R., y Heene, A. (1997). "Reinventing strategic management: New theory and practice for competence-based competition". European Management Journal 15(3), 303.

Sanchez, R., Heene, A., y Thomas H.. (1996). Dynamics of competence-based competition : theory and practice in the new strategic management / edited by Ron Sanchez, Aime Heene, and Howard Thomas. Technology, innovation, entrepreneurship, and competitive strategy series. Oxford, UK; New York: Pergamon, Oxford, UK; New York: Pergamon.

Savage, L. J. (1954). The foundations of statistics. Wiley.

Schilling, J., y Kluge, A. (2009). "Barriers to organizational learning: An integration of theory and research". International Journal of Management Reviews 11 (3), 337-360.

Schulz, M., y Jobe, L.A. (2001). "Codification and tactiness as knowledge management strategies: An empirical exploration”. Journal of High Technology Management Research 12 (1), 139.

Senge, P. M. (1990). The fifth discipline: the art and practice of the learning organization. Doubleday, New York. 
Selznik, P. (1957). Leadership in Administration. A sociological interpretation. Cambridge, Maas.: Harvard University Press.

Segarra, M. (2006). Estudio de la naturaleza estratégica del conocimiento y las capacidades de gestión del conocimiento: Aplicación a empresas innovadoras de base tecnológica. Tesis Doctoral, Castellón España: Universidad Jaume.

Steyn, C., y Kahn, M.. (2008). "Towards the development of a knowledge management practices survey for application in knowledge intensive organizations". South Arican Journal of Business Mangement, 39(1).

Scott, W. R. (1987). "The Adolescence of Institutional Theory". Administrative Science Quarterly 32 (4), 493-511.

Shaw, G., y Williams, A. (2009). "Knowledge transfer and management in tourism organizations: An emerging research agenda". Tourism Management 30 (3), 325-335.

Shin, M., Holden, T. y Schmidt, R.A. (2001). "From knowledge theory to management practice: towards an integrated approach". Information Processing \& Management 37 (2), 335.

Simon, H. (1947). Administrative behavior; a study of decision-making processes in administrative organization; with a foreword by Chester I. Barnard. Macmillan, New York.

Simon, H. (1961). The New Science of Management Decision. Harvard Business School Publication Corp., Enero. http://libraries.ou.edu/access.aspx?url=http://search.ebscohost.com/login.a spx?direct=true $\& \mathrm{db}=$ buh $\& A N=23614898 \&$ site $=$ eds-live .

Simonin, B.L. (1999). "Ambiguity and the Process of Knowledge Transfer in Strategic Alliances”. Strategic Management Journal 20 (7), 595-623.

Sparks, B.A., y Browning, A. (2011).The impact of online reviews on hotel booking intentions and perception of trust». Tourism Management (Enero). doi:10.1016/j.tourman.2010.12.011. http://linkinghub.elsevier.com/retrieve/pii/S0261517711000033.

Spencer, L., y S. Spencer. (1993). Competence at Work Model for Superior Performance. New York: John Wiley \& Sons.

Spender, J. C. (1996). "Making knowledge the basis of a dynamic theory of the firm”. Strategic management journal 17, 45-62.

Spender, J. C., y Grant R. M. (1996). "Knowledge and the firm: overview". Strategic management journal 17, 5-9.

Staples, D. S., Greenaway, K. y McKeen, J. (2001). “Opportunities for research 
about managing the knowledge-based enterprise". International Journal of Management Reviews 3 (1), 1.

Swieringa, J., y Wierdsma, A. (1992). Becoming a Learning Organization.

Szulanski, G. (2000). "The Process of Knowledge Transfer: A Diachronic Analysis of Stickiness". Ed. L. Argote, P. Ingram, J. M. Levine, y R. L. Moreland. Organizational Behavior and Human Decision Processes 82. The Psychological Foundations of Knowledge Transfer in Organizations: 9-27.

Szulanski, G. (1996). "Exploring internal stickiness: Impediments to the transfer of best practice within the firm". Strategic management journal 17, 27-43.

Tallon, P.P. (2007). "Inside the adaptive enterprise: an information technology capabilities perspective on business process agility". Information Technology and Management 9 (1)(8), 21-36.

Taylor, F.W. 1911. The Principles of Scientific Management.

Taylor, F.W. (2008). Shop Management. NuVision Publications, LLC, Mayo.

Teece, D.J. (1998). "Research Directions for Knowledge Management". California Management Review 40 (3), 289-292.

Teece, D.J. (1998). "Capturing Value from Knowledge Assets: The New Economy, Markets for Know - How, and Intangible Assets". California Management Review 40 (3), 55-79.

Teece, D.J. (2000). "Strategies for Managing Knowledge Assets: the Role of Firm Structure and Industrial Context”. Long Range Planning 33 (1), 3554.

Teece, D.J., Pisano, G. y Shuen, A. (1997). "Dynamic capabilities and strategic management". Managing Strategic Innovation and Change, 308-332.

Teece, D.J. (2007). "Explicating dynamic capabilities: the nature and microfoundations of (sustainable) enterprise performance". Strategic Management Journal 28 (13), 1319-1350.

Templeton, G.F., Lewis, B.R., y Snyder, C.A.. (2002). "Development of a Measure for the Organizational Learning Construct". Journal of Management Information Systems 19 (2), 175-218.

Tsai, W. (2001). "Knowledge Transfer in Intraorganizational Networks: Effects of Network Position and Absorptive Capacity on Business Unit Innovation and Performance". Academy of Management Journal 44 (5), 996-1004.

Venzin, M., G. von Krogh, G. y Roos, J. (1998). "Future research into knowledge management". En G. von Krogh, Ross J. y Kleine D. (Eds.), Knowing in firms. Understanding managing and measuring knowledge, pp. 26 - 66. London, SAGE Publications. 
Wade, M., y Hulland, J. (2004). "The Resource - Based View and Information Systems Research. Review, Extension, and Suggestions for Future Research". MIS Quarterly 28 (1), 107-142.

Wald, R.M., y Doty, R.A. (1954). "The TOP EXECUTIVE: a Firsthand Profile". Harvard Business Review 32 (4), 45-54.

Walsh, J.P., y Ungson, G.R. (1991). “Organizational Memory”. Academy of Management Review 16 (1), 57-91.

Wang, Y., Lo, H. P., Zhang, Q., y Xue, Y.. (2006). "How technological capability influences business performance: An integrated framework based on the contingency approach". Journal of Technology Management in China 1 (1), 27-52.

Wenger, E., McDermott, R.A. y Snyder, W. (2002). Cultivating communities of practice: a guide to managing knowledge. Harvard Business Press, Marzo 1 .

Wernerfelt, B. (1984). "A resource-based view of the firm". Strategic Management Journal 5 (2), 171-180.

Whittington, R. (2002).¿Qué es la estrategia? ¿realmente importa? Thomson, Septiembre 10.

Williamson, O.E. (1979). "Transaction-Cost Economics: The Governance of Contractual Relations". Journal of Law and Economics 22 (2), 233-261.

Wiig, K.M. (1999). "What future knowledge management users may expect". Journal of Knowledge Management 3 (2), 155 - 166

Williamson, O.E. (1991). "Comparative Economic Organization: The Analysis of Discrete Structural Alternatives". Administrative Science Quarterly 36 (2), 269-296.

Winter, S.G. (1987). "Knowledge and competencies at strategic assets", en D.J. Teece (Ed.), The Competitive Challenge: Strategies for Industrial Innovation and Renewal, pp. 159 - 184. Cambridge, MA: Ballinger.

Winter, S.G. (2003). "Understanding Dynamic Capabilities". Strategic Management Journal 24 (10), 991-995.

WWolf, P., Späth, S., y Haefliger, S. (2011). "Participation in intra-firm communities of practice: a case study from the automotive industry". Journal of Knowledge a Management 15 (1), 22-39.

Woodward, J. (1965). Industrial organization: theory and practice. Oxford University Press.

Xiang, Z., y Gretzel, U.. (2010). "Role of social media in online travel information search". Tourism Management 31 (2), 179-188. 
Xue, Y., Bradley, J. y Liang, H. (2011). “Team climate, empowering leadership, and knowledge sharing". Journal of Knowledge Management 15 (2), 299312.

Yang, J. T, y Wan, C. S. (2004). "Advancing organizational effectiveness and knowledge management implementation". Tourism Management 25 (5), 593-601.

Yi, J. (2009). "A measure of knowledge sharing behavior: scale development and validation". Knowledge Management Research \& Practice 7 (1), 65-81.

Zack, M.H. (1999). "Managing Codified Knowledge". Sloan Management Review 40 (4), 45-58.

Zahra, S.A., y Gerard G. (2002). "Absorptive Capacity: A Review, Reconceptualization, and Extension”. Academy of Management Review 27 (2) (Abril): 185-203.

Zaim, H., E. Tatoglu, y S. Zaim. (2007). "Performance of knowledge management practices: a causal analysis". Journal of knowledge management 11 , no. 6: 54-67.

Zhang, M., y Tansuhaj, P.S. (2007). "Organizational culture, information technology capability, and performance: the case of born global firms". Multinational Business Review 15, no. 3: 43-78.

Zander, U, y Kogut, B. (1995). "Knowledge and the Speed of the Transfer and Imitation of Organizational Capabilities: An Empirical Test". Organization Science 6, no. 1 (Enero): 76-92.

Zehrer, A., Crotts, J. C, y Magnini, V. P. (2010)."The perceived usefulness of blog postings: An extension of the expectancy-disconfirmation paradigm". Tourism Management.

Zárraga, C., y Bonache, J. (2003). "Assessing the team environment for knowledge sharing: An empirical analysis". The International Journal of Human Resource Management 14 (7): 1227-1245. 
ANEXOS 


\section{CUESTIONARIO}

\section{PEERFIL DELL ENCUESTAADO}

Por favor marque (con X) la opción que se ajusta a sus características personales en cada una de las siguientes preguntas:

\begin{tabular}{|c|c|c|c|c|c|}
\hline 1.1 Genero: & JMasculino & JFemenino & & & \\
\hline 1.2 Edad: & ]25 a 35 años & ] 36 a 45 años & más de 46 años & & \\
\hline 1.3 Nivel académico & JBachiller & ]Técnico & Licenciatura & ]Maestría & ]Doctorado \\
\hline $\begin{array}{l}\text { 1.4 Antiguedad en la } \\
\text { empresa actual: }\end{array}$ & 」1 a 2 años & 3 a 10 años & 11 a 15 años & Jmas de15 años & \\
\hline $\begin{array}{l}1.5 \text { Cargo actual en } \\
\text { la empresa: }\end{array}$ & $\begin{array}{l}\text { Gerente General o } \\
\text { de Área }\end{array}$ & J Jefatura de Área & Administrativo & Operario & \\
\hline
\end{tabular}

\section{PERFIL DE LA ORGANIZACIÓN}

Por favor seleccione (con X), en cada una de las preguntas siguientes, la opción que se ajusta a las características de su empresa: 2.1 Número de Empleados:

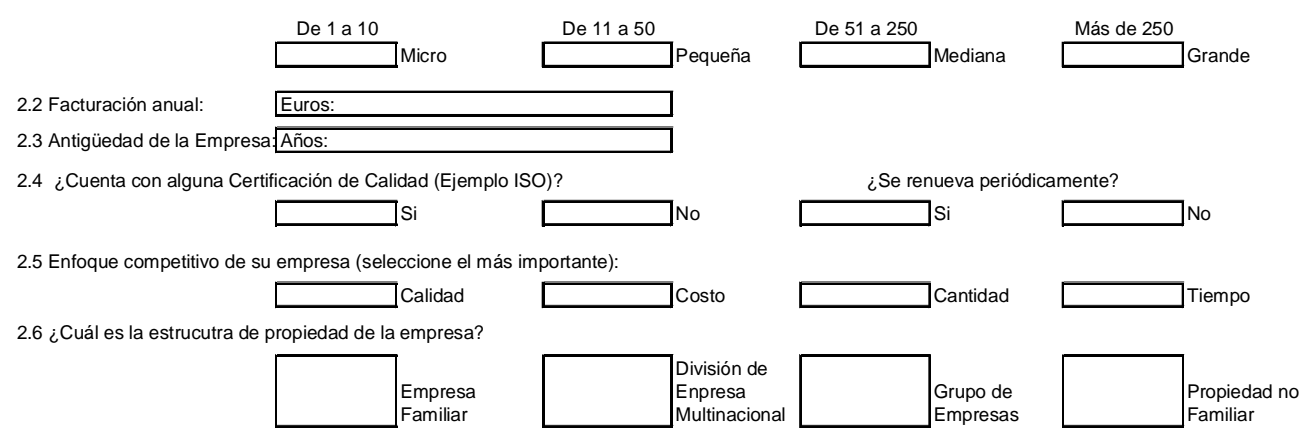


ANEXOS

\section{Visión Holística de la Organización (Palacios, 2006)}

or favor, indique el grado de acuerdo o esacuerdo con las siguientes

firmaciones con respecto a la situación

ə su empresa. Si está totalmente de

suerdo marque 7 , si está completamente

1 desacuerdo marque 1 , si no está

efinida marque un número intermedio.

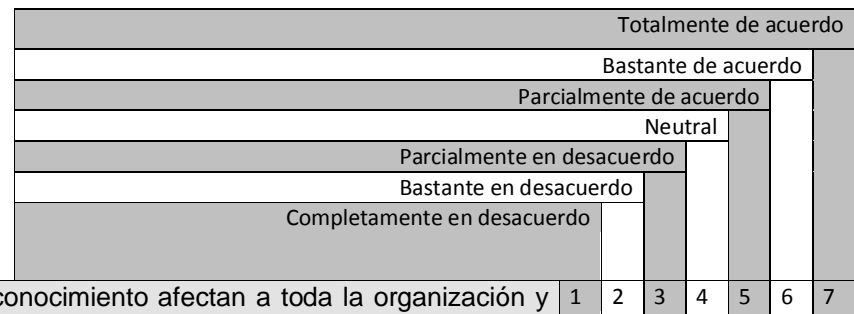

a estrategia y la política de gestión del conocimiento afectan a toda la organización y

percuten en la forma de concebir y gestionar la empresa

o es posible la elaboración de políticas y estrategias sin tener en cuenta a toda la

ganización incluyendo proveedores y clientes

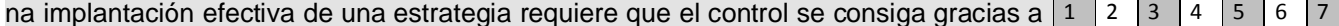

s valores y la visión compartida por todos los miembros de la empresa

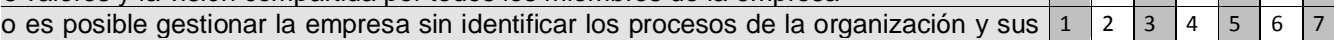

terrelaciones

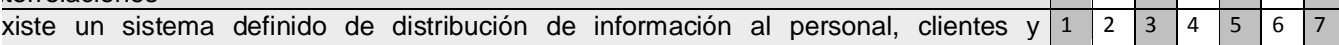

oveedores de acuerdo a las necesidades detectadas

a empresa dispone de sistemas de captación y tratamiento integral de la información 1

obre los procesos (tipo sistemas ERP "Enterprise resource planning")

a empresa desarrolla proyectos que cruzan las barreras entre departamentos

xisten incentivos por el cumplimiento de los objetivos globales de la organización

\section{Gestión por competencias (Palacios, 2006)}

or favor, indique el grado de acuerdo o

esacuerdo con las siguientes

firmaciones con respecto a la situación ə su empresa. Si está totalmente de

zuerdo marque 7 , si está completamente

ר desacuerdo marque 1 , si no está

efinida marque un número intermedio.

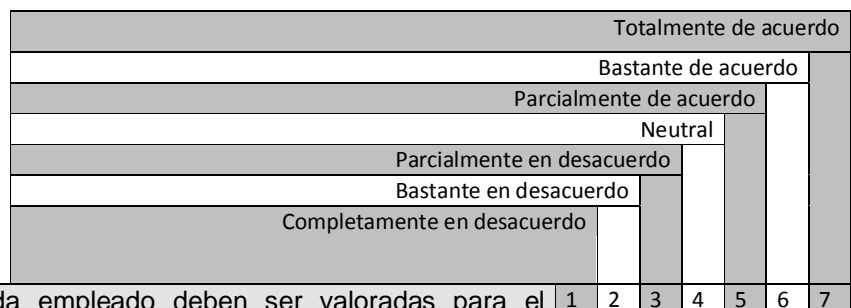

as habilidades y competencias de cada empleado deben ser valoradas para el esarrollo de su carrera profesional

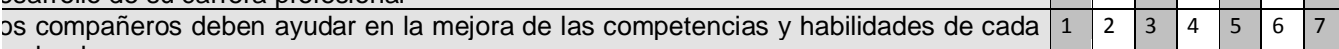
npleado

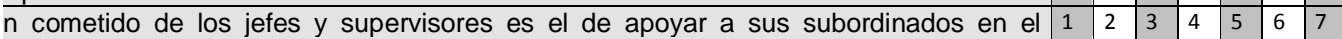
esarrollo de nuevas competencias

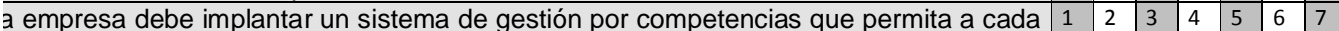
npleado recibir un salario acorde con las competencias desarrolladas

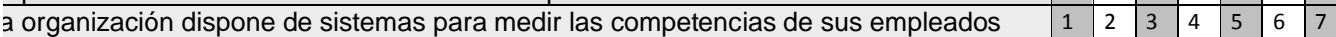

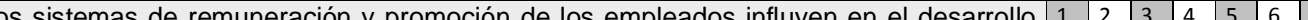

a competencias, ideas y conocimientos por los empleados

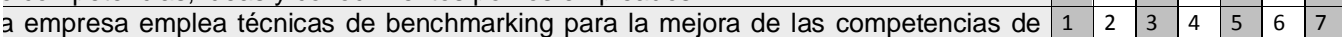
is empleados 


\section{ANEXOS}

\section{Aprendizaje Organizacional (Palacios, 2006)}

or favor, indique el grado de acuerdo o esacuerdo con las siguientes

firmaciones con respecto a la situación

ə su empresa. Si está totalmente de

zuerdo marque 7 , si está completamente

ר desacuerdo marque 1 , si no está

efinida marque un número intermedio.

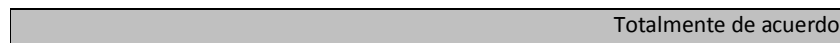

n la empresa se ha de fomentar la reflexión, la crítica y el cambio para la mejora ontinua

as nuevas ideas deben ser muy valoradas, independientemente del empleado que las irmule

n una organización se debe esperar de todos, no sólo de los directivos, que resuelvan s problemas y ofrezcan sugerencias

os empleados deben ver su trabajo en la empresa como un proceso de aprendizaje Ie nunca termina

a empresa posee un plan de carrera que incentiva a sus empleados al aprendizaje 1 ontinuo

Js empleados reciben formación generalista que posteriormente aplican a sus tareas abituales

xiste un sistema de mejora continua que permite mejorar los procesos que hayan canzado los estándares de calidad fijados 


\section{ANEXOS}

Infraestructura Técnica de las Tecnologías de Información (Byrd y Turner ,2000)

or favor, evalúe de 1 a 5 las siguientes

firmaciones respecto a su empresa

narque un 5 si está completamente de

zuerdo y un 1 si está completamente en

əsacuerdo; marque un número

termedio en otro caso)

uestra empresa tiene lo último en sistemas y conexiones de Tecnología Informática, TI, sponibles (ej. ADSL, VDSL, ATM, SDV)

uestra empresa ha tratado formalmente el tema de la seguridad de los datos con diversos otocolos (ej. Kerberos, V.5, MIME, PGP, S-HTTP).

odas las oficinas y sucursales remotas están conectadas a la oficina central

uestra empresa utiliza mecanismos de red de sistemas abiertos para estimular la conectividad

n nuestra empresa no existen cuellos de botella en la comunicación

uestra empresa utiliza una red virtual o VLAN para conectarse a los usuarios finales

Completamente de acuerdo De acuerdo

módulos de software reusables son ampliamente utilizados en el desarrollo de nuevos stemas

e utilizan herramientas orientadas a objetos para crear las aplicaciones de los usuarios finales ר colaboración con éstos.

I personal de TI utiliza tecnologías orientadas a objetos para minimizar el tiempo de desarrollo ə las aplicaciones.

os sistemas heredados en nuestra organización no limitan el desarrollo de nuevas Jicaciones.

penas se utilizan funciones programadas para otras aplicaciones en el desarrollo de nuevas olicaciones.

as oficinas remotas tienen que realizar pasos adicionales o procedimientos para acceder a la icina central

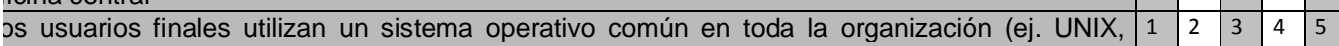
INUX, OS/2)

as aplicaciones de software pueden ser fácilmente transportadas y usadas en múltiples ataformas

uestra empresa ofrece una amplia variedad de tipos de información a los usuarios finales nultimedia).

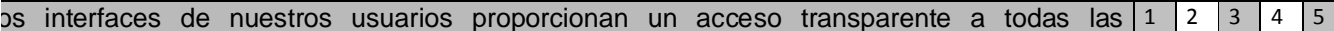
ataformas y aplicaciones.

uestra empresa proporciona múltiples interfaces o puntos de entrada (ej. Acceso web) para s usuarios externos.

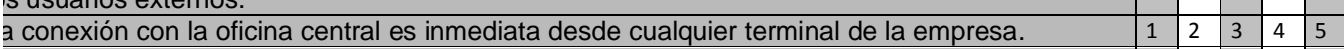

uestra base de datos corporativa es capaz de comunicarse a través de varios protocolos (ej.

$\mathrm{QL}, \mathrm{ODBC}$ ).

os empleados que trabajan fuera de la oficina tienen acceso rápido a los mismos datos tilizados en los PC de la oficina.

xisten dificultades para adaptarse a los estándares y protocolos de bases de datos de algunos oveedores.

os datos capturados en cualquier parte de nuestra empresa están inmediatamente disponibles

l la base de datos. 
ANEXOS

Transferencia y distribución del conocimiento (Yi, 2009)

or favor, evalúe de 1 a 5 las siguientes firmaciones respecto al comportamiento ə los empleados de su empresa, para ompartir y distribuir conocimiento narque un 5 si está completamente de zuerdo y un 1 si está completamente en esacuerdo; marque un número termedio en otro caso)

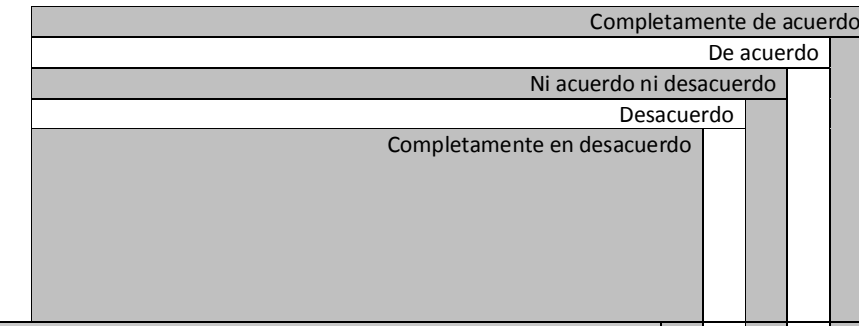

resentar regularmente documentos e informes

ublicar artículos en revistas de la empresa, revistas especializadas o boletines de noticias ompartir la documentación de los archivos personales relacionados con el trabajo actual ontribuir con ideas y pensamientos a la empresa mediante bases de datos en línea antener a otros empleados al día con información importante de la empresa a través de foros e discusión en línea

xpresar ideas y pensamientos en las reuniones de la empresa

articipar plenamente en sesiones de lluvia de ideas ("brainstorming")

roponer sugerencias para resolver problemas en las reuniones de equipo

esponder a las preguntas de los demás en reuniones de equipo \begin{tabular}{l|l|l|l|l|l|l|l|l|}
\hline & & & 2 & & \\
\hline
\end{tabular} ompartir historias de éxito que pueden beneficiar a la empresa en las reuniones de ganización

ompartir los fracasos relacionados con el trabajo, para ayudar a otros a evitar la repetición de stas en las reuniones de la empresa

acer presentaciones en las reuniones de la empresa

poyar a los empleados con menos experiencia durante el tiempo de trabajo persona articipar en las acciones de entrenamiento a largo plazo de los empleados más jóvenes asar tiempo en conversaciones personales (por ejemplo, la discusión en el pasillo, durante el muerzo, a través del teléfono) con otros, para ayudarles a resolver problemas del trabajo. lantener a otros empleados al día con información importante de la empresa a través de una onversación personal

ompartir la pasión y la emoción de algunos temas específicos con los demás mediante la onversación personal

ompartir experiencias que pueden ayudar a otros a evitar riesgos y problemas mediante la onversación personal.

ener charlas en línea con otros empleados para ayudarles con sus problemas relacionados on el trabajo.

asar tiempo en la comunicación por email con otros empleados para ayudarlos con sus oblemas relacionados con el trabajo

euniones de la "Comunidad" para crear soluciones innovadoras a los problemas del trabajo Jomunidad: una red informal de personas dentro o en todas las organizaciones que Juntariamente participan en temas de interés común relacionado con el trabajo

euniones de la "Comunidad" para compartir la propia experiencia y la práctica sobre temas specíficos de común interés.

euniones de la "Comunidad" para compartir el éxito y malos resultados y sobre temas specíficos de común interés.

euniones de la "Comunidad" para fomentar la excelencia en el trabajo

poyo personal de desarrollo de nuevas "Comunidades"

Eviar información relacionada a los miembros de la "Comunidad" a través lista de correo ectrónico.

ompartir ideas y pensamientos sobre temas específicos a los miembros de la "Comunidad"

ilizando los sistemas en línea 
ANEXOS

Desempeño de la Organización (Nakata, 2008)

Por favor, evalúe de 1 a 5 los siguientes aspectos con relación a sus competidores (marque un 5 si es Sobresaliente, mucho mejor que la competencia y un 1 si es muy malo, los peores de la industria; marque un número intermedio en otro caso)

Sobresaliente, mucho mejor que la competencia Notable, por encima de la competencia Normal, en el promedio de la competencia Malo, por debajo de la competencia Muy malo, somos de los peores de la industria

\begin{tabular}{|c|c|c|c|c|c|}
\hline La calidad del producto o servicio & 1 & 2 & 3 & 4 & 5 \\
\hline El éxito de nuevos productos o servicios & 1 & 2 & 3 & 4 & 5 \\
\hline La tasa de retención de clientes & 1 & 2 & 3 & 4 & 5 \\
\hline El nivel de Ventas & 1 & 2 & 3 & 4 & 5 \\
\hline El retorno sobre capital & 1 & 2 & 3 & 4 & 5 \\
\hline El margen Bruto de utilidad & 1 & 2 & 3 & 4 & 5 \\
\hline El retorno sobre inversión & 1 & 2 & 3 & 4 & 5 \\
\hline
\end{tabular}




\section{INTERNATIONAL TRADE CENTER}

CTAP Capacity Building Event

Geneva, Swtzerland, 25 - 29 July 2011

Mingrativina
Thade.

Comise

Ducuramag
roncocas

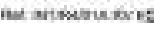

Hemen Monsins

Dentor zones

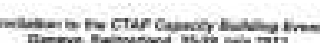

1E

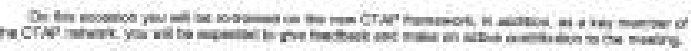

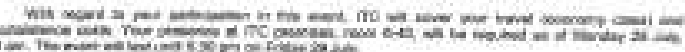

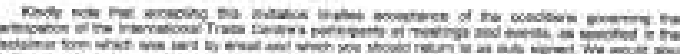

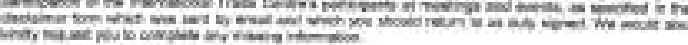

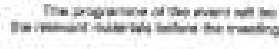

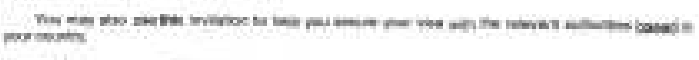

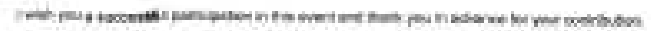

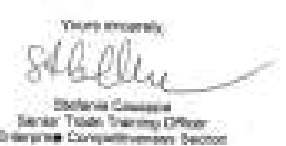

intoris

compins

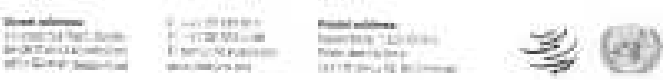
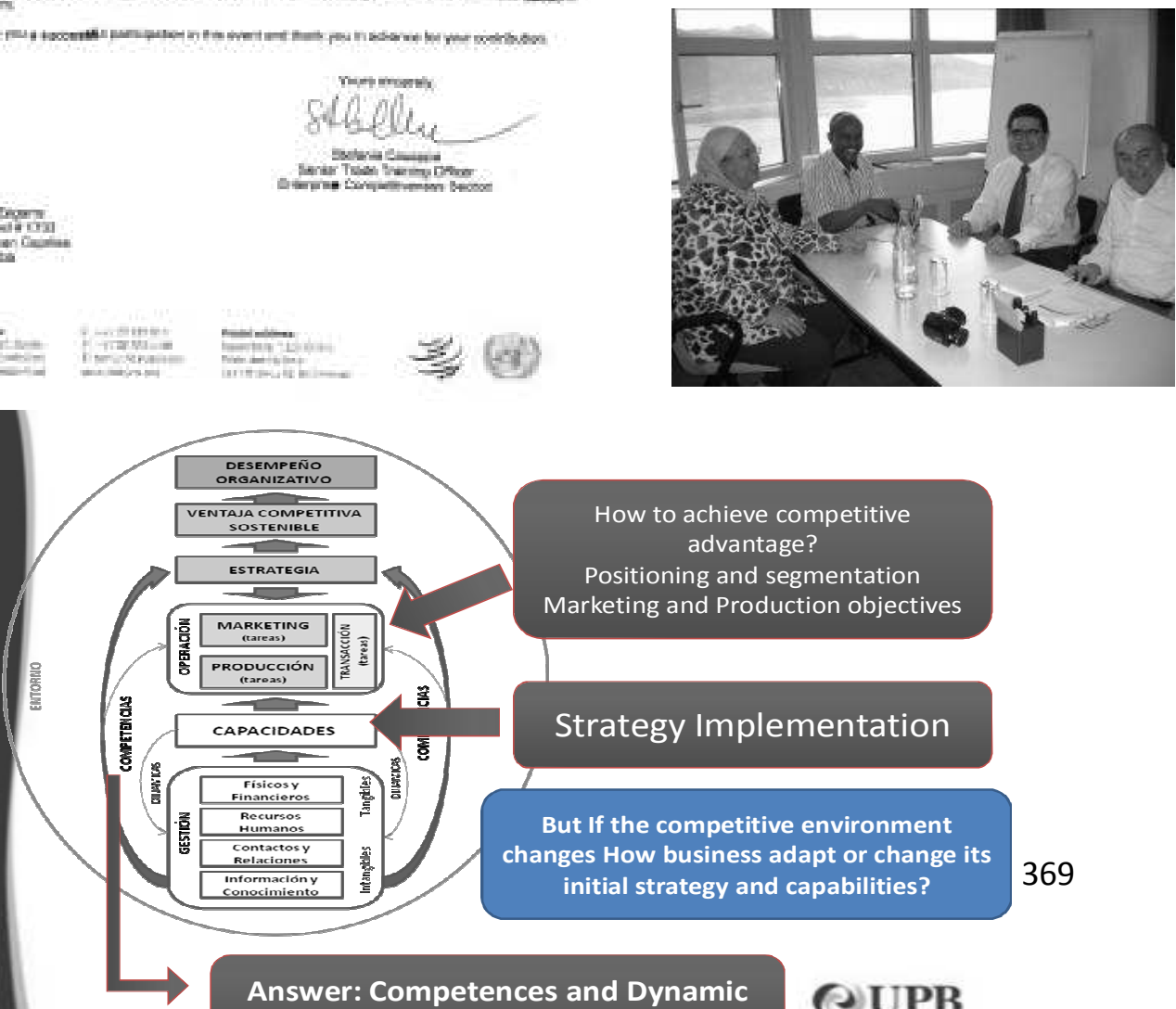

Answer: Competences and Dynamic capabilities

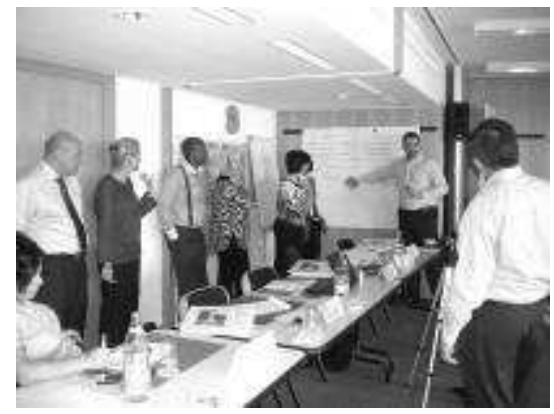

How to achieve competitive

advantage?

Positioning and segmentation

Marketing and Production objectives

Strategy Implementation

But If the competitive environment changes How business adapt or change its

initial strategy and capabilities? 